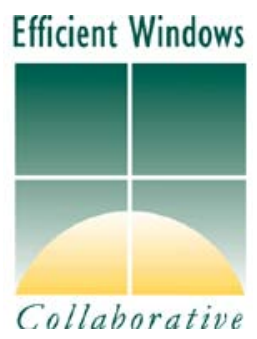

Final Technical Report

Prepared for the U.S. Department of Energy

by the Alliance to Save Energy

\title{
Efficient Windows Collaborative
}

\section{Research Tool Dissemination to Increase Energy Efficient Fenestration Product Penetration}

DE-FC26-06NT42766

May 15, 2006 - February 28, 2010

Principal Investigator

Nils Petermann

Project Manager

Alliance to Save Energy

(202) 530-2254

npetermann@ase.org

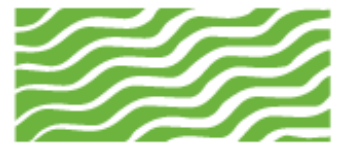

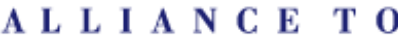
SAVE ENERGY 


\section{Acknowledgement and Disclaimer}

Acknowledgment: This report is based upon work supported by the Department of Energy under Award Number DE-FC26-06NT42766.

Disclaimer: This report was prepared as an account of work sponsored by an agency of the United States Government. Neither the United States Government nor any agency thereof, nor any of their employees, makes any warranty, express or implied, or assumes any legal liability or responsibility for the accuracy, completeness, or usefulness of any information, apparatus, product, or process disclosed, or represents that its use would not infringe privately owned rights. Reference herein to any specific commercial product, process, or service by trade name, trademark, manufacturer, or otherwise does not necessarily constitute or imply its endorsement, recommendation, or favoring by the United States Government or any agency thereof. The views and opinions of authors expressed herein do not necessarily state or reflect those of the United States Government or any agency thereof. 


\section{TABLE OF CONTENTS}

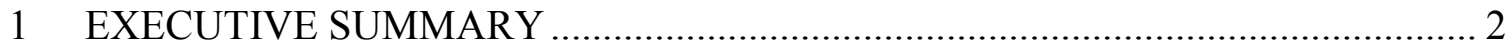

2 PROJECT GOALS AND ACCOMPLISHMENTS …………………………...... 3

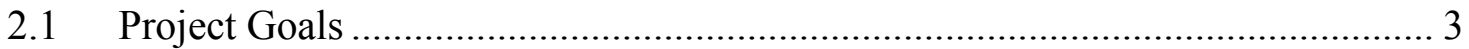

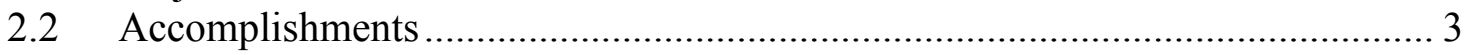

3 PROJECT STUCTURE.................................................................................. 5

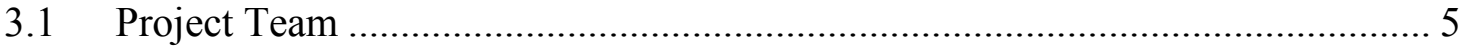

3.2 Project Advisory Council ............................................................................. 5

3.3 Efficient Windows Collaborative Membership.................................................. 7

4 PROJECT OBJECTIVES AND TASKS …………………............................... 8

$4.1 \quad$ Project Background and Objectives ……………........................................... 8

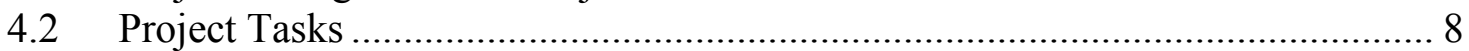

4.2 Shifts in Task Focus during the Project Period ................................................ 10

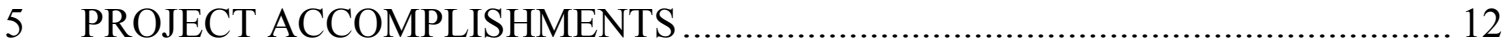

Task 1: Promotion of Design and Rating Tools to Manufacturers .............................. 12

Task 2: Promotion of ENERGY STAR Compliant and More Efficient Products....... 19

Task 3: Promotion of Research Tools to Suppliers, Contractors and Architects......... 26

Task 4: Promotion of Market Transformation Programs (Utility Rebate Programs) .. 35

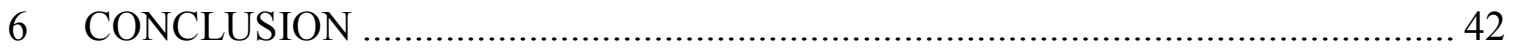

Appendix A - RESFEN and COMFEN Modeling Assumptions ……………………..... A

Appendix B - Efficient Windows Collaborative Toolkits.................................................. B

Appendix C - Fact Sheets and Poster Presentations...........................................................

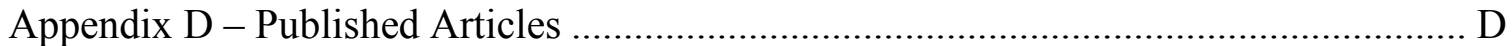

Appendix E - Discussions of Energy Performance Tiers and Indicators ............................ E

Appendix F - Utility Program Listings, Analyses and Recommendations ........................ F 


\section{Final Technical Report \\ Efficient Windows Collaborative \\ Research Tool Dissemination to Increase Energy Efficient \\ Fenestration Product Penetration \\ DE-FC26-06NT42766 \\ Project Period: May 15, 2006 to February 28, 2010}

\section{EXECUTIVE SUMMARY}

Through this cooperative agreement the Alliance to Save Energy (Alliance) and its project partners in the Efficient Windows Collaborative disseminated fenestration energy efficiency research tools and educational material and supported market transformation strategies to increase the share of energyefficient fenestration products (windows, doors, etc.) in the United States residential and commercial markets. This project, funded from May 15, 2006 to February 28, 2010, supported understanding of the energy-efficient fenestration market among manufacturers, consumers, builders, code officials, specifiers, architects and utility program managers through the following activities:

1. Promotion of design and rating tools to manufacturers

2. Promotion of ENERGY STAR compliant and more efficient products to consumers, builders associations, code officials and others

3. Dissemination of research tools to specifiers, designers and architects

4. Promotion of windows market transformation programs to utility rebate program providers

The Alliance and its project partners (the project team) collaborated with Lawrence Berkeley National Laboratory (LBNL) and the National Fenestration Rating Council (NFRC) to leverage these organizations' simulation, design and rating tools and to provide the project's audiences with credible and reliable information. The project team also engaged with prominent organizations working on building energy and sustainability programs and codes in order to increase recognition for efficient fenestration among builders, architects and utility program providers without duplicating other energy efficiency efforts in the buildings sector. These organizations included the National Association of Home Builders, the U.S. Green Building Council, the Consortium for Energy Efficiency and the South Carolina Code Council, among others. The project's reliance on collaboration with other organizations' tools and programs allowed the Alliance to more effectively pursue some tasks than others, depending on the opportunities for leveraging related tools and efforts. The Alliance adjusted the focus of its scope of work accordingly over the course of the project period.

The benefits of disseminating research tools for energy-efficient fenestration are improved awareness of energy efficiency selection criteria for fenestration products among consumers and professional specifiers. The ability to make educated choices among fenestration products is critical given that many such products remain in place for decades and that if investing in fenestration products without reliable information entails a high risk given the often substantial cost. The project activities not only provided audiences with tools and information on how to reduce this risk, but also on how to reduce cost by taking advantage of energy efficiency incentives and integrated design. The project also supported market transformation toward highly-insulating windows. The long-term impact of this effort cannot be assessed yet but may be among the most significant benefits resulting from the project activities. The savings potential from widespread transition to highly-insulating windows in the residential sector is estimated to be up to 0.5 quadrillion Btu. ${ }^{1}$ Through the Efficient Windows Collaborative, the Alliance supported the Department of Energy in setting the stage for the first steps transforming the market in the direction of highly advanced fenestration options by raising awareness among key stakeholders.

\footnotetext{
${ }^{1}$ Arasteh D. et al. 2006. Zero Energy Windows. U.S. DOE and LBNL.
} 


\section{PROJECT GOALS AND ACCOMPLISHMENTS}

\subsection{Project Goals}

The project goals covered both the residential and commercial windows markets and involved a range of audiences such as window manufacturers, builders, homeowners, design professionals, utilities, and public agencies. Essential goals included:

1. Creation of "Master Toolkits" of information that integrate diverse tools, rating systems, and incentive programs, customized for key audiences such as window manufacturers, design professionals, and utility programs.

2. Delivery of education and outreach programs to multiple audiences through conference presentations, publication of articles for builders and other industry professionals, and targeted dissemination of efficient window curricula to professionals and students.

3. Design and implementation of mechanisms to encourage and track sales of more efficient products through the existing Window Products Database as an incentive for manufacturers to improve products and participate in programs such as NFRC and ENERGY STAR.

4. Development of utility incentive programs to promote more efficient residential and commercial windows. Partnership with regional and local entities on the development of programs and customized information to move the market toward the highest performing products.

An overarching project goal was to ensure that different audiences adopt and use the developed information, design and promotion tools and thus increase the market penetration of energy efficient fenestration products. In particular, a crucial success criterion was to move gas and electric utilities to increase the promotion of energy efficient windows through demand side management programs as an important step toward increasing the market share of energy efficient windows.

\subsection{Accomplishments}

Over the project period, from May 15, 2006 to February 28, 2010, the Alliance and its project partners accomplished the following progress toward the project's primary goals:

Goal 1 Creation of Master Toolkits: The Alliance and its project partners developed toolkits for window manufacturers, residential designers, educational building designers and decision makers, and office building façade designers. Key project partners updated the content of the book Residential Windows: A Guide to New Technologies and Energy Performance, which was released in its third edition. These toolkits and publication, which the project team disseminated at conferences and educational sessions and made available online, supported the promotion of the other program goals.

Goal 2 Delivery of education and outreach programs: The Alliance and its project partners performed substantial outreach to professional and consumer audiences, reaching about 4,000 design professionals, code officials, utility program implementers, and consumers directly through a combination of educational sessions, webinars, advice via the Efficient Windows

Collaborative email and phone hotline, and interaction through trade show booths. This direct outreach was leveraged through newspaper, magazine and online articles, reaching a far greater audience.

Goal 3 Mechanisms to encourage and track sales of more efficient products: The EWC Window Selection Tool (http://efficientwindows.org/selection.cfm) and a listing of tax-credit qualifying products (http://efficientwindows.org/taxcredit/taxcredit.cfm) directed significant traffic (more than 90,000 referrals) to information about products meeting enhanced performance tiers. The Window Selection Tool in particular helped promote products with superior insulating values. To offer visitors a wider range of choices among higher 
performance tiers, the Alliance recruited increased participation among manufacturers of highly-insulating windows.

Goal 4 Development of utility incentive programs: The Alliance helped pave the way for in-depth dialog among utility companies on advanced window incentive programs. However, it did not accomplish the actual implementation of additional programs during the project period. Prior to the revision of the ENERGY STAR criteria in 2010, a major share of utilities considered window programs to lack cost-effectiveness and savings potential beyond business-as-usual, while utilities with a more favorable view of window programs continued their pre-existing programs. The Alliance initiated in-depth discussion with utility members of the Consortium of Energy Efficiency (CEE) about the feasibility of market transformation programs for highly-insulating windows. While these discussions did not result in immediate program implementation, the Alliance and CEE collaborated on tools and documents to help interested utilities consider such options and raise awareness among utility program managers of the potential for window performance tiers that would offer substantial improvements over business as usual.

In addition to these accomplishments, the Alliance and its project partners took advantage of opportunities with significant potential to encourage the use of design and rating tools and to increase market penetration of high-efficiency fenestration products. This included the improvement of fenestration provisions in the ICC 700 National Green Building Standard and LEED for Homes, support for the development and implementation of the NFRC Component Modeling Approach (CMA) through participation in the NFRC Board of Directors, support to code officials in South Carolina in adopting window energy efficiency provisions in the South Carolina state building energy code, and technical assistance to DOE's preparation of a "Highly-Insulating (R-5) Windows and Low-E Storm Windows Volume Purchase Program”. 


\section{PROJECT STUCTURE}

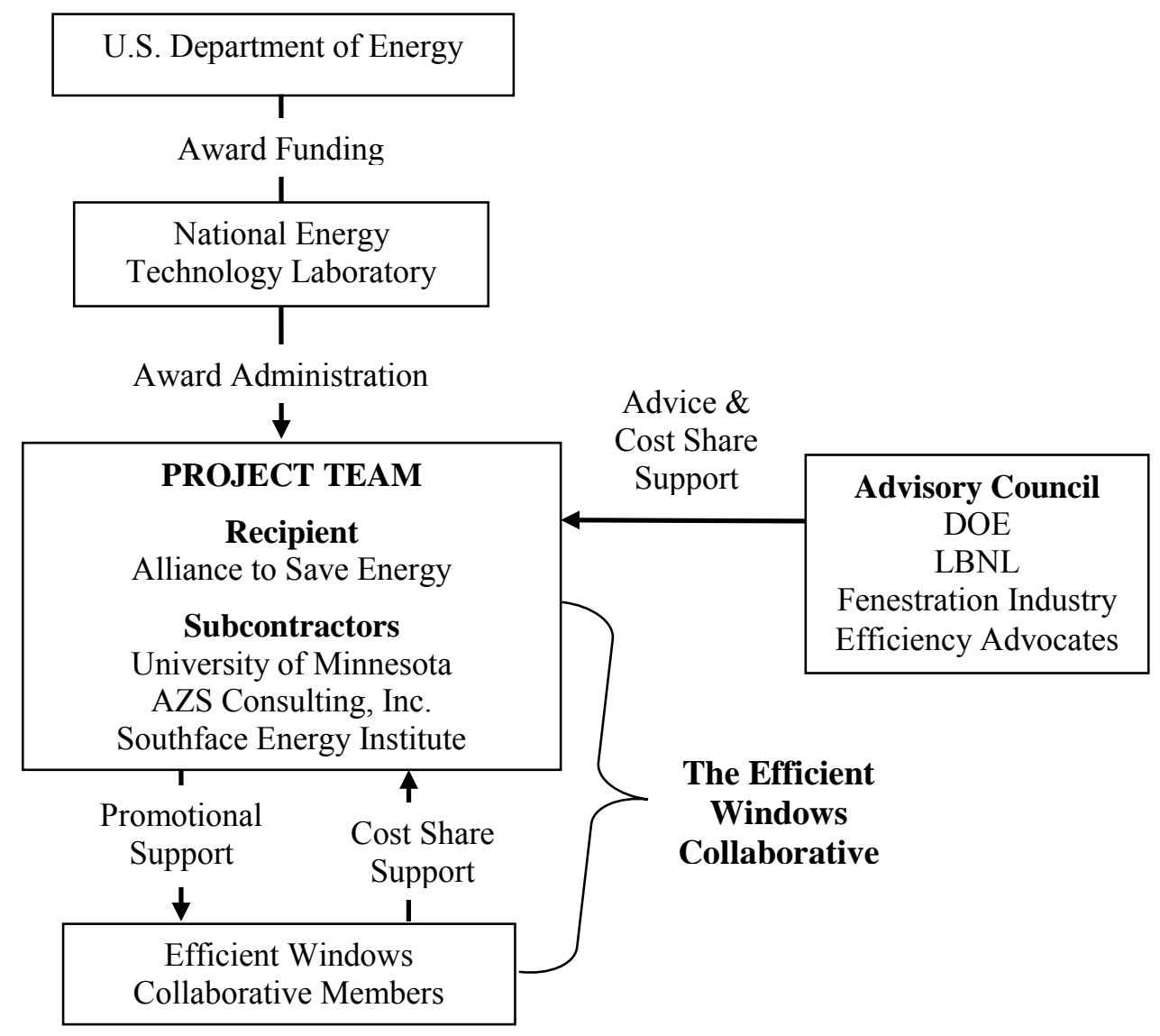

Figure 1. The Efficient Windows Collaborative Project Structure

\subsection{Project Team}

The EWC project implementation team was led by the Alliance to Save Energy (Alliance), the direct recipient under this cooperative agreement. The Alliance was responsible for overall project implementation and the role of the principal investigator. The University of Minnesota (UMN), as a subcontractor under this agreement, was responsible for creating key educational material and coinvestigation from a technical perspective. Outreach support in addition to the Alliance's outreach activities was provided by subcontractor AZS Consulting, Inc. and, during the final phase of the project, Southface Energy Institute assisted with targeted educational activities through a six-month subcontract.

While not funded through this cooperative agreement, Lawrence Berkeley National Laboratory (LBNL) provided this project with a foundation of simulation tools, advice, analysis and technical publications.

\subsection{Project Advisory Council}

In preparation for this project, the Alliance and UMN created an advisory council drawn from the residential and commercial window industry, DOE, LBNL, state government, expert consultants and regional market transformation groups. The project team held advisory council meetings two-to-three times each year to discuss Efficient Windows Collaborative activities and strategic plans as well as to provide updates on research and design tool developments. The advisory council provided the project 
team with feedback from the market perspective and with advice on regional and sector-specific project opportunities.

Participants in the advisory council represented the following energy-efficiency and industry stakeholders:

Regional energy efficiency groups:

- Midwest Energy Efficiency Alliance (MEEA)

- Northeast Energy Efficiency Partnerships (NEEP)

Government and federal laboratories

- California Energy Commission

- Lawrence Berkeley National Laboratory

- U.S. Department of Energy

Fenestration industry organizations:

- American Architectural Manufacturers Association (AAMA)

- Glass Association of North America (GANA)

- Insulating Glass Manufacturers Alliance (IGMA)

- National Fenestration Rating Council (NFRC)

- Window and Door Manufacturers Association (WDMA)

Residential fenestration manufacturers:

- Andersen

- Jeld-Wen

- Marvin

- Pella

- PGT Industries

Commercial fenestration manufacturers:

- Arch Aluminum

- Azon

- Graham Architectural

- Oldcastle Glass

- Traco

- Viracon

Fenestration Component Suppliers:

- Cardinal Glass

- Pilkington North America

- SAGE Electrochromics

- Southwall Technologies

Consultants and researchers:

- Brickfield, Burchette, Ritts \& Stone

- Birch Point Consulting

- DesignBuilder Software

- Frontier Associates

- MC Squared

- West Wall Group 


\subsection{Efficient Windows Collaborative Membership}

Members of the Efficient Windows Collaborative (EWC) are companies or organizations with a commitment to support energy efficiency in the fenestration market. Since its inception, the Efficient Windows Collaborative has been supported by industry members, through funding support for important web features as well as through advice and technical input. In return, EWC members are given recognition on the EWC website and in EWC material. Prior to 2008, there were no dues for EWC membership, and participation in the NFRC and ENERGY STAR programs were the main commitments for manufacturer members. By the start of this project period, participation in these programs had become commonplace among the majority of manufacturers. Therefore, the Alliance decided to add annual dues to the EWC member commitments. In return, the Alliance expanded the promotion of EWC members' products through listings in the EWC Window Selection Tool. The Alliance leveraged the EWC membership dues by expanding its work on the project beyond the activities covered by federal funding. Expanded activities included EWC web content, advisory group meetings, and participation in industry association events.

EWC membership is divided into three categories: manufacturers, suppliers and affiliates. The manufacturer category encompasses producers of whole fenestration products including windows, doors and skylights. The supplier category includes producers and suppliers of components such as glazing, lineals, and spacers. Affiliates are non-manufacturing interested parties such as remodelers and contractors, trade associations, utilities, and energy efficiency organizations. Non-profit organizations among the EWC members are exempt from membership dues.

Upon beginning their membership, EWC members were also asked to declare their commitment to supporting EWC initiatives that increase awareness and market penetration of energy-efficient windows. Different EWC members provided in-kind and sponsoring support to outreach and training activities conducted by the Alliance under this project. By disseminating EWC educational material among their prospective customers, EWC members also helped the Alliance in reaching wider audiences for its energy efficiency information.

The number of EWC members varied over the funding period. Before the Alliance implemented membership dues in 2008, the number had surpassed 160. After the introduction of dues, the number has remained between 75 and 100. At the end of this project period, EWC had 82 members. 


\section{PROJECT OBJECTIVES AND TASKS}

\subsection{Project Background and Objectives}

The objective of this project was to build on previous successes by the Efficient Windows Collaborative (EWC) and expand its leverage to the commercial fenestration market and to sectors of the residential fenestration market with yet unattained energy-efficiency potential. Prior to this project, the Efficient Windows Collaborative (EWC), led by the Alliance to Save Energy, the University of Minnesota and Lawrence Berkeley National Laboratory, leveraged the potential of the ENERGY STAR for Windows, Doors and Skylights program since its inception in 1997. Through an interactive website, industry involvement and end-user education, the EWC encouraged supply and demand for energy-efficient residential windows and thus supported the rise in market share for ENERGY STAR windows to over 50 percent by 2005 . Nevertheless, large potentials remained for the penetration of energy-efficient fenestration products in residential new construction in the Southeastern United States, in large portions of the commercial construction sector, and in the adoption of high-end window options such as highly-insulating windows for cold climates. The tasks under this project aimed at addressing these potentials by further improving, expanding and disseminating the design and rating tools available in both the residential and commercial fenestration markets.

With a particular focus on market segments with a high potential for more energy-efficiency - the residential market in the Southeast, the market for highly-insulating windows in cold climates, and the commercial fenestration market - the objectives of this project were to 1) encourage the supply side to design and rate more energy-efficient fenestration; 2) encourage demand for more fenestration energy efficiency; 3) facilitate more effective integration of fenestration in energy-efficient building design; and 4) encourage the creation or expansion of market transformation programs by utilities and other entities to help realize these segments' potential. The project tasks were designed according to these objectives.

\subsection{Project Tasks}

The scope of work under this project addressed both the residential and commercial windows markets, focusing on the residential sector in the first years with an increasing emphasis on the commercial sector in later years. The project tasks built on past DOE investments in the National Fenestration Rating Council, ENERGY STAR, and the Efficient Windows Collaborative. The tasks were designed to involve and reach a range of audiences such as window manufacturers, builders, homeowners, design professionals, utilities, and public agencies. The essential elements of the work scope included:

1. Promotion of design and rating tools to manufacturers

2. Promotion of ENERGY STAR compliant and more efficient products to consumers, builders associations, code officials and others

3. Dissemination of research tools to specifiers, designers and architects

4. Promotion of fenestration market transformation programs to utility rebate program developers

The following table provides a listing and description of the four major tasks, each of which correspond to a project objective stated above, along with associated subtasks. Specific accomplishments in each task area are described in section 5 of this report. 
Table 1 Tasks

TASK 1 Promotion of design and rating tools to manufacturers

\begin{tabular}{|c|c|c|}
\hline Sector & Task Title & Description \\
\hline \multirow[t]{2}{*}{ Residential } & $\begin{array}{l}\text { 1.1 Small Residential } \\
\text { Manufacturers Recruitment }\end{array}$ & $\begin{array}{l}\text { Develop information packages and training } \\
\text { materials to facilitate recruitment of smaller } \\
\text { window manufacturers to use NFRC window } \\
\text { rating procedures }\end{array}$ \\
\hline & 1.2 Residential Master Toolkit & $\begin{array}{l}\text { Develop a Master Toolkit for residential window } \\
\text { manufacturers }\end{array}$ \\
\hline \multirow[t]{2}{*}{ Commercial } & 1.3 NFRC Commercial Ratings & $\begin{array}{l}\text { Provide technical support and information to the } \\
\text { NFRC commercial windows rating procedure } \\
\text { under development }\end{array}$ \\
\hline & 1.4 Commercial Master Toolkit & $\begin{array}{l}\text { Develop a Master Toolkit for commercial } \\
\text { window manufacturers }\end{array}$ \\
\hline \multicolumn{3}{|c|}{ TASK 2 Promotion of ENERGY STAR compliant and more efficient products } \\
\hline Sector & Task Title & Description \\
\hline \multirow[t]{2}{*}{ Residential } & 2.1 Energy Star Promotion & $\begin{array}{l}\text { Provide technical support to those responsible } \\
\text { for promoting Energy Star windows in other } \\
\text { related efforts }\end{array}$ \\
\hline & $\begin{array}{l}2.2 \text { Residential Performance } \\
\text { Tiers }\end{array}$ & $\begin{array}{l}\text { Develop residential windows performance tiers } \\
\text { that promote benefits of windows that exceed } \\
\text { Energy Star requirements }\end{array}$ \\
\hline Commercial & $\begin{array}{l}2.3 \text { Commercial Performance } \\
\text { Tiers }\end{array}$ & $\begin{array}{l}\text { Develop performance criteria and tiers for } \\
\text { commercial windows that emphasize high } \\
\text { energy efficiency performance }\end{array}$ \\
\hline \multicolumn{3}{|c|}{ TASK 3 Promotion of research tools to suppliers, contractors and architects } \\
\hline Sector & Task Title & Description \\
\hline \multirow[t]{3}{*}{ Residential } & $\begin{array}{l}\text { 3.1 Residential Products } \\
\text { Database Expansion }\end{array}$ & $\begin{array}{l}\text { Recruit new window manufacturer participants } \\
\text { into the EWC data base used by consumers to } \\
\text { evaluate windows choices }\end{array}$ \\
\hline & $\begin{array}{l}\text { 3.2 Residential Designers' } \\
\text { Master Toolkit }\end{array}$ & $\begin{array}{l}\text { Develop a Master Toolkit for residential } \\
\text { designers along with related curriculum } \\
\text { materials. Present to building science educators } \\
\text { and schools of architecture }\end{array}$ \\
\hline & $\begin{array}{l}3.3 \text { Energy Efficient Residential } \\
\text { Windows Articles }\end{array}$ & $\begin{array}{l}\text { Prepare and publish articles on energy efficient } \\
\text { residential windows in the trade press }\end{array}$ \\
\hline \multirow[t]{3}{*}{ Commercial } & $\begin{array}{l}\text { 3.4 Commercial Products } \\
\text { Database }\end{array}$ & $\begin{array}{l}\text { Develop prototype data base to link } \\
\text { manufacturers' products to designers and } \\
\text { specifiers }\end{array}$ \\
\hline & $\begin{array}{l}3.5 \text { Commercial Designers' } \\
\text { Master Toolkit }\end{array}$ & $\begin{array}{l}\text { Develop a Master Toolkit for commercial } \\
\text { designers along with related curriculum } \\
\text { materials. Develop and present technical } \\
\text { information at key conferences }\end{array}$ \\
\hline & $\begin{array}{l}\text { 3.6 Energy Efficient } \\
\text { Commercial Windows Articles }\end{array}$ & $\begin{array}{l}\text { Prepare and publish articles on energy efficient } \\
\text { commercial windows in the trade press }\end{array}$ \\
\hline
\end{tabular}




\begin{tabular}{|l|l|l|}
\hline \multicolumn{3}{|l|}{ TASK 4 Promotion of market transformation programs (utility rebate programs) } \\
\hline Sector & Task Title & Description \\
\hline Residential & $\begin{array}{l}\text { 4.1 Residential Windows Utility } \\
\text { Provider Promotional Inventory }\end{array}$ & $\begin{array}{l}\text { Compile inventory and profiles of residential } \\
\text { energy efficient windows promotion programs } \\
\text { at electric and natural gas utilities }\end{array}$ \\
\cline { 2 - 3 } & $\begin{array}{l}\text { 4.2 Residential Utility Provider } \\
\text { Outreach }\end{array}$ & $\begin{array}{l}\text { Prepare an outreach plan to disseminate Master } \\
\text { Toolkits and training materials to residential } \\
\text { utility program providers }\end{array}$ \\
\cline { 2 - 3 } & $\begin{array}{l}\text { 4.3 CEE Special Residential } \\
\text { Windows Project }\end{array}$ & $\begin{array}{l}\text { Develop benefit-cost information and data on } \\
\text { advanced window technologies for the } \\
\text { Consortium for Energy Efficiency }\end{array}$ \\
\cline { 2 - 3 } & $\begin{array}{l}\text { 4.4 Characterization of Gas } \\
\text { Utility Provider Promotionals }\end{array}$ & $\begin{array}{l}\text { Determine potential to promote efficient } \\
\text { windows through gas utility efficiency programs }\end{array}$ \\
\hline Commercial & $\begin{array}{l}\text { 4.5 Commercial Windows } \\
\text { Utility Provider Promotional } \\
\text { Inventory }\end{array}$ & $\begin{array}{l}\text { Compile inventory and profiles of commercial } \\
\text { energy efficient windows promotion programs } \\
\text { at electric and natural gas utilities }\end{array}$ \\
\cline { 2 - 3 } & $\begin{array}{l}4.6 \text { Commercial Windows } \\
\text { Utility Provider Promotional } \\
\text { Toolkit }\end{array}$ & $\begin{array}{l}\text { Develop technical fact sheets and toolkit } \\
\text { materials that can be used to develop } \\
\text { commercial windows promotion programs with } \\
\text { utilities }\end{array}$ \\
\cline { 2 - 3 } & $\begin{array}{l}\text { 4.7 Commercial Windows } \\
\text { Utility Provider Outreach }\end{array}$ & $\begin{array}{l}\text { Prepare an outreach plan to disseminate Master } \\
\text { Toolkits and training materials to commercial } \\
\text { utility program providers }\end{array}$ \\
\hline
\end{tabular}

\subsection{Shifts in Task Focus during the Project Period}

Due to problems encountered with some tasks and opportunities arising for other tasks, the project team shifted some of the focus of the scope of work over the project period. In particular, the project team found fewer opportunities than envisioned for promoting tools and utility programs for commercial windows due to the later-than-anticipated implementation of the NFRC Component Modeling Approach (CMA). On the other hand, the project team identified substantial opportunities for promoting efficient residential windows among stakeholders in the Southeastern United States and for raising awareness of highly insulating windows among sustainable design program developers, utility program providers, architects and builders. These challenges and opportunities are summarized here and are described in greater detail in section 5 "Project Accomplishments".

Task 1: Promotion of design and rating tools to manufacturers

Due to the importance of the development of CMA for commercial window ratings, the Alliance and its project partners focused on supporting the NFRC's preparation of CMA until its full implementation in January 2010 (Task 1.3) but did not complete a comprehensive toolkit for commercial window manufacturers (Task 1.4).

Task 2: Promotion of ENERGY STAR compliant and more efficient products

In addition to the envisioned technical support to those responsible for promoting ENERGY STAR windows (Task 2.1), the project team found significant opportunities to support the adoption of energy efficient windows in the Southeastern United States through training and outreach. The Alliance also took advantage of significant opportunities for promoting higher tiers for residential windows (Task 2.2) while it found few opportunities for promoting higher tiers for commercial windows (Task 2.3).

Task 3: Promotion of research tools to suppliers, contractors and architects Instead of developing a single master toolkit for commercial designers (Task 3.5), the project team offered separate tools for office façades and schools while reaching out to design 
professionals through seminars and conferences. This allowed the project team to provide more audience-specific information while CMA and COMFEN were still under development.

Task 4: Promotion of market transformation programs

Opportunities for discussing utility programs were substantially greater with regards to residential windows than regarding commercial windows. Programs considering commercial building envelope performance are much more likely to evaluate windows on a building-specific basis, while programs for residential windows may rely on general window performance tiers. The Alliance thus focused most of its discussion with utility program providers on residential window performance tiers, although it also explored options for commercial window utility programs. 


\section{PROJECT ACCOMPLISHMENTS}

This section describes the accomplishments by the Alliance and its project partners under the four project tasks outlined above. Work on these tasks began on February 15, 2006, as this cooperative agreement recognized limited pre-award costs incurred up to 90 days prior to the effective award start date on May 15, 2006. The work under this cooperative agreement ended with the award end date on February 28, 2010.

\section{Task 1: Promotion of Design and Rating Tools to Manufacturers}

This task was designed to address the supply side in the fenestration market by encouraging manufacturers to produce and certify more energy-efficient fenestration products. Critical activities under this task included improving design and rating tools for manufacturers and outreach to manufacturers to raise awareness of market opportunities for higher fenestration energy efficiency.

\section{Task 1.1: Small residential manufacturers recruitment}

Task objective: Develop information packages and training materials to facilitate recruitment of smaller window manufacturers to use NFRC window rating procedures.

Background

and hypothesis: As of 2005, an estimated eighty percent of the residential fenestration market participated in the National Fenestration Rating Council (NFRC) certification program. ${ }^{2}$ However, NFRC certification can be complicated and daunting to smaller manufacturers. Moreover, the cost of NFRC certification limits the enthusiasm of manufacturers with smaller, regional markets where the benefits of certification may not yet be as apparent as on the national scale. The non-participation by many smaller, regional or local manufacturers can hamper the implementation of efficient windows by opposing local market transformation efforts such as building energy codes or the inclusion of NFRC ratings criteria in voluntary incentive programs. This task was designed to address this barrier by educating smaller manufacturers about both the benefits of NFRC certification and about the necessary steps to start participation in the NFRC program.

Approaches: One of the EWC's most important messages is the importance of the NFRC label. Prior to this funding period, however, EWC material on the NFRC label was targeted at consumers and code officials and did not address manufacturers' possible questions about product certification. Under this task, the project team provided manufacturers with targeted information about the benefits and processes of the NFRC program. The main approaches for disseminating this information were web content on the EWC website, a trade press article and direct outreach through industry association meetings and trade shows.

Web content on the benefits of the NFRC program was included in the Manufacturers Toolkit developed under Task 1.2 (Appendix B-1). This web content, developed in March 2007, pointed toward NFRC certification as a prerequisite for participation in the ENERGY STAR program, for code compliance in many states, for different utility incentives and green building programs as well as for qualification for the federal tax credit for replacement windows. The Manufacturers Toolkit also included short summaries of the certification steps to help manufacturers form realistic expectations about the time and financial commitment required for certification. This information was developed in consultation with NFRC staff. In particular, the web content emphasized that smaller manufacturers are eligible for discounted NFRC participation fees if their annual sales do not exceed two million dollars.

\footnotetext{
${ }^{2}$ Stewart, A. 2006. Removing barriers to NFRC participation by small manufacturers. Alliance to Save Energy.
} 
To emphasize the need for NFRC certification and proper labeling as a prerequisite for participation in energy efficiency programs, project consultant Arlene Stewart of AZS Consulting contributed an EWC article titled "Lapsed NFRC label blows ENERGY STAR job" to the November 2007 issue of Door and Window Manufacturer Magazine, a trade publication with over 30,000 subscribers (see Task 3.3 ). ${ }^{3}$

Perhaps the most promising means of engaging manufacturers was direct outreach through fenestration industry trade shows and association meetings. The EWC project team targeted its direct outreach at the Southeastern region, where several states do not require NFRC certification through their building energy codes or where code enforcement is not strong enough to compel manufacturers to seek NFRC certification. Florida was a particular focus due to its large amount of construction and lacking requirements for NFRC certification in its energy code. The project team reached about 260 representatives of fenestration manufacturing companies, including small manufacturers, through presentations at the following meetings:

- Fenestration Manufacturers Association (FMA) spring meeting, Tampa FL, April 13, 2006. 69 participants, including smaller window manufacturers.

- Florida Windows Workshop, $54^{\text {th }}$ Annual Building Officials Association of Florida Educational Conference, June 7, 2006. 200 attendees, including 120 window manufacturers.

- AAMA Southeast Region 2006 Fall Meeting, St. Augustine FL, August 16, 2006. 75 attendees, among whom a minority were smaller manufacturers.

The project team also reached out to manufacturers with information on NFRC processes through booths at the Southeast Builder Show in Orlando, FL on August 3-5, 2006 and at four annual Glassbuild America conferences in Atlanta, GA and Las Vegas, NV in the falls of 2006-2009. Among the manufacturers reached at these trade shows, however, only a small number (about 10 in total) did not already participate in the NFRC program or were not already in the process for participation. The project team followed up electronically with those manufacturers who indicated an interest in learning more about the program.

The Alliance directly contacted five smaller manufacturers of highly-insulating replacement windows who claimed product performance that exceeded the ENERGY STAR criteria but was not based on NFRC ratings. Reasons for non-participation by these manufacturers were a combination of the program cost, the lack of code enforcement in the replacement market, as well as the fact that the ENERGY STAR program does not give credit for performance beyond its minimum criteria. The Alliance won participation by one of these manufacturers in the EWC Window Selection Tool, which requires NFRC certification and emphasizes the benefits of highly-insulating windows.

Through the contact information on the EWC web site, the Alliance received requests from four manufacturers for specific advice on how to commence with NFRC certification and provided these with information from its Manufacturers Toolkit and NFRC fact sheets as well as with NFRC staff contact information.

Assessment: The success of this task was measured by the number of smaller manufacturers reached and then engaged in the NFRC program. The project team estimates to have reached more than 400 manufacturers with NFRC information through direct outreach at trade shows, conference presentations and by phone. Among these, the project team identified about 20 smaller manufacturers who did not already participate in the NFRC program, although the presentations in Florida likely reached a larger, yet unknown number of non-

\footnotetext{
${ }^{3}$ Circulation as of June 2008 (http://www.dwmmag.com/index.php/about).
} 
participants. The project team could later confirm that five among these manufacturers had gained NFRC certification, but aside from these, the directly engaged manufacturers did either not seek NFRC certification, went out of business, or changed their contact information. The number of smaller manufacturers that used the online EWC information about NFRC certification is unknown.

Manufacturers without NFRC certification were mainly to be found in states where NFRC labeling is not needed for building energy code compliance (e.g. Florida, Alabama, Mississippi, South Carolina). In South Carolina, this situation has changed since the energy code was modified in 2009, and the Alliance provided code officials with information on how to verify compliance based on NFRC certification. In Florida, project consultant AZS Consulting has repeatedly emphasized the benefit of NFRC certification for gaining full credit for window performance under the state code. However, it remains possible under the code's performance path for buildings to qualify regardless of window performance.

In the replacement windows market, the consumer demand for ENERGY STAR windows and particularly for the window replacement tax credit included in the American Recovery and Reinvestment Act can be expected to increase demand for NFRC-certified windows even in the Southeastern states. Even so, the project team has found through discussions with manufacturers that demand for energy-efficient windows is substantially lower along the Gulf Coast and especially in Florida, and even the tax credit may not always sway buyers away from substantially lower-priced windows that lack energyefficiency features and NFRC certification.

Without the compelling reasons of code compliance and consumer demand at the local level, smaller manufacturers are not likely to embrace the costs of NFRC certification. Some of these costs are absolute: they are the same regardless of the size of the company. This is a potential barrier for small manufacturers because a greater portion of the budget is needed to execute the transition as compared to larger companies. The NFRC discount for companies with less than two million dollars in annual sales is of significant help for the companies concerned, but financial barriers are still significant for small companies with somewhat higher sales. A rebate for companies with up to five million dollars in annual sales was suggested by the Alliance in 2006 but has not found serious consideration among the NFRC during the funding period. Participation cost for the NFRC program thus remains a barrier for smaller manufacturers, but accelerated code adoption and enforcement as well as strengthened tax credits, if sustained over time, are likely to compel most companies to seek NFRC certification to remain competitive.

\section{Task 1.2: Residential Master Toolkit}

Task objective: Develop a Master Toolkit for residential window manufacturers.

Background and hypothesis: The intent of this task was to provide smaller residential manufacturers with critical information about fenestration energy efficiency programs through a comprehensive toolkit. The project team assumed smaller manufacturers as the main target audience since mid-sized and larger manufacturers are more likely to already possess adequate information about the NFRC program, ENERGY STAR, incentive programs and other energy-efficiency related information. In addition to this toolkit the project team sought to provide manufacturers of all sizes with information about energy-efficiency policy and program developments affecting the market for energy-efficient residential windows.

Approaches: In March 2007, the project team included a Manufacturers Toolkit in the EWC web site (www.efficientwindows.org/toolkits/tk_manufacturer1_0.cfm, see Appendix B-1 for an 
excerpt). This toolkit provided window manufacturers with accessible information on the following topics:

- Why energy efficiency is important for manufacturer's business

- How products can be certified and designated as energy efficient

- How to market the energy efficiency of windows

Items of particular relevance were:

- Explaining the process for NFRC certification and the market benefits for certified products in support of the objective to recruit smaller manufacturers as participants in the NFRC program (Task 1.1).

- The latest version of the International Energy Conservation Code (IECC), of which the 2006 version was being adopted by the first states as the project team developed the Manufacturers Toolkit in 2007. Fact sheets with the 2006 IECC fenestration requirements by state were provided with the toolkit.

- LEED for Homes and the National Green Building Standard. These sustainable design standards were developed in 2007 and 2008 and offered credits for windows with performance exceeding ENERGY STAR criteria. To encourage manufacturers to aim for these higher performance tiers, the project team included information about these standards' criteria in the toolkit.

To supplement the information provided in the Manufacturer Toolkit, the Alliance provided regular updates on developments in the energy efficiency market through the EWC newsletter Word on Windows. Examples of Articles of particular relevance to residential manufacturers are:

- The Tax Credit for Efficient Windows (Spring 2006)

- Florida Code Change Implications (Summer 2006)

- Zero Energy Windows on the Horizon (Winter 2006-07)

- New U-factor Specification in the Pacific Northwest (Winter 2006-07)

- Coming to Grips with Windows and Comfort (Fall 2007)

- Efficient Windows Receive Credit in LEED for Homes (Summer 2008)

- Vacuum Glazing Developments Across the Globe (Summer 2008)

- Weatherizing for the Future (Fall 2008)

- I-Codes: What Changed for Fenestration? (Fall 2008)

- IRS Guidelines for Tax Credit Compliance (Summer 2009)

- National Green Building Standard (Summer 2009)

- Improved Weatherization Software Captures Benefits of Efficient Windows (Fall 2009)

- New National Policies Proposed for Energy Efficiency in Existing Buildings (Fall 2009)

As opportunities arose, the project team provided further information on energy efficiency market developments for the residential fenestration supply side through the following presentations and panel discussions (in addition to the sessions listed under Task 1.1):

- Fenestration Manufacturers Association (FMA) fall meeting, Daytona Beach FL, first week of October 2008. AZS Consulting participated in a round-table discussion on the FL Energy Code and the levels of fenestration energy efficiency suggested as a result of these changes. 
- Northeast Window and Door Association (NWDA) winter meeting, Atlantic City NJ, January 15, 2008. The Alliance presented on the status of existing utility programs for windows and about plausible future programs with higher performance tiers. Attendance: about 60 representatives of the Northeastern window and door industry.

- Window and Door Manufacturers Association (WDMA) Leadership Summit, Tucson AZ, February 16, 2009. Nils Petermann of the Alliance participated in a podium discussion on the relevance of political developments, including the American Recovery and Reinvestment Act (ARRA), for the fenestration industry. Petermann pointed out the importance of providing accurate and credible metrics of energy savings that can be achieved with energy-efficient fenestration. About 100 WDMA members attended this educational session.

- Home Improvement Economic Summit, Fairfax County VA, April 1, 2009. Nils Petermann of the Alliance discussed the tax credit provisions for window energy efficiency improvements contained in ARRA. The audience consisted of 80-100 home improvement professionals and manufacturers.

The Alliance also provided EWC members with email updates to keep them abreast of critical developments, such as the ARRA tax credit or the DOE R-5 Volume Purchase Program.

Assessment: While the original idea for the Manufacturers Toolkit was to offer comprehensive information on a wide range of issues relevant to manufacturers, the project team eventually decided to focus the toolkit content on introducing energy efficiency ratings and market opportunities to manufacturers who are new to these aspects of the fenestration market. This information also included new developments in programs such as building energy codes or green home rating programs. The project team concluded that in order to disseminate this information to manufacturers who are more established in the energy efficiency market, concise newsletter articles or email updates were more effective than comprehensive toolkits, which would invariably contain information that is already well understood by manufacturers who are involved in the NFRC and ENERGY STAR programs. Regardless, manufacturers of any size could find valuable information about energy performance targets among the energy codes fact sheets and utility incentive programs listings provided by the Manufacturers Toolkit.

\section{Task 1.3: NFRC Commercial Ratings}

Task objective: Provide technical support and information to the NFRC commercial windows rating procedure under development.

Background and hypothesis: Prior to this funding period (starting in May 2006), NFRC had decided to develop a Component Modeling Approach (CMA) as its new commercial fenestration rating program. The following framework was proposed for CMA:

- A NFRC-approved component library, made up of 3 items: frames, glazing and spacers.

- A CMA software tool to calculate whole product ratings (U-factor, SHGC, and VT) of fenestration systems assembled with items taken from the library.

- A certification procedure in which an Approved Calculation Entity (ACE) calculates the ratings on behalf of the Specifying Authority and generates a label certificate for each project. 
- Third-party verification by an Inspection Agency (IA), who reviews calculations and conducts a documentation trail audit to ensure the systems listed on the label certificate are reflective o the actual systems installed.

The CMA rating and certification system promises to address the shortcomings of NFRC's prior commercial rating system for site-built fenestration, which requires validation testing of whole product samples. The software-based CMA allows faster project creation from predefined and NFRC-approved components and thus has the potential to increase the use of NFRC label certificates and facilitate code enforcement. For these reasons, the project team supported CMA's development and implementation.

Approaches: The project team supported CMA through participation in the relevant NFRC committees as well as in the NFRC board of directors. The Alliance, University of Minnesota (UMN), and AZS Consulting are NFRC members and were represented at all NFRC membership meetings during the funding period, where they voted on ballots to define the CMA documents before these were finalized and passed to the board of directors for implementation. In addition, the Alliance and UMN contributed to the preparation for CMA implementation through the NFRC board of directors, on which both organizations held one seat since November 2006.

On the NFRC board of directors, Kerry Haglund (UMN), Jeff Harris (Alliance), and later Nils Petermann (Alliance) were actively involved in decisions regarding the structure and implementation of CMA. Haglund served as chair of the CMA Marketing Committee, which developed a marketing plan including promotion of the program to architects, contractors and the fenestration industry, an educational program to increase understanding of how CMA works among industry and code officials, and an enforcement plan to ensure coordination with state and local energy codes. In addition, Haglund also followed current developments regarding AAMA 507 by attending AAMA membership meetings in 2007 and 2008. This standard has been developed by the American Architectural Manufacturers Association as an alternative to NFRC 100 and eventually to CMA, albeit without the third-party verification mechanisms included in the CMA program. Proponents of AAMA 507 repeatedly proposed it as an alternative to NFRC certification in model energy codes, but their proposals have so far been declined.

At the NFRC board of directors meeting on July 23, 2009 in Baltimore MD, the board approved the Component Modeling Approach Software Tool (CMAST) for use in a CMA pilot phase starting the same month. During the pilot phase, component manufacturers were allowed to submit their products for inclusion in the CMA libraries.

In December 2009, the NFRC board of directors approved the NFRC Component Modeling Approach for implementation in January 2010 as the primary energy ratings and certification approach for non-residential fenestration. Some issues needing to be resolved were identified during the pilot phase, however, the NFRC board decided to address these after full implementation. Additional issues needing correction were also anticipated after extensive use following implementation.

Assessment: In January 2010, the NFRC Component Modeling Approach was launched. At the same time, the 2008 version of the California Title 24 building energy standards came into effect, which references CMA. The success of the program will likely depend on successful implementation in California, where the California Energy Commission and utility companies are partnering with the NFRC to educate stakeholders and improve adoption of CMA certification. Kerry Haglund and Nils Petermann remain involved in the NFRC board, which continues to monitor CMA's progress. So far, low participation by component suppliers presents a hurdle to wider use by specifying authorities, but it is uncertain whether this will continue to be an issue in the long run. 


\section{Task 1.4: Commercial Master Toolkit}

Task Objective: Develop a Master Toolkit for commercial window manufacturers.

Background

and hypothesis: At the onset of the funding period, the project team planned to develop a toolkit for commercial fenestration manufacturers based on two main tools which were expected to be available toward the middle of the funding period: the NFRC Component Modeling Approach (CMA) and COMFEN, a tool under development by Lawrence Berkeley National Laboratory (LBNL) for early assessments of façade design options. These tools were intended as the centerpieces of a Commercial Manufacturers Toolkit, to be supplemented with information on codes and standards.

Approaches: A cornerstone of the planned Commercial Manufacturers Toolkit, the NFRC Component Modeling Approach, was not finalized before the final months of this funding period. The other intended central element, COMFEN, was released as a first pilot version in November 2007 and modified in two subsequent versions over the following years. With both CMA and COMFEN still under development, the project team did not develop a Commercial Manufacturers Toolkit. Instead, the team disseminated information to commercial manufacturers though trade shows and meetings.

As exhibitors at the annual fenestration trade show GlassBuild from 2006 through 2009, the project team disseminated copies of the book Window Systems for High Performance Buildings and, after the release of the first pilot version in 2007, info flyers about COMFEN. The same information was provided to commercial manufacturers at the Greenbuild shows in 2007, 2008 and 2009. About 20 copies of Window Systems for High Performance Buildings were disseminated to manufacturers in this way.

Through the EWC advisory council meetings, LBNL kept the commercial manufacturers represented in the advisory council up to date on the development of COMFEN. LBNL presented on this tool during advisory council meetings in July and November 2007, in November 2008 and in November 2009.

To more effectively work with the commercial fenestration industry on energy efficiency promotion, the Alliance participated in the first Energy Committee meeting of the Glass Association of North America (GANA) on February 13, 2009 in Las Vegas. The Alliance introduced the EWC and offered assistance in developing tools in collaboration with the committee. Since this meeting, the GANA Energy Committee has primarily been occupied with proposed changes to ASHRAE Standard 90.1 and had no further communication with the Alliance except for requesting a copy of an article on daylighting released by the Alliance in February 2010 (Word on Windows http://efficientwindows.org/newsletter/WoWSpring2010.pdf, page 4).

Assessment: Due to delays in the implementation of CMA and the completion of COMFEN, the project team did not develop a comprehensive Commercial Manufacturers Toolkit. Instead, the project team promoted the COMFEN pilot versions through direct interaction with manufacturers. Education about CMA was provided by NFRC contractors once the program entered its pilot phase in the summer of 2009.

More in-depth collaboration with the commercial fenestration industry would have been needed for the project team to develop comprehensive toolkits in the absence of final versions of COMFEN and CMA. The project team pursued collaboration through its advisory group meetings and by reaching out to the GANA Energy Committee. These communications resulted in exchange of information on individual topics rather than in a comprehensive toolkit. Such direct interaction appeared valuable for large, specialized commercial manufacturers. Outreach to smaller commercial fabricators and contractors through comprehensive online information would be a worthwhile future activity. 


\section{Task 2: Promotion of ENERGY STAR Compliant and More Efficient Products}

This task was designed to address the demand side in the fenestration market by encouraging the inclusion of ENERGY STAR criteria in purchasing decisions or specifications or the development of more stringent criteria. This task included the promotion of such criteria among consumers, builders associations, code officials and others.

\section{Task 2.1: ENERGY STAR promotion}

Objectives: Provide technical support to those responsible for promoting ENERGY STAR windows in other related efforts.

Background and hypothesis: Prior to this funding period, the EWC's primary goal was wider market penetration for ENERGY STAR windows or other energy-efficient windows. Alongside ENERGY STAR, building energy codes have played a significant role in furthering this goal, as energy code requirements are often comparable to ENERGY STAR criteria in that they call for the use of low-E glazing. Although the market share of low-E windows surpassed 50 percent prior to the start of this funding phase, significant untapped energy savings potential remained from the adoption of energy-efficient fenestration products in the Southeastern United States, particularly in new construction, which was still a booming sector at the start of this funding period.

Approaches: The Alliance and its project partners supported the promotion and adoption of ENERGY STAR windows and other energy-efficient windows as well as the improvement of the ENERGY STAR program through:

- EWC hotline for window performance inquiries by consumers, media, builders, and others

- Outreach to consumers, salespeople and builders at events and trade-shows

- Media input by the Alliance media team

- Support for window energy efficiency through building codes and voluntary standards

- Technical support to energy-efficiency advocates

- Consumer information on the tax credit for energy-efficient replacement windows

- Recommendation for ENERGY STAR labeling modifications

EWC hotline

Through the Efficient Windows Collaborative contact information (ewc@ase.org or 202530-2254) more than 1,000 consumers and professionals contacted the Alliance during the funding period with questions about window energy performance, selection criteria, incentive programs and other inquiries. While the inquiry topics varied and often included very specific issues such as the pros and cons of frame materials or passive solar design, about 30 percent of the questions focused on how to identify energy-efficient windows. The Alliance used this opportunity to explain the concept and benefits of ENERGY STAR for Windows, Doors and Skylights.

Events and trade shows

Through trade show booths, the project team reached more than 900 consumers, builders and contractors with material about energy-efficient windows:

- $\quad$ Southeast Builder Show, Orlando FL, August 3-5, 2006. Partnered with D\&R International on an ENERGY STAR \& EWC booth. 280 visitors: consumers, builders, window manufacturers, contractors, and realtors 
- EE Global, Washington DC, November 12-13, 2007. 15-20 visitors: energy efficiency advocates and program planners

- GreenBuild 2007, 2008 and 2009 in Chicago IL, Boston MA and Phoenix AZ. More than 450 visitors overall: architects, builders and consumers

- Pella Green Pro Expo, Medina MN, April 16, 2008. 40 visitors: builders, remodelers, contractors and architects

- Green DC Day, Washington DC, April 22, 2008. 80 visitors: consumers

- Building Energy 09, Boston MA, March 11-12, 2009. 60 visitors: contractors, design professionals

The project team also partnered with Northeast Energy Efficiency Partnerships on providing four ENERGY STAR Windows sales training workshops in Kentucky, Maryland and Delaware between May and November 2006 for 76 participants in total.

Alliance to Save Energy media team

Over the funding period, the Alliance media team, in collaboration with program staff, provided 28 newspapers and magazines with information on the benefits of ENERGY STAR windows and the windows tax credit. Among these publications were the New York Times, Wall Street Journal, Washington Post, Money Magazine, Chicago Tribune, Home Energy, Replacement Contractor, Glass Magazine and others. In 2007, the combined circulation of articles containing EWC information was 3.77 million. The Alliance does not have data on the circulation of EWC-related articles over the rest of the funding period.

Support for window energy efficiency in building codes

The project team targeted specific opportunities for improving the adoption of low-E or ENERGY STAR windows through voluntary and mandatory standards and codes. The Southeastern United States were identified as a promising region for targeted promotion due to the low market penetration of ENERGY STAR windows reported in this region by D\&R International, the contractor for ENERGY STAR windows promotion on behalf of DOE. 2006 estimates of ENERFGY STAR market penetration by D\&R International assumed 26 to 29 percent for the combined new construction and replacement market in states with ineffective or missing window energy efficiency code criteria, such as Florida, Alabama, and Mississippi. This compared to a national market penetration above 50 percent. During a Southeastern window stakeholders roundtable, hosted by the project team and D\&R International on August 4, 2006, representatives of window suppliers and utility companies identified insufficient signals through energy codes as a barrier for market transformation. Cases in point were South Carolina, Mississippi and Alabama, where building energy codes did not require energy-efficient windows, or Florida, where code enforcement was lacking. The project team decided to focus its efforts on Florida and South Carolina with their high volume of new construction.

Throughout the funding period, AZS Consulting reached almost 500 building code officials, builders, contractors, and window industry representatives with information specific to windows in the Florida energy code. AZS Consulting had been active in the promotion of efficient windows in Florida for years and educated about 80 building code officials and 120 window manufacturers about the role of efficient windows in helping homes meet code performance levels at a workshop during the Annual Building Officials Association of Florida Educational Conference on June 7, 2006. Further education activities by AZS Consulting targeted at Florida code enforcement with regards to windows included:

- Symposium on Energy Efficiency and Moisture Control in Florida, Tampa FL, February 28, 2007. Attendees: 75 window and door manufacturers, HVAC 
manufacturers and contractors, energy raters and builders. Raised awareness of Florida code changes, the increased need for low-solar-gain glass, and potential ramifications for moisture control.

http://www.dwmmag.com/articles/newsSymposium20070308.htm

- Florida Association of Plumbing, Gas and Mechanical Inspectors, North Central Chapter, June 12, 2007. Attendees: 10 association members.

- Simonton Coastal Conference, Saint Augustine FL, June 19, 2007. Attendees: 45 builders and window dealers.

- Simonton Coastal Conference, Clearwater FL, July 31, 2007. Attendees: 100 builders and window dealers.

- $\quad$ Simonton Coastal Conference, Ft. Myers FL, August 9, 2007. Attendees: 50 builders and window dealers.

To also strengthen the role of energy-efficient doors in the Florida energy code, AZS Consulting submitted a code change proposal in December 2008 to allow the input of NFRC-certified values for door energy performance in the software used for the code's performance path. This code change, which allows full credit for the energy properties of high performance doors, was accepted and adopted as of March 1, 2009.

In South Carolina, the Alliance initiated discussions with the South Carolina Energy Office and Code Council as well as with the SC Home Builders Association about the window energy efficiency benefits of implementing an up-to-date energy code. The Alliance held a meeting involving these parties on September 14, 2007 in Columbia SC, and provided the SC Home Builder Association with topic sheets about this issue (Appendix C-1). These discussions showed that, although builders and state policy makers recognized the benefits of energy-efficient windows, improvements in the state energy code would require a substantial coalition of supporters. Such a coalition, including the Alliance and AZS Consulting among 47 other supporting organizations and companies, came together following a 2008 study by the SC Climate, Energy and Commerce Advisory Committee recommending implementation of an up-to-date energy code. This coalition achieved adoption of the 2006 International Energy Conservation Code (IECC) for implementation as of July 1, 2009. By implementing the 2006 IECC, the state ensures the transition to low-solar-gain low-E windows in the state's new residential construction. To help ensure proper application of the 2006 IECC code requirements, particularly as these relate to windows, the Alliance organized code training workshops for more than 200 code officials and builders:

- Central Chapter of the Building Officials Association of South Carolina, Lexington SC, October 14, 2009. Attendees: 31. Six-hour training.

- Coastal Chapter of the Building Officials Association of South Carolina, Folly Beach SC, December 7, 2009. Attendees: 64. Three-hour training.

- Upper State Chapter of the Building Officials Association of South Carolina, Greer SC, January 20, 2010. Attendees: 79. Three-hour training.

- Tri County Chapter of the Building Officials Association of South Carolina, Clemson SC, February 11, 2010. Attendees: 42. Three-hour training.

Funding for these trainings was provided through cost sharing among this agreement, another cooperative agreement between DOE and the Alliance, and support from EWC members and the Sierra Club.

ENERGY STAR requirements in voluntary standards

In April 2007, the National Association of Home Builders started the process of establishing a National Green Building Standard. In the original draft, the standard offered credits for ENERGY STAR windows, but no recognition of even higher 
performance. The Alliance and partners among the EWC advisory group achieved recognition of ENERGY STAR windows as the mandatory minimum performance in the standard, which was released in early 2009.

Technical support to energy efficiency advocates

The Alliance provided technical information on the costs and benefits of energy-efficient windows to supporters of energy efficiency policies that included criteria for window performance. In August 2008, the Natural Resource Defense Council (NRDC) received data from the Alliance for discussions with Fannie Mae and Freddie Mac about possible efforts toward offering energy efficient mortgages that would help finance residential energy efficiency improvements. This data included RESFEN energy use simulations comparing standard single- and double-pane windows with energy efficient low-E double- and triple-pane options as well as average window and installation cost information from RSMeans Repair and Remodeling Cost Data.

The Building Codes Assistance Project (BCAP) was supported with data on the cost and benefits of proposed more stringent building energy code provisions for windows in Delaware, West Virginia, and Texas. Cost assumptions were based on conversations with local window retailers while energy savings estimates were based on RESFEN simulations.

Tax credit information

The Alliance provided information to help consumers take advantage of the federal tax credit for energy-efficient replacement windows - based on ENERGY STAR in 2006-07 and on more stringent criteria in 2009-10. The tax credit criteria are explained on the web page www.efficientwindows.org/taxcredit.pdf, which also includes a list of EWC members who offer qualifying products.

Recommendations for ENERGY STAR labeling modifications In response to the 2008-09 revision process for the ENERGY STAR for Windows, Doors and Skylights program, the Alliance recommended adding an indicator to the ENERGY STAR label that categorizes qualifying windows as high-, medium- or low-solar-gain products to educate consumers about the importance of the solar heat gain coefficient. Prior to submitting these comments, the Alliance sought support among the EWC advisory group. Among window manufacturers, however, there was little enthusiasm for increasing the amount of information to be included on the label. Nevertheless, since the Alliance regarded consumer education about window solar heat gain as an important issue it submitted comments to DOE included in Appendix E-1. http://www.energystar.gov/index.cfm?c=archives.windows criteria amendment.

These recommendations were not adopted by DOE.

Assessment: While the project team's support for ENERGY STAR Windows and other energyefficient windows extended to both the replacement market and new construction, its impact on the market penetration of efficient windows was likely greatest in new construction due to the already high saturation of the replacement market with energyefficient windows. Before the start of this funding period, in 2005, the market penetration of ENERGY STAR windows was 53 percent according to the 2006 edition of the Study of the U.S. Market for Windows, Doors and Skylights by Ducker Research Company. In 2008, U.S. DOE estimated the market penetration to be 59 percent overall and 90 percent in the replacement market. ${ }^{4}$ Regardless of the high market penetration of ENERGY STAR windows in the replacement market, the project team's outreach and education work benefited consumers by explaining how ENERGY STAR windows can differ in

\footnotetext{
${ }^{4}$ U.S DOE ENERGY STAR Program. 2008. Windows, Doors, and Skylights: Draft Criteria and Analysis. Prepared by D\&R International.
} 
their solar heat control attributes, how the impact of efficient windows differs by climate, and how to take advantage of the substantial tax credit for replacement windows that came into effect in 2009. The project team must have achieved a more significant and longer-lasting impact on the use of energy-efficient windows through its work in the new construction sector, in particular by promoting ENERGY STAR windows as a mandatory measure in the National Green Building Standard and through the enforcement of effective energy code requirements in Florida and South Carolina. Conversations with the South Carolina Code Council indicate that during the phase-in period of the new code in 2009, window suppliers in the state were eager to rid their inventories of conventional windows to stock low-E windows instead.

During this funding period, the Alliance and its project partners offered direct advice and educational material on energy-efficient residential windows to about 1,900 consumers and professionals, trained about 700 code officials, builders and members of the residential windows business about the role of energy code requirements on window energy efficiency and provided window energy efficiency information to newspapers and magazines with a combined circulation of several million.

\section{Task 2.2: Residential Performance Tiers}

Objectives: Develop residential windows performance tiers that promote benefits of windows that exceed ENERGY STAR criteria.

Background

and hypothesis: Before the start of this funding period, more than 50 percent of the windows market already met the energy-performance tier set by the ENERGY STAR program. This inclusion of the majority of the market, which this project further supported through Task 2.1, marked significant progress relative to the year 2000, when the ENERGY STAR market penetration was about 35 percent. However, since the ENERGY STAR criteria had not substantially changed since 2000 , few products exceeded this moderately high performance tier by any large margin. Prior to this funding period, no significant programs existed to encourage window performance beyond U-factor 0.35 and/or SHGC 0.40 , which were the most stringent criteria of the ENERGY STAR program and among common energy codes. To encourage the production and use of significantly more energy-efficient windows, higher performance tiers were needed.

Approaches: To explore ways of improving not only the breadth, but also the depth of energy efficiency improvements in the windows market, the project team worked with developers of voluntary window performance tiers that would encourage the use of highly-efficient windows. For initial discussion among the team, LBNL and DOE, the Alliance drafted a memo on Higher Performance Tiers for Residential Windows in March 2007 (Appendix E-2). This discussion resulted in a strategy for higher performance tiers that focused on utility programs, awareness-raising outreach, and voluntary sustainable home programs.

The Alliance's support for higher performance tiers in utility programs focused on collaboration with the Consortium for Energy Efficiency (CEE), which is summarized under Task 4.3. In addition, the Alliance created awareness among the EWC window industry members for a performance tier initiated by Bonneville Power Administration (BPA), which in the fall of 2006 changed the area-weighted U-factor specification for its weatherization program from 0.35 to 0.30 , thereby exceeding ENERGY STAR criteria.

In its support for higher performance tiers, the Alliance focused on U-factor criteria between 0.25 and 0.20 for northern-climate windows and on SHGC 0.25 or dynamic solar control for southern climate windows. Such criteria would support the bestperforming products in the market by encouraging the use of triple-pane windows in the 
north and windows with new triple-silver low-E coatings or dynamic glazing in the south. The Alliance raised awareness for this savings potential with available technologies through articles on zero energy windows in the Winter 2006/07 issue of the EWC newsletter Word on Windows and in an article on a field study with highly-insulating windows in the Fall 2007 issue (see http://efficientwindows.org/newsletters.cfm). The Alliance also did a poster presentation on highly-insulating windows at the Affordable Comfort conference in Cleveland, OH on April 24, 2007 (Appendix C-2) and presented performance and market information on highly-insulating windows to about 500 building professionals at the Greenbuild conference in Chicago, IL on November 8, 2007.

A major opportunity for the promotion of higher window performance tiers was the simultaneous development of two sustainable home programs - LEED Residential by the U.S. Green Building Council (USGBC) and the National Green Building Standard (NGBS) by the National Association of Home Builders (NAHB). As both organizations sought input on their criteria development during the first half of 2007, the Alliance collaborated with LBNL to submit proposals for criteria that, while requiring ENERGY STAR windows as a minimum performance tiers, would reward the use of windows meeting higher performance tiers. The tiers recommended by the Alliance and LBNL included U-factor 0.25 and 0.20 in the north and SHGC 0.30 and 0.25 in the south. The Alliance provided energy savings estimates for typical homes and counts of known manufacturers offering products that met these criteria. Based on this information and on input from LBNL, the standard development committee for NGBS approved higher performance tiers going as far as U-factor 0.25 in the north and SHGC 0.25 in the south. The committee for LEED Residential, on the other hand, was more concerned about product availability and thus limited the highest tier to U-factor 0.28 in the north and SHGC 0.30 in the south. Once LEED Residential and NGBS were published in early 2008 and 2009 respectively, the Alliance informed industry members of these voluntary performance tiers through the EWC Manufacturers Toolkit and the Word on Windows newsletter. Summaries of these performance tiers are also presented at http://efficientwindows.org/homesnew_certificationprograms.cfm.

Starting in December 2008, the Alliance participated in organizing a volume purchase program for R-5 (U-factor around 0.2) windows and low-E storm windows initiated by the DOE Building Technology Program. The Alliance assisted DOE in developing fact sheets and presentation content and in discussions with interested parties for promoting U-factor 0.22 as a high-performance tier as well as low-E storm windows as an effective solution for energy efficiency upgrades. In addition, The Alliance provided input to the detailed specifications for product eligibility and kept EWC members abreast of the program's development while including information about this program in a webinar mentioned under Task 3.2. The program launch was set for May 2010.

Assessment: This task aimed to achieve the introduction and promotion of new products and the penetration of higher performing products in the market. The project team promoted windows that meet performance tiers beyond ENERGY STAR specifications primarily through criteria in the National Green Building Standard and LEED Residential. These programs are the most widely used voluntary sustainable home programs, and the inclusion of higher window performance tiers in these programs offers an opportunity for window manufacturers to market advanced products.

The Alliance's presentations on high-performance windows at the Greenbuild, Ecobuild, Affordable Comfort and CEE conferences as well as through a June 2009 webinar reached about 850 design professionals and utility program managers. This outreach raised awareness for higher performance tiers but could not address potential incremental cost barriers with advanced products. 
Incremental cost may be addressed by DOE's volume purchase program for highlyinsulating windows, in the preparation of which the Alliance has been involved since December 2008. The implementation of this program is scheduled after the end of this funding period.

\section{Task 2.3: Commercial Performance Tiers}

Objectives: Develop performance criteria and tiers for commercial windows that emphasize high energy efficiency performance.

Background and hypothesis: There is no simple indicator of energy efficiency for commercial windows that would equal ENERGY STAR for residential windows. Building energy codes provide energy efficiency criteria for commercial fenestration, but these depend on the code used in a given jurisdiction, and in many codes the U-factor and SHGC requirements vary by window area and shading conditions. To help design professionals and utility incentive providers specify energy-efficient windows that would likely exceed local energy code requirements, the project team developed draft guidance on commercial window performance tiers.

Approaches: To develop performance tier recommendations, the Alliance compared existing standards, guidelines, and energy-efficiency programs for commercial windows. These sources provided a range of energy performance specifications for different climates that were developed with stakeholder input. Based on these sources, the Alliance developed recommendations for performance tiers based on the following approach:

- Two tiers: Tier 1 criteria would reflect relatively common, but energy-efficient practice. Tier 2 criteria would be ambitious but still achievable.

- Tier 1 based on the most stringent prescriptive requirements found among prominent building energy standards. These requirements may already be in place in parts of the country, but even where this is the case, meeting the prescriptive criteria is not a given due to compliance alternatives.

- Tier 2 based on advanced criteria in prominent voluntary programs or highperformance standards such as ASHRAE Standard 189, the Core Performance Guide by the New Buildings Institute, and other initiatives.

The Alliance listed and explained these recommended tiers in a report "Performance Tiers for Energy Efficient Commercial Windows" completed in September 2008 (Appendix E-3). Since this report offers an overview of criteria set by different standards and guidelines, the Alliance disseminated these recommendations to a few organizations interested in commercial performance tiers with the disclaimer that these recommendations had not gone through stakeholder review.

Assessment: The Alliance used the developed recommendations for discussions with individual stakeholders only, including architects and consulting companies requesting guidance on performance specifications and one utility company considering criteria for incentive programs. The Alliance did not make its recommendations public, given that these could either have been ignored by stakeholders or could have interfered with ongoing discussions about fenestration criteria for ASHRAE Standards 189 and 90.1-2010.

Nevertheless, the Alliance will use these preliminary performance tier recommendations as a basis for future research on the availability and structural performance of products meeting Tier 2 criteria, which may result in more specific and publicly available recommendations for design professionals. Furthermore, the Alliance may use its research on performance tiers as a basis for recommendations for the eventual development of ENERGY STAR criteria for some commercial windows. 


\section{Task 3: Promotion of Research Tools to Suppliers, Contractors and Architects}

This task was designed to promote not only supply and demand for efficient windows, but also their optimum application to ensure energy savings. This task included the delivery of education and outreach programs to multiple audiences through conference presentations, publication of articles, educational material and online databases.

\section{Task 3.1: Residential Products Database Expansion}

Objectives: Recruit new window manufacturer participants into the EWC data base used by consumers to evaluate windows choices.

Background and hypothesis: In 2004, the Alliance and University of Minnesota established the EWC Window Selection Tool, a product database that allows consumers to evaluate window choices based on energy performance (see http://efficientwindows.org/selection.cfm). Funding was supplied through joiner fees by those window manufacturers who wished to have their products included in the Window Selection Tool. The joiner fee was set at $\$ 3,000$ per manufacturer. While a number of mostly larger manufacturers joined the database, medium sized and smaller manufacturers found it difficult to provide this fee. The project team sought to make it easier for manufacturers to be included in the window selection tool so as to give consumers good information on where they can find products of the energy performance they are looking for.

Approaches: An obvious first step to help the recruitment of more manufacturers for the window selection tool was to offer discounted joiner fees. In January 2007, the Alliance changed the fee structure for the database to a joiner's fee of $\$ 1,000$ to $\$ 3,000$ depending on the manufacturer's size. In early 2008 , however, the project team decided to expand the products database to products from all its manufacturer members and replace the database-specific fees with dues for all EWC members. These dues served as cost share contributions to fund the data entry work involved in the expansion of the database as well as other updates and refinements of the EWC website. Due to the substantial number of EWC members, it was possible to keep individual member dues low enough ( $\$ 500$ $\$ 1,000)$ to allow the participation of smaller manufacturers.

In the spring of 2009, in response to the tax credit for energy-efficient replacement windows, doors and skylights established by the American Recovery and Reinvestment Act (ARRA), the project team created a database of qualifying products manufactured by EWC members (http://efficientwindows.org/taxcredit/taxcredit.cfm).

Assessment: Between 2006 and 2009, the project team increased the number of manufacturers with products in the Window Selection Tool from 16 to 38. The number of referrals from the Window Selection Tool to manufacturers' websites were tracked and increased as follows:

2006: 16 manufacturers, 13,973 referrals to manufacturers' websites 2007: 20 manufacturers, 23,299 referrals to manufacturers' websites 2008: 25 manufacturers, 24,483 referrals to manufacturers' websites 2009: 38 manufacturers, 31,010 referrals to manufacturers' websites

While some individual manufacturers offer hundreds or even thousands of product variations, the project team limited the number of products displayed in the Window Selection Tool so as to avoid consumer confusion. Only prominent product options with representative features were included, which limited the number of displayed options to about 5-25 per generic window type offered by one manufacturer. Different generic window types, differentiated by frame type, glazing layers and low-E type are displayed 
in the Window Selection Tool to allow users to differentiate product categories based on typical energy efficiency attributes.

The directory of products qualifying for the ARRA tax credit included 41 brands. The project team did not track referrals generated through this directory.

\section{Task 3.2: Residential Designers' Master Toolkit}

Objectives: Develop a Master Toolkit for residential designers along with related curriculum materials. Present to building science educators and schools of architecture.

Background and hypothesis: The intent of this task was to provide residential design professionals, builders and building science educators with critical information about window energy efficiency through a comprehensive toolkit and through presentations and educational material.

Approaches: $\quad$ Residential Designers' Toolkit

In March 2007, the project team developed an online toolkit for residential designers (http://www.efficientwindows.org/toolkits/tk designer1 0.cfm), including the following topics:

- Why window energy efficiency is essential to home design

- Window design and product selection issues for energy-efficient homes

- Tools for window selection and energy simulations

Among the window design issues, this toolkit emphasized the importance of quality installation, related guidelines and standards, building energy codes, and heating and cooling system downsizing opportunities due to energy-efficient windows.

Educational publications and material In the summer of 2007, the University of Minnesota completed the third version of Residential Windows: a Guide to New Technologies and Energy Performance with support from this cooperative agreement and input from Lawrence Berkeley National Laboratory and in-kind contributions from industry partners in terms of technical information and graphics. This book provides the information necessary to evaluate and select windows and to effectively integrate them in home design. The revised information includes updated energy-performance and cost information; advances in emerging technologies; revised and expanded sections on comfort and condensation, durability information, life-cycle performance; new information on window installation methods, building codes, and impact-resistant windows.

The project team disseminated Residential Windows and updated versions of its 8-page EWC Builder Toolkit (http://efficientwindows.org/toolkits/BuilderToolkit.pdf or Appendix B-2) to select building science educators and industry partners, to attendees of the 2008 and 2009 Greenbuild conferences and, via the Ohio Community Development Corporation to builders, construction supervisors and developers participating in training programs in Columbus, Ohio on April 23-24, 2008.

In September 2008, the Alliance and University of Minnesota created a Multiple Benefits Fact Sheet on the benefits of energy-efficient residential windows besides energy savings: peak demand reduction, summer and winter comfort, and less condensation. The project team distributed copies of this 10-page brochure at Greenbuild conferences in 2008 and 2009.

Cooperation with Army Corps of Engineers residential retrofit assessment In the spring of 2008, the Alliance provided information on typical window options by climate, typical performance values, and estimated typical window prices in the form of fact sheets to support the U.S. Army Corps of Engineers (USACE) in its efforts to 
model the impact of window choices on energy use in barracks and to determine the costeffectiveness of energy-efficient window choices (Appendix C-4). The Alliance based its window pricing estimates on published average construction cost data (RSMeans) ${ }^{5}$, on input from glazing and window supply companies and on feedback from the USACE procurement department. The cost-effectiveness modeling results were included in the International Energy Agency Annex 46 effort "Holistic Assessment Toolkit on Energy Efficient Retrofit Measures" and were presented by James Miller of USACE at a workshop on energy-efficient technologies for government buildings on January 28, 2009 in Chicago, IL (http://www.annex46.org/workshops_seminars/fifth_workshop).

Conclusions were that although premium replacement windows did not meet cost effectiveness criteria for energy conservation projects, they were determined cost effective for major renovation and repair projects where the focus is on marginal cost compared to conventional windows.

Education sessions

The Alliance organized the following educational sessions on energy-efficient residential window design:

- Ecobuild Conferences, Efficient Windows Collaborative Educational Theaters

o December 12 and 13, 2007 in Washington DC

o May 21 and 22, 2008 in Anaheim CA

o December 10 and 11, 2008 in Washington DC

The Alliance invited speakers to three educational session tracks on the trade show floors of separate Ecobuild conferences. Each session consisted of 5-6 short presentations and discussions with the audience. A total of about 100 attendees were reached this way. Most of the presentations focused on commercial windows issues (see Task 3.5) but residential window design principles were also discussed.

- On June 11, 2009, the Alliance hosted a webinar on Window Energy Efficiency Beyond Business as Usual. The focus of the 75 minutes webinar was on high-end window technologies, but low-E storm windows and the specific needs of lowincome weatherization programs were also discussed. Presenters and presentations were:

o Marc LaFrance, DOE: Advanced Window Products - A Key Strategy to Save Energy, Save Money, and Mitigate Carbon

o Christian Kohler, LBNL: Highly Insulating Windows

o Brandon Tinianov, Serious Materials: Advance Window Technolgies: Overview and Benefits

o Tim McGlinchey, GED Integrated Solutions: $\underline{\mathrm{R}-5 \text { Windows }}$

o John Hamilton, Community and Economic Development Association of Cook County: The WAP Effect: High-Efficiency Windows \& The Dilemma (Tyranny?) of Audit Algorithms

The Webinar recording is available at http://ase.org/content/article/detail/5666. Serious Materials provided cost share for hosting the webinar. It was joined by 176 attendees, including builders, utility program managers, weatherization professionals, window industry members, energy efficiency advocates and others.

The project team also presented at the following events:

- Energy and Environmental Building Association (EEBA) Excellence in Building Conference. Minneapolis MN, October 10, 2007. The University of Minnesota

5. RSMeans. 2006. Repair \& Remodeling Cost Data 2007: Commercial/Residential. Reed Construction Data. 
presented fundamental and detailed information about residential and commercial window energy efficiency to an audience of about 40.

- Greenbuild, Chicago IL, November 8, 2007. John Carmody of the University of Minnesota and Nils Petermann of the Alliance to Save Energy presented on window rating and simulation tools and window performance tiers and advanced technologies. These presentations included both residential and commercial content. Attendance: 450-500, mainly architects.

- On March 12, 2008, the Alliance presented information about window performance considerations to builders in Latham, NY. This presentation was part of an effort to educate participants in the NYSERDA High Performance Residential Development Challenge. The goal of the challenge was to construct homes that are 63 percent more energy efficient than if built to minimum code requirements. Since efficient windows are needed for this task, the Alliance facilitates information exchange between EWC members and builders about window options with a low U-factor and a range of SHGC values for optimum solar heat gain. To facilitate window solar gain considerations, the Alliance offered a customized fact sheet (Appendix $C$-3).

Assessment: The project team in collaboration with its project partners reached 650 to 700 design professionals and students through presentations on residential design considerations for window energy efficiency. In addition, the project team distributed 200 copies of the Residential Windows book, the EWC Builder Toolkit and the EWC Multi Benefits Fact Sheet to design professionals and building science educators. The latter two publications were also posted online for a wider audience along with the Residential Designers' Toolkit.

\section{Task 3.3: Energy Efficient Residential Windows Articles}

Objectives: Prepare and publish articles on energy efficient residential windows in the trade press.

Background and hypothesis: This task supplemented the project's outreach to both the supply and demand side of the residential windows market through articles in publications reaching key audiences.

Approaches: $\quad$ Starting with its June 2007 issue, the Door and Window Manufacturer Magazine agreed to publish articles provided by AZS Consulting of the project team on a regular basis for the magazine's "Eye on Energy" column. The resulting articles (Appendix D-1) were:

- June 2007: "Think Green to Stay Out of the Red"

- August 2007: "When Good Windows Look Bad"

- November 2007: "Lapsed NFRC Label Blows ENERGY STAR Job"

- June 2008: "The FTC is Watching: Make Sure You Back Up Your Green Claims"

- September 2008: "An Energy Modeling Primer: How Do Windows Fit In?"

- November 2008: "Where Does Your Cradle Fall?"

Furthermore, AZS Consulting contributed an article on "Window Labels: Missing in Action" to the September/October issue of Home Energy. This article reports experiences with wrong or incomplete field labeling of windows and describes the correct procedure for NFRC field labeling. This article can be viewed at http://www.homeenergy.org/article preview.php?id=557\&article title=Window Labels: Missing_in_Action.

The Alliance contributed an article about window options, energy efficiency and thermal comfort to the March 2008 edition of the Cabin Life magazine (Appendix D-2). The Alliance addressed other topics through the EWC newsletter Word on Windows, which 
was issued nine times between spring 2006 and spring 2010

(http://efficientwindows.org/newsletters.cfm).

Assessment: The number of articles and the publications' circulation was as follows:

- 6 Door and Window Manufacturer Magazine articles. Circulation: 30,000 each. ${ }^{6}$

- 1 Home Energy article. Circulation: 5,000.

- 1 Cabin Life article. Circulation: 57,000.

- 7 Word on Windows issues. Circulation: about 900 each.

- Cumulative circulation: more than 245,000

\section{Task 3.4: Commercial Products Database}

Objectives: Develop prototype data base to link manufacturers' products to designers and specifiers.

Background

and hypothesis: Based on its experience with the EWC residential products database, the Alliance planned to also develop the prototype of a database for commercial products. This database would allow designers and specifiers to find products that meet specific energy performance criteria. According to these plans, the product database would not only offer linkage to products but also serve as a tool to show the energy performance impacts of different product options.

Approaches: The project team regarded the further development of the NFRC Component Modeling Approach (CMA) as a vital basis for the design of this tool. Assuming that CMA would be established during the funding period, the project team planned to collaborate with the NFRC to develop a database that would provide an accessible source for performance information on a variety of fenestration components and include energy performance assessments of fenestration system options depending on climate, the combination of different components, and relevant building characteristics.

CMA was not fully implemented before January 2010. Since the project was continued as a no-cost extension after May 2009, this did not allow sufficient time or funding for the project team to integrate CMA product data into a database before the end of the funding period.

Assessment: The project team did not develop the planned commercial products database due to the delayed implementation of CMA and the shortage of remaining time and funding once CMA came into effect in January 2010. Nevertheless, the revised Façade Design Tool developed under Task 3.5, which allows users to rank and compare window system performance, may be further developed in the future to offer information on available components that can be used for such window systems and that are also included in the CMA rating system.

\section{Task 3.5: Commercial Designers’ Master Toolkit}

Objectives: Develop a Master Toolkit for commercial designers along with related curriculum materials. Develop and present technical information at key conferences.

Background and hypothesis: The intent of this task was to provide commercial design professionals, building owners and building science educators with critical information about window energy efficiency through online information and through presentations and educational material. Through its advisory group meetings, the EWC gathered substantial input on challenges facing energy efficient fenestration in the commercial sector. The project team gained further

\footnotetext{
${ }^{6}$ Circulation as of June 2008 (see www.dwmmag.com/index.php/about)
} 
Approaches: Based on input from the EWC's commercial advisory group, the project team decided to focus on three building types: schools, office buildings, and smaller commercial buildings with site-built fenestration such as retail buildings.

Information tools development The NFRC's Component Modeling Approach (CMA) and COMFEN by LBNL were intended as central components of the Commercial Designers' Toolkit. However, CMA was not implemented before January 2010 and COMFEN was only available in pilot versions until the end of the funding period. As these components were not yet finalized, the project team decided to address office buildings and schools individually by developing "Tools for Schools", an information package on window design for schools, and by enhancing the Façade Design Tool for office buildings:

- Tools for Schools: Narrative information about window design in school buildings (Appendix B-3). This document for school window design decision makers is available on the EWC website and was disseminated at Greenbuild conferences in 2008 and 2009 and was shared with DOE's Technology Validation and Market Introduction Initiative (TVMI) in support of DOE's EnergySmart Schools program.

- Façade Design Tool: The University of Minnesota further developed the Façade Design Tool for office buildings (www.commercialwindows.umn.edu). The Facade Design Tool allows users to choose the design conditions of a window and rank and compare the performance data in terms of annual energy, peak demand, carbon, daylight illuminance, glare, and thermal comfort. The revised tool based its data on a pilot version of COMFEN and included a new user interface and graphic items. This revised version was presented to interested attendees at the EWC booth at the 2008 Greenbuild conference.

Input to other organizations' efforts

The project team also provided input to other organization's work on design tools and information for windows in offices and other commercial buildings. The University of Minnesota collaborated with LBNL on designing the third pilot version of COMFEN, a simulation tool for office façade design. In August 2008, the Alliance supported the National Institute of Building Sciences with updated information on fenestration standards and energy efficiency guidance for the windows section of the Whole Building Design Guide (http://www.wbdg.org/design/env_fenestration_win.php), a web-based portal providing government and industry practitioners with a wide range of buildingrelated guidance. Many of the Alliance's suggestions were integrated in the updated Whole Building Design Guide section.

In the spring of 2008, the Alliance provided information on typical window options by climate, typical performance values, and estimated typical window prices in the form of fact sheets to support the U.S. Army Corps of Engineers (USACE) in its efforts to model the impact of window choices on energy use in office buildings and to determine the cost-effectiveness of energy-efficient window choices (Appendix C-5). The Alliance based its window pricing estimates on published average construction cost data (RSMeans) ${ }^{7}$ and on input from glazing and window supply companies.

Educational sessions

7. RSMeans. 2006. Repair \& Remodeling Cost Data 2007: Commercial/Residential. Reed Construction Data. 
The Alliance organized the following educational sessions on energy-efficient commercial window design:

- Ecobuild Conferences, Efficient Windows Collaborative Educational Theaters: The Alliance gathered speakers to three educational session tracks on the trade show floors of separate Ecobuild conferences. Each session consisted of 5-6 short presentations and discussions with the audience. A total of about 100 attendees were reached this way. Although residential issues were also discussed, most of the presentations focused on commercial window design:

Sessions on December 12 and 13, 2007 in Washington DC:

Glazing trends for sustainable design

John Carmody, University of Minnesota

Don McCann, Viracon Architectural Glass

New developments in pultruded fiberglass fenestration products Jeff Miller, Comfort Line Inc.

An overview of fenestration energy performance ratings Jim Benney, National Fenestration Rating Council

High-performance window films John Meade, Southwall Technologies

Recent and upcoming developments in efficient window technologies Nils Petermann, Alliance to Save Energy Lou Podbelski, SAGE Electrochromics, Inc. John Meade, Southwall Technologies

Sessions on May 21 and 22, 2008 in Anaheim CA:

Architectural trends for sustainable glazing design Nils Petermann, Alliance to Save Energy

Enhancing glass' solar control performance with window film John Meade, Southwall Technologies

California Energy Commission Window \& Daylighting Projects Michael Seaman, California Energy Commission

The leading edge of efficient window technologies Nils Petermann, Efficient Windows Collaborative John Meade, Southwall Technologies

Visions of smart, dynamic glazing Barbara Lang, Glass Paradigm

December 10 and 11 in Washington DC

Tools for Choosing Energy Efficient Windows Ray McGowan, National Fenestration Rating Council Nils Petermann, Alliance to Save Energy

Existing Window Upgrades with High R.O.I. Dave Martin, Allied Windows

Frank Hetman, Jr., Mon-Ray

Built Tough: Efficient Windows, Commercial Grade Mario Tarquinio, Traco

Specifying and Installing Windows for Air tightness and Water resistance Frank Hetman, Jr., Mon-Ray Tom Patterson, The WindowMan

Fiberglass Windows: Versatile Options for Durable Efficiency Anthony Bartolini, Inline Fiberglass

The leading edge of efficient window technologies

Nils Petermann, Alliance to Save Energy

Tim Finley, SAGE Electrochromics 
Robin Roy, Serious Materials

The project team also presented at the following events:

- Energy and Environmental Building Association (EEBA) Excellence in Building Conference. Minneapolis MN, October 10, 2007. The University of Minnesota presented fundamental and detailed information about residential and commercial window energy efficiency to an audience of about 40 .

- Greenbuild, Chicago IL, November 8, 2007. John Carmody of the University of Minnesota and Nils Petermann of the Alliance to Save Energy presented on window rating and simulation tools and window performance tiers and advanced technologies. These presentations included both residential and commercial content. Attendance: 450-500, mainly architects.

- Ecobuild, Washington DC, December 13, 2007. 1-hour session on window specification for commercial architects, specifiers, and energy program managers. Don McCann (Viracon), Jim Benney (NFRC) and John Carmody (University of Minnesota) presented. Attendance: 25.

- PBDewberry, architectural design firm, Arlington VA, April 21, 2008. Presented commercial windows information to architects working on Job Corps centers for the Department of Labor. Attendance: 16 architects.

- Ecobuild, Anaheim CA, May 22, 2008. 1-hour session introducing COMFEN. Attendance: 8 architects.

- Ecobuild, Washington DC, December 11, 2008. 1-hour session introducing COMFEN. Attendance: 6 architects.

- ASHRAE's Net-Zero Conference, San Francisco CA, March 30. University of Minnesota presented on "The Role of Windows in Achieving Net Zero Buildings" provided an overview of tools for assessing the energy relevance of window design options. Available at www.ashrae.org/events/page/2198. Attendance: about 40.

The University of Minnesota also prepared a course on commercial fenestration energy efficiency for American Institute of Architects continuing education credits hosted at the University. However, this course, scheduled for late September 2007, had to be cancelled due to low registration.

Assessment: The project team in collaboration with its project partners reached about 600 design professionals and building science educators through presentations on commercial design considerations for window energy efficiency. In addition, the project team distributed about 60 copies of "Tools for Schools" to design professionals and made this information package available online. By updating information for the Whole Building Design Guide, the Alliance provided input to an online resource with more than 400,000 users per month.

The project team did not develop its material in the originally intended form of a comprehensive toolkit because central components (CMA and COMFEN) were not finalized during until shortly before the end of the funding period. However, design guidance for windows in schools and the enhanced Façade Design Tool for office facades addressed these two building types. The project team also discussed information tools for retail stores and other smaller buildings with site-built fenestration, but input from advisory group members indicated this as a sector that is difficult to effectively address without codes, standards, and programs such as CMA. 


\section{Task 3.6: Energy Efficient Commercial Windows Articles}

Objectives: Prepare and publish articles on energy efficient commercial windows in the trade press.

Background

and hypothesis: This task supplemented the project's outreach to both the supply and demand side of the commercial windows market through articles in publications reaching key audiences.

Approaches: The Alliance authored an article on "Energy Efficient Glazing Basics" for the September 2009 issue of Buildings, a magazine for facilities professionals (Appendix D-3).

The Alliance provided Building Design and Construction magazine with critical content for articles in the May 2008 and the October 2009 issues. These articles focused on "Novel Glass Technologies" and "The Structural Power of Glass", and the Alliance contributed content on energy-efficient glazing trends, design tools such as COMFEN, and information on codes and standards. The content of both articles served as the basis for an online AIA continuing education credit exam. These articles are posted at http://sc.leadix.com/bdcuniversity/course/overview.php?courseid=1062 and http://sc.leadix.com/bdcuniversity/course/overview.php?courseid=1799.

Assessment: The Alliance authored one article for a magazine with a circulation of more than 57,000 (Buildings) and contributed substantial input to two articles for a magazine with a circulation of 74,500 (Building Science and Construction). 


\section{Task 4: Promotion of Market Transformation Programs (Utility Rebate Programs)}

This task was designed to facilitate the development of utility incentive programs to promote more efficient residential and commercial windows. This included partnership with regional and local entities on the development of programs and customized information to move the market toward the highest performing products.

\section{Task 4.1: Residential Windows Utility Provider Promotional Inventory}

Objectives: Compile inventory and profiles of residential energy efficient windows promotion programs at electric and natural gas utilities.

Background

and hypothesis: Utility companies across the country offer energy efficiency assistance to their customers in the form of rebates, low-interest loans, free services, advice or by other means. Although different resources on the range of energy-efficiency programs are available online, a directory dedicated to window-specific programs makes it easier to find relevant information for utility customers who wish to learn about programs for window upgrades or replacements.

Approaches: The Alliance annually updated an inventory of utility and state window energy efficiency program providers posted at http://efficientwindows.org/UtilityIncentivesWindows.pdf. This inventory includes rebate and incentive programs for energy-efficient replacement windows and after-market products such as window film and storm windows, windowrelated low-income energy-efficiency assistance, as well as whole-house energy efficiency incentives that can also apply to windows. As main resources, the Alliance used the Database of State Incentives for Renewable Energy (www.dsireusa.org) and a utility programs listing by the Edison Electric Institute.

Assessment: The latest (February 2010) update of the residential windows utility provider promotional inventory included summary information and web links for window-related programs by 122 utility companies and state agencies in 32 states. The highest concentration of programs was listed for Oregon (24), Washington (13), California (10) and Massachusetts (9).

\section{Task 4.2: Residential Utility Provider Outreach}

Objectives: Prepare an outreach plan to disseminate Master Toolkits and training materials to residential utility program providers.

Background and hypothesis: From the start of the funding period, the residential windows utility provider promotional inventory informed the Alliance of the status of promotional programs for energyefficient windows across the United States. Such programs were offered by a wide range of utilities in many states. However, such programs were unevenly spread and several programs were diminishing in relevance since building energy code requirements and average product performance in the market were catching up with performance levels incentivized by many programs. Utility provider demand for educational outreach depended on previous experience and local regulatory, market and climatic conditions.

Approaches: From initial conversations with the Consortium for Energy Efficiency and the California Public Utilities Commission, the Alliance learned that utility interest in window programs was not commonplace since the often high cost of window measures was a barrier in many cases. Nevertheless, the Alliance learned of cases where window programs were being strengthened and thus adopted the approach to address utilities' demand for 
information and materials on a case-by-case basis. Interactions with utility program providers in different regions of the country were as follows:

- Pacific Northwest: Bonneville Power Administration - Since October 1, 2006, BPA required window replacements to meet an area-weighted average $U$-factor of 0.30 in order to qualify for BPA incentives. This specification was based on a market assessment by BPA and represented the most stringent performance level among utility programs at that time. The Alliance contacted BPA for details and disseminated this information to industry stakeholders through the EWC membership and to utility companies through the June 2006 CEE meeting in order to raise awareness of the viability of more stringent specification than the $0.35 \mathrm{U}$-factor limit for northern ENERGY STAR windows.

- Florida: Progress Energy - In the spring of 2007, Progress Energy Florida implemented an incentive program for ENERGY STAR windows for replacement and new construction. AZS Consulting supported this implementation through four trainings on critical window energy efficiency issues in Florida. The workshop dates and locations were: January 23 and February 1, 2006 in Orlando, January 23 and 24, 2006 in St. Petersburg. Attendance was 20-25 per workshop, including staff from the consumer line center and field inspectors.

- South Carolina: SCANA - Through its involvement in South Carolina for educating stakeholders about the benefits of low-E windows (see Task 2.2), the Alliance also reached out to the gas and electricity utility SCANA in October 2007 with simulated data to illustrate the energy and peak demand reduction potential of low-E windows.

- Midwest: different utilities - At the Midwest Energy Solutions conference in Chicago, IL on January 11, 2008, the Alliance presented to about 30 energyefficiency professionals, including utility program representatives, on the role of utility programs for window energy efficiency and opportunities offered by highly-insulating windows and low-E storm windows. The majority of the represented utilities did not offer windows programs. Although it was stated that window repair or storm windows were preferred over window replacement due to lower cost, program providers acknowledged that it was harder to find contractors willing to provide these services than contractors for window replacement.

- Tennessee Valley Authority - The Alliance to Save Energy's VP of programs, Jeff Harris, testified at the TVA Board of Director's Public Listening Session on Energy Efficiency and Demand Response in Knoxville, TN on March 4, 2008. Among other energy-efficiency measures, Harris pointed out the peak demand and energy use reduction potential of energy-efficient windows and disseminated the EWC fact sheet "Selecting Energy Efficient Windows in Tennessee".

- Connecticut: State Senator John Fonfara - Per request by Senator Fonfara, the Alliance estimated energy and cost savings from replacing typical pre-1990 windows in Connecticut with ENERGY STAR windows (Appendix F-1). This analysis helped to inform considerations of a loan fund for window and boiler replacements.

- Oregon: In August 2009, upon request by the Energy Trust of Oregon, the Alliance provided information about triple-pane window performance and the windows volume purchase program for highly-insulating windows under 
preparation by DOE. The Energy Trust explored the viability of incentivizing products meeting $\mathrm{U}$-factor criteria as low as 0.22 .

Assessment: The project team presented window energy efficiency information at six outreach engagements to utilities in Florida and the Midwest and to the Tennessee Valley Authority. The Alliance also offered analysis of the energy savings potential of higher window performance to utility and state energy efficiency program planners in South Carolina, Connecticut and Oregon. While some of this support for window energy efficiency programs did not result in concrete action, direct benefits were provided in the cases of Progress Energy Florida, which implemented its windows incentive program with training support from AZS Consulting, and the Energy Trust of Oregon, which proceeded to develop incentives for a higher performance tier.

\section{Task 4.3: CEE Special Residential Windows Project}

Objectives: Develop benefit-cost information and data on advanced window technologies for the Consortium for Energy Efficiency.

Background

and hypothesis: The Consortium for Energy Efficiency (CEE) is a leading forum for the development of advanced energy efficiency tiers for a variety of products and for voluntary adoption by energy efficiency programs. Several of the largest utility companies across North America are members of CEE and contribute to developing CEE performance tiers. Utility companies are also the main beneficiaries of CEE performance tiers, which they may adopt for their energy efficiency programs. Prior to the start of the project period, the Alliance and CEE agreed that CEE members could have an interest in benefit-cost information about window performance tiers that could be used to update utility DSM and market transformation program offerings. Any possible tiers established by CEE would have a significant market transformation effect.

Approaches: At the beginning of the project period, when discussing the idea of window performance tiers with its members, CEE found little enthusiasm for window programs due to the high cost of windows as a measure. Therefore, the Alliance initially approached this task by reaching out to CEE members and emphasizing the market transformation opportunity from higher window performance tiers and the focus on incremental instead of absolute cost. On June 13, 2007, the Alliance presented on the potential of highly-insulating windows at the CEE summer membership meeting in Boston, MA. Following this presentation and a follow-up conference call involving interested CEE members, DOE and LBNL, CEE agreed with the Alliance on the benefits of providing cost-benefit estimates of window performance tiers to the CEE Whole House Committee. With input from LBNL, CEE and members of the working group, the Alliance established a spreadsheet with estimated savings generated with RESFEN for different window performance tiers at representative locations and with different cost-benefit expressions (rate of return, simple payback period, cents per saved $\mathrm{kWh}$ ) based on Alliance assumptions of incremental cost. In December 2007, the Alliance disseminated this spreadsheet to the working group members and summed up results and findings in a report (Appendix F-2). This report also explains the incremental cost assumptions, the energy price assumptions and the home sizes chosen for the simulation. The assumed home characteristics matched the default RESFEN 5.0 modeling assumptions (http://windows.lbl.gov/software/resfen/resfen.html) with the exception of cooling equipment efficiency in new homes, which the Alliance assumed to be SEER 13 instead of SEER 10 as assumed in RESFEN 5.0. These assumptions are listed in Appendix A.

In the summer of 2008, the CEE Whole House Committee focused its attention regarding windows on DOE's proposed revision of the ENERGY STAR criteria for windows, doors and skylights. As a member of this committee, the Alliance gave input to CEE's 
discussion of comments on DOE's proposal by clarifying some technical points in the draft analysis for the ENERGY STAR revision and by emphasizing DOE's vision for significantly improved window performance as a basis for later revisions. In its comments to DOE, CEE was largely supportive of DOE's intent to establish more stringent criteria but also stressed the importance of considerations such as peak demand and installation quality.

In April 2009, the CEE Existing Homes Working Group started to compile information for a Existing Homes Program Guide as a resource for utility companies establishing programs for existing homes. The Alliance contributed summary information on window energy efficiency (Appendix F-3), which, after review by CEE's Whole House Committee was included in the program guide draft. This windows section includes an explanation of the potential for higher window performance tiers and mentions the R-5 Windows Volume Purchase Program organized by DOE in 2009, which is based on a $0.22 \mathrm{U}$-factor specification.

Assessment: Even though at the start of this project period CEE did not have a windows working group and windows were not high on CEE members' priority list due to their high cost, the Alliance in collaboration with LBNL convinced some CEE members to at least consider the benefits of window performance tiers that are substantially more stringent than ENERGY STAR criteria. In early 2008, two CEE member companies (Xcel and Questar) used the data provided by the Alliance to confirm that higher window performance tiers (U-factor 0.25 or 0.20 ) would meet the total resource cost test in these utility's service areas (Utah and Minnesota) as long as the incremental cost did not exceed the assumptions used by the Alliance for its analysis.

More in-depth analysis of higher window-performance tiers was sidetracked when CEE members with an interest in windows programs instead focused on the revision of the ENERGY STAR for windows criteria that DOE started in the summer of 2008. This revision, which established more stringent criteria than the requirements of common building energy codes, reduced the problem of free ridership in incentive programs that reference ENERGY STAR criteria. However, since the ENERGY STAR revision meant only an incremental criteria change (with 0.30 as the most stringent U-factor limit), the potential for exploring higher performance tiers remained, which CEE decided to further explore through a working group under its Whole House Committee. Of particular interest to CEE will be DOE's R-5 Windows Volume Purchase Program with its 0.22 Ufactor specification. This program will start in 2010 and the Alliance will continue to work with CEE to evaluate the potential for CEE member utility programs.

\section{Task 4.4: Characterization of Gas Utility Provider Promotionals}

Objectives: Determine potential to promote efficient windows through gas utility efficiency programs.

Background and hypothesis: Utility program considerations by natural gas utilities differ from those by electric utilities in that natural gas savings from efficient windows are primarily achieved by reducing heat loss (low U-factor), whereas the SHGC, which is very relevant with respect for cooling electricity use, is of less relevance to natural gas programs. Since the most significant natural gas demand reductions through windows can be achieved with a very low U-factor, the Alliance examined natural gas utility program providers as potential supporters of performance tiers for highly insulating windows.

Approaches: In May 2008, the Alliance identified eleven programs for natural gas customers among the window utility programs in the inventory established through Task 4.1. Many more window-specific programs were offered by electric utilities, many of which require customers to have electric heating to qualify. 
Based on the identified natural gas utilities with windows programs and on the heating demand focus of natural gas efficiency programs, the Alliance drafted an Outreach Plan for Gas Utility Window Efficiency Programs in May 2008 (Appendix F-4). This outreach plan focused on 1) promotion of ENERGY STAR windows by utility companies; 2) promotion of highly insulating windows; 3 ) promotion of low-E storm windows. The Alliance pursued the latter two priorities through its involvement with CEE (Task 4.3) and its support for the DOE Highly Insulating Windows and Low-E Storm Windows Volume Purchase Program, for which preparation started in late 2008.

Assessment: $\quad$ Through its coordination with CEE (Task 4.3), the Alliance communicated with three of the eleven natural gas program providers it identified: Gas Networks (New England), Questar (Utah), and the Energy Trust of Oregon. Questar and the Energy Trust of Oregon showed an interest in highly insulating windows, and in 2009, the Energy Trust of Oregon decided to create a higher performance tier beyond U-factor 0.30, as it had offered so far (see Task 4.2). It is not clear to the Alliance whether the consideration of window programs by these natural gas program providers differed substantially from those of electric utilities as all programs need to pass cost effectiveness tests (e.g. total resource cost tests).

\section{Task 4.5: Commercial Windows Utility Provider Promotional Inventory}

Objectives: Compile inventory and profiles of commercial energy efficient windows promotion programs at electric and natural gas utilities.

Background and hypothesis: Utility companies across the country offer energy efficiency assistance to their customers in the form of rebates, low-interest loans, free services, advice or by other means. The main purpose of this task was to give the project team an overview of available window programs for commercial customers that could inform activities under Tasks 4.6 and 4.7.

Approaches: In July 2008, the Alliance compiled an inventory of utility programs for the promotion of energy-efficient commercial windows (Appendix F-5). As main resources, the Alliance used the Database of State Incentives for Renewable Energy (www.dsireusa.org) and a utility programs listing by the Edison Electric Institute. The Alliance categorized these programs depending on whether incentives are based on energy or peak demand savings, on window performance specifications, or on other criteria. Of the programs which based incentives on specific window energy performance criteria, as opposed to modeled energy savings or incremental cost, only some specifically called for NFRC ratings. When the NFRC started outreach to utility companies for the promotion of its Component Modeling Approach in the summer of 2009, the Alliance shared this inventory to help inform the outreach plan.

Assessment: The Alliance's July 2008 inventory of commercial windows utility provider programs included summary information on 31 program providers that offered incentives for window energy efficiency, either directly by rewarding the use of efficient windows or window film, or indirectly by rewarding energy and demand savings in new building design or through retrofits. 12 of these 31 program providers offered direct incentives for the use of efficient windows, and 9 of these specified window performance based on NFRC ratings (U-factor, SHGC, and/or visual transmittance). In addition, 7 of the 31 program providers offered direct incentives for solar control window film, either specifying the film's SHGC or its shading coefficient (SC). 15 program providers in the sample incentivized windows only indirectly, either by requiring energy modeling of new construction or renovations and awarding incentives for projected energy or peak demand savings, or by providing low-interest loans for/rebates on the incremental cost of efficiency improvements. 


\section{Task 4.6: Commercial Windows Utility Provider Promotional Toolkit}

Objectives: Develop technical fact sheets and toolkit materials that can be used to develop commercial windows promotion programs with utilities.

Background

and hypothesis: Although several utility companies offer design assistance programs for commercial construction and some offer window-specific incentives, these programs rarely specify window energy performance based on NFRC ratings. The development of the NFRC Component Modeling Approach (CMA) presented a good opportunity to educate utility companies about NFRC ratings that can help program managers and designers with specifying efficient commercial windows.

Approaches: Before CMA became available for pilot implementation in the summer of 2009, the Alliance worked with Xcel Energy to explore prescriptive performance criteria for commercial window incentives. This collaboration with Xcel Energy helped to identify possible means of establishing criteria for other utilities' programs as well. The Alliance produced information to help Xcel Energy determine the cost effectiveness of possible performance tiers for window replacement rebates for older office buildings. The Alliance summarized this information in a document on incremental cost estimates for higher window performance tiers (Appendix F-6), based on the performance tiers established under Task 2.3 and on pricing information from RSMeans Repair and Remodeling Cost Data 2007 and correspondence with one glass manufacturer. The Alliance illustrated the savings potential from these performance tiers by providing Xcel Energy with COMFEN 2.2 simulation results for façade examples in the Minneapolis and Denver climates. The assumptions used for these simulations are summarized in Appendix A.

Once CMA became available in the summer of 2009, the development of information and outreach to utilities was performed by a NFRC contractor. As a consequence, the Alliance did not take on this particular task.

Assessment: By providing input to Xcel Energy's consideration of prescriptive criteria for a commercial windows incentive program, the Alliance sought to explore what information may be most useful for other utilities considering commercial windows performance criteria. However, Xcel Energy did not adopt prescriptive windows criteria and instead retained its more flexible design assistance for individual buildings. The Alliance also learned from other utility programs that the difficulty of making general estimates of the savings from window measures is a barrier for simple prescriptive criteria. If utilities are considering prescriptive criteria, however, they can use several recent publications for guidance: The ASHRAE Advanced Energy Design Guides, the Core Performance Guide by the New Buildings Institute, ASHRAE Standard 189, and others.

Utility program providers can play an important role in promoting the NFRC Component Modeling Approach. A NFRC contractor has assumed the role of coordinating with utilities on this task and has found valuable partners among California utilities.

\section{Task 4.7: Commercial Windows Utility Provider Outreach}

Objectives: Prepare an outreach plan to disseminate Master Toolkits and training materials to commercial utility program providers.

Background

and hypothesis: The intention for this task was to disseminate toolkit material developed under Task 3.5 and targeted utility fact sheets developed under Task 4.6. 
Approaches: For most of the project period, neither the NFRC Component Modeling Approach nor COMFEN were available in their final form, and the project team created only individual commercial tools instead of a comprehensive Commercial Master Toolkit under Task 3.5. Consequently, the project team had only limited tools available for dissemination under this task.

The Alliance explored the possibility of communicating with utility program providers on commercial window performance through the commercial committees of the Consortium for Energy Efficiency. However, since these committees concentrated on either whole building benchmarking or on non-envelope components of commercial buildings, window performance in particular was not part of the scope. To reach out to utilities more directly, the Alliance exhibited at the Utility Energy Forum on April 30 to May 2, 2008 in Tahoe City CA where it offered information about the NFRC Component Modeling Approach under development, fact sheets on the first pilot version of COMFEN and copies of the book Window Systems for High Performance Buildings to utility companies across California and other western states.

In March 2009, the Alliance discussed with Electric Utility Consultants Inc. (EUCI) about organizing a webinar for electric utility program providers with a focus on commercial windows, but this plan was put on hold due to the time commitment for organizing an Alliance webinar on highly insulating windows in June 2009 (Task 3.2).

Assessment: From discussing with the Consortium for Energy Efficiency (CEE) and from reaching out to utilities at the 2008 Utility Energy Forum, the Alliance found that commercial window energy performance as an individual issue does not rank high among the priorities of utility program providers. Reasons are that new construction energy efficiency may be best achieved through a whole-building approach, while window replacement is less common in commercial buildings and may call for building-specific assessment of window options. Nonetheless, utility program providers may benefit from promoting tools that facilitate the incorporation of energy efficient window in commercial building design, such as the NFRC Component Modeling Approach (CMA) and LBNL's schematic design tool COMFEN. The Alliance will coordinate with NFRC and LBNL on opportunities to promote these tools to utilities through CEE or other channels. 


\section{CONCLUSION}

The primary accomplishments by the Alliance and its project partners over the project period were:

- Educated stakeholders Florida and South Carolina - markets with high construction volume and a low market share for efficient windows. In 2005, residential construction in these two states accounted for 16 percent of the national total, while the market share of low-E windows (29 percent in Florida) was far below the national average (53 percent). ${ }^{8}$ Through extensive training for code officials, utility program providers and builders, the Alliance, AZS Consulting and Southface Energy Institute supported the adoption of energy efficient windows in these states.

- Increased awareness for the energy savings and market potential of highly-insulating windows that exceed ENERGY STAR performance. The Alliance successfully encouraged the inclusion of higher window performance tiers in the ICC 700 National Green Building Standard, educated builders and architects through webinar and conference sessions focused on highly-insulating windows, and raised awareness among utility program providers by initiating discussion of potential higher window performance tiers through the Consortium of Energy Efficiency (CEE).

- Updated and expanded window energy efficiency resources and tools. The University of Minnesota, with input from Lawrence Berkeley National Laboratory and cost share partners, revised the book Residential Windows: a Guide to New Technologies and Energy Performance to include critical new information on emerging technologies, comfort, installation methods, building codes, etc. The project team made fundamental portions of this information available online through residential toolkits. The University of Minnesota also updated and expanded the Façade Design Tool for office window assessments (www.commercialwindows.org) to expand options for design comparisons and base results on COMFEN simulations.

- Disseminated customized information and education to multiple audiences in the residential and commercial sectors. The project team reached about 3,900 design professionals, code officials, utility program implementers, and consumers directly through a combination of educational sessions, webinars, advice via the Efficient Windows Collaborative email and phone hotline, and interaction through trade shows. The project team ensured that this outreach was tailored to the different audiences' needs and offered opportunities for questions and feedback. This direct outreach was leveraged through online tools and media articles, reaching a far greater audience the EWC residential products database facilitated more than 90,000 referrals to manufacturers of high-performance windows, and articles by the project team had a cumulative circulation of more than 300,000 among professional audiences.

In addition to these primary accomplishments, the Alliance and its project partners actively supported important related programs and developments:

- The NFRC Component Modeling Approach (CMA), a commercial windows rating and certification system which was implemented in January 2010. The project team supported this program through participation in NFRC committees and the NFRC board of directors.

- The Department of Energy's "Highly-Insulating (R-5) Windows and Low-E Storm Windows Volume Purchase Program". The Alliance supported the preparation of this program through participation in the organizing team.

- The federal tax credit for home energy efficiency improvements implemented in January 2006 and modified in February 2009. Through web material, newsletters, presentations and the EWC hotline, the project team educated consumers, manufacturers and vendors about the basis preconditions for windows to qualify for the tax credit and pointed out available information from the Internal Revenue Service.

These and other window energy efficiency developments and initiative will continue to transform the United States windows market toward greater energy savings in commercial and residential buildings, and the Alliance and its project partners will continue to support this progress through tools and information.

\footnotetext{
${ }^{8} 2006$ estimates by D\&R International.
} 


\section{Appendix A - RESFEN and COMFEN Modeling Assumptions}

The tables below summarize the modeling assumptions used for the Alliance's simulations of energy and peak demand savings with different window performance tiers for both residential windows (Task 4.3) and commercial windows (Task 4.6). Residential windows simulations were performed with RESFEN 5.0, a simulation tool developed by Lawrence Berkeley National Laboratory (LBNL); commercial windows simulations were performed with COMFEN 2.2, a simulation tool also developed by LBNL.

Table 2 Residential window energy modeling assumptions

\begin{tabular}{|c|c|}
\hline \multicolumn{2}{|c|}{ RESFEN 5.0 modeling assumptions used for simulations under Task 4.3} \\
\hline \multicolumn{2}{|c|}{ RESFEN can be downloaded at http://windows.lbl.gov/software/resfen/resfen.html } \\
\hline Home Size & $\begin{array}{l}\text { Existing homes: } 2,000 \text { sq. } \mathrm{ft} . \\
\text { New homes: } 2,400 \text { sq. ft. }\end{array}$ \\
\hline Window Area & $\begin{array}{l}\text { Existing homes: } 300 \text { sq. ft., evenly oriented toward all four cardinal directions } \\
\text { New homes: } 360 \text { sq. ft., evenly oriented toward all four cardinal directions }\end{array}$ \\
\hline Structural Mass & $3.5 \mathrm{lb} / \mathrm{sq}$. ft. of floor area \\
\hline Internal Mass & $8 \mathrm{lb} / \mathrm{sq}$. ft. of floor area \\
\hline Typical Shading & $\begin{array}{l}\text { 1' overhang, some nearby obstructions, some internal shading } \\
\text { Winter SHGC multiplier of } 0.8 \\
\text { Summer SHGC multiplier of } 0.7\end{array}$ \\
\hline Window Distribution & Equal area in cardinal directions \\
\hline HVAC System & $\begin{array}{l}\text { Gas furnace, AFUE }=0.78 \\
\text { Central AC, SEER } 10 / 13^{*}\end{array}$ \\
\hline HVAC System Sizing & Based on climate, using DOE-2 auto-sizing, 1.3 multiplier to account for safety factor \\
\hline Duct losses & $\begin{array}{l}\text { Heating: } 10 \% \text { (fixed) } \\
\text { Cooling: } 10 \% \text { (fixed) }\end{array}$ \\
\hline $\begin{array}{l}\text { Part-load } \\
\text { performance }\end{array}$ & Part-load curves for new construction \\
\hline Thermostat settings & $\begin{array}{l}\text { Heating: } 70 \text { degrees } F \\
\text { Cooling: } 78 \text { degrees } F \\
\text { Basement: heating } 62 \text {, cooling } 85\end{array}$ \\
\hline $\begin{array}{l}\text { Night Heating } \\
\text { Setback }\end{array}$ & 65 degrees $\mathrm{F}(11 \mathrm{pm}-6 \mathrm{am})$ \\
\hline Internal Loads & $\begin{array}{l}\text { Sensible: } 43,033 \mathrm{Btu} / \text { day }+(\text { floor area } * 8.42 \mathrm{Btu} / \mathrm{sq} . \mathrm{ft} \text {-day for lighting) } \\
\text { Latent: } 12.2 \mathrm{kBtu} / \text { day }\end{array}$ \\
\hline Natural ventilation & Enthalpic - Sherman-Grimsrud ( $78 \mathrm{~F} / 72 \mathrm{~F}$ based on 4 days history) \\
\hline Weather Data & TMY2 \\
\hline Calculation Tool & DOE-2.1 E \\
\hline
\end{tabular}

* Note: RESFEN simulations assume SEER 10 cooling efficiency. Since SEER 13 has become the federal standard in 2006, the Alliance assumed that new homes have SEER 13 air conditioning and use only $10 / 13=77 \%$ of the cooling energy simulated by RESFEN. 
Table 3 Commercial window energy modeling assumptions

COMFEN 2.2 modeling assumptions used for simulations under Task 4.6

COMFEN can be downloaded at http://windows.lbl.gov/software/comfen/comfen.html

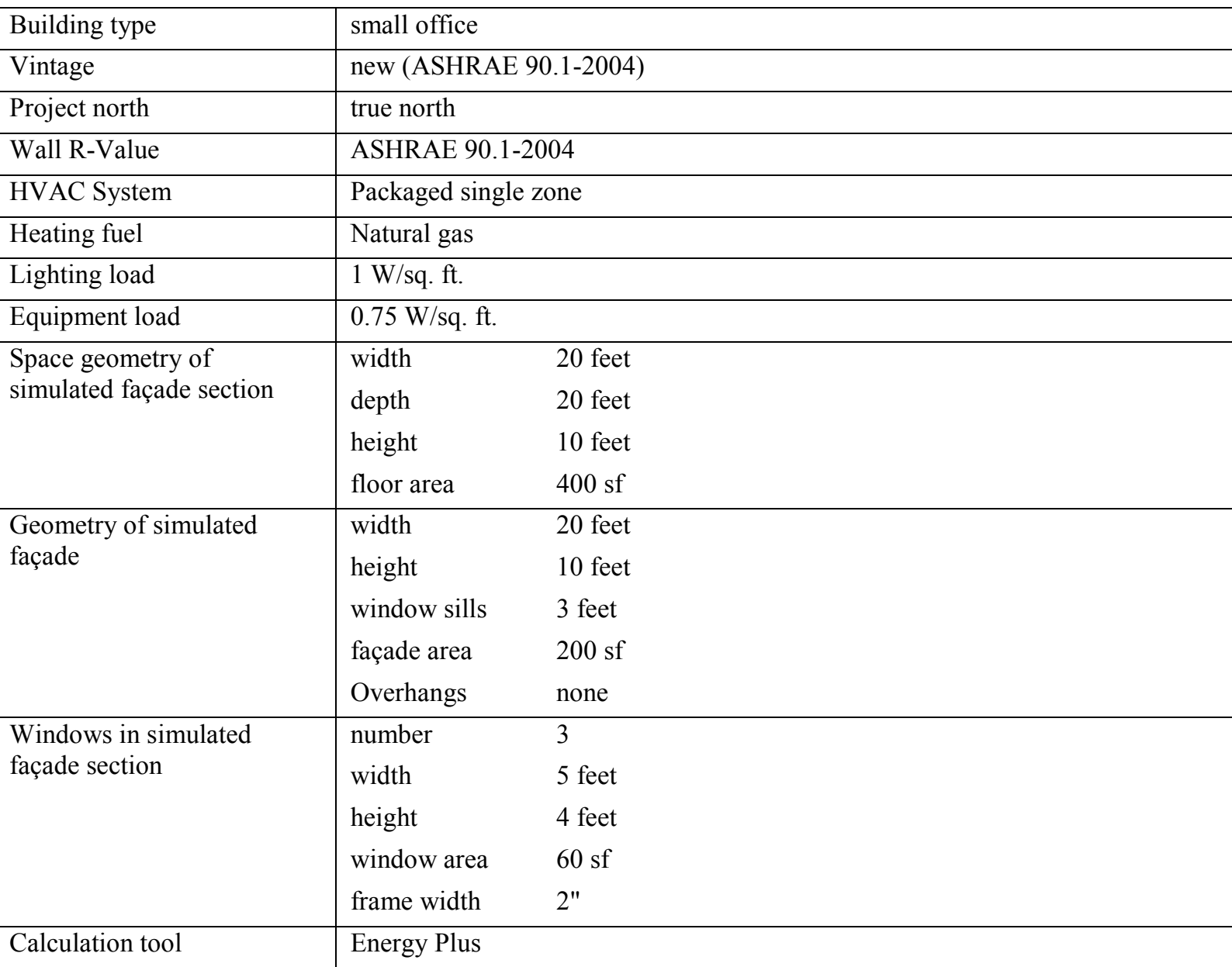




\section{Appendix B - Efficient Windows Collaborative Toolkits}

B-1 Excerpt from EWC Manufacturers Toolkit

(www.efficientwindows.org/toolkits/tk_manufacturer1_0.cfm)

B-2 EWC Builder Toolkit

B-3 EWC Tools for Schools 


\section{Efficient Windows Collaborative \\ EWC Home \\ Toolkits \\ Frequently Asked Questions \\ Contact Us}

\section{Contents}

Why energy-efficient windows? »

Consumer Demand

Code Requirements»

Green Building Programs»

Utility \& Tax Incentives»

Staying Competitive

What is the process? 》 Join NFRC \& Label Products» J oin ENERGY STAR Program» Join EWC Product Database»

What tools can help enhance sales? 》

Resource Materials»»

Window Selection Tool»

Tax Credit Fact Sheet»

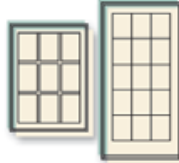

Why should a manufacturer make energy-efficient windows?

\section{Consumer Demand for Energy Efficiency}

With increasing attention on energy prices and supplies, consumers are more energy conscious. Energy-efficient windows also meet consumer demand for increased comfort and reduced condensation.

More Stringent Code Requirements 》

Building energy codes are continually being revised to require greater energy efficiency in buildings and windows in particular. Many codes refer to the NFRC label as the means of certifying window energy performance. Manufacturers must meet these requirements to compete in each state.

Expansion of Green Building Programs »

An increasingly important trend in the building industry is the emergence of the sustainable or green building movement. Awareness of global warming and climate change has become a particularly strong driving force in this movement. In the residential sector, there are many green building guidelines, rating systems and standards. High performance windows will be necessary to meet the requirements of these programs.

Taking Advantage of Utility Programs and Tax I ncentives 》

Utility-sponsored programs stimulate the adoption of energy-efficient technologies in a variety of ways including providing customers or builders with information, technical assistance, and direct (e.g., cash rebates and discounted rates) and indirect (e.g., lower cost financing) financial incentives. In addition, federal and state governments may offer tax credits to encourage efficient technologies.

\section{Staying Competitive}

ENERGY STAR Homes and various green building programs are increasingly used to distinguish superior builders. Similarly, ENERGY STAR windows and NFRC labels are used to distinguish superior windows in the marketplace.

Copyright (c) 1998-2007

Regents of the University of Minnesota, Twin Cities Campus, College of Design, Center for Sustainable Building Research All rights reserved.

This site was developed jointly by the Center for Sustainable Building Research, Alliance to Save Energy, and Lawrence Berkeley National Laboratory. Disclaimer | Search 


\section{Efficient Windows Collaborative

EWC Home

Toolkits

Frequently Asked Questions

Contact Us

\section{Contents}

Why energy-efficient windows? »

Consumer Demand Code Requirements» Green Building Programs» Utility \& Tax Incentives» Staying Competitive

What is the process? J oin NFRC \& Label Products» J oin ENERGY STAR Program» Join EWC Product Database»

What tools can help enhance sales?» Resource Materials»» Window Selection Tool» Tax Credit Fact Sheet»
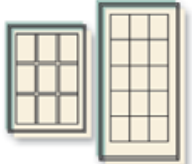
products. The NFRC label appears on all products rated to the NFRC standards and on al How to Get Your Products Certified by the National Fenestration Rating Council (NFRC)

The precondition for fenestration products to be recognized as energy efficient is that they are rated according to the standards of the National Fenestration Rating Council (NFRC). The NFRC label is recognized nationwide as the reliable indicator of fenestration energy properties. While not all windows with the NFRC label are necessarily energy efficient, energy efficient windows will not be recognized as such without the trustworthy values displayed on the label. The NFRC label is also the precondition for a window, door, or skylight to qualify for the ENERGY STAR label - if the product's NFRC-certified values meet the ENERGY STAR qualification criteria.

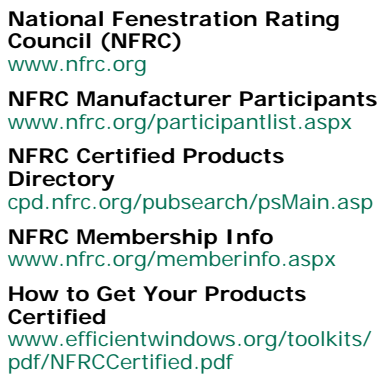

\section{What is the NFRC?}

The National Fenestration Rating Council (NFRC) is a nonprofit, public/private organization created by the window, door, and skylight industry. It is composed of manufacturers, suppliers, builders, architects and designers, specifiers, code officials, utilities, and government agencies. The NFRC has developed a fenestration energy rating system based on whole product performance.

The NFRC Label

The NFRC label provides the only reliable way to determine energy properties and thus compare the energy-efficiency of fenestration window, door, and skylight products which are part of the ENERGY STAR ${ }^{\circ}$ program. NFRC labels

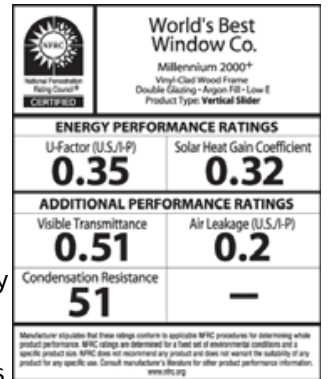
on fenestration units give ratings for U-factor, Solar Heat Gain Coefficient (SHGC), and Visible Light Transmittance (VT), as well as optional ratings for Air Leakage $(A L)$ and Condensation Resistance $(C R)$. Somewhat different information is provided on labels for window films.

\section{Starting the Certification Process}

In order to get the NFRC certification process started, window, door, and skylight manufacturers should first contact NFRC and order a Product Certification Program (PCP) Package. This package will contain information on how to follow these further steps:

- Select an NFRC licensed Independent Agency to verify the testing process

- Have your product tested by an accredited simulation lab

- Have your product tested by an accredited thermal testing lab

- Sign the NFRC License Agreement

- Label the product with the NFRC label

\section{What is the time and financial commitment?}

Certification of a small number of product types may be completed in less than half a year, whereas a larger number of product types can mean a somewhat longer certification process. Once a product type has been certified, this certification will be valid for a four-year period.

The costs for participation in the NFRC certification program vary depending on the number of product lines to be certified, label usage, and membership status. Including the costs for thermal testing, simulation labs, and an independent certification and inspection agent, total annual costs of a few thousand dollars for multiple product lines should be expected.

Please note that manufacturers with sales of less than $\$ 2$ million qualify for a small business discount that substantially decreases program costs.

\section{NFRC membership}

Those manufacturers of windows, doors, and skylights who want to get involved in the further development and refinement of NFRC rating and certification procedures can become members of the NFRC. However, NFRC membership is not necessary for participation in the NFRC certification program and is thus strictly optional. Learn more about NFRC membership.

Copyright $\odot$ 1998-2007

Regents of the University of Minnesota, Twin Cities Campus, College of Design, Center for Sustainable Building Research All rights reserved. 


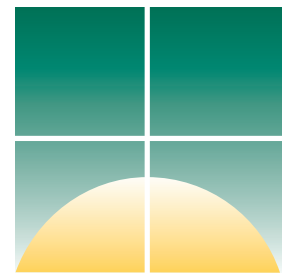

\section{The Efficient Windows Collaborative Builder Toolkit}

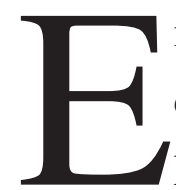
nergy-efficient windows are integral components of high quality homes and help homeowners save heating and cooling costs. With efficient windows, homes can more easily meet energy code requirements, achieve ENERGY STAR ${ }^{\circledR}$ homes recognition, or meet utility incentive requirements. In many cases, using efficient windows allows builders to reduce home energy demand while increasing the amount of glazed area - and marketing studies have shown that larger glazed areas appeal to prospective buyers.

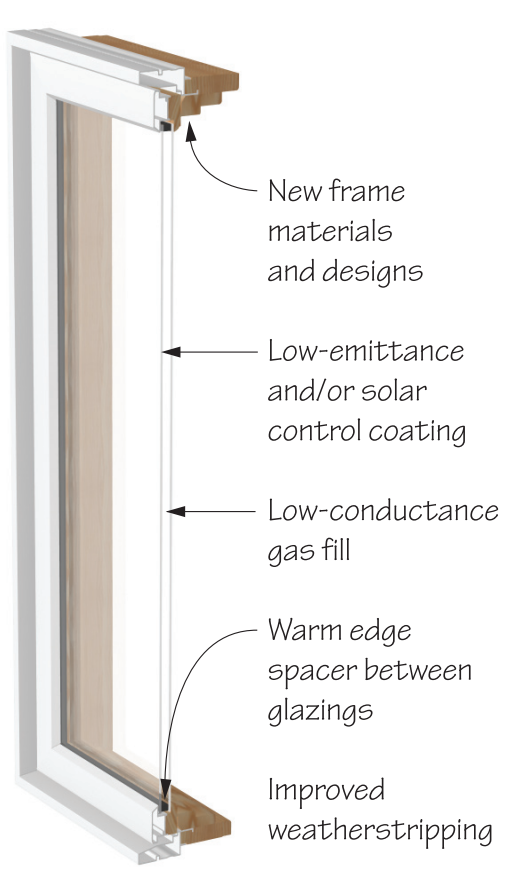

Technological advances have significantly improved window energy performance. Many of these advances are invisible, but the ENERGY STAR $^{\circledR}$ label designates high-performance products and the NFRC label provides reliable information about the performance details (see page 8).

Visit www.efficientwindows.org for more information on the benefits of efficient windows, how windows work, how to select an efficient window, and what manufacturers provide efficient windows.

\section{Builder Toolkit Contents}

\section{Why Energy Efficient Windows?}

Energy and Cost Savings Page 2

Improved Comfort Page 4

Less Condensation Page 4

Increased Light and View Page 5

Greater Protection from UV Fading. Page 5

\section{How to Finance Energy Efficient Windows in New Homes}

Energy-efficient windows increase the value and comfort of a house, but they also raise a cost issue. Windows are an expensive part of the building envelope, and although higher energy performance is more than offset by long-term energy cost savings, it may add to the upfront cost.

Learn how to cope with these costs Page 6

\section{How to Make the Most of Energy Efficient Windows}

Builders can provide the best indoor comfort and energy performance by selecting windows that are best suited for a home's climate and orientation.

Information about choosing and orienting windows Page 7

\section{Efficient Windows Collaborative}

This toolkit was produced with funding from the Windows and Glazings Program at the U.S. Department of Energy (www.eere.energy.gov) in support of the EWC. For more information, contact:

\section{EWC/Alliance to Save Energy}

1850 M Street NW, Suite 600

Washington, D.C. 20036

phone: $202-530-2254$

fax: 202-331-9588

www.ase.org

www.efficientwindows.org

\section{Residential Windows Book}

Carmody, J., S. Selkowitz, D. Arasteh, and L. Heschong. Residential Windows: New Technologies and Energy Performance, 3rd ed. New York, NY: W.W. Norton \& Company, 2007. 


\section{Why Energy Efficient Windows?}

\section{Energy and Cost Savings}

Energy efficient windows are designed so that heat is kept inside the home in the winter and outside the home in the summer. This reduces heating and cooling costs, minimizes energy consumption that impacts the environment and limits the size of the HVAC equipment required for keeping the home comfortable.

\section{Cooling Season Savings}

In climates that mainly require cooling, windows have represented a major source of unwanted heat gain. In recent years, windows have undergone a technological revolution. It is now possible to significantly reduce solar heat gain and improve comfort while providing clear views and daylight. This means that high performance windows can face into the sun if desired without great energy penalties - although shading techniques remain important.

The graph below illustrates the significant savings in cooling season costs associated with improved windows. Installing low-solar-gain low-E windows instead of traditional dual-pane windows in a typical 2,000 square foot house in Phoenix, Arizona would reduce the air conditioner peak load from 4.5 tons to 3.5 tons. The low-E coating would avoid the up-front cost of one ton of air conditioning and save the homeowner about $19 \%$ of cooling costs.

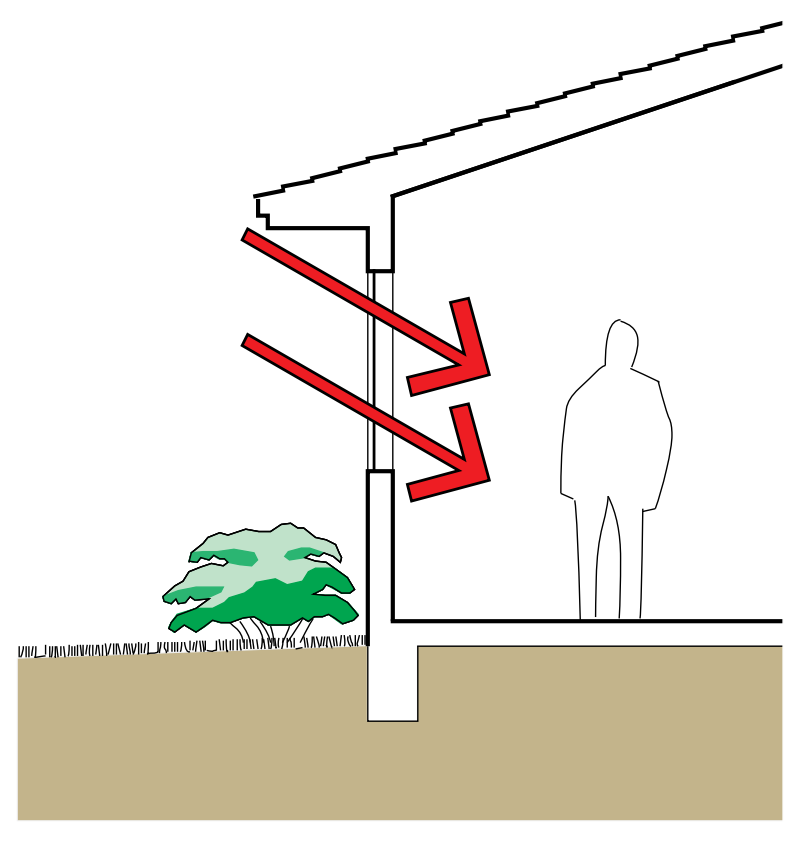

\section{Downsize HVAC systems}

High-performance windows not only provide reduced annual heating and cooling bills; they reduce the peak heating and cooling loads as well. This means that smaller HVAC systems (including the furnace, heat pump, air conditioner, and fans) may be installed in energy efficient homes. Smaller HVAC systems cost less, consume less energy and are just as effective as larger systems if energy efficient windows keep peak demand low.

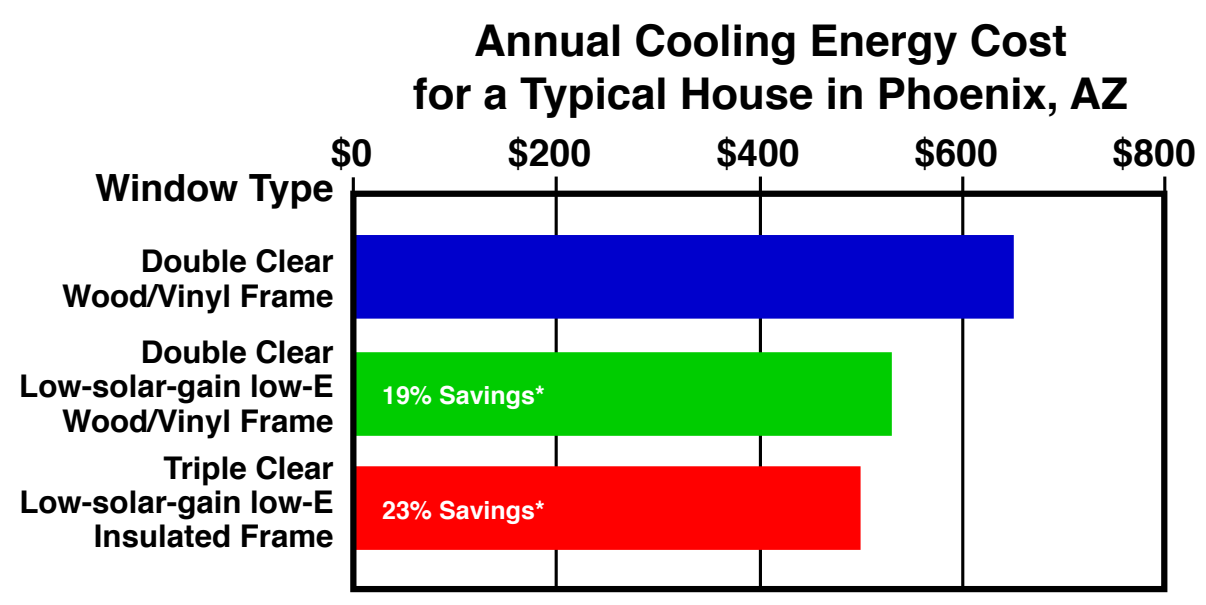

*Compared to the same 2000 sf house with clear, doubl glazing in a wood/vinyl frame. 


\section{Heating Season Savings}

In climates with a significant heating season, windows have represented a major source of unwanted heat loss, discomfort, and condensation problems. With modern windows, it is now possible to have lower heat loss, less air leakage, and warmer window surfaces that improve comfort and minimize condensation. This means that windows do not any longer have to be an energy loser to be avoided - increasing glazing area with high performance windows can have little or no affect on total energy use.

The graph below illustrates the significant savings in heating season costs associated with energy efficient windows for a house in a heating-dominated climate. For a typical 2,000 square foot house in Boston, Massachusetts, double-glazed low-E windows instead of conventional double-pane windows reduce heating costs by 7\%. Triple-pane low-E windows with insulated frames would save as much as $16 \%$.

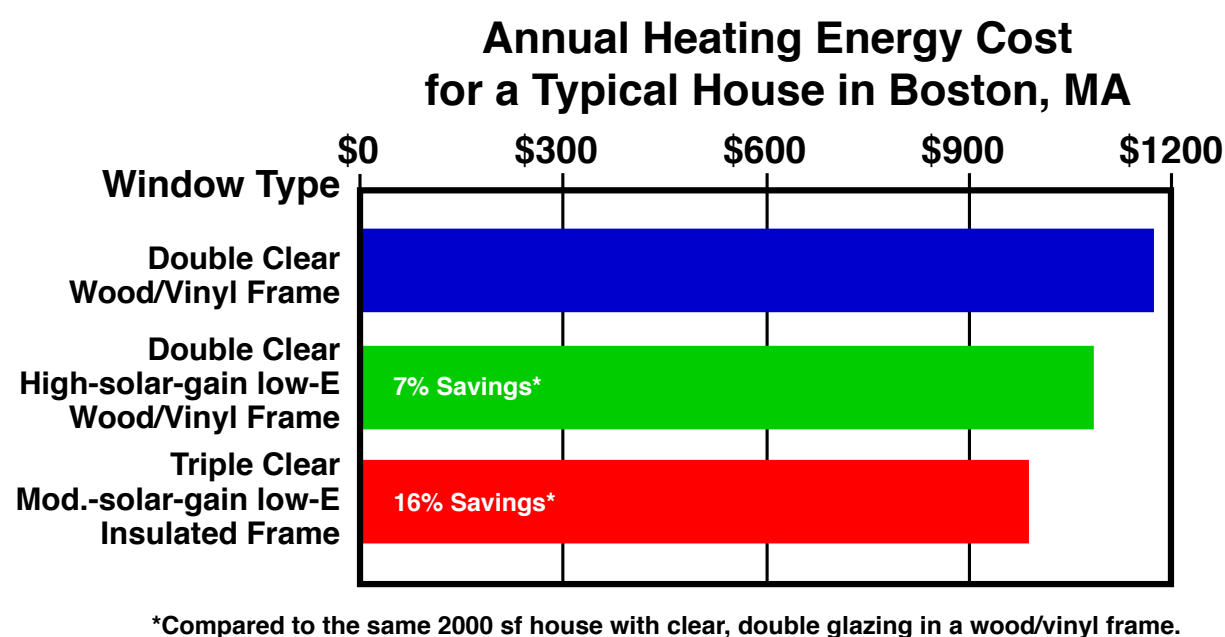




\section{Improved Comfort}

\section{Improved Winter Comfort}

Energy-efficient windows improve comfort within homes by providing a warmer interior surface during the cold winter months, preventing the living space near windows from getting uncomfortably cold. Air adjacent to inefficient windows is cooled and floats to the ground. This feels like a cold draft, even though the windows may not be leaky at all.

\section{Improved Summer Comfort}

By reducing the need for air conditioning, windows that control solar heat gain also reduce the risk of possible health effects from air conditioning - for instance, the overuse of air conditioning can cause headaches or aggravate the effects of arthritis and neuritis.

\section{Less Condensation}

High-performance windows with warm edge technology and insulating frames have warmer interior surfaces, so that the likelihood of condensation is significantly reduced under all climate and humidity conditions.

\section{Impact of Low-E Glass and Insulating Spacers on Condensation}

The adjacent images show interior surface temperature patterns of a clear double-glazed unit (left) and an energy-efficient low-E insulated glazing unit with an improved spacer (see illustration below).

Under typical winter conditions, (i.e. $20^{\circ} \mathrm{F}$ outside), condensation on the glass under typical humidity levels is shown by purple and blue. With a conventional clear double glazing (left), condensation occurs in a band a couple inches wide along the edge of the sightline, with more condensation along the bottom than at the top. With the energy-efficient low-E insulated glass unit (right), condensation will be greatly reduced (a small strip less then 1 inch high along the bottom).

Under extreme winter conditions (i.e. $0^{\circ} \mathrm{F}$ outside), condensation is shown by purple, blue and green. With clear double glazing, there is condensation over
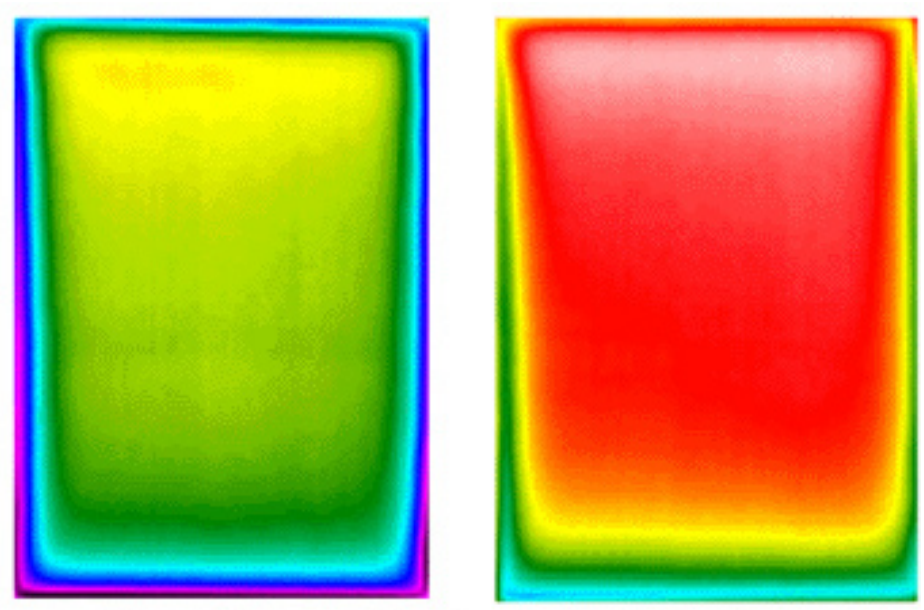

Source: Lawrence Berkeley National Laboratory the entire unit. With energy-efficient low-E glazing, there is only condensation on a band along the bottom and up along the edges. 


\section{Increased Light and View}

Daylight and view are two fundamental attributes of a window. Unfortunately, windows are also the source of significant solar heat gain during times when it is unwanted. Traditional solutions to reducing solar heat gain, such as tinted glazing or shades, mean that the amount of light is reduced as well. New glazings with low-solar-gain low-E (spectrally selective) coatings can provide better solar heat gain reduction than tinted glass, with a minimal loss of visible light. This also means that views can be clearer and unobstructed.

\section{Greater Protection from UV Fading}

Many organic materials, such as carpet, fabrics, paper, artwork, paints, and wood may fade upon exposure to sunlight. Window selection can influence

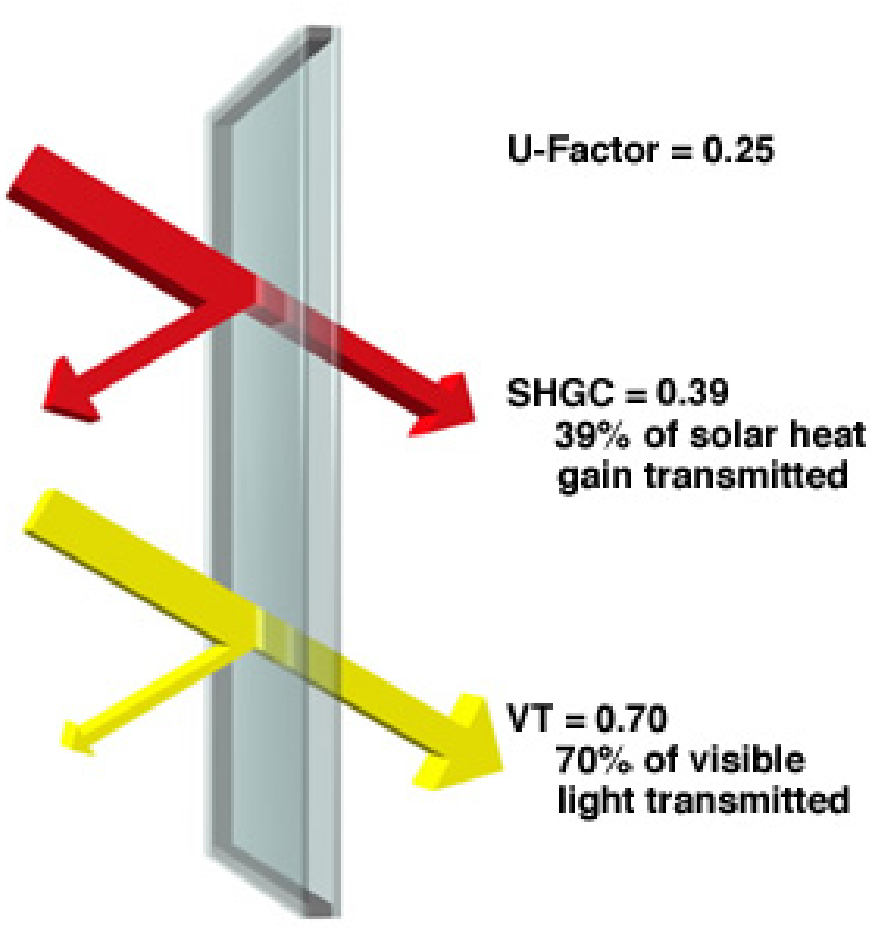
the type and intensity of transmitted radiation. The most harmful radiation in sunlight are ultraviolet

(UV) rays, which are the most likely to break chemical bonds, leading to fading and degradation. Glass blocks all UV radiation below $300 \mathrm{~nm}$, but transmits UV from 300-380 $\mathrm{nm}$. Coatings on glass can reduce the transmission of UV radiation by up to $75 \%$. UV absorbers can also be incorporated into thin plastic films in multilayer windows or as an interlayer in laminated glass. In both cases, the UV transmission can be reduced to less than $1 \%$. However, it is important to note that the remaining visible light that is transmitted can still cause fading in some materials. But low-E coated glass or plastic films reduce fading to a minimum for many modern interior furnishings. 


\section{How to Finance Energy Efficient Windows in New Homes}

Energy-efficient windows can raise a cost issue. Windows are an expensive part of the building envelope, and although the extra cost of energy-efficient windows will be more than offset by energy cost savings, higher energy performance adds a premium to the upfront cost. There are options to deal with this upfront cost if funds are limited.

\section{Make Windows a Priority}

Many other home improvements can be made later on, once a house has been completed and the homeowner has more funds available. Windows, however, should always be installed in the best available quality in order to prevent later regrets. To replace windows later results in extra cost that is avoidable if the right decisions are made while the home is first constructed. Homebuilders can point out to homebuyers that windows should be a priority - the garden decoration can be added later.

\section{Energy Efficient Mortgages}

Energy efficient mortgages (EEM) promote the design, construction, and purchase of more energy-efficient homes. With EEMs, homeowners' qualifying ratios for higher loans increase if energy efficiency features, such as high-performance windows, are added to their homes. EEMs make sense because homeowners that save on heating and cooling or other energy expenses can repay loans far easier than the owners of less efficient homes. Energy efficient mortgages are one tool that allows homeowners to offset the financial constraints that might otherwise prevent them from considering the best quality windows in their new home.

\section{Energy Efficient Mortgages}

Energy efficient mortgages are offered through several different programs in the secondary mortgage market. Fannie Mae, Freddie Mac, the Department of Housing and Urban Development, Federal Housing Administration, and the Veteran's Administration offer programs to increase energy efficiency through EEMs. The number of banks offering this type of mortgage has grown significantly in recent years.

More information on EEMs can be found at:

- www.energystar.gov/index.cfm? c=bldrs_lenders_ raters.energy_efficient_mortgage

- www.natresnet.org/ratings/default.htm

- www.hud.gov/offices/hsg/sfh/eem/energy-r.cfm

- www.ase.org/section/_audience/consumers/ refinanceremodel/refinancing/

\section{Tax Credits}

Provisions in the Federal Energy Policy Act of 2005 allow home builders to claim a tax credit of $\$ 2000$ for qualifying energy-efficient homes. The qualification criterion is the estimated heating and cooling energy consumption of the home. It must be at least $50 \%$ below the heating and cooling consumption of a comparable home that meets the standards of the 2004 supplement to the 2003 International Energy Conservation Code (IECC). Energy-efficient windows are crucial for achieving such low consumption of heating and cooling energy.

The credit goes directly to the home builder. In order to claim the credit, a builder must have the home's energy performance estimated and certified by an independent certifier that is accredited by the Residential Energy Service Network (RESNET).

Currently, the tax can be claimed for homes placed in service until December 31, 2009. Renewal of the tax credit is pending in Congress. For more information, view www.energytaxincentives.org/builders/new_homes. php. 


\section{How to Make the Most of Energy Efficient Windows}

Builders can provide the best indoor comfort and energy performance by selecting windows that are suited for a home's climate and orientation. .

Most windows and skylights now have labels that display energy ratings to help builders and homeowners choose energy-efficient products. These labels have been developed by the National Fenestration Rating Council (NFRC), a not-for-profit organization that administers the only uniform, independent rating and labeling system for the energy performance of fenestration products (windows, doors, skylights and attachment products). The most important rating criteria for heat loss and gain are U-Factor and Solar Heat Gain Coefficient (SHGC).

The U-factor measures the rate a window conducts non-solar heat flow, representing the performance of the entire window, including the frame and

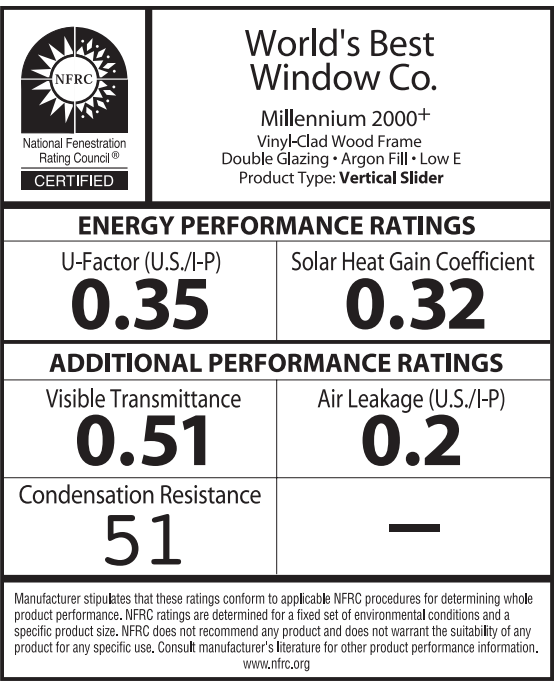
spacer materials. The lower the U-factor a window has, the more energy efficient it is. Window U-factors generally range from 0.15 for high-performance triple-pane units to 1.20 for older single-pane units.

A window with a high solar heat gain coefficient (SHGC) is collects more solar heat, which is beneficial during the winter but can increase cooling demand if no shading is provided. A window with a low SHGC more effectively controls cooling loads but limits the potential for free winter heating from the sun. SHGCs range between 0 and 1 .

\section{What is the difference between R-value and U-factor?}

The R-value is used formost parts of the building envelope in ordertoindicate insulating performance. TheU-factor is used to express the insulation value of windows. $R$ value and $U$-factor are similar in measuring non-solar heat flow. But the term R-value is usually used for wall or ceiling insulating value and does not translate well to windows and other fenestration products. Therefore, the U-factor is used for fenestration products. It is important to note that these ratings relate to each other inversely: A higher R-value means betterinsulated walls and ceilings, while alowerU-factorindicates better performing windows.

To determine the $R$-value equivalent of a window $U$ factor, divide 1 by the $U$-factor number.

E.g.: a $0.25 \mathrm{U}$-factor equals a $1 / 0.25=4$ R-value.

\section{Low or High Solar Heat Gain?}

In climates with a clear dominance of either cooling or heating energy use, the decision of whether to choose windows with a higher or a lower SHGC is relatively straightforward. AlowSHGC helps reduce coolingloads, whereas more solar heat gain reduces winter heating needs. In most U.S. climates, however both heating and cooling needs can be significant, so the question of the optimum SHGC is not as easy to answer. It depends on the design of the house and the specific climate of its location. Here are some rules of thumb for mixed climates:

- A higher SHGC (above 0.40) can be considered for southfacing windows if overhangs provide shading in the summer. South-facing windows are a good source of passive winter heat gain.

- East-and west-facing windows should provide good solar control because they are a source of much unwanted summer heat gain unless well shaded, e.g. by trees (overhangs don't work well against the low morning and evening sun).

- Ideal windows have a low U-factor. This keeps the home warm in the winter, even if the SHGC is low to keep the summer heat out.

- The Efficient Window Collaborative's Window Selection Tool helps you choose suitable window types for specific climatic conditions. Also, Lawrence Berkeley National Laboratory provides a computer program to calculate energy use based on window selection. The name of the program is RESFEN and can be download at windows.lbl.gov/software. 


\section{Window Orientation can Greatly Influence the Energy Efficiency of a Home.}

Orientation in a northern climate (mostly heating)

It is generally accepted that orienting the majority of windows to the south in a heating-dominated climate will result in greater solar gain and less heating energy use. This is a very important consideration if less efficient windows with a higher U-factor are used. On the other hand, by using high-performance windows, the impact of window orientation on heating energy use is diminished. For example, north-facing windows with triple glazing and low-E perform about as well in keeping heating use low as south-facing windows with clear double glazing. With a greater window area, the difference between less efficient and more efficient windows as well as the difference between north-facing and southfacing windows becomes greater.

Orientation in a mixed climate (heating and cooling)

Orienting windows to the south will result in greater solar gain in winter while overhangs can be designed to reduce summer solar gain.

East and west window are more difficult to shade. Their glazing area should either be kept at a minimum or consist of highly energy-efficient windows with a low SHGC.

North facing windows perform the best in summer but are worse in providing winter heat gain. However, well-insulated windows with a low U-factor prevent heat loss and even in winter provide for energy efficient north-facing glazing.

The difference between orientations is diminished when higher-performance windows with lower U-factors and SHGCs are used. The less external shading and the greater the window area, the greater the difference in energy costs between less efficient and more efficient windows, and between different window orientations.

Orientation in a southern climate (mostly cooling)

In predominantly cooling climates, the goal is to face most windows north, where there is little direct exposure, or to the south, where they can be designed with overhangs that will keep out most of the hot summer sun. Overhangs are much less effective against the lower angles of the east and west sun. Therefore, simply reducing the size and number of east and west windows can be the best strategy.

The orientation of windows has a significant impact when typical clear-glazed windows are used. Notethat high-solar-gain low-E windows perform worse than low-solar-gain low-E windows. When higher-performance windows with low-solargain low-E coatings are used, window orientation and the size of the glazing area have a greatly diminished impact on energy use. Shading provided by overhangs or trees, however, should always be considered as an additional means of reducing cooling loads. 


\section{Window Design Tools for Schools}

s energy prices increase and school budgets
tighten, school districts are looking for cost-
effective ways to improve building energy efficiency and operation. With almost one quarter of Americans spending their day in the classroom, efficient window design is an important opportunity to not only save energy and money but also to enhance the learning environment. Windows affect heating and cooling needs, the potential for natural ventilation, and the availability and quality of daylight. Integrated design that takes these factors into account can improve a school's energy performance as well as students' visual and thermal comfort.

As shown in Figure 1, several factors need to be considered to achieve these improvements.

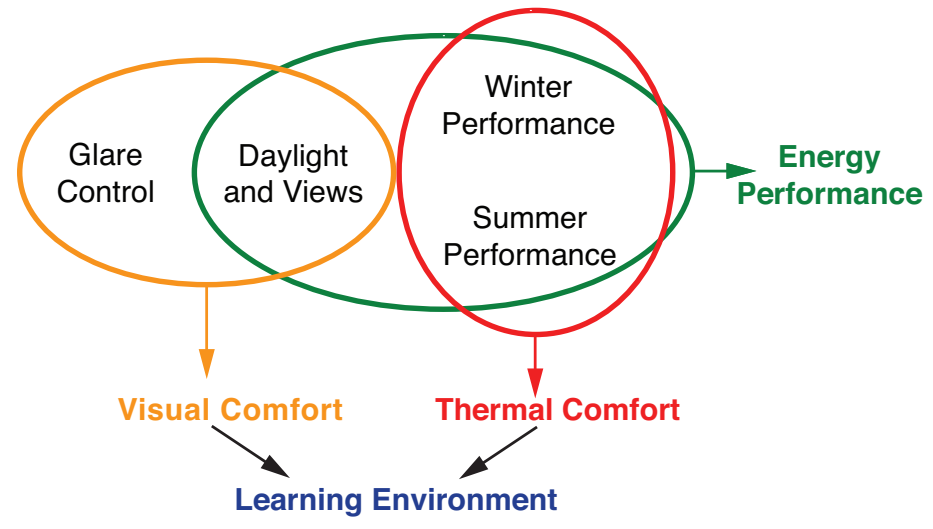

Figure 1: Window System Performance Factors

\section{Tools for Schools Contents}

I. Window Design Parameters ........................................... 1

II. Window Design Parameters............................................ 2

Orientation ..........................................................................

Daylight Controls .................................................................

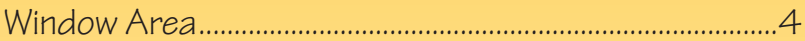

Shading Conditions ......................................................................

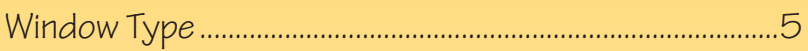

III. Window Performance Factors .................................... 6

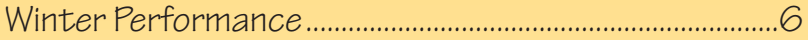

Summer Performance ...........................................................

Daylighting and Views .........................................................

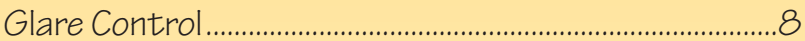

IV. Efficient Window Technology Options ........................ 8

Energy-related Window Properties...................................... 8

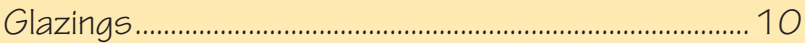

Frame Materials ................................................................ 12

Toplighting Fenestration ................................................... 13

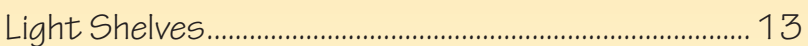

Natural Ventilation.................................................................. 14

V. Glossary .................................................................. 15

V. References and Resources.................................... 17

\section{Efficient Windows Collaborative (EWC)}

This fact sheet was produced with funding from the Windows and Glazings Program at the U.S. Department of Energy (www.eren.doe.gov) in support of the EWC. For more information, contact:

EWC / Alliance to Save Energy

1850 M Street NW, Suite 600

Washington, D.C. 20036

phone: 202-530-2254 / fax: 202-331-9588

www.efficientwindows.org / www.ase.org

Center for Sustainable Building Research (CSBR)

College of Design, University of Minnesota

www.csbr.umn.edu 


\section{Energy Performance}

Windows can affect energy use in classrooms in several important ways. Heat loss and heat gain through windows impact heating and cooling demand. Operable windows can provide natural ventilation, and daylight penetrating into classrooms may diminish or eliminate the need for electrical lighting.

\section{Learning Environment}

Windows can provide vital elements for a healthy learning environment: natural light, views, and fresh air. Although light and air can also be provided by electric and mechanical means, there is growing recognition that views, natural light and ventilation contribute to the satisfaction, health, and productivity of students and teachers.
Windows can have both positive and negative impacts on student comfort and performance. Access to natural light and pleasant views are positive factors, but student performance can be negatively impacted by factors such as glare, uncomfortabletemperatureextremes, stuffy air and noise pollution. Proper window design and operation can help mitigate these issues, creating more comfortable and productive learning environments. $\sim($ Heschong Mahone Group, 2003)

\section{Window Design Parameters}

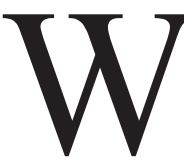

indow design involves climate and solar conditions based on location and building type. Within these conditions, several design variables can strongly influence the impact of windows on energy performance and the learning environment. Computer simulations and professional design analysis can help determining this impact. As a starting point, however, the following pages summarize several of the key parameters involved in an integrated window design. Figure 2 on the next page shows a recommended sequence of design decisions to account for these parameters.

\section{Orientation}

The orientation of classroom windows determines the potential for solar heat gain, daylight, and glare. East and west are usually the least favorable orientations since they permit little control over solar radiation. A south orientation is most likely to permit daylighting throughout the school day, although the indirect and ambient light through north-facing glazing can also be substantial.

\section{Orientation affects:}

- Winter performance - South-facing windows provide the best potential for passive solar heating.

- Summer performance - Solar heat gain through east- and west-facing windows is most difficult to control.

- Daylighting \& views - Year-round potential for daylighting can best be achieved with south-facing windows.

- Glare control - Glare is most difficult to control with east- and west-facing windows. 
ORIENTATION
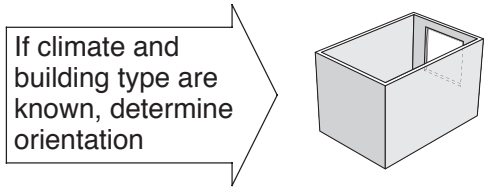

North

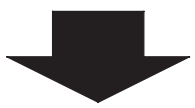

DAYLIGHT CONTROLS
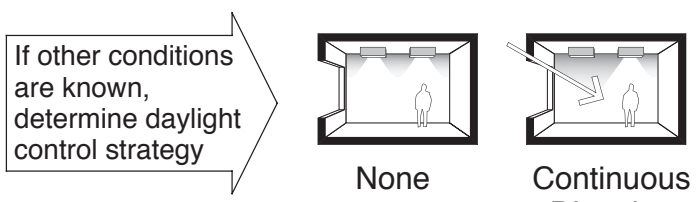

Dimming

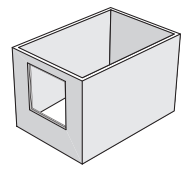

South

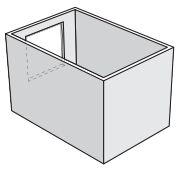

West

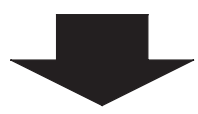

WINDOW AREA (window-to-wall ratio)
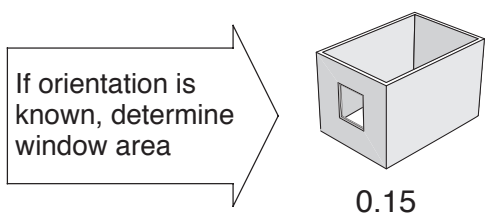

0.15

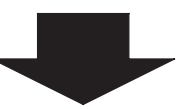

SHADING CONDITION
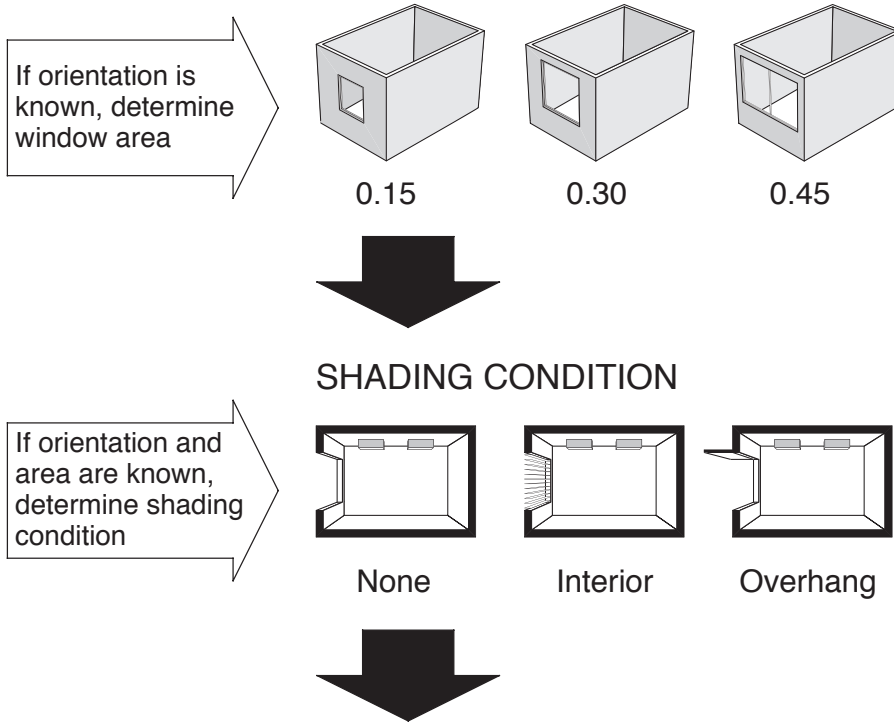

0.30

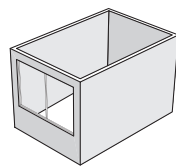

0.45

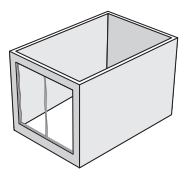

0.60

\section{WINDOW TYPE}

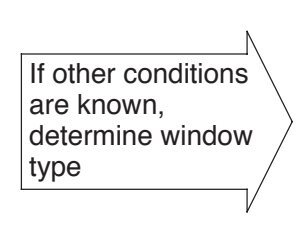

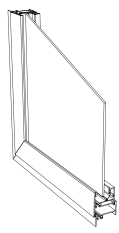

A

single clear

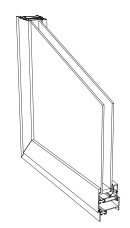

B double clear

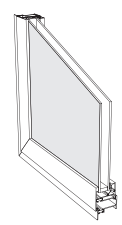

C double bronze tint

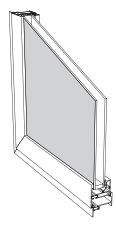

D

double reflective

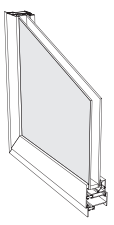

E double bronze tint spectrally low-E selective tint low-E

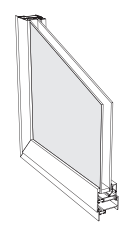

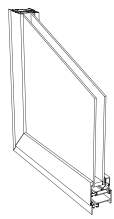
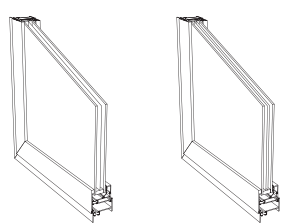

G double clear low-E
$\mathrm{H}$ triple clear low-E
I

quadruple clear low-E

Figure 2: Window Design Parameters (source: Carmody et al.) 


\section{Daylight Controls}

If the building location and window orientation allow for sufficient daylighting, an integrated daylight control system should be considered early in the design process. Daylight control systems dim and/or switch off lights when sufficient daylight is available. The graphs below show how simulations of a Chicago classroom predict significant savings in lighting and cooling — through avoided waste heat — resulting from the use of daylighting controls (Figure 3 ). The effect of daylighting controls provides useful information for subsequent window design decisions.

\section{Window Area}

Windows should be sized to allow for access to daylight and views while avoiding excessive glare, solar heat gain, and winter heat loss. The desirable size of windows depends on their placement and orientation. If windows face east or west, glare and solar heat gain are more difficult to control. The Advanced Energy Design Guide for K-12 School Buildings, developed with support from the Department of Energy, recommends avoiding large window areas on the east and west façades and limiting overall vertical window area to no more than 35 percent of the gross exterior wall area. Nevertheless,

Daylight controls affect:

- Summer performance - Daylight controls limit peak cooling demand by limiting excess heat from electric lighting.

- Daylighting \&views -Daylightcontrols greatly reduce lighting energy use.

Window area affects:

- Winter performance - Larger window areas increase the importance of insulating value.

- Summerperformance-Largerwindowareaspotentially increase solar heat gain.

- Daylighting \&views - Sufficient glazingarea is required for daylighting and views.

- Glare control - Glare potential increases with larger glazing areas. north- and south-facing windows should be sufficiently large to provide daylight and views while skylights and other means of toplighting, such as tubular daylighting devices and clerestory monitors, can provide additional high-quality daylighting.

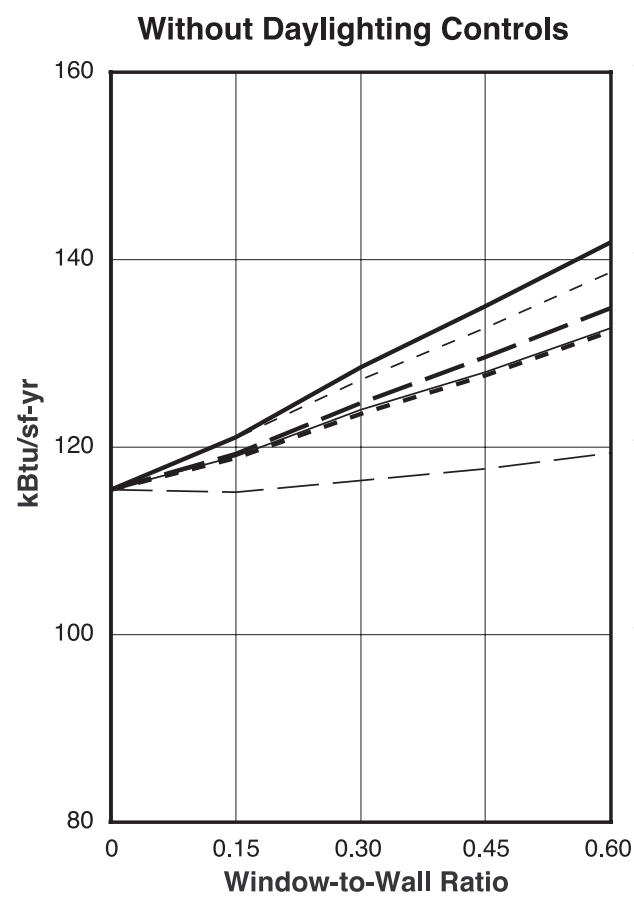

With Daylighting Controls

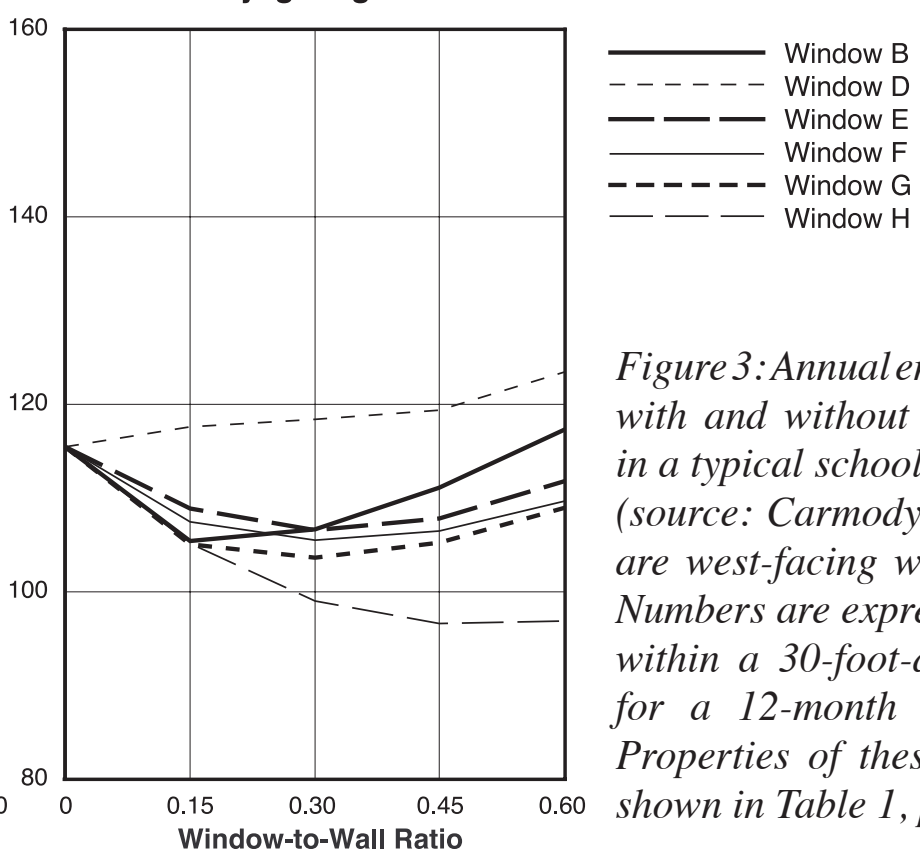

80

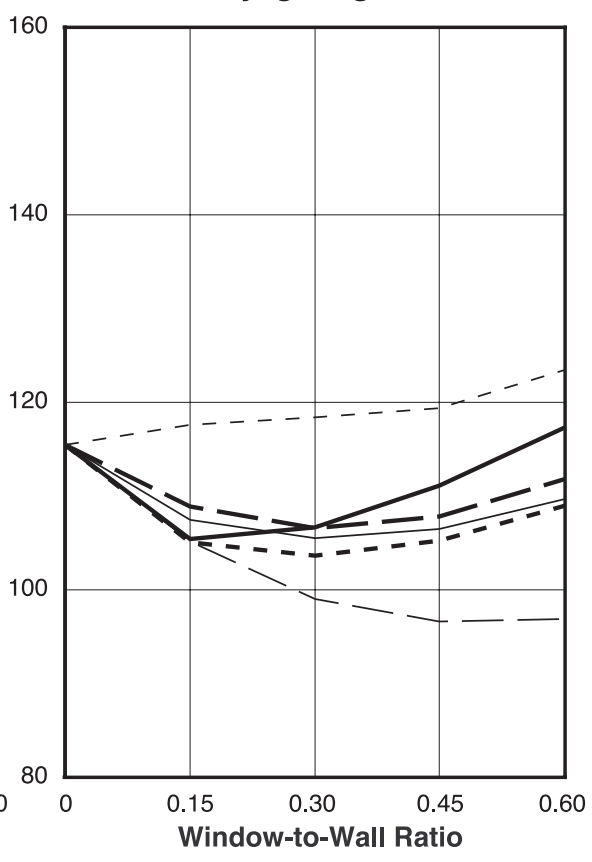

B-3-4 


\section{Shading Conditions}

Some shading conditions, such as trees or nearby buildings, may precede the design process. Other shading elements are up to the designer to optimize. Shading can be designed so that it controls solar heat gain but permits daylight access. For instance, light shelves can shade large window areas while redirecting visible light through high clerestory windows to the room's ceiling. To darken the room for projections, some form of operable shading is also required in most classrooms.

\section{Window Type}

Once orientation, daylighting, window area, and shading conditions are known, the window type must be chosen. Considerations include the glazing and frame type, which affect the energy-related window properties. Operator type and the potential for natural ventilation also need to be considered. Apart from vertical windows, skylights, clerestory windows, and other toplighting fenestration may be considered to enhance daylighting.

When the window type is chosen, the effect of the window design on HVAC demand should be taken into account. Energy-efficient window design often allows for smaller and less costly HVAC systems, thus freeing funds that can be allocated to the efficient window technologies.

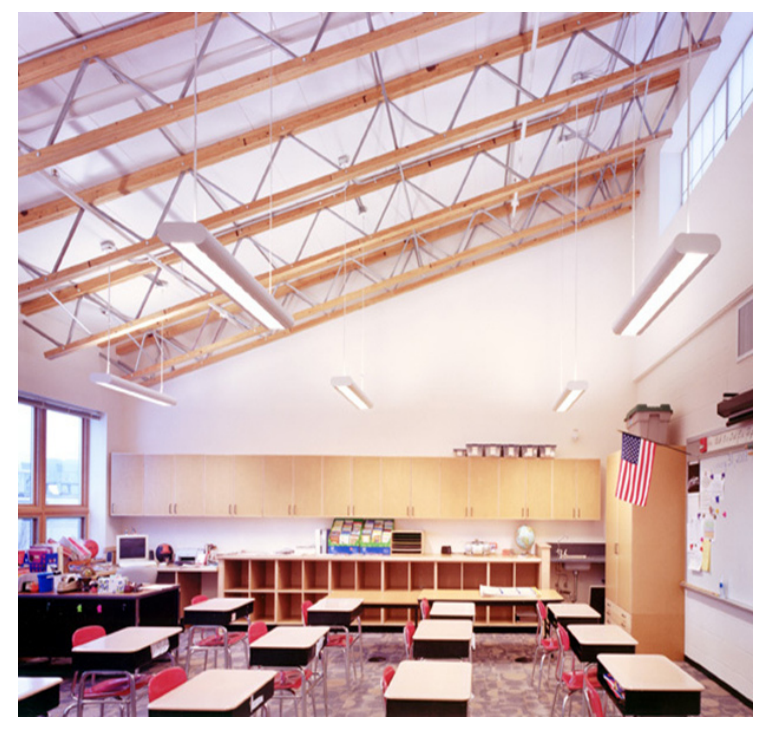

Shading conditions affect:

- Summer performance - Interior and exterior shading reduce solar heat gain.

- Daylighting \& views -Shading systems such as light shelves and overhangs can allow daylight and views

- Glare control - Shading can be crucial for glare control.

Window types affect:

- Winterperformance-Goodinsulating value is required to limit heat loss.

- Summer performance - High-performance glazing options can limit solar heat gain.

- Daylighting \& views - The visible transmittance of windows impacts daylight access. Daylighting design typically distinguishes between daylighting glazing and view glazing.

- Glare control-Somewindowsreduce glare by providing for indirect daylighting and blocking or filtering direct sunbeams.

Figures 4 and 5: The use of various glazing and design elements in schools can enhance daylighting, views, and student performance. Photo: (OJim Schafer www.jimschaferphotography.com.

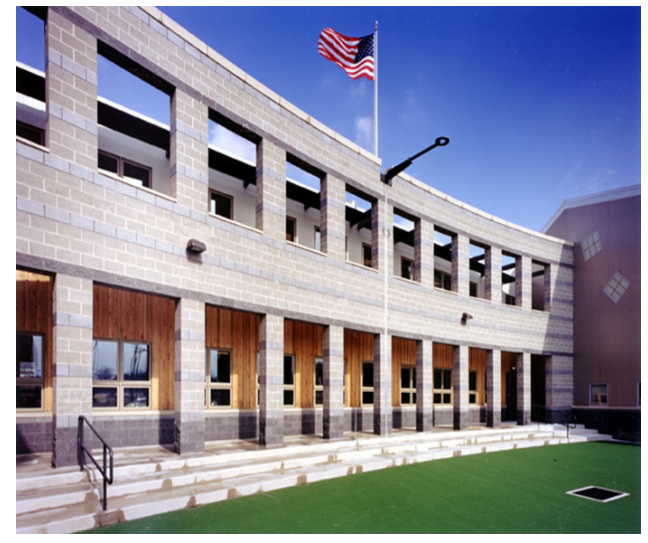




\section{Window Performance Factors}

\section{Winter Performance}

The winter performance of windows depends on their ability to control heat loss and to prevent discomfort from cold window surfaces. The principle measure of heat loss is the window U-factor.

It is important to consider the impact of window performance on the heating system requirements. Conventional windows are usually places of temperature variation and winter discomfort, requiring perimeter heating to counter the effect of cold window surfaces. High-performance windows with a very low U-factor, on the other hand, retain higher glass temperatures, which in some cases allows for the elimination of perimeter heating and a significant reduction in heating system size - in turn offsetting much of the cost premium for the high-performance windows. The Advanced Energy Design Guide for K-12 School Buildings (see References) recommends U-factors of 0.42 or less in a mixed climate and of 0.33 or less in a heating-dominated climate.

\section{Summer Performance}

The summer performance of windows depends on orientation, shading, and their ability to control solar heat gain through a low solar heat gain coefficient (SHGC), their potential to reduce electric lighting via daylighting, and on the natural ventilation they offer. Solar heat gain is a significant contributor to cooling demand and the heat generated by electric lighting is an additional factor. Control of solar heat gain combined with daylighting to offset electric lighting effectively reduces the peak demand on the cooling system. Reduced peak demand may in turn allow for smaller cooling equipment or, in moderate climates, may eliminate the need for mechanical cooling. Figure 6 illustrates how window options and the use of daylighting controls impact peak cooling demand.

Without Daylighting Controls

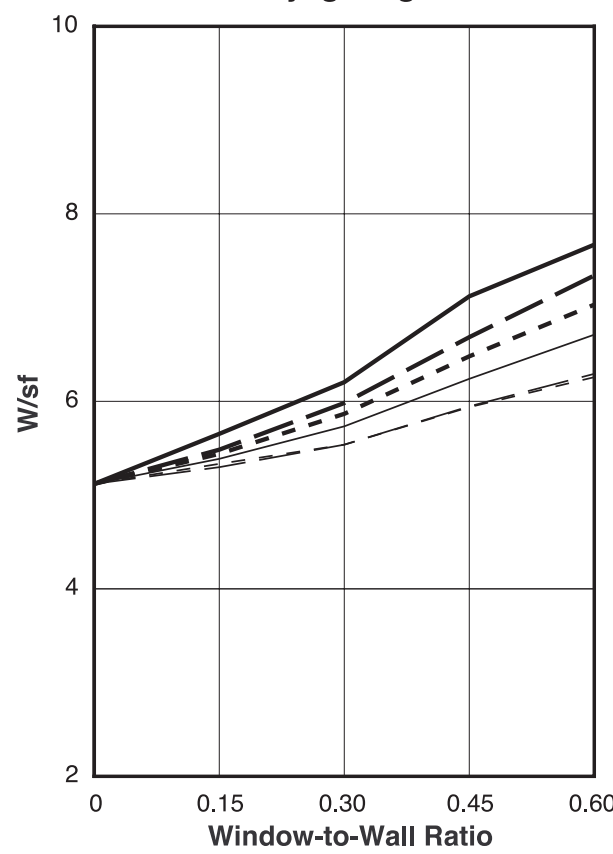

With Daylighting Controls

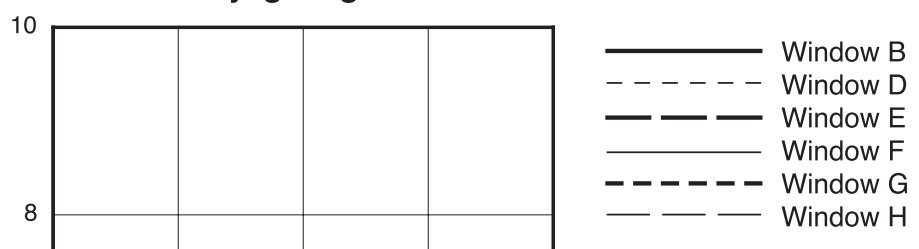

Figure 6: Comparison of peak demand for cooling using daylighting controls in a typical school building in Chicago (source: Carmody et al.). All cases are west-facing with interior shading. Numbers are expressed per square foot within a 30-foot-deep perimeter zone for a 12-month operating schedule. Properties of these window types are shown in Table 1, page 9. 


\section{Daylighting and Views}

Daylight has qualities that cannot be replicated by electrical light. The changing intensity, direction, and color of natural light connect building occupants to the weather, season, and time of day. Views through windows, especially those including elements from nature, stimulate the well-being and productivity of students. With careful design and daylighting controls, daylighting can also substantially reduce lighting energy use.

The potential for daylighting and view is largely a function of orientation, window placement and window area, as well as the windows' visible transmittance. However, modern daylight design is far more sophisticated than simply providing windows with high visible transmittance. To balance daylight admission with glare and solar heat gain control and provide uniform light distribution, modern daylight design suggests that glazing is separated into glazing for daylighting and glazing for views.

Daylight glazing is typically placed high in the wall, or ceiling in the case of toplighting. Daylight glazing can be designed to keep light beams from directly entering the room - which could cause glare - but instead reflect the light deep into the room via light shelves, reflective blinds, or other reflective surfaces.

Resources for daylight design and daylight control systems

- Lawrence Berkeley National Laboratory's Windows andDaylighting Group (windows.|bl.gov) has developed a detailed daylight design guide: Tips for Daylighting with Windows (btech.lbl.gov/pub/designguide/dlg. pdf).

- Illuminating Engineering Society of North America (IESNA): a resource for literature, standards, codes, guidelines and a monthly journal covering lighting, daylighting, and visual comfort. Local chapters may also offerclasses orotherresources. Forpublications, call (212) 248-5000, ext. 112 or view www.iesna. org.

- Electric Power Research Institute (EPRI): has an extensive collection of fact sheets, brochures, guidelines and software.Call EPRILighting Information Office (800) 525-8555 or view www.epri.com.

View glazing is located lower in the wall, offering a view to the outdoors for occupants seated in a room. If sufficient daylight is provided through separate daylight glazing, shading can be increased for view glazing to control glare and solar heat gain without a daylighting penalty.

Reaping the full benefits of daylight design requires daylight control systems as described above. The first requirement for an integrated daylight control system is that electric lights are controlled such that energy savings will occur. For example, lights near windows must be switched off separately from the rest. In addition, individual fluorescent tubes within light fixtures may be switched separately allowing for a range of light levels instead of only 100 percent on or off. Dimmable light fixtures also permit electric light levels to be reduced.

To take advantage of the natural light from a window, either people or automatic controls must switch off the electric lights. Occupant switching can be effective but requires active participation and usually will not be done optimally to reduce energy use. If the daylighting is plentiful and uniformly distributed, there is a greater chance that people will switch off the lights. Portions of the electric lighting can also be switched off or dimmed automatically in response to a photo sensor. This type of system is designed to operate optimally without depending on occupant participation. However, these systems are more expensive than simple switching and represent emerging technology where their installation and operation must be carefully monitored to ensure the projected savings. 


\section{Glare Control}

Too much daylight can produce excessive glare, resulting in eye strain that negatively affects the learning environment. The likelihood of glare varies depending on orientation, window area, shading conditions, and window type. South-facing windows, can be shielded from direct glare with overhangs and fins whereas glare control is more difficult with east- and west-facing windows. Smaller window areas and glazing with lower visible transmittance can reduce glare, but may lower the potential for beneficial daylighting. Solutions to this are glazing designs that separate daylight glazing from shaded view glazing and redirect daylight by means of light shelves or other elements. Toplighting fenestration such as clerestory monitors or tubular daylighting devices can help with controlled daylight access.

\section{Efficient Window Technology Options}

7 his section provides an introduction to window components and to the energy related properties of windows. It starts with a summary of the quantitative measures that help to determine winter and summer performance, daylight access, and glare: U-factor, solar heat gain coefficient, visible transmittance, and air leakage. Window materials and technologies are presented next. Finally, the potential for natural ventilation is discussed.

\section{Energy-related Window Properties}

The four metrics listed below define window energy performance. These performance metrics should be measured and rated over the entire window assembly, not just the center of glass. Labels denoting that the window rating is certified by the National Fenestration Rating Council (NFRC) assure that the whole window assembly has been rated in a consistent manner.

- Insulation value (U-factor). When there is a temperature difference between inside and outside, heat is lost or gained through the window frame and glazing by the combined effects of conduction, convection, and radiation. The $\mathrm{U}$-factor of a window assembly represents its insulating value.

The U-factor is a measure of the rate of non-solar heat loss or gain through a window assembly. It is expressed in units of Btu $/ \mathrm{hr}-\mathrm{sq} \mathrm{ft}-{ }^{\circ} \mathrm{F}$. The lower the U-factor, the greater a window's resistance to heat flow and the better its insulating value. Typical U-factors range between 1.25 for single glazing in aluminum frames to U-factors as low as 0.15 for low-E coated triple glazing in insulated frames.

- Solar Heat Gain Coefficient (SHGC). Regardless of outside temperature, heat can be gained through windows by direct or indirect solar radiation. The ability to control this heat gain through windows is measured in terms of the solar heat gain coefficient of the window.

The SHGC is the fraction of solar radiation admitted through a window or skylight, both directly transmitted, and absorbed and subsequently released inward. It is expressed as a number between 0 and 1 . The lower a window's solar heat gain coefficient, the less solar heat it transmits, and the greater its shading ability. 
- Visible Transmittance (VT). Visible transmittance is an optical property that indicates the portion of incoming visible light transmitted through the window (also referred to as visible light transmittance - VLT). It affects energy by providing daylight that creates the opportunity to reduce electric lighting loads and thus, indirectly, reduce cooling loads through reduced lighting use.

- Air Leakage (AL). Heat loss and gain also occur by air leakage through cracks in the window assembly. This effect is measured in terms of the amount of air that passes through a unit area of window under given pressure conditions. In reality, infiltration varies slightly with wind-driven and temperature-driven pressure changes. Air leakage may also contribute to summer cooling loads by raising the interior humidity level.

The air leakage rating is a measure of the rate of air-leakage around a window or skylight in the presence of a specific pressure difference. It is expressed in units of cubic feet per minute per square foot of frame area (cfm/sq ft). The lower a window's air-leakage rating, the better is its airtightness.

Window properties differ from product to product. Typical window properties for a few common window types are shown in Table 1. Note that air leakage is not shown in this table since it largely depends on factors such as workmanship and the window operator type.

Table 1: Typical Window Properties for Selected Common Window Types

\begin{tabular}{|c|l|c|c|c|}
\hline \multicolumn{1}{|c|}{ Window type } & U-factor & SHGC & VT \\
\hline A & Single glazing, clear, aluminum frame & 1.25 & 0.72 & 0.71 \\
\hline B & Double glazing, clear, aluminum frame & 0.60 & 0.60 & 0.63 \\
\hline C & Double glazing, bronze tint, aluminum frame & 0.60 & 0.42 & 0.38 \\
\hline D & Double glazing, reflective coating, aluminum frame & 0.54 & 0.17 & 0.10 \\
\hline E & Double glazing, low-E, bronze tint, aluminum frame & 0.49 & 0.39 & 0.36 \\
\hline F & Double glazing, selective low-E, bronze tint, aluminum frame & 0.46 & 0.27 & 0.43 \\
\hline G & Double glazing, spectrally selective low-E, aluminum frame & 0.46 & 0.34 & 0.57 \\
\hline H & Triple glazing, low-E, insulated frame & 0.20 & 0.22 & 0.37 \\
\hline I & Quadruple glazing, low-E, insulated frame & 0.14 & 0.20 & 0.34 \\
\hline
\end{tabular}




\section{Window Technologies and Designs}

Designers can choose from a wide range of possible window materials and assemblies. Different glazing and frame materials and special assemblies can provide insulation value, sun control, and daylight redirection as appropriate for a given room or building. The following is a quick overview of different glazing options, frame options, and emerging window technologies.

\section{Glazing}

\section{Low-E coatings}

Low-E (low-emittance) coatings reduce radiant heat transfer through window glazing, thus improving its insulating properties. In addition, the solar reflectance of low-E coatings can be manipulated so that desirable wavelengths of the solar spectrum are transmitted and others specifically reflected. Of particular value for school buildings are coatings that reflect heat from solar infrared radiation (resulting in a low SHGC) while allowing the visible light spectrum to enter (high VT). These coatings are called spectrally selective.

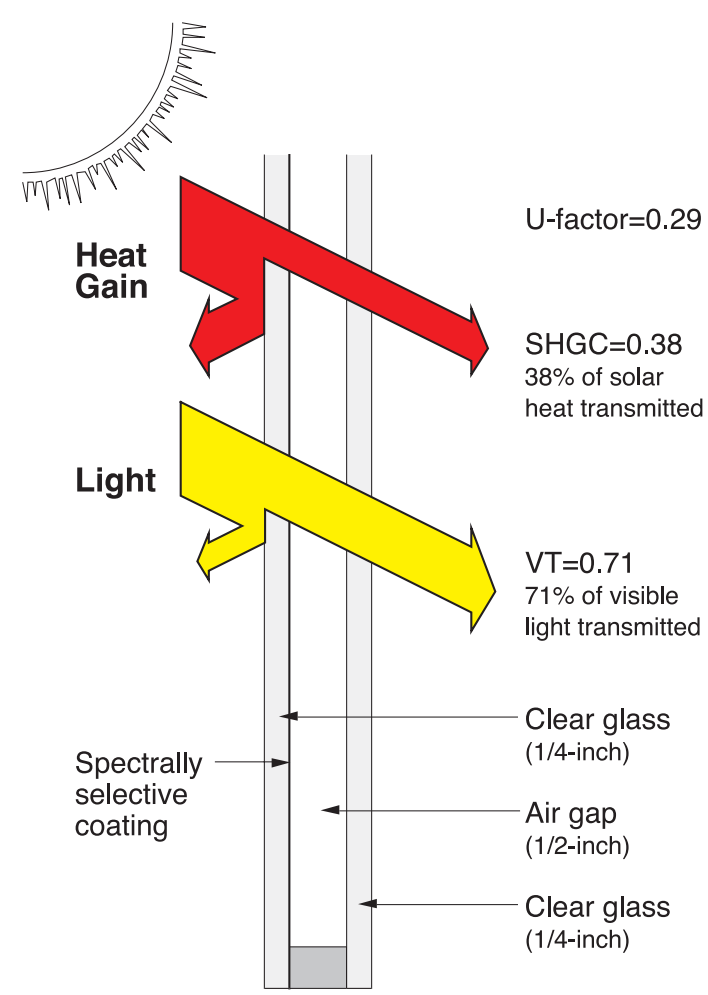

Figure 7: Double glazing with low-E coating on spectrally selective tinted glass. All values are for the glazing alone (center-of-glass). Values for the total window will vary with frame type.

\section{Tinted glass}

The primary uses for tinted glass are reducing glare from the bright outdoors and reducing the amount of solar heat transmitted through the glass. Tinted glass retains its transparency from the inside, although the brightness of the outward view is reduced and the color is changed.

Traditional bronze and gray tinted glass diminishes the amount of daylight entering the room. For windows where daylighting is desirable, it may be more satisfactory to use clear low-E coatings ( see Figure 7) or high-performance tints that preferentially transmit the daylight portion of the solar spectrum but absorb the near-infrared part of sunlight. High-performance tints are light blue or light green with a relatively high visible transmittance. They can also be combined with low-E coatings to enhance their performance further.

\section{Reflective coatings}

If larger reductions or glare and solar heat gain are desired, a reflective coating can be used. By increasing the surface reflectivity of the glass, these coatings can reduce solar heat gain substantially, but visible transmittance usually declines even more, which is problematic if daylighting is desired. Reflective glazings are usually used for glare control or for large windows in hot climates. 


\section{Highly-insulating glazing}

In addition to the insulating capabilities of doubleglazing and low-E coatings, gas fills and additional glazing layers can further improve the insulating value of glazing. Triple- and quadruple-glazed windows are available with the middle layers consisting either of glass or of suspended plastic films. These middle layers decrease the U-factor of the unit by dividing the inner air space into multiple chambers, which can be filled with insulating gas. In addition to reducing heat loss, these additional layers also reduce visible light transmission and solar heat gain.

\section{Laminated glass}

Laminated glass consists of a tough plastic interlayer made of polyvinyl butyral (PVB) bonded between two panes of glass under heat and pressure. Once sealed, the glass sandwich behaves as a single unit and looks like normal glass. Laminated glass offers increased protection from the effects of disasters such as hurricanes, earthquakes, and bomb blasts. Another benefit is that laminated glass reduces noise transmission due to the PVB layer's sound-dampening characteristics.

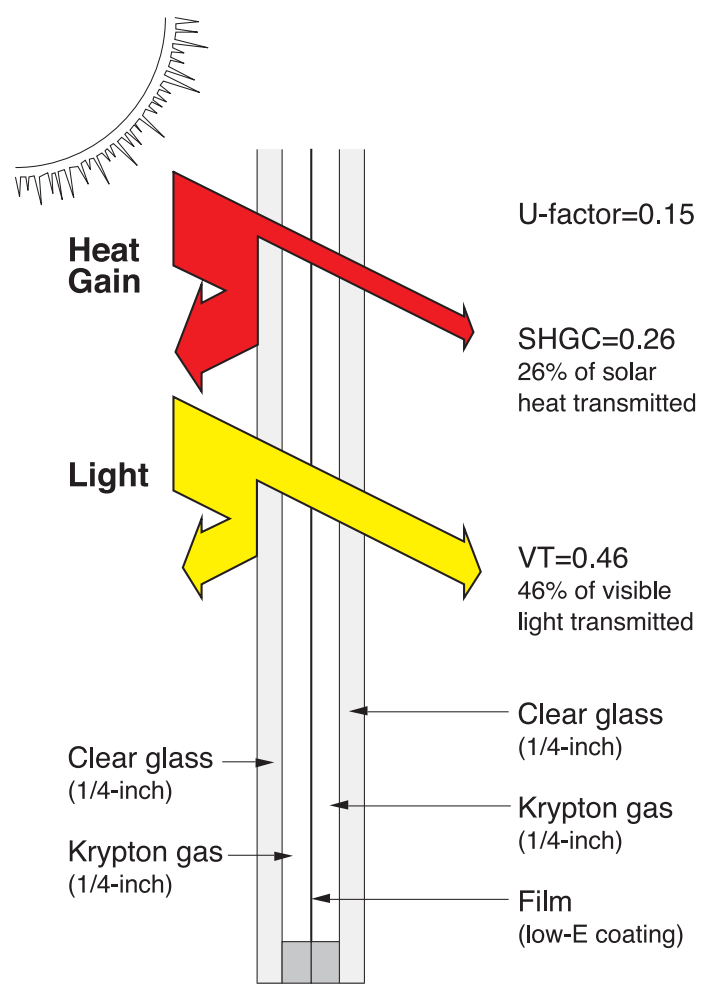

Figure 8: Triple glazing with clear glass and a low-E coating on plastic film. All values are for the glazing alone (center-of-glass). Values for the total window will vary with frame type.

\section{Smart glazing}

An emerging concept for state-of-the-art windows is "smart glazing" that can be changed from a clear to a tinted state in response to solar heat gain and glare. By actively managing lighting and cooling, smart glazing could reduce peak electric loads by 20-30 percent in many buildings, increase daylighting benefits, and improve comfort and learning environments in schools.

The most promising smart glazing technology today is electrochromic glazing. When a small voltage is applied to an electrochromic coating, it switches between a clear and tinted state, similar in appearance to photochromic sunglasses. Electrochromic glazing has been commercially available for some years, and is undergoing steady improvements. 


\section{Frame Materials}

\section{Aluminum}

Aluminum frames can provide great structural strength. However, aluminum as a material is of high thermal conductance, which raises the overall U-factor of a window unit and increases the potential for heat loss and condensation. The most common solution to this are thermal breaks, which split the frame components into interior and exterior parts, joined by a less conductive material. Current thermal breaks can cut heat transfer through aluminum frames in half.

\section{Wood}

Wood has good thermal performance, so that thicker wood frames provide more insulation. Wood is susceptible to rot and can have high maintenance requirements, but well-built and well-maintained wood windows can have a very long life. Cladding the exterior face of a wood frame with either vinyl or aluminum creates a permanent weather-resistant surface and thus lowers maintenance requirements.

\section{Wood/Polymer Composites}

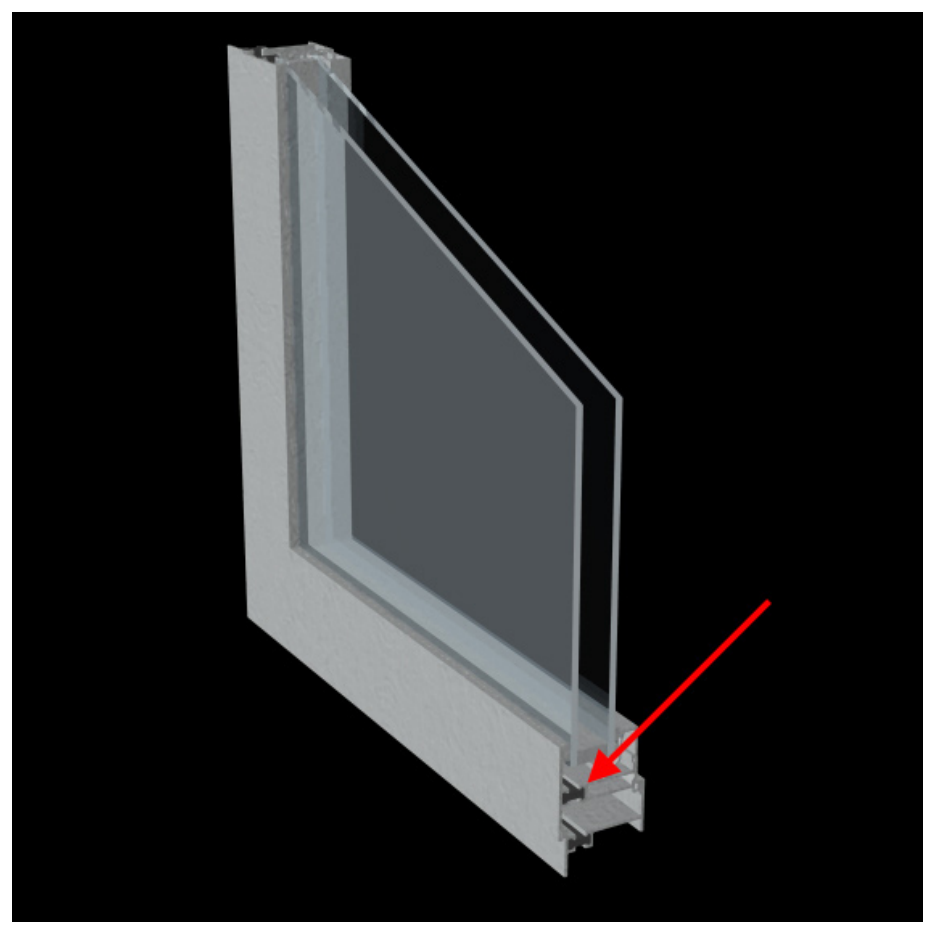

Figure 9: Thermal breaks split the aluminum frame components into interior and exterior parts, joined by a less conductive material-cutting heat transfer through the frame.

A new generation of wood/polymer composites can be extruded into a series of lineal shapes for window frame and sash members. These composites are very stable, and are comparable to or exceed the structural and thermal properties of conventional wood, with better moisture resistance and more decay resistance.

\section{Vinyl}

In terms of thermal performance, most vinyl frames are comparable to wood, and can be filled with insulation for superior thermal performance. Vinyl window frames require very little maintenance, do not require painting, and have good moisture resistance. For structural integrity, larger vinyl units will often need to incorporate metal or wood stiffeners. Vinyl has a higher coefficient of expansion than wood, aluminum, or fiberglass, meaning that it expands or contracts when temperatures change.

\section{Fiberglass}

Frames made from fiberglass are dimensionally stable and achieve good thermal performance by incorporating air cavities which can be filled with insulation. The strength of fiberglass allows the use of sleek frames like in aluminum windows while achieving significantly lower U-factors. The low coefficient of thermal expansion maintains seal integrity and minimizes warping or leakage in case of high inside/outside temperature differentials. 


\section{Toplighting Fenestration}

Daylight from vertical windows cannot always adequately light the deep ends of a room. Toplighting with skylights, clerestory windows, or tubular daylighting devices helps bringing daylight deeper into rooms. Since many schools buildings are low-rise with the classrooms directly under the roof, toplighting is a very feasible as a supplement to sidelighting.

\section{Skylights}

Appropriately placed skylights can illuminate rooms where daylight from vertical fenestration does not reach. Horizontal skylights provide light from above, but also solar heat during the summer. However strategically placed skylights with solar-heat-reducing low-E coatings may save more electricity through daylighting than they increase energy use for cooling. Low sun angles in northern latitudes limit the effectiveness of horizontal skylights in the winter. This drawback can be addressed by tilting the skylights, or with clerestories.

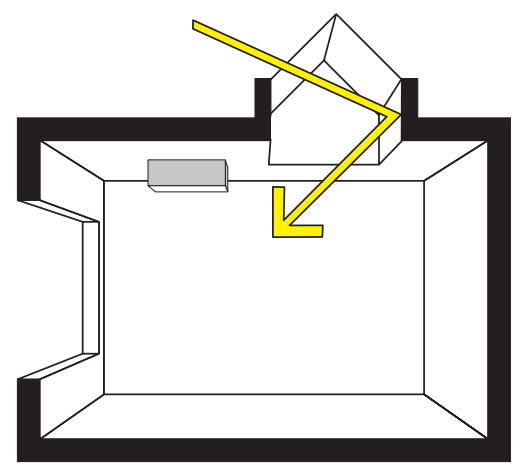

\section{Tubular daylighting devices}

Tubular daylighting devices (TDDs) capture daylight through a glazed dome protruding from the roof and reflect it down to the interior space through highly reflective shafts. Since no framing is necessary, TDDs are simpler to install than traditional skylights and are a good option for retrofits.

\section{Clerestory Monitors}

With their vertical glazing, clerestory monitors capture low sun angles more easily than skylights. North-facing clerestories can capture indirect daylight, avoiding direct solar heat gain. Clerestories facing the sun can be shaded with overhangs or louvers in the same way as vertical windows. Baffles beneath clerestories can provide diffuse glare-free daylight to the back of a room. Reflective roof surfaces help enhance the amount of daylight captured by clerestories.

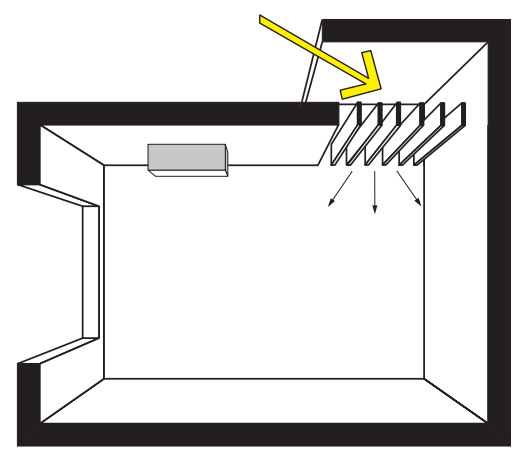

\section{Light Shelves}

Light shelves are flat or curved elements in the window façade that reflect incoming light to the ceiling- bouncing the light deep into the room. Light shelves typically divide the window aperture into a view window below the shelf - to which the shelf can provide shading and daylight glazing above. Light shelves improve the quantity and quality of light in a space and should be designed specifically for each window orientation, room configuration, building latitude, and climate. They are most appropriate for south-facing glazing.

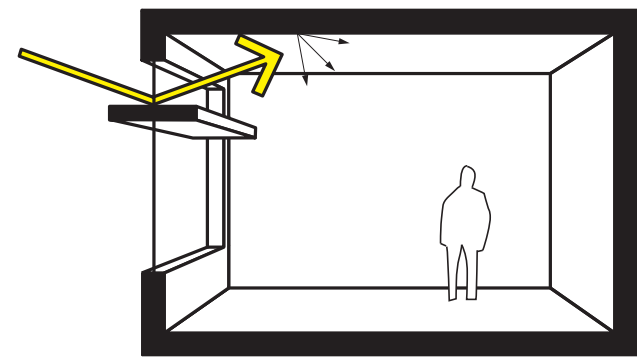




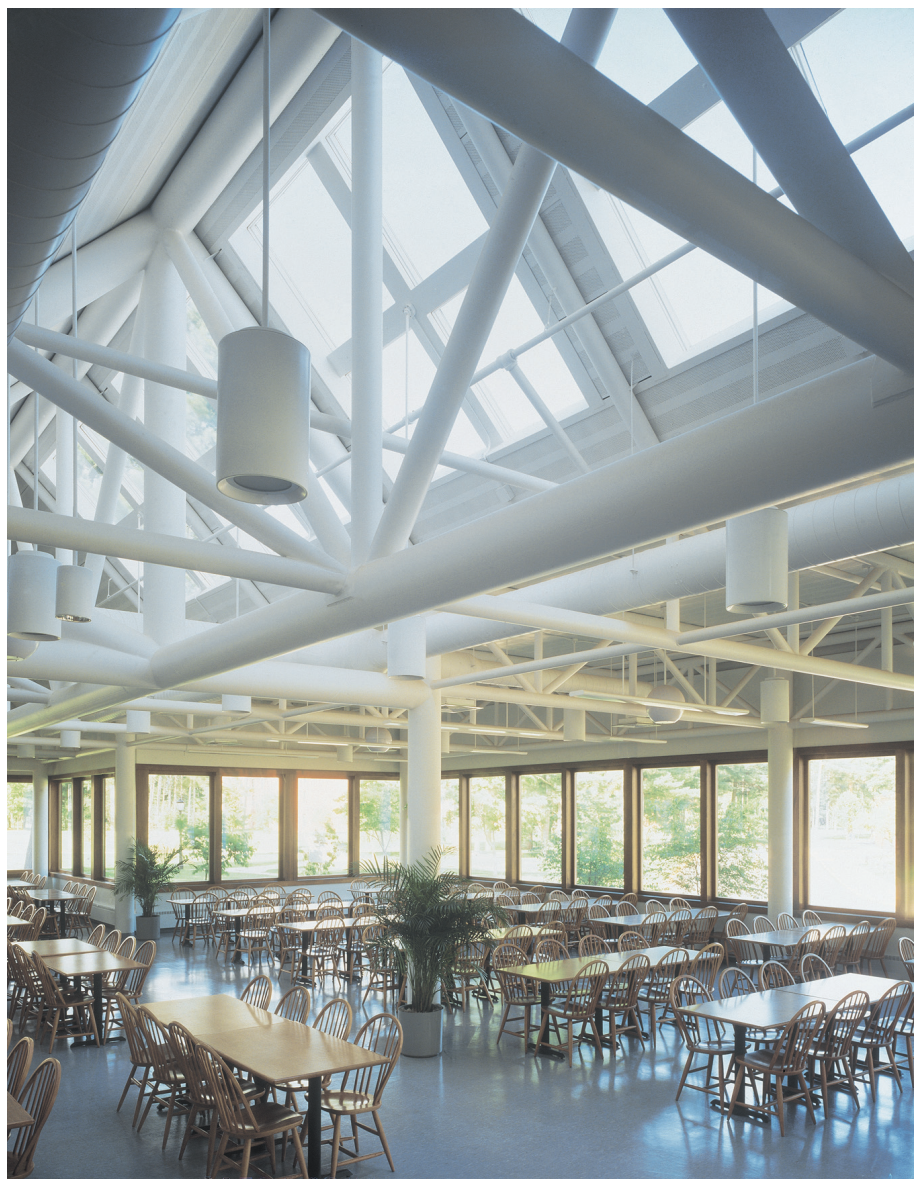

Figure 10: Toplighting with skylights, clerestory windows, or tubular daylighting devices helps to bring daylight deeper into rooms. Toplighting is feasible as a supplement to sidelighting. Photo: Velux America.

\section{Natural Ventilation}

Operable windows allow for natural ventilation, which may improve occupant comfort and the learning environment. Especially during moderate temperatures in spring or fall, fresh outdoor air can provide an inspiring connection to the environment and reduce HVAC use.

Open windows can also increase HVAC use if temperatures outdoors are significantly lower or higher than indoors. Nevertheless, as is reflected in the 2004 version of ASHRAE Standard 55, Thermal Environmental Conditions for Human Occupancy, occupants in naturally vented spaces are likely to be comfortable with a wider range of temperatures than occupants in mechanically cooled spaces. Therefore, natural ventilation is an acceptable practice for a range of moderate outdoor temperatures. To avoid that the HVAC system operates while natural ventilation is provided, HVAC systems should shut off when and where windows are open for a longer time. Automatic controls such as interlocks are available for this purpose. 


\section{Glossary}

Air leakage (AL). Air leakage ratings indicate the amount of air leaking in and out of a building through closed windows, doors, or skylights in the presence of a specific pressure difference. These ratings are expressed in units of cubic feet per minute per square foot of frame area (cfm/sq ft). The lower a window's air-leakage rating, the better its airtightness.

ASHRAE. American Society of Heating, Refrigerating and Air Conditioning Engineers.

Clerestory. A window in the upper part of a lofty room that admits light to the center of the room.

Conduction. Heat transfer through a solid material by contact of one molecule to the next. Heat flows from a higher-temperature area to a lower-temperature one.

Convection. A heat transfer process involving motion in a fluid (such as air) caused by the difference in density of the fluid and the action of gravity. Convection affects heat transfer from the glass surface to room air, and between two panes of glass.

Double glazing. In general, two sheets of glass separated by an air space within an opening to improve insulation against heat transfer and/or sound transmission. In factory-made double glazing units, the air between the glass sheets is thoroughly dried and the space is sealed airtight, eliminating possible condensation and improving insulating properties.

Electrochromics. Glazing with optical properties that can be varied continuously from clear to dark with a lowvoltage signal. Ions are reversibly injected or removed from an electrochromic material, causing the optical density to change.

Fenestration. The placement of window openings in a building wall, one of the important elements in controlling the exterior appearance of a building. Also, a window, door, or skylight and its associated interior or exterior elements, such as shades or blinds.

Fiberglass. A composite material made by embedding glass fibers in a polymer matrix. May be used as a diffusing material in sheet form, or as a standard sash and frame element.

Gas fill. A gas other than air, usually argon or krypton, placed between window or skylight glazing panes to reduce the U-factor by suppressing conduction and convection.

Glazing. The glass or plastic panes in a window, door, or skylight.

Insulating glass. Two or more pieces of glass spaced apart and hermetically sealed to form a single glazed unit with one or more air spaces in between. Also called double glazing.

Low emittance (low-E) coating. Microscopically thin, virtually invisible, metal or metallic oxide layers deposited on a window or skylight glazing surface primarily to reduce the U-factor by suppressing radiative heat flow. Low-E coatings are typically highly transparent to visible light but can reflect heat from infrared radiation. 
NFRC. National Fenestration Rating Council. A nonprofit, public/private organization created by the window, door, and skylight industry. It is composed of manufacturers, suppliers, builders, architects and designers, specifiers, code officials, utilities, and government agencies. The NFRC has developed a window energy rating system based on whole product performance.

Operable window. Window that can be opened for ventilation.

Radiation. The transfer of heat in the form of electromagnetic waves from one separate surface to another. Energy from the sun reaches the earth by radiation, and a person's body can lose heat to a cold window or skylight surface in a similar way.

Reflective coatings. Coatings on window glass that reflect radiation striking the surface of the glass.

Solar heat gain coefficient (SHGC). The fraction of solar radiation admitted through a window or skylight, both directly transmitted, and absorbed and subsequently released inward. The solar heat gain coefficient has replaced the shading coefficient as the standard indicator of a window's shading ability. It is expressed as a number between 0 and 1 . The lower a window's solar heat gain coefficient, the less solar heat it transmits, and the greater its shading ability. SHGC can be expressed in terms of the glass alone or can refer to the entire window assembly.

Solar radiation. The total radiant energy from the sun, including ultraviolet and infrared wave lengths as well as visible light.

Spectrally selective coating. A coated or tinted glazing with optical properties that are transparent to some wavelengths of energy and reflective to others. Typical spectrally selective coatings are transparent to visible light and reflect short-wave and long-wave infrared radiation.

Thermal break. An element of low conductance placed between elements of higher conductance to reduce the flow of heat. Often used in aluminum windows.

Tinted glass. Glass colored by incorporation of a mineral admixture. Any tinting reduces both visual and radiant transmittance.

Triple glazing. Three panes of glass and/or plastic with two air spaces between.

U-factor (U-value). A measure of the rate of non-solar heat loss or gain through a material or assembly. It is expressed in units of Btu/hr-sq $\mathrm{ft}-{ }^{\circ} \mathrm{F}\left(\mathrm{W} / \mathrm{sq}^{\mathrm{m}}-{ }^{\circ} \mathrm{C}\right)$. Values are normally given for NFRC/ASHRAE winter conditions of $0^{\circ} \mathrm{F}\left(18^{\circ} \mathrm{C}\right)$ outdoor temperature, $70^{\circ} \mathrm{F}\left(21^{\circ} \mathrm{C}\right)$ indoor temperature, $15 \mathrm{mph}$ wind, and no solar load. The U-factor may be expressed for the glass alone or the entire window, which includes the effect of the frame and the spacer materials. The lower the U-factor, the greater a window's resistance to heat flow and the better its insulating value.

Visible transmittance (VT). The percentage or fraction of the visible spectrum (380 to 720 nanometers) weighted by the sensitivity of the eye, that is transmitted through the glazing. 


\section{References and Resources}

\section{Reference Books}

Carmody J., S. Selkowitz, E. S. Lee, D. Arasteh, T. Willmert. Window Systems for High Performance Buildings. New York, NY: Norton, 2004.

\section{Guidelines}

Advanced Energy Design Guide for K-12 School Buildings. ASHRAE, AIA, IESNA, USGBC, DOE, 2008.

Guide to Financing EnergySmart Schools. Department of Energy, www1.eere.energy.gov/buildings/ energysmartschools/financing_guide.html.

\section{Studies and Reports}

Heschong Mahone Group. Daylighting in Schools, An Investigation into the Relationship Between Daylight and Human Performance. A Report to Pacific Gas and Electric, 1999.

Heschong Mahone Group. Windows and Classrooms: A Study of Student Performance and the Indoor Environment. California Energy Commission, 2003.

\section{Web Sites}

Collaborative for High-Performance Schools (CHPS), www.chps.net.

Council of Educational Facility Planners (CEFPI), www.cefpi.org.

U.S. Department of Energy, Energy Smart Schools, www1.eere.energy.gov/buildings/energysmartschools.

Windows for High Performance Commercial Buildings, www.commercialwindows.umn.edu. 


\section{Appendix C - Fact Sheets and Poster Presentations}

C-1 Topic sheets for South Carolina home builders about efficient windows in the International Energy Conservation Code "South Carolina + Modern Energy Code = Housing Affordability”

C-2 Poster presentation "Energy and Comfort Benefits of Highly Insulating Windows" at Affordable Comfort National Home Performance Conference 2007.

C-3 “Window Design with Attention to the Sun”. Fact sheet for homebuilders in New York State

C-4 Fact sheet draft to support U.S. Army Corps of Engineers assessment of residential window options

C-5 Fact sheet draft to support U.S. Army Corps of Engineers assessment of commercial window options 


\section{South Carolina + Modern Energy Code = Housing Affordability}

Homeowners, Builders and the South Carolina state economy would benefit if all homes were built to the standards of the International Energy Conservation Code ${ }^{\circledR}$ (IECC), the nationally recognized code for cost-effective energy efficiency in buildings. Yet South Carolina does not presently implement the IECC for lowrise residential buildings, instead referring to an outdated energy efficiency standard from 1976.

\section{IECC: A National Standard for Efficient \& Affordable Homes}

The IECC places builders on a common ground, providing a baseline for solid energy performance. Following the IECC is the first step toward building an ENERGY STAR ${ }^{\circledR}$ Home or another high-performance home. In both South Carolina and the nation, the demand for energy-efficient homes is increasing, as is the number of builders using energy-efficient design. However, without the IECC being enforced in South Carolina, there is no guarantee that all homes meet modern energy-efficiency standards, which are crucial to help homeowners alleviate the financial burden of rising energy prices.

\section{South Carolina's Current Situation:}

Although South Carolina has adopted the IECC, low-rise residential buildings are currently exempt. Instead, the Building Energy Efficiency Standards Act of 1976 applies. This old standard is close to the IECC in most of its requirements, but does not require rated, energy-efficient windows as in the IECC. The standard from 1976 only requires windows with two panes of glass, regardless of performance. As a result, homebuyers do not always receive the benefits of energy-efficient windows, and the South Carolina market for such windows is not as mature as in neighboring states.

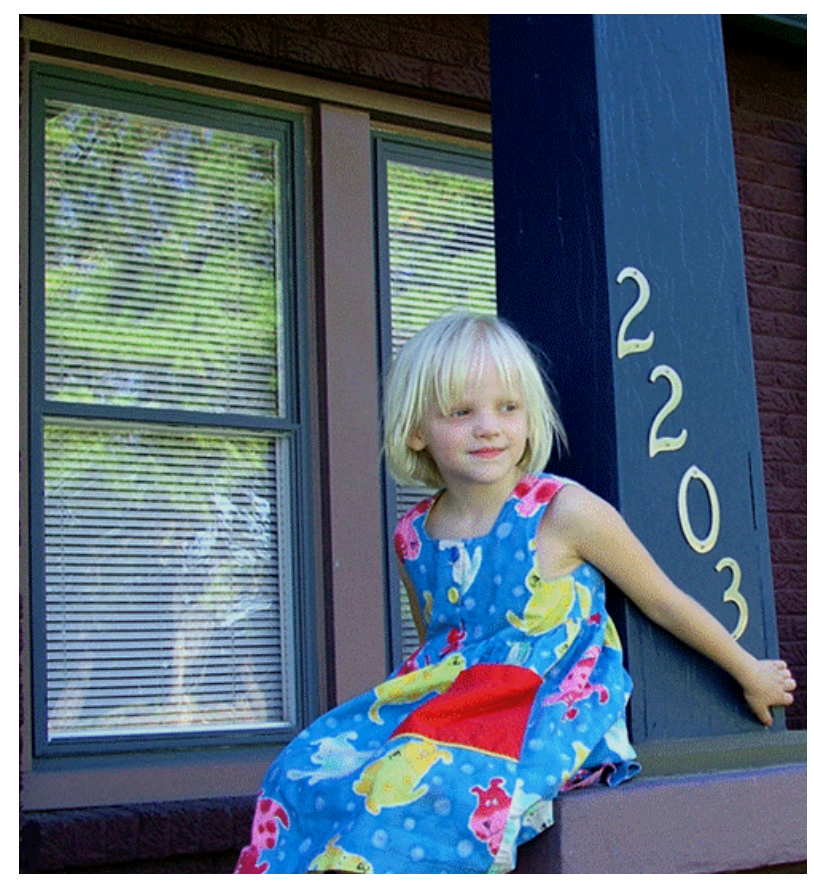

\section{IECC Advantages}

South Carolina has adopted the 2006 IECC (in effect in 2008), but it does not apply to low-rise residential buildings. Applying this modern and user-friendly code to all new homes would reap great benefits for South Carolina, such as...

- Lower energy bills and more comfortable homes;

- More affordable energy efficient products due to economies of scale;

- Increased knowledge amongst builders and contractors of cost-effective energy efficient design;

- $\quad$ And marking the first step towards wider use of green building programs and the ENERGY STAR for Homes program.

\section{The major difference - window requirements!}

\begin{tabular}{|c|c|c|c|c|c|c|c|c|}
\cline { 2 - 8 } & $\begin{array}{c}\text { Window or } \\
\text { Skylight } \\
\text { U-Factor }\end{array}$ & $\begin{array}{c}\text { Window and } \\
\text { Skylight } \\
\text { SHGC }\end{array}$ & $\begin{array}{c}\text { Ceiling R- } \\
\text { Value }\end{array}$ & $\begin{array}{c}\text { Wood } \\
\text { Frame Wall } \\
\text { R-Value }\end{array}$ & $\begin{array}{c}\text { Mass Wall } \\
\text { R-Value }\end{array}$ & $\begin{array}{c}\text { Crawl } \\
\text { Space } \\
\text { R-Value }\end{array}$ & $\begin{array}{c}\text { Floor } \\
\text { R-Value }\end{array}$ & $\begin{array}{c}\text { Ducts not } \\
\text { completely } \\
\text { within thermal } \\
\text { envelope }\end{array}$ \\
\hline $\begin{array}{c}2006 \\
\text { IECC }\end{array}$ & 0.65 & 0.40 & $\mathrm{R}-30$ & $\mathrm{R}-13$ & $\mathrm{R}-5$ & $\mathrm{R}-5 / 13^{\mathbf{b}}$ & $\mathrm{R}-19$ & $\mathrm{R}-8^{\mathbf{c}}$ \\
\hline $\begin{array}{c}\text { SC 1976 } \\
\text { Statute }\end{array}$ & Two panes of glass & $\mathrm{R}-30^{\mathbf{a}}$ & \multicolumn{3}{|c|}{$\mathrm{R}-13$} & & $\mathrm{R}-19$ & $\mathrm{R}-6$ \\
\hline
\end{tabular}

The 2006 IECC compared to the 1976 South Carolina Energy Efficiency Act 


\section{What windows meet the IECC U-factor 0.65 and SHGC 0.40?}

With low-E coatings that reduce solar gain and heat loss, most double-pane windows can meet the requirements of the IECC. For example, windows with typical frame types and low-E coatings have the following performance values:

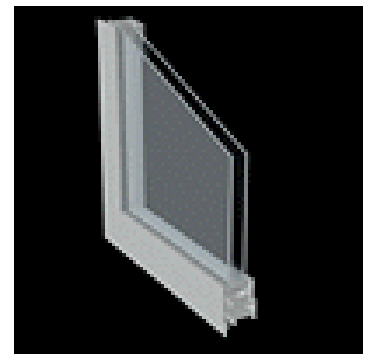

Typical aluminum window with lowsolar-gain low-E

U-factor: 0.59

SHGC: 0.37
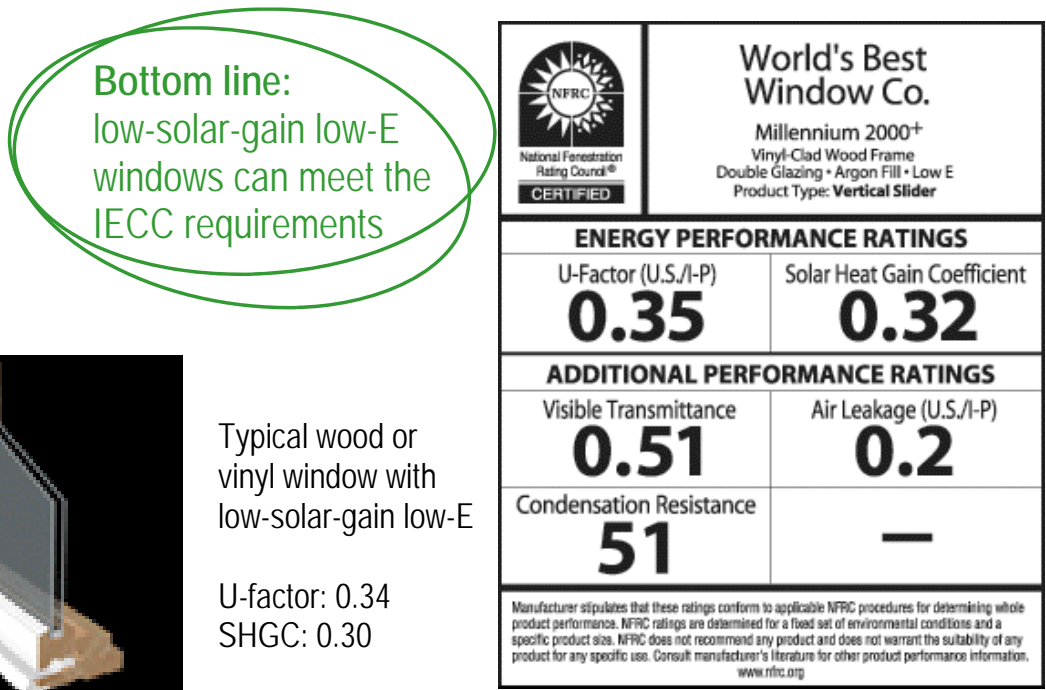

\section{The Economics of Low-E Windows}

\section{Initial Cost and Savings}

Even though low-E windows cost more than conventional windows, this higher initial cost can be partially or fully offset by reduced HVAC equipment cost. Low-E glass reduces cooling demand and thus allows for downsizing of air conditioning units.

In a mature market, the average cost premium for low-E windows is about $\$ 1$ per $\mathrm{ft}^{2}$ of window area. In a typical South Carolina home with $1,700 \mathrm{ft}^{2}$ floor area and $300 \mathrm{ft}^{2}$ window area, the economics of using low-E windows would typically be as follows:

- Cost premium for low-E windows: $\$ 300$

- Downsizing potential for HVAC units: 1/3 to 1 ton, depending on orientation and location

- Initial cost savings from HVAC downsizing:\$150-\$500

These costs and savings vary with building size, window placement and other factors. The bottom line is that a large part if not all of the incremental cost for low-E windows can be offset by taking the better window performance into account and sizing the HVAC system accordingly.

\section{Right-Sizing Air Conditioners}

Tried and tested sizing methods such as Manual $\mathrm{J}$ by the Air Conditioning Contractors of America (ACCA) take into account the downsizing potential due to better windows. Use of these methods also prevents oversizing, which usually results from the use of rules of thumb. Right-sized HVAC equipment not only costs less than oversized units, it also runs more evenly, thus increasing comfort and reducing operating costs.

\section{Long-Term Savings}

Most important for the homeowner's pocket book are the heating and cooling energy savings from high-performance windows. Windows with spectrally selective low-E coatings can significantly reduce winter heat loss and summer heat gain. In South Carolina, both of these benefits are almost equally important.

\section{Annual heating and cooling cost for a $\mathbf{1 7 0 0}$ square feet Columbia home}

\begin{tabular}{|c|c|c|c|c|c|c|c|}
\hline Standard dual pane & \multicolumn{3}{|c|}{ Heating } & \multicolumn{2}{|r|}{ Cooling } & & \\
\hline \multirow[t]{2}{*}{ Low-E dual pane } & \multicolumn{3}{|c|}{ Heating } & \multicolumn{2}{|c|}{ Cooling } & & \\
\hline & $\$ 200$ & $\$ 400$ & $\$ 600$ & $\$ 800$ & $\$ 1,000$ & $\$ 1,200$ & $\$ 1,400$ \\
\hline
\end{tabular}

Comparison: heating and cooling cost in a Columbia home depending on window choices

The simulated home has $1700 \mathrm{ft}^{2}$ floor area and $300 \mathrm{ft}^{2}$ window area. For heating and cooling cost, $\$ 1.60 /$ therm for natural gas and $\$ 0.093 / \mathrm{kWh}$ for electricity are assumed. 


\section{Homeowner Benefits of High-Performance Low-E Windows}

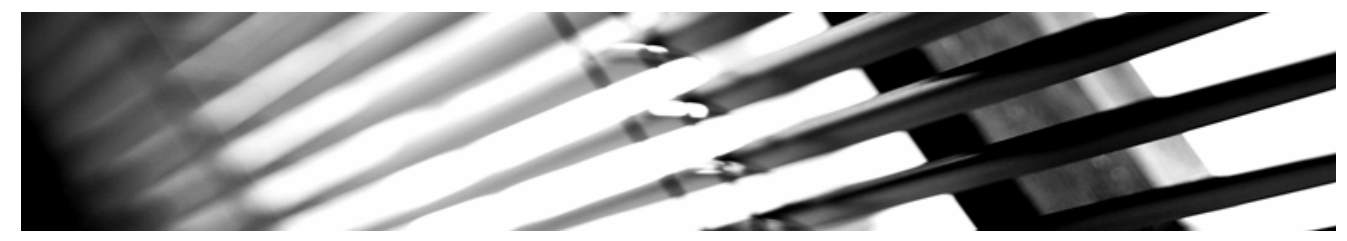

\section{Comfort}

Low-E windows improve occupant comfort in summer and winter; window temperatures are more moderate and there are fewer cold drafts. Discomfort from hot summer sunlight is also reduced.

These graphs show the average percentages of people who report discomfort during cold winter nights and during sunny summer days with different window options. The comfort benefits from energy-efficient low- $E$ windows cannot be substituted for by simply using more heating and air conditioning.

\section{Probability of Discomfort in Summer}

\section{Reduced Fading}

Low-E coatings can significantly reduce the ultraviolet (UV) radiation which causes fading of fabrics and furnishings.

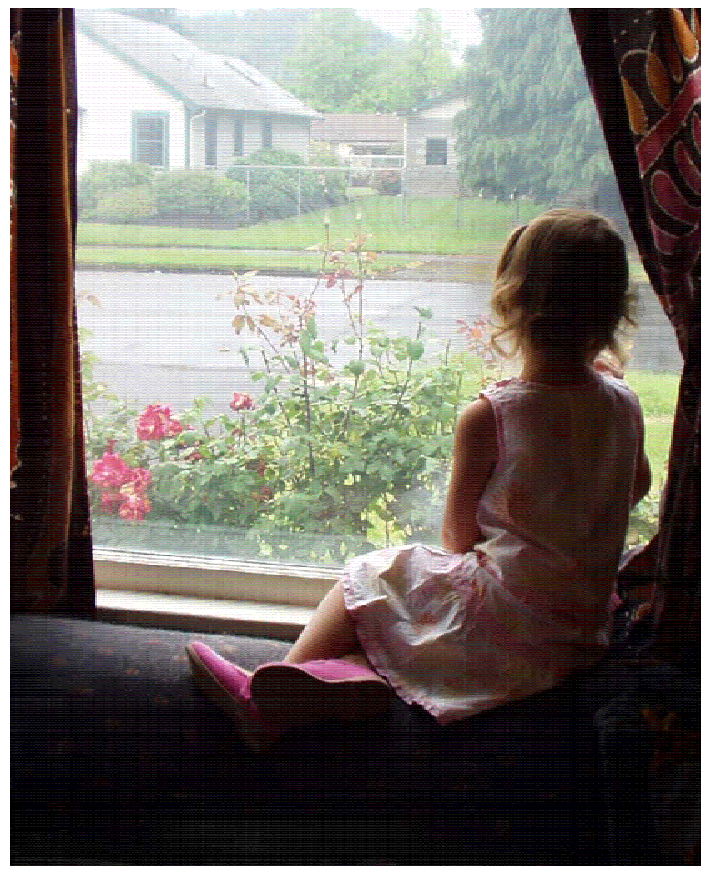

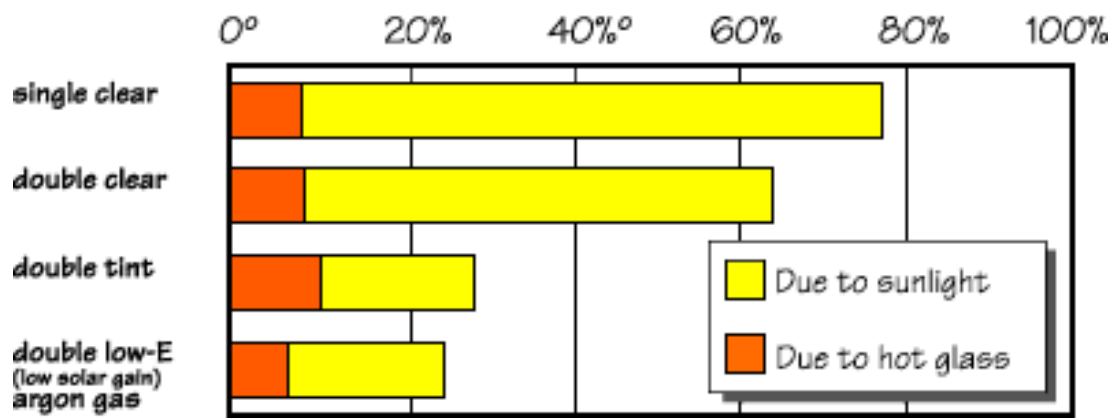

Probability of Discomfort in Winter

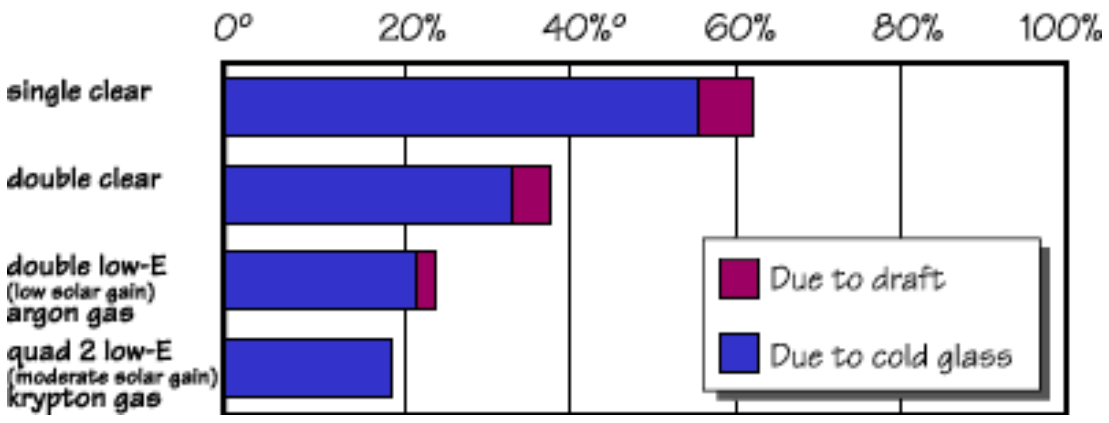

Source: Lawrence Berkeley National Laboratory

(Lyons and Arasteh)
Efficient Windows

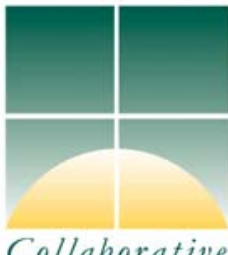

For more information on energyefficient windows, check out the website of the Efficient Windows Collaborative, a program funded by the U.S. Department of Energy: www.efficientwindows.org. 


\section{Energy and Comfort Benefits of Highly Insulating Windows}

Collaborative

\section{What's a highly insulating window?}

- Significantly more insulating value (U-factor 0.15-0.25) than the standard ENERGY STAR $®$ Window (U-factor 0.30-0.35)

- Two or more air (or gas) spaces

- The most energy-efficient window choice in climates with substantial heating loads (5500 HDD or more)

\section{Energy Benefits}

- Savings depend on climate. Heat loss of top performing windows can be $50 \%$ below that of common low-E windows

- Lower heating and cooling loads allow for downsized HVAC systems

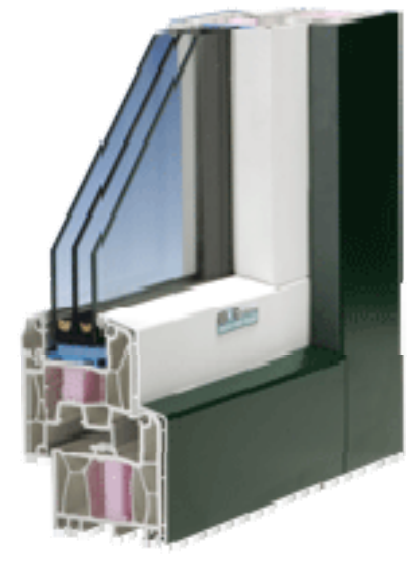

Comfort benefits

- Minimal temperature asymmetry across living space

- Similar temperature for head and feet

- Warmer interior surfaces

- Comfortable interior even if heat registers are not placed under windows

Passive House Institute (Germany) recommends windows with U-factors below 0.18 for optimal Comfort 


\section{Highly Insulating Windows: Cost Considerations}

Cost Effectiveness Example (simulated 2,000 $\mathrm{ft}^{2}$ house, $300 \mathrm{ft}^{2}$ window area, Washington, DC)

\begin{tabular}{|c|c|c|c|}
\hline & $\begin{array}{l}\text { Dual-pane low } \\
\text {-E }\end{array}$ & $\begin{array}{l}\text { Triple-pane } \\
\text { low-E }\end{array}$ & 2. Realize HVAC downsizing o \\
\hline U-factor & 0.37 & 0.18 & 3. Build economies of scale \\
\hline SHGC & 0.53 & 0.40 & $\begin{array}{l}\text { - If it's not a special order } \\
\text { goes down }\end{array}$ \\
\hline $\begin{array}{l}\text { Annual } \\
\text { energy cost }\end{array}$ & $\$ 990$ & $\$ 880$ & $\begin{array}{l}\text { - Higher volume would im } \\
\text { production and distribut }\end{array}$ \\
\hline $\begin{array}{l}\text { Lifetime } \\
\text { energy cost }\end{array}$ & $\$ 16,390$ & $\$ 14,450$ & $\begin{array}{l}\text { DOE Target for } 2010 \\
\text { Incremental cost for U-factor } 0.17\end{array}$ \\
\hline $\begin{array}{l}\text { Lifetime } \\
\text { energy cost } \\
\text { savings }\end{array}$ & & $\$ 1,990$ & $\begin{array}{l}\Rightarrow 3 \% \text { annual discount rate } \\
\Rightarrow \text { Cost effective at } \$ 6.60 \text { per } \mathrm{ft}^{2} \\
\text { cost premium }\end{array}$ \\
\hline \multicolumn{3}{|c|}{ Source: Federal Energy Management Progran } & $\begin{array}{l}\Rightarrow \text { More cost effective if HVAC is } \\
\text { sized down! }\end{array}$ \\
\hline
\end{tabular}

Three ways to improve economic feasibility of highly insulating windows:

1. Programs emphasizing long-term over first cost (energy-efficient mortgages or loan programs)

2. Realize HVAC downsizing opportunity

- Reduces first cost

- Reduces duct and pipe losses

- If it's not a special order item, cost

goes down

Higher volume would improve production and distribution efficiency

DOE Target for 2010

Incremental cost for $\mathrm{U}$-factor 0.17 : $\$ 5$ per $\mathrm{ft}^{2}$ 


\section{C-2-3 \\ The Market for \\ Highly Insulating Windows}

\section{Currently less than $1 \%$ market share}

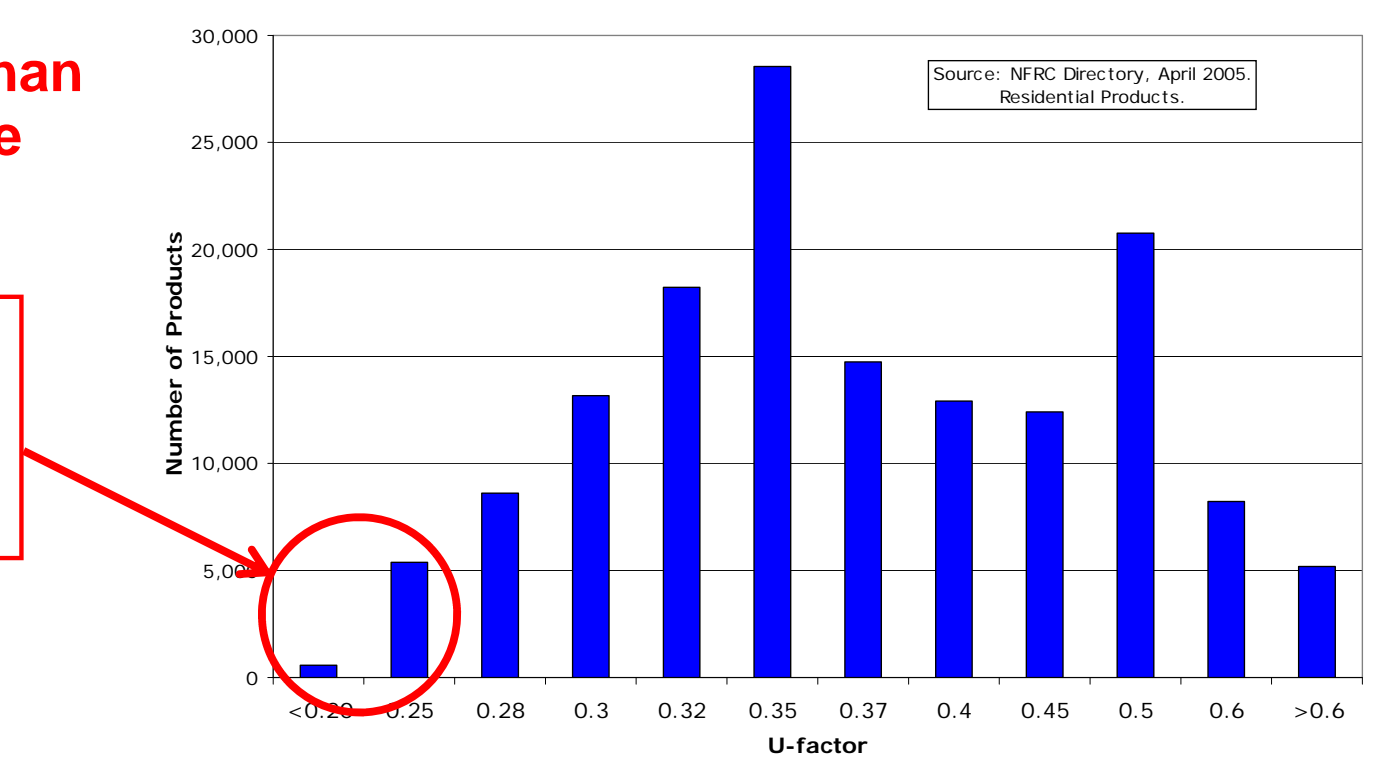

Admittedly - not everyone needs highly insulating windows. But they're a too valuable option to remain a niche product.

How to make them a more common option?

Recognition and Awareness

Official recognition of the benefits would increase consumer awareness and interest

LBNL estimates up to 0.8 quads energy savings if highly insulating windows were widely adopted in the replacement market.

- Info material

- Utility programs

- Tax credits

- Green homes programs

- ENERGY STAR

Many consumers are willing to invest in high performance if they are sure of the benefits

\section{Incentives}

Home builders need incentives-monetary or recognition-for choosing premium products 


\section{Window Design with Attention to the Sun: For Energy-Efficient Homes in the New York Climate}

The energy performance of window depends on their insulation value (their U-factor) and on how much solar heat they transmit (their SHGC or solar heat gain coefficient). In climates with a significant heating season, reducing heat loss and therefore the U-factor is rightly seen as a priority. However, reducing the U-factor can become expensive at some point, while many of the design steps that save energy by paying attention to solar heat gain cost little or nothing. It is very worthwhile to consider the sun's potential to heat the home through its windows- whether wanted or unwanted.

Literature about suntempered or passive solar design gives detailed advice on considering solar heat gain in decisions about orientation, thermal mass, shading etc. While this fact sheet mentions only the most important considerations concerning windows, these can be helpful even if not every single principle of passive solar design is followed.

- The biggest bang for the buck: Orient a major share of the house's windows to the south. This helps making the most out of the sun's winter benefits while limiting solar heat gain in the summer.

- With a little more attention to detail, wanted solar gain can be increased and unwanted solar gain reduced by adding overhangs and applying glazing with different SHGC to different orientations.

- Finally, consider comprehensive passive solar design, including shade trees, natural ventilation, and increased thermal mass.

Following as many principles of passive solar design as possible is a low-cost means of improving a home's energy performance and brings great benefits to homeowners. It may also allow for downsized HVAC systems, thus keeping initial cost down.

\section{Following the Sun: Steps toward Window Design for Solar Advantage}

Ideally, start with orienting the house for southern exposure. Where that's not possible, consider the subsequent steps.

Orientation

Orient major glass area south

Thermal mass

Increase thermal mass in sunlit rooms

Shading

Overhangs for south-facing windows

Consider trees for east and west

\section{Window type}

Shaded south-facing windows: High SHGC

Exposed windows facing east and west: Low SHGC

All windows: Low U-factor

HVAC sizing

Improved design reduces heating and cooling loads

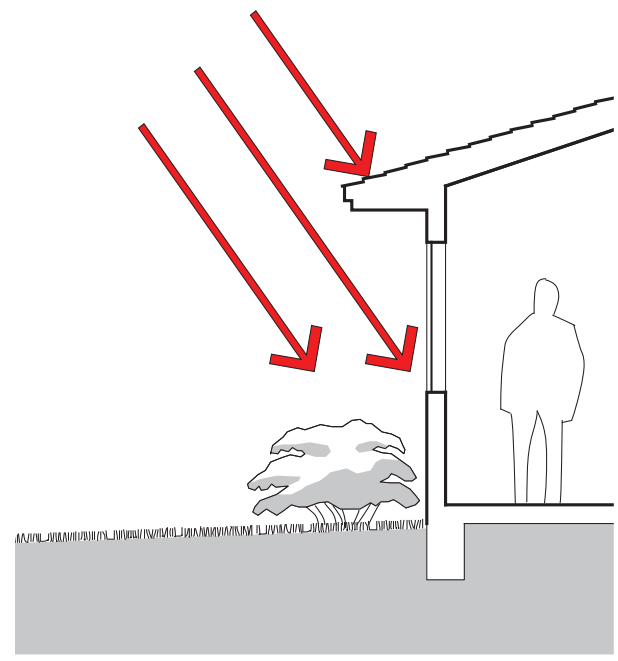

Overhangs on the south side can shade windows against the high summer sun while allowing the low winter sun to enter. This does not work as well on the east and west side, where the summer sun is low in the mornings and afternoons. 


\section{Choosing Windows Depending on Orientation}

Ideally, windows allow solar heat gain in the winter and block it in the summer. This goal is best approached in the following way:

- Southern façade with overhang: Large windows with a higher SHGC

- Western and eastern façades: Smaller windows with lower SHGC

This rule of thumb assumes that south-facing windows are well shaded against the summer sun whereas proper shading for east- and west-facing windows is harder to provide.

\section{Low-E windows with a higher SHGC}

Some low-E windows come with a relatively high SHGC, allowing the sun to help heat the home while reducing heat loss to the outside. A SHGC of between 0.35 and 0.60 can be considered high. Summer solar-gain can be a problem with these windows, so proper shading is recommended.

\section{Low-E windows with a lower SHGC}

Many low-E windows have a SHGC of less than 0.35. A low SHGC helps with keeping the home cool in the summer but does not provide a high potential for passive solar heating.

\section{Window sizes and operator types}

Apotential problem for using different glass options for different orientations is that windows could be switched on the job site, so that the wrong SHGC would be used for the wrong orientation. Nonetheless, there is a practical solution: It makes sense to use larger windows on the south side than on the other sides. This way, windows meant for the south side fit only in their intended spot, and their size assures that enough light and solar heat enter the home during the winter.

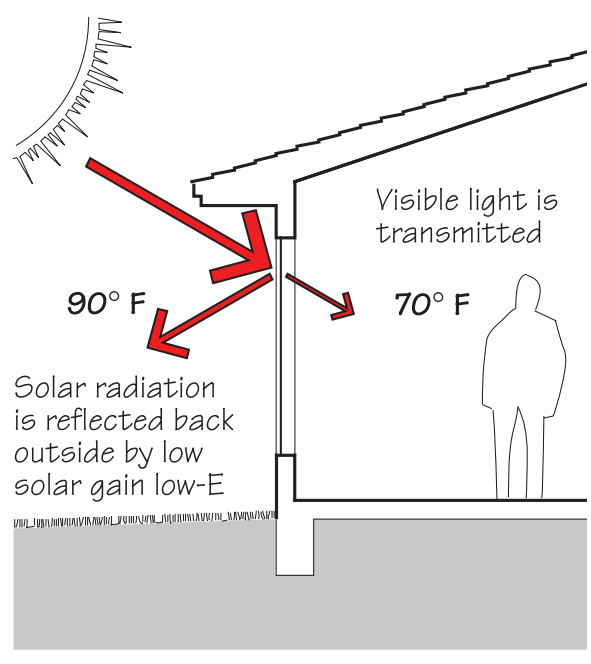

Summer performance of low-E windows for low solar gain.

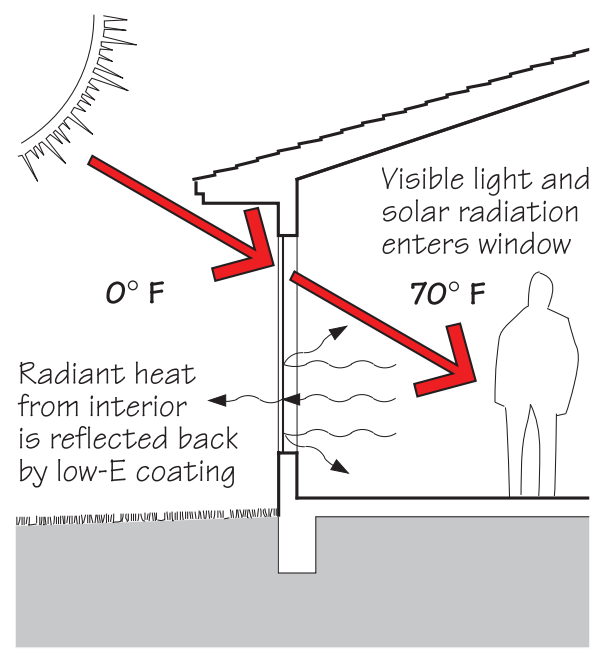

Winter performance of low-E windows for high solar gain.

\section{For more Information}

The website of the Efficient Windows Collaborative (www.efficientwindows.org) has detailed information on different windowoptions, as well as a Window Selection Tool that helps find manufacturers of different window types.

Some resources on passive solar design:

U.S. Department of Energy: Technology Fact Sheet: Passive SolarDesign. www.eere.energy.gov/buildings/info/documents/pdfs/29236. pdf

U.S.Department ofEnergy:PassiveSolarHomeDesign:RoofOverhangs.www.eere.energy.gov/consumer/your_home/designing_remodeling/ index.cfm/mytopic $=10280$

U.S. Department of Energy / Sustainable Building Industry Council: Green Building Guidelines: Meeting the Demand for Low-Energy, Resource-Efficient Homes. 


\title{
Residential Windows
}

\author{
Application: Residential
}

Category: Building envelope

\section{Description}

Windows can provide the benefits of light, fresh air, and views, but may increase heating and cooling energy use.

\section{Energy Savings Concept}

Replacing old windows can be expensive, but may substantially improve visual and thermal comfort and present an important opportunity for energy savings. Which window options are considered energy efficient depends on the climate. In a cold climate, a window's ability to retain heat inside the building is most important, whereas the capacity to block heat gain from the sun and infiltration is a priority in warm climates. The main energy parameters of a window are its insulation value, transparency to solar radiation, and air tightness.

\section{Energy Parameters}

- The U-factor expresses a window's insulation value, its resistance to heat flow when there is a difference between inside and outside temperature. The U-factor is measured in Btu/hr-sq ft- ${ }^{\circ} \mathrm{F}\left(\mathrm{W} / \mathrm{sq} \mathrm{m}-{ }^{\circ} \mathrm{C}\right)$. The lower the U-factor, the greater a window's resistance to heat flow.

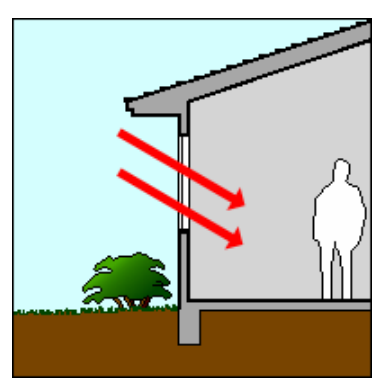

Fig. 2: Solar heat gain

- A window's transparency to the heat carried by solar radiation is expressed in the solar heat gain coefficient (SHGC). The SHGC is the fraction of solar heat admitted by the window on a range of 0 to 1 .

- A window's transparency to visible light is expressed as its visible transmittance (VT) on a range of 0 to 1 .

- The air-leakage (AL) rating of a window indicates its air tightness. It expresses the rate of air-leakage around a window at a specific pressure difference in units of cubic feet per minute per square foot of frame area $(\mathrm{cfm} / \mathrm{sq} \mathrm{ft})$ or cubic meters per minute per square meter of frame area.(cmm/sq $\mathrm{m}$ ).

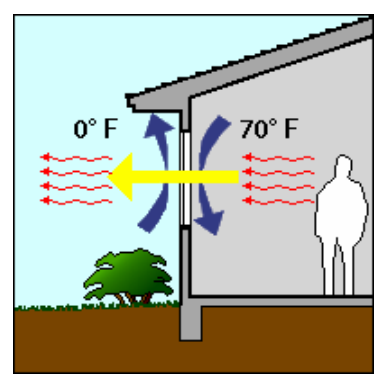

Figure 1: Heat flow

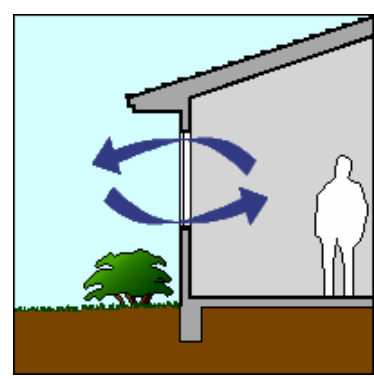

Figure 3: Air leakage

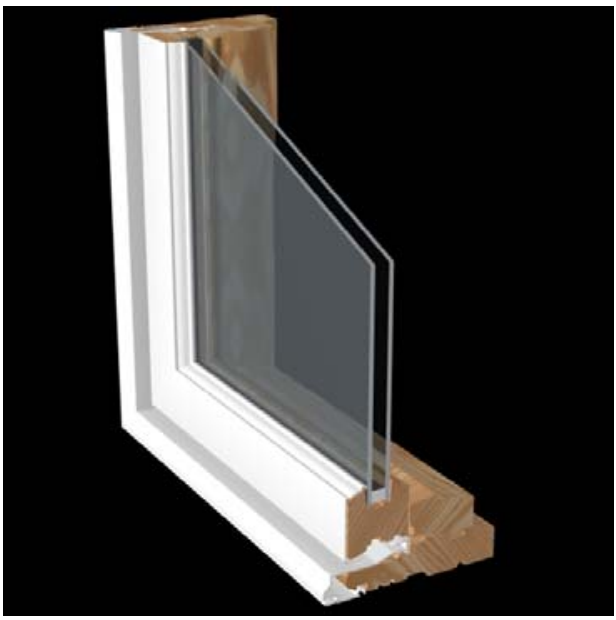

Figure 5: Double-pane window, vinylclad wood frame

Picture sources: Efficient Windows Collaborative (www.efficientwindows.org), except Figure 4: National Fenestration Rating Council (www.nfrc.org)

C-4-1 


\section{Window Options}

The table below shows a range of window options and their energy-related characteristics. Window options I and II are conventional windows with only minimal energy-efficiency, whereas the other options (A through F) provide different energy-efficiency benefits in different climates.

\begin{tabular}{|c|c|c|c|c|c|c|c|c|}
\hline \multicolumn{7}{|c|}{ Window Options with Default Performance Values } & \multicolumn{2}{|c|}{$\begin{array}{l}\text { Cost per window } \\
(12 \mathrm{sq} \mathrm{ft})\end{array}$} \\
\hline \# & Glazing type & Frame type & $\begin{array}{c}\text { U-factor } \\
\text { (imp./metric) }\end{array}$ & SHGC & VT & $\begin{array}{c}\mathrm{AL} \\
\text { (imp./metric) } \\
\end{array}$ & $\begin{array}{c}\text { Installed } \\
\text { cost }\end{array}$ & $\begin{array}{c}\text { Cost } \\
\text { premium* }\end{array}$ \\
\hline 1 & 2-pane, tinted & Aluminum & $0.76 / 4.3$ & 0.56 & 0.51 & $0.2 / 0.06$ & $\$ 300$ & baseline \\
\hline II & 2-pane, uncoated & Non-metal & $0.49 / 2.8$ & 0.56 & 0.59 & $0.2 / 0.06$ & $\$ 350$ & baseline \\
\hline A & $\begin{array}{l}\text { 2-pane, } \\
\text { low-solar-gain low-E }\end{array}$ & $\begin{array}{l}\text { Aluminum, } \\
\text { thermal break }\end{array}$ & $0.47 / 2.7$ & 0.33 & 0.55 & $0.2 / 0.06$ & $\$ 325$ & $\$ 25$ \\
\hline B & $\begin{array}{l}\text { 2-pane, } \\
\text { low-solar-gain low-E }\end{array}$ & Non-metal & $0.34 / 1.9$ & 0.30 & 0.51 & $0.2 / 0.06$ & $\$ 375$ & $\$ 25$ \\
\hline C & $\begin{array}{l}\text { 2-pane, } \\
\text { high-solar-gain low-E }\end{array}$ & Non-metal & $0.36 / 2.0$ & 0.49 & 0.54 & $0.2 / 0.06$ & $\$ 375$ & $\$ 25$ \\
\hline D & $\begin{array}{l}\text { 3-pane, } \\
\text { low-solar-gain low-E }\end{array}$ & Non-metal & $0.26 / 1.4$ & 0.25 & 0.40 & $0.1 / 0.03$ & $\$ 450$ & $\$ 100$ \\
\hline E & $\begin{array}{l}\text { 3-pane, } \\
\text { high-solar-gain low-E }\end{array}$ & Non-metal & $0.27 / 1.5$ & 0.38 & 0.47 & $0.1 / 0.03$ & $\$ 450$ & $\$ 100$ \\
\hline $\mathbf{F}$ & $\begin{array}{l}\text { 3-pane, high-solar- } \\
\text { gain low-E }\end{array}$ & $\begin{array}{l}\text { Non-metal, } \\
\text { insulated }\end{array}$ & $0.18 / 1.0$ & 0.40 & 0.50 & $0.1 / 0.03$ & $\$ 500$ & $\$ 150$ \\
\hline
\end{tabular}

* The cost premium compares efficient window options with the standard options (I \& II) of the equivalent frame material (e.g. aluminum vs. aluminum).

In climates dominated by cooling demand, control of solar heat gain and thus a low SHGC is more important than the insulation value (U-factor). In colder climates, however, the U-factor is of critical importance, whereas solar heat gain can be either a liability (during cooling seasons) or an asset (during heating seasons).

The SHGC mainly depends on the glazing used, with low-solar-gain low-E and tinted glass reducing solar heat gain. Because of its ability to reduce heat gain without a significant effect on visible transmittance, lowsolar-gain low-E is strongly recommended for cooling-dominated climates. In climates where the benefits of solar heat gain outweigh the costs, high-solar-gain low-E coatings may be more appropriate. While low-E coatings can differ strongly in their effect on the SHGC, they generally reduce the U-factor.

The U-factor is a function of the number of glazing layers, the use of low-E coatings, and the conductance of the frame and spacers. Aluminum frames offer structural strength for high-rise applications or hurricane regions but are very conductive to heat unless equipped with thermal breaks. In cold climates, windows with very low U-factors, achieved through triple-glazing and insulated frames are often cost-effective.

Air leakage increases heating as well as cooling demand. It depends mainly on the operator type, with projecting windows (tilt-and-turn, casement, etc.) offering more air tightness than sliding windows. Projecting operator types are common for heavier triple-glazing and generally among windows in continental Europe.

Sliding windows are more common in North America, the British Isles, and Southern Europe.

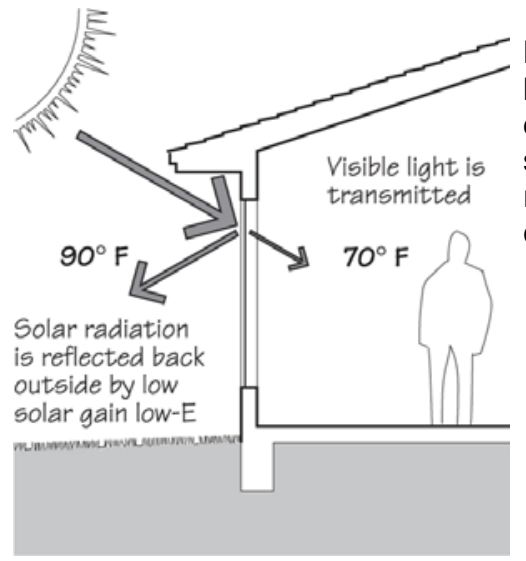

Figure 6: Low-solar-gain low-E reduces cooling demand during warm seasons while also reducing heat loss during cold seasons.

Picture sources: Efficient Windows Collaborative (www.efficientwindows.org) 


\section{Common Window Options by Climate}

The table below lists 15 U.S. climate zones and window options that would be commonly considered in these climates. The conventional options shown are not recommended, but are still being used in the absence of energy-efficiency considerations. Efficient window options are recommended based on the climate-specific considerations described on the previous page—a low SHGC for warm climates and a low U-factor for cold climates. Aluminum-framed window A is among the recommended options for regions where hurricane considerations might require the sturdiness of aluminum (1A, 2A, 2B, 3A).

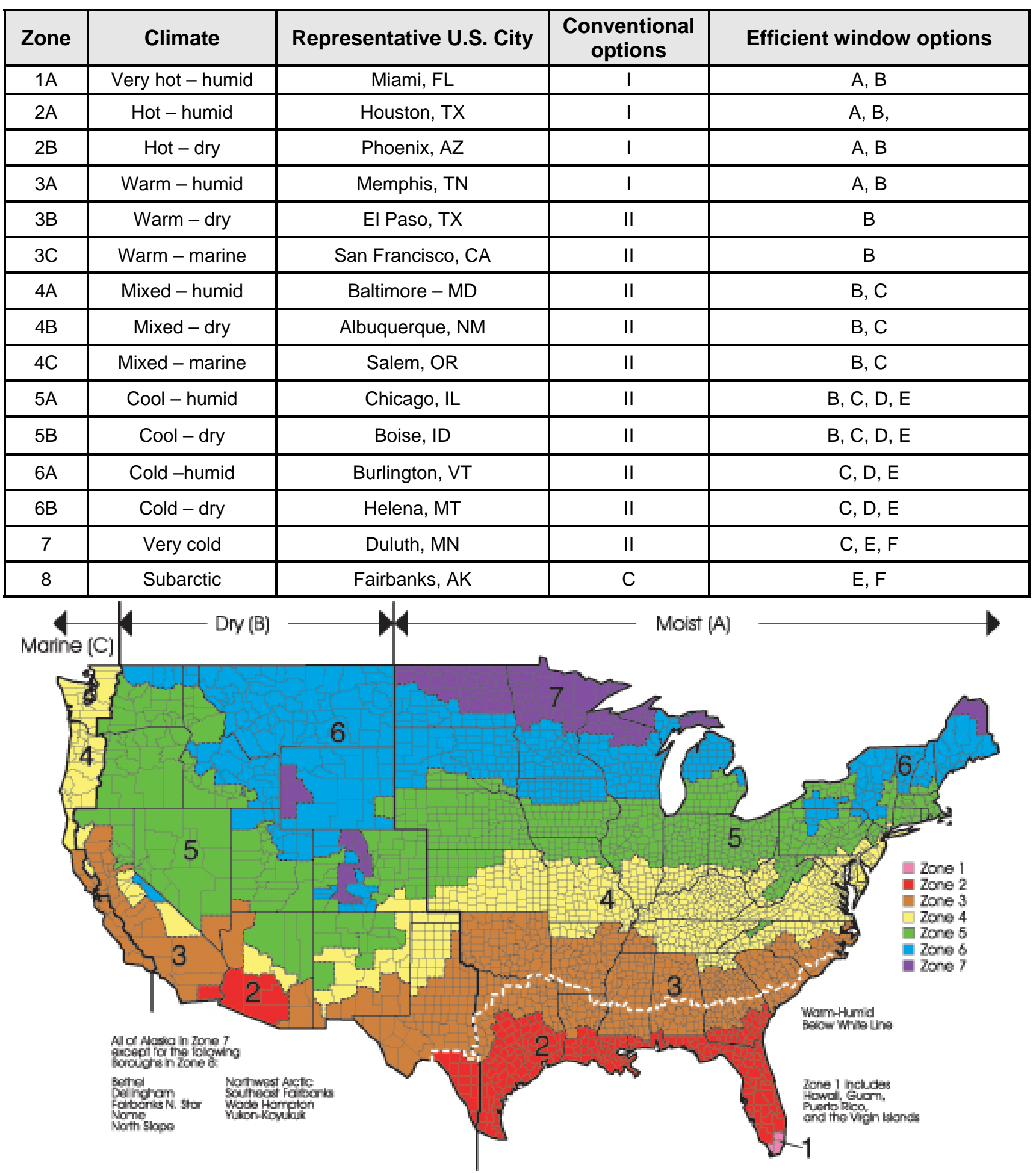

Figure 8: This climate zone map is used for ASHRAE standard 90.1-2007 and the 2006 version of the International Energy Conservation Code (IECC). 


\title{
Commercial Windows
}

\author{
Application: Commercial
}

Category: Building envelope

\section{Description}

Windows can provide the benefits of daylighting, fresh air, and views, but may increase heating and cooling energy use.

\section{Energy Savings Concept}

Replacing old windows can be expensive, but may substantially improve visual and thermal comfort and present an important opportunity for energy savings. Which window options are considered energy efficient depends on the climate, building type, orientation, and the existence of daylighting controls. The ability of windows to retain heat inside the building may be very important in cold climates. In many buildings, however, the capacity to provide daylight while blocking solar heat gain is even more important. The main energy parameters of windows are thus their insulation value and their transparency to solar heat and visible light.

\section{Energy Parameters}

- The U-factor expresses a window's insulation value, its resistance to heat flow when there is a difference between inside and outside temperature. The U-factor is measured in Btu/hr-sq ft- ${ }^{\circ} \mathrm{F}\left(\mathrm{W} / \mathrm{sq} \mathrm{m}-{ }^{\circ} \mathrm{C}\right)$. The lower the U-factor, the greater a window's resistance to heat flow. A low U-factors are particularly important in cold climates.

- A window's transparency to the heat carried by solar radiation is expressed in the solar heat gain coefficient (SHGC). The SHGC is the fraction of solar heat admitted by the window on a range of 0 to 1 . A low SHGC helps control cooling loads.

- A window's transparency to visible light is expressed as its visible transmittance (VT) on a range of 0 to 1 . Moderate to high visible transmittance is required if windows are intended to provide daylighting.

\section{Thermal Comfort Considerations}

Windows affect human comfort in several ways. Cold interior glass surfaces can cause discomfort through radiant heat loss and can create uncomfortable air movements. These effects are less pronounced with wellinsulated windows with a low U-factor. Discomfort from solar radiation can be controlled through shading and through low-SHGC glazing. Operable windows can contribute to improved thermal comfort by giving occupants the opportunity to regulate their own thermal environment and to benefit from natural ventilation.

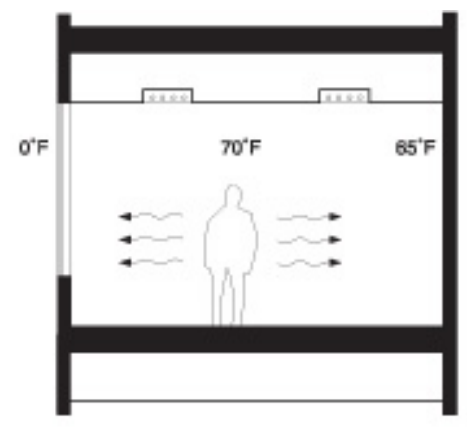

Figure 2-43. Radiation from a warmer body to the colder glass causes discomfort because the two sides of the body have very different rates of radiant heat loss

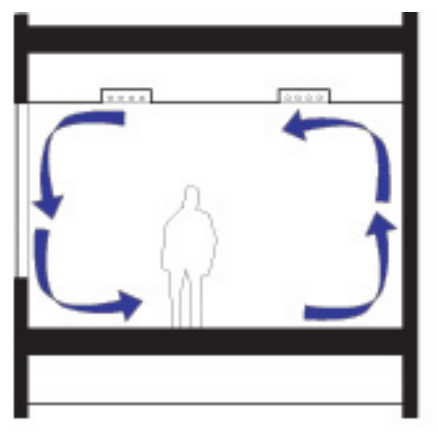

Figure 2-45. Cold glass temperatures can cause air near the window to fall, setting up uncomfortable air movement in a convective loop

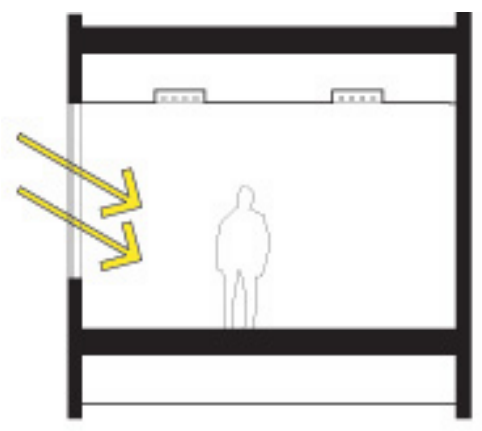

Figure 2-46. Direct solar radiation through windows can cause discomfort

Picture source: Center for Sustainable Building Research, University of Minnesota (www.commercialwindows.umn.edu) 


\section{Window Options}

The table below shows a range of window options and their energy-related characteristics. Window options I and II are conventional windows of moderate energy-efficiency, whereas the other options (A through D) provide special energy-efficiency benefits in different climates.

\begin{tabular}{|c|l|l|c|c|c|c|}
\hline \multicolumn{9}{|c|}{ Window Options with Default Performance Values } \\
\hline \# & Glazing type & Frame type & $\begin{array}{c}\text { U-factor } \\
\text { (imp./metric) }\end{array}$ & SHGC & VT & $\begin{array}{c}\text { Incremental } \\
\text { cost } \mathbf{( \$ ~} \mathbf{p e r} \mathbf{f t}^{2} \text { ) }\end{array}$ \\
\hline I & 2-pane, uncoated glass & Aluminum, thermal break & $0.60 / 3.4$ & 0.60 & 0.63 & Baseline cost \\
\hline II & 2-pane, tinted & Aluminum, thermal break & $0.60 / 3.4$ & 0.42 & 0.38 & $\$ 0.50$ \\
\hline A & 2-pane, reflective coating & Aluminum, thermal break & $0.54 / 3.1$ & 0.17 & 0.10 & $\$ 1.25$ \\
\hline B & 2-pane, low-E, tinted & Aluminum, thermal break & $0.46 / 2.6$ & 0.27 & 0.43 & $\$ 1.75$ \\
\hline C & 2-pane, low-E & Aluminum, thermal break & $0.46 / 2.6$ & 0.34 & 0.57 & $\$ 1.50$ \\
\hline D & 3-pane, low-E & Insulated & $0.20 / 1.1$ & 0.22 & 0.37 & $\$ 8.00$ \\
\hline
\end{tabular}

In climates dominated by cooling demand, control of solar heat gain and thus a low SHGC is a priority whereas the insulation value (U-factor) plays a subordinate role. In colder climates, on the other hand, the U-factor is of critical importance for controlling heat loss and providing thermal comfort.

Low-E coatings, tinted glass, and reflective coatings reduce solar heat gain. Tinted glass and reflective coatings also reduce visible transmittance. Low-E coatings, on the other hand, can improve both the SHGC and the $\mathbf{U}$-factor without a significant effect on visible transmittance.

The U-factor is a function of the number of glazing layers, the use of low-E coatings, and the conductance of the frame and spacers. Aluminum frames are very conductive to heat unless equipped with thermal breaks of low-conducting materials. In cold climates, windows with very low U-factors, achieved through triple-glazing and insulated frames can be cost-effective.

\section{The Effect of Windows on Mechanical System Design}

Areas near conventional windows are usually places of the greatest temperature variation and discomfort in buildings, so that additional radiant perimeter heating may be required. However, highperformance windows with low U-factors retain significantly more constant interior surface temperatures, which can eliminate the need for perimeter heating and slot diffusers.

By lowering peak heating and cooling loads, high performance windows can also reduce the mechanical system size and thus the initial cost. A low SHGC reduces cooling peak demand, which is particularly important on summer days when demand charges are

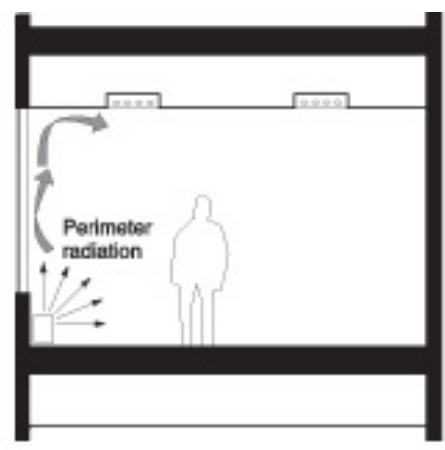

Figure 2-25. Perimeter heat provided near windows may not be necessary with highperformance windows 


\section{Common Window Options by Climate}

The table below lists 15 U.S. climate zones and energy-efficient window options that could be recommended based on climate-specific considerations:

- Window A: In hot climates, the solar control benefits of reflective coatings may outweigh the drawback of low visible transmittance and low daylighting potential.

- Window B: A low U-factor and SHGC is recommended in many climates.

- Window C: In cooler climates, the higher SHGC of non-tinted glass may be acceptable to allow for higher visible transmittance.

- Window D: Triple-glazing and insulated frames can be cost-effective in cold climates.

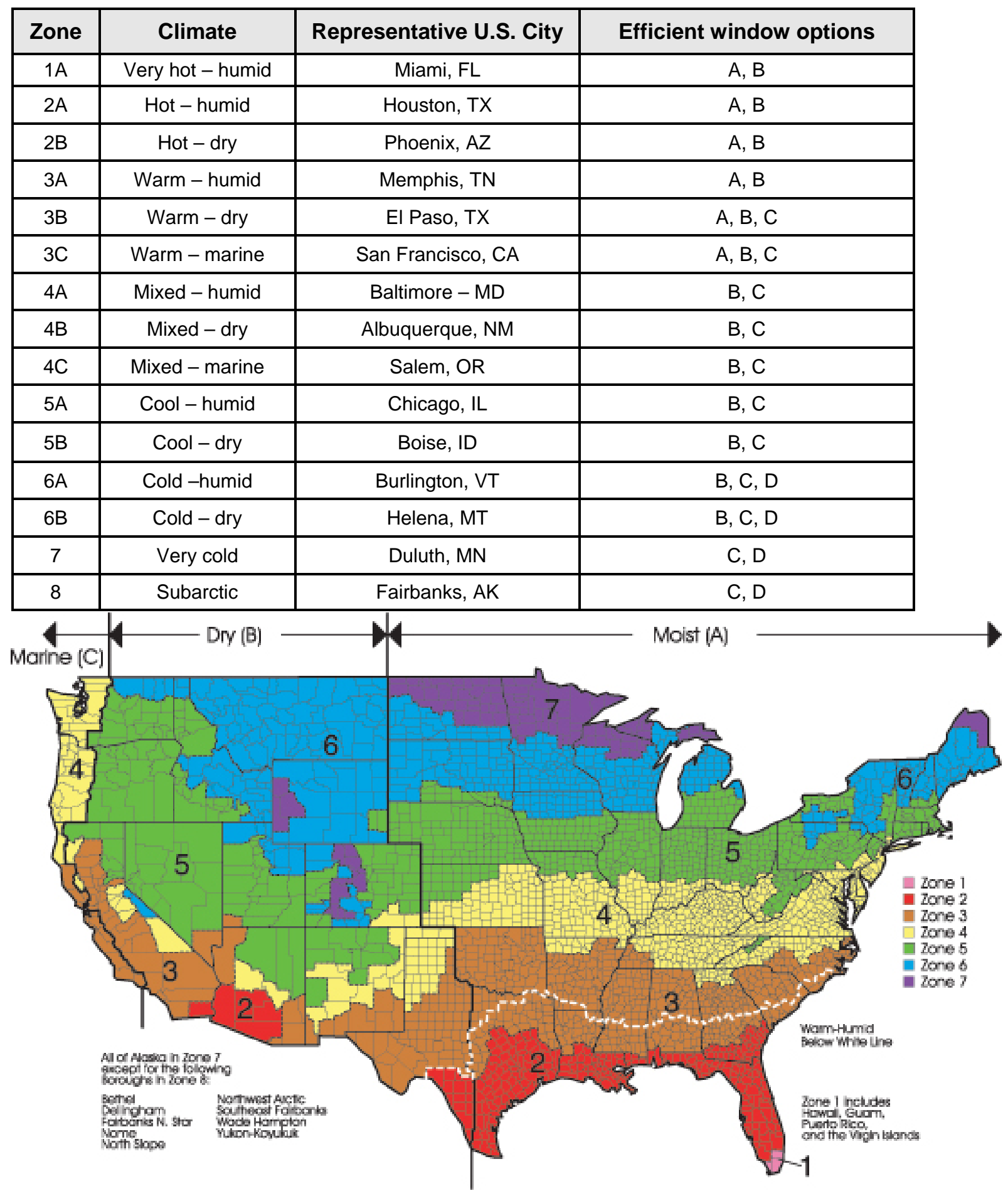

Figure 8: This climate zone map is used for ASHRAE standard 90.1-2007 and the 2006 version of the International Energy Conservation Code (IECC). 


\section{Appendix D - Published Articles}

D-1 Articles by project partner AZS Consulting for the Door and Window Manufacturer Magazine

D-2 Cabin Life magazine article "A Perfect Match: How to get the best windows for your place”

D-3 “Energy Efficient Glazing Basics”, Buildings, September 2009 


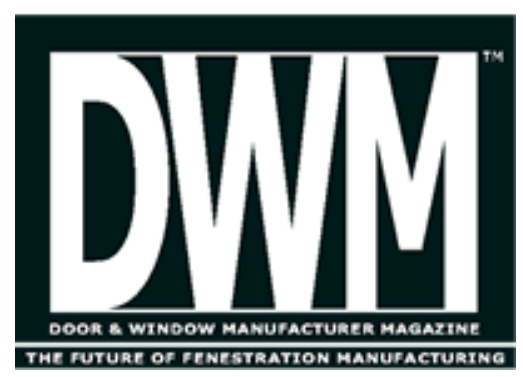

Volume 8, Issue 6 - June 2007

\section{Eye on Energy}

\section{Think Green to Stay Out of the Red by Arlene Zavocki Stewart}

A few months ago, there was a lot of buzz when the U.S. Green Building Council (USGBC) released its long-awaited report on vinyl. Five years in the making, this groundbreaking report had the potential to turn the window industry on its ear. Would the hottest trend in construction shut down the fastest growing sector of the window market?

Summary of findings: "No single material shows up as the best across all the human health and environmental impact categories, nor as the worst." WHEW! A collective sigh of relief could be heard from stockholders across the country. So people stopped reading. That was a mistake because it's arguable that how these impacts were evaluated is far more important in the long-term than the actual results. It illustrates what the people who are driving the hottest trend in construction really care about, and that's important, no matter what framing material you use. Two overriding, prophetic points were written on the proverbial wall and manufacturers ought to start thinking about them now.

\section{Prophetic point 1: Sales will be linked to how well other companies market their materials.}

The USGBC report is rather unique in the world of windows. It reads like a materials safety data sheet or a medical paper, discussing parts-per-million-this, exposure-rates-that, and big-long-chemical-name the other thing. All this is for the purpose of determining three human health impacts and seven environmental impacts.

The scary thing is that the report evaluated aspects of material production into which window manufacturers don't traditionally have any input. Manufacturers buy components, then assemble them. Typically, you ask the cost, what it does and can you get as many as you want when you want them. Then you sell the assembly for what it can do for your client. In a green market, you not only need to know what your product does, but also what went into it from the very start and what's going to happen to it when your client is done with it. That's the data that those Leadership in Energy and Environmental Design (LEED) APs are looking for to get those elusive credits.

Right now, you may think that finding out all those details is far too complicated and no one really cares. That will last only until you lose the big sale to a company that quantified those details well enough to get their new client the credits.

\section{Prophetic point 2: The biggest way your company can improve the impacts will be through product energy performance.}

The seven environmental impacts mentioned above were assessed on a cradle-through-use basis with some end-of-life considerations. For windows, the usage period is 50 years, only a small slice of which is the creation of the components and the window itself. By far the largest segment is the time the window "lives" in the building. When you consider the individual impactsacidification, eutrophication, eco-toxicity, smog formation, ozone depletion potentials, global climate change and fossil fuel depletion, you realize that they are all affected by emissions. Ergo, use efficient windows to reduce environmental impacts by reducing energy usage in buildings to reduce loads in power plants to reduce emissions. So, if you want to reduce the significance of someone else's materials on environmental impacts (prophetic point 1), you need to increase your product's energy efficiency.

That's going to take a while to do, so you better start now. If you haven't been following the U.S. Department of Energy's activities to develop the next generation of efficient windows, you should be. These high-risk projects explore several new technologies to develop an affordable $0.10 \mathrm{U}$-factor window. Transparent insulating materials such as aerogels, vacuum windows and honeycombs, and multilayer low-conductance window systems are just some of the approaches being considered. Granted, these technologies aren't ready yet for prime time, but prime time will be here soon.

\section{D-1-1}


Both of these points will require a paradigm shift. Don't be lulled into complacency by thinking that these changes won't happen for another 20 years. Some companies are looking at these right now and they will start serving that growing core of environmental leaders who are getting green standards adopted city by city, state by state. Think green now to stay out of the red tomorrow.

Arlene Zavocki Stewart is a member of the Efficient Windows Collaborative and an energy code advocate. She can be reached at azstewart@azsconsultinginc.com. The views and opinions expressed in this article do not necessarily reflect those of the U.S. Government, nor do they represent the opinions of this magazine.

\section{DWM}

(C) Copyright 2007 Key Communications Inc. All rights reserved.

No reproduction of any type without expressed written permission.

\section{D-1-2}

http://www.usglassmag.com/Door_and_Window_Maker/Backissues/2007/June07/eyeonen... 6/20/2010 


\section{When Good Windows Look Bad By Arlene Zavocki Stewart}

I shouldn’t have said anything, but I did. “Buy ENERGY STAR windows,” I recommended when my mother-in-law asked about replacing the single-glazed ones with storm panels after her husband had died. She had had concerns that the windows were really worth the investment since they would be more efficient than the walls in her 1940s house. I assured her that any improvement in the building envelope was a good thing. Time passed, the windows were installed...and then the dreaded call came. "If these are so good, why do I have water on the window now?”

Sigh. Over the past ten years, I'm usually assured one question about condensation per training. Now it was my turn to trouble shoot. I went through the litany of basic things that could be wrong. Did you receive the window you ordered? Yes. She kept the NFRC label. Was it installed properly? InstallationMasters. Yes, she had done everything I said. She became more impatient with each question as I became more responsible for giving bad advice in the first place. Then, I asked the question I should have asked first. Where is the condensation?

Surprisingly, it was inside the house in the fall. It might have made more sense in winter, but according to John Carmody, in his Residential Windows book (now in its third edition), the vinyl framed, LowE, argon windows should have alleviated the problem. Instead, we had the opposite. My mother-in-law had condensation on an efficient window where she had never had it with the worst window on the market.

That situation was occurring in a temperate month made it even more puzzling. I went back to thermodynamics 101 - hot goes to cold, wet goes to dry. Somehow, she had humid air in the house that was warmer and wetter than the inside surface of the window. I would have had an answer if she lived in the South. The air conditioner was now oversized, so the unit was short cycling and not pulling out humidity. But in upstate New York? where she didn't have an air conditioner? At a time when she was leaving the windows open during the day because it was so nice out?

Ah, maybe that was the problem. Maybe the air outside was too humid and there was enough humidity trapped in the house during the day to condensate at night when the temperature dropped. Except, these were efficient windows - there shouldn't have been much difference in temperature between the air and the window surface. I checked the Weather Channel and the data - the temperature difference between night and day, the dewpoint and the humidity levels - all indicated that the moisture source originated inside the house.

So I started quizzing my mother-in-law about what she was doing differently that was creating more moisture in the house. Her feathers obviously ruffled, she asked why it was her fault. The conversation ended when the UPS guy arrived, each of us secretly relieved as we were growing more and more frustrated. I'm sure my mother-in-law was questioning my expertise and truthfully, I was too. Still I kept pondering where the source 
was as I was also certain that there was even more condensation in the walls. I really didn't want her to have rotting issues. But I didn’t bring it up.

I probably should have. Several nights later, she called to tell me the OTHER family expert, her contractor nephew, provided the answer. Silly me, I live in Florida, so how was I supposed to know year's weather patterns? Apparently, heavy rains that spring and summer had saturated the earth. As drier and cooler fall came, physics took over. Hot goes to cold, wet goes to dry, wicking the moisture right up the empty wooden walls of the 1930s house that had never been air sealed.

Moral of the story? Remember physics is your friend when you give advice to relatives.

Arlene Zavocki Stewart is the principal for AZS Consulting, Inc., a member of the Efficient Windows Collaborative, a market transformation project, funded by the Energy Efficiency and Renewable Energy division of the US Department of Energy. 


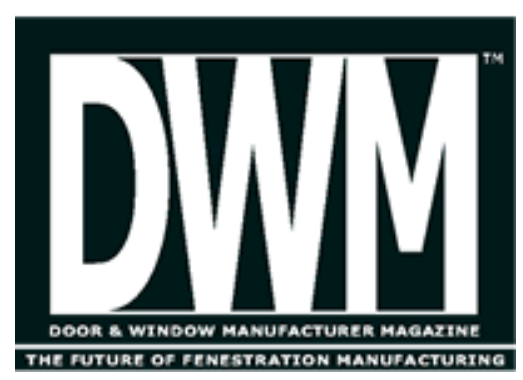

Volume 8, Issue 10 - November 2007

\section{Eye On Energy}

\section{Lapsed NFRC Label Blows ENERGY STAR ${ }^{\circledR}$ job by Arlene Zavocki Stewart}

A few months ago, I wrote a column forecasting that your business would soon be dependent on the green choices of your component suppliers. Little did I know this would also apply to me! See, I lost a job last month and I'm pretty irritated about it.

Most people in the fenestration industry know my work with the Efficient Windows Collaborative. Many are surprised to learn that I don't just do windows. Among many other things, I do ENERGY STAR home certification as a Home Energy Rating System (HERS) rater.

An owner/builder came to me who wanted to certify an ENERGY STAR home. (I've had quite of few of these lately.) It seems with the slowdown of the market coupled with the rising profile of global warming, every builder and developer wants to do energyefficient, green building. We're more than happy to oblige.

However, construction was already underway and it was time for the insulation inspection, a required pre-requisite. Therefore, we dropped everything to fly out to the site.

The builder had done a pretty fair job. There were a few hiccups but all in all, it looked good-until I looked at the windows. Then I grabbed my phone while my new client watched.

I immediately called a contact that I've known my entire time in window world. He represented a company that believed wholeheartedly in energy-efficient windows, but wasn't all that thrilled with the National Fenestration Rating Council (NFRC). After a couple of years of griping, the company decided to test to NFRC 100 and 200 and then self-certify since that was what the Florida Energy Code allowed and most of their market was in-state. I distinctly remember when this happened because it was a hard-won decision.

"Blankity blank! What are you doing to me here? I'm doing an ENERGY STAR home inspection and I've got your windows here and the only label I see is a green dot that says 'low-E.' What's going on?"

“Well, Arlene, they aren't my windows anymore. I'm no longer with X company. I had heard that the new guys let NFRC lapse. But if it's the vinyl window made in the last three months, I think ABC lineal supplier has an NFRC test report."

I thanked my contact, took a deep breath and said to Mr. Builder, "I'm sorry, I can't give you credit for your windows."

The builder was dumfounded. He had done his research, knew what he wanted and decided upon a local manufacturer, because one tenant of green building is using local materials.

Except the Energy Rating law says that I can't give him credit for an unlabeled product. My state certification is on the linesomeone is randomly checking a sample of my evaluations. I can't stretch it since the window is no longer an energy codeapproved alternative. I can't make a professional judgment call because I know how often the wrong window gets installed. (I make a pretty penny recalculating HERS ratings with new values and then figuring out what has to be done to compensate for the wrong window.)

I tell my client that he doesn't have to replace the windows, but his ENERGY STAR rating won't be as high. Perhaps he'll have to buy

$$
\text { D-1-5 }
$$

http://www.usglassmag.com/Door_and_Window_Maker/Backissues/2007/November07/en... 6/20/2010 
something else. We finish our inspection, making an appointment for the next one. The next day I get an e-mail that wasn't altogether unexpected: The builder has decided to not pursue ENERGY STAR Home certification. My sweet, easy gig is dead.

Some readers are going to shake their heads in empathetic frustration. Others are going to see this as justification about why they don't need to do NFRC certification in the first place. I see it as a reminder that we don't exist in a vacuum. Your pinch-a-penny strategy may be right in the short term, but it may hurt someone's livelihood. They'll never forget. In the long run, that's bad for your business. For my private practice, I'll probably recommend against this window for future HERS ratings.

Lastly, using my author's prerogative, I'd like to thank AAMA's Larry Livermore for reminding me that stories from the field are the most interesting.

Arlene Zavocki Stewart is the principal for AZS Consulting, Inc., a member of the Efficient Windows Collaborative. She can be reached at azstewart@azsconsultinginc.com. The views and opinions expressed in this article and in materials of the Collaborative do not necessarily reflect those of this magazine.

\section{DWM}

(C) Copyright 2007 Key Communications Inc. All rights reserved.

No reproduction of any type without expressed written permission.

\section{D-1-6}




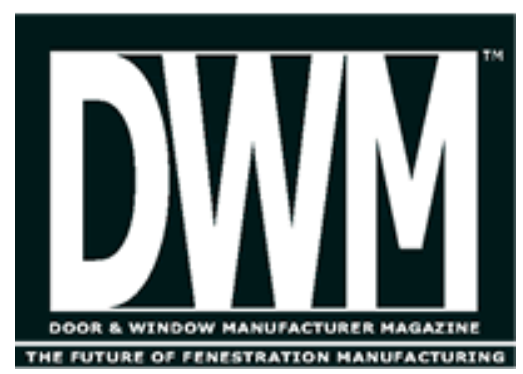

Volume 9, Issue 6 - June 2008

\section{eye on energy}

\section{The FTC is Watching}

\section{Make Sure You Back up your Green Claims by Arlene Z. Stewart}

When I walked around the International Builders' Show back in February, I saw a Federal Trade Commission (FTC) environmental claims suit waiting to happen. The entire West Hall had been bitten by the green bug. New products that were environmentally preferred, eco-friendly, recyclable, recycled and/or sustainable dominated every corner of the hall.

\section{Don't Wash the Message}

Except most of them were green-washed, meaning that more money was spent on marketing something as green than actually making it green. In the entire hall, I found only one company that got it right. "We're expecting the test report back from the lab next week. We think we're going to have 50-percent recycled, post-industrial content," said a rep from a company that made nails. Wow! Only one company seemed to have actually read the FTC Green Guides. Only one company had backed and educated its salesforce enough to make a reasonably accurate claim.

Now, truth be told, I didn't include fenestration manufacturers in my informal survey. I didn't think this was necessary as I am very familiar with various companies and people in the industry who have been looking at green issues for a long time. In fact, there's been enough interest that the American Architectural Manufacturers Association (AAMA) announced recently that it will develop a green certification program.

But let's get back to the FTC for a minute, so I can explain its Green Guide. These are documents from FTC staff that "provide insight about general principles for all environmental marketing claims and provide specifics about certain green claims, such as degradability .... recyclability, recycled content and ozone safety." Laura Koss from the FTC staff indicated that the guides were slated to be updated every ten years, but that the review period was moved up a year because of all the green activity. Many topics simply are not covered currently, so FTC is taking public comment. There are more workshops planned and Koss tells me that one of the topics they are considering is building materials.

\section{Green Certification Program for Fenestration}

Now, I suspect that some readers are grousing, "Not another meeting! Why do we need another regulation? Another hoop to jump through?"

This reaction always puzzles me, especially from an industry with such pride in its certification programs. Fenestration manufacturers have struggled to find their niche in the green marketplace and yet, in my mind, it's been sitting under our collective noses all the time.

Truly, there is nothing that I have seen in the green community that could touch a certification program developed by the fenestration industry. I'm not singling any particular one out, because it wouldn't matter. Pick one-they all have better infrastructure than any of the green certifications to which I've been privy. I firmly believe that when FTC starts to focus on building materials, it will be the fenestration industry that sets the bar for all other green programs.

So the timing to develop a green fenestration program is perfect. The window industry can let the FTC know that they are developing a program with the substantiation and specificity needed for proper environmental claims. The process isn't so far along that a lot of work will be wasted should FTC change its policies.

As for the industry program, the development process is going to take a while. The 101 standard and its subsequent certification

$$
\text { D-1-7 }
$$


program weren't created in a day. I suspect it wasn't created in a decade either. However, I can see far, far down the road that the green certification will eventually have the same sort of set up. Instead of air and water and structural and forced entry, we might wind up using topics defined by FTC. Until then, it appears that the first iteration of the AAMA program will be based on points, following the current popular pattern.

Until the program hits the streets, I would caution manufacturers to be wary of the seven deadly sins as identified by Terra Choice Environmental Markets: Avoid hidden trade-offs, false or thinly supported claims, vague or irrelevant claims or promoting environmental qualities when they are of questionable value.

Arlene Zavocki Stewart is a member of the Efficient Windows Collaborative and an energy code advocate. She can be reached at azstewart@azsconsultinginc.com. The views and opinions expressed in this article and in materials of the Collaborative do not necessarily reflect those of this magazine.

\section{DWM}

(C) Copyright 2008 Key Communications Inc. All rights reserved. No reproduction of any type without expressed written permission.

\section{D-1-8}




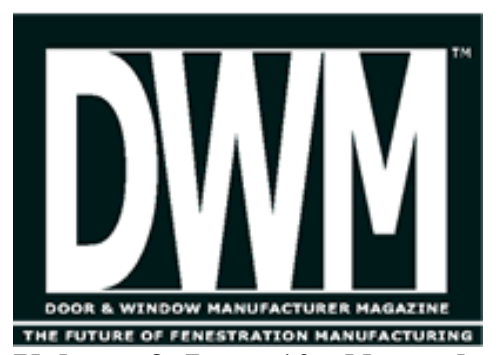

Volume 9, Issue 10 - November 2008

\section{EYEONENER GY}

Where Does Your Cradle Fall?

B Y ARLENEZAVOCKI STEW ART

I've been thinking a lot lately about the transition to cradleto- cradle from cradle-tograve. No, I'm not talking about how to prevent my two-year-old from breaking his neck when he finally figures out he's tall enough to scamper out of his crib. I'm referring to Life Cycle Assessment (LCA). According to Wikipedia, "the term 'life cycle' refers to the notion that a fair, holistic assessment requires the assessment of raw material production, manufacture, distribution, use and disposal including all intervening transportation steps necessary or caused by the product's existence. The sum of all those steps-or phases- is the life cycle of the product."

I first became aware of LCA in a meaningful way in 2004 at a brainstorming session at GreenBuild in Portland, Ore. As I packed into a room far too tiny for the volume of interested parties, I quickly became aware that, while green building advocates wanted LCA to play a larger role in their decision-making process, the sheer volume of information needed to make such an assessment was staggering.

Indeed, LCA is a great example of "if you can't measure it, you can't manage it." According to ISO 14040 (Environmental management- Life cycle assessment-principles and framework), a scope of LCA would include raw material acquisition, transport, production, use, reuse/recycling, energy supply and waste treatment. Moreover, the "essential property of a product system is characterized by its function, and cannot be defined solely in terms of the final products." Theoretically, manufacturers would need a similar LCA on every individual component from lineals to glass to spacers to hardware to adhesives and sealants in order to complete their own LCA. I might be underestimating that there are thousands of tidbits of information to be gathered.

How to Manage the Data Pool

Luckily, databases and calculation engines have been developed and currently are being improved to manage all this data, since it's just as important to manage this data as it is to measure it. Currently, the Window and Door Manufacturers Association (WDMA) is working with one of the leaders in the LCA field, the Athena Institute, who led that fateful meeting back in 2004 and produces the Eco-Calculator (http://www.athenasmi.org/).

"Right now, we're learning what LCA really means for window manufacturers," says J eff Lowinski, vice president of the WDMA. "We need to gain a better understanding of how whole building LCAs are done, fenestration's role within it and what type of information should be gathered to make a reasonable, yet valuable LCA."

The inherent expectation is that improvements can-and should - be made. A vast number of products and byproducts go into a landfill when the user is done with them-hence the term "grave." Once the process is known, can improvements be made that would return the product back to the cradle, or beginning of, something else? If so, can it do this without adversely affecting overall product performance?

LCA Demand is Growing As a green building certifier, I know that no product can be absolutely environmentally benign. I'm interested in products that reduce environmental impact. Products that are truly cradle-to-cradle products are few and far between but I'm looking for them. In spite of the fact that the green industry has been speaking about LCA for at least ten years, the field is still in its infancy in terms of implementation. Still, as we fast-forward to 2008, as that packed room foreshadowed, the demand for cradleto- cradle products has grown. LCA pioneer William McDonough spoke at this year's the International Builders' Show and his company has certified more than 20 building products for cradle- to-cradle. I'm expecting that green building programs will begin placing parameters on product impacts during production and deconstruction, not just during usage through the lifetime of the building. LCA will be essential to knowing where to implement those parameters.

So, where does your cradle fall? Remember, a journey of a thousand miles begins with the first step. Those material safety data sheets will only cut it for so long.

\section{DWM}

(c) Copyright 2008 Key Communications Inc. All rights reserved.

No reproduction of any type without expressed written permission.

\section{D-1-10}




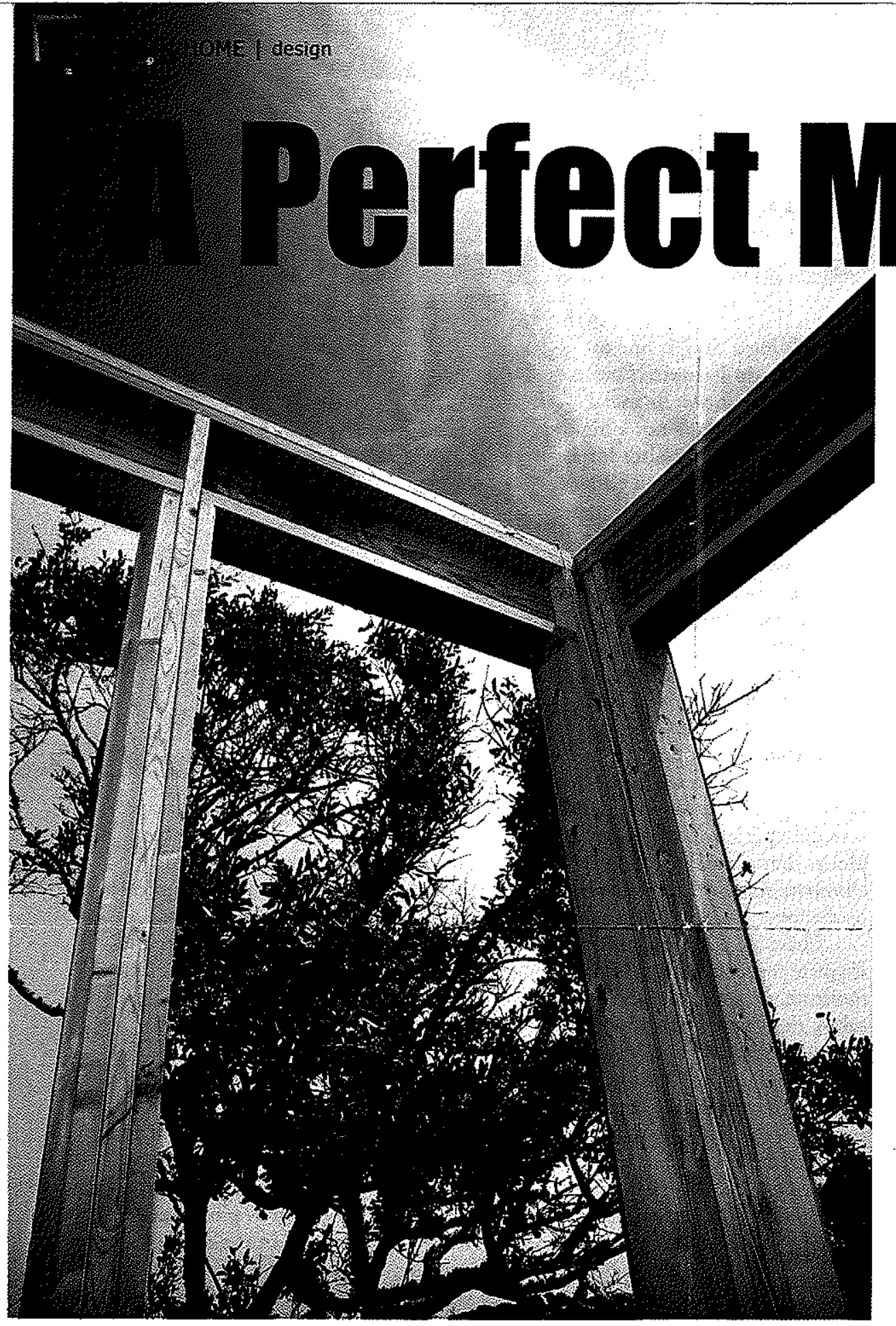

\section{How to get the best windows for your place}

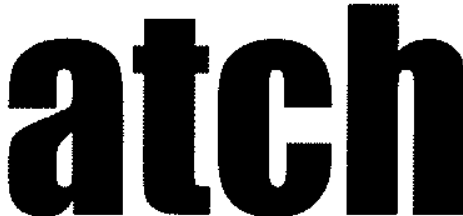

by Nils Petermann

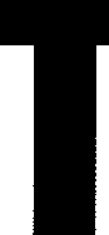

here are a large variety of window types you can consider for your cabin. Facrors such as appearance and view, thermal comfort, energyperformance and ventilation all play a role in your choices. Of course, your cabin's design and your personal tastes will dictate which window size, shape and frame type offer the best appearance, daylight and view.

Following is an overview of some window options that can help you make an informed decision that takes aesthetic, as well as long-term energy and maintenance considerations into account.

\section{Energy Efficiency \& Thermal Comfort}

Just by looking at a window you can't necessarily see whether it will keep you warm in the winter and keep intense solar heat out in the summer. So the U.S. Department of Energy and the Environmental Protection Agency have developed the ENERGY STAR label to help you choose the appropriate windows for your climate. For more detailed information, consult the website of the Efficient Windows Collaborative (www.efficientwindows.org), which includes a Window Selection Tool for different climates across the U.S. and Cànada.

\section{Window Types}

When you select a window, there are numerous types to consider.

Fixed (or picture) windows have two main advantages: Their large glass areas enhance light and view, and they leak only minimal amounts of air if installed correctly. However, to provide ventilation and egress (an escape route), fixed windows need to be combined with operable windows.

Traditional operable window 
types include the hinged types such as casement, awning and hopper. These windows swing outward or inward. Operable windows also include sliding types such as double- and single-hung and horizontal sliding. Hinged windows generally have lower air leakage rates than sliding windows from the same manufacturer because a compressive larch increases the effecriveness of the weather-stripping when the sash closes by pressing against the frame.

\section{Breaking it Bown}

- Casement Windows - are hinged at the side. Casement windows project ourward, providing significantly better ventilation than sliders of equal size. Because the sash protrudes from the plane of the wall, it can be controlled to catch passing breezes, but screens must be placed on the interior side. Virtually the entire casement window area can be opened, while sliders are limited to less than half of the window area. However, you may not want to install these windows over a deck or walkway where they can interfere with traffic patterns.

- Awning Windows - are hinged at the top and open outward. Screens are placed on the interior of the window unit. Similar to casements, the entire window area can be opened. Be wary near walkways and decks.

- Hopper Windows - are hinged at the bottom and open inward. Screens are placed on the exterior of the window unit. Similar to casements, as the entire window area can be opened. Suitable for deck or walkway areas, but you will want to make sure they don't interfere with traffic areas inside your cabin.

- Single and Double Hung Windows - are double-hung units; both sashes slide vertically. Only the bottom sash slides upward in a single-hung window. Ventilation area can vary from a small crack to an opening of one-half the total glass area. Screens can be placed on the exterior or interior of the window unit. These types of windows work well in high-traffic areas.

- Slider Windows - are models in which both sashes slide horizontally

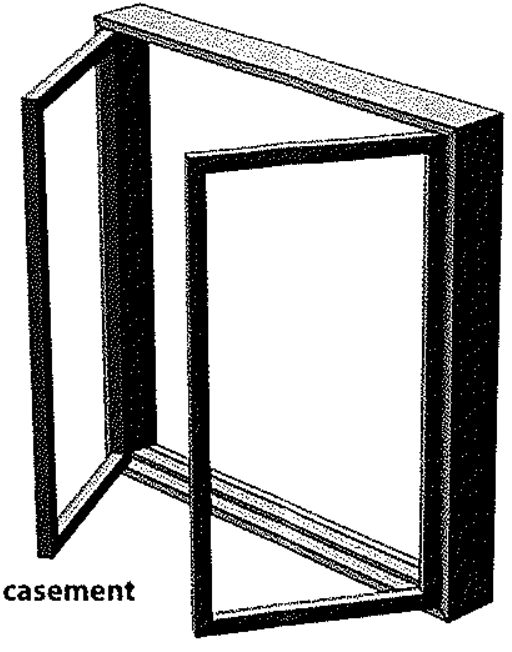

in a double-sliding window. Only one sash slides in a single-sliding window. A major advantage: The flexible ventilation area can vary from a small crack to an opening of one-half the total glass area. Screens can be placed on the exterior or interior of the window unit. Like single and double-hung windows, sliders don't interfere with traffic inside or outside.

- Skylights and Roof Windows are actually two different things. Skylights, which are installed in outof-reach applications, are mostly permanently fixed in place, mounted on a curb above a flat or sloped roof. Roof windows are installed in places where they are accessible.

Operable skylights and roof windows that can be opened by hand - with an extended crank or remote control motor - are becoming increasingly more common. The beauty of this: You can allow hot air that rises to the ceiling level to be exhausted from your cabin. This can be a big relief to those sleeping in loft areas!

Roof windows and skylights are available with most of the glazing options of standard windows and can be equipped with operable interior shading systems.

You can mix all different types of windows throughout your place. The key is to thoughtfully balance your aesthetic preferences with your energy-saving goals, ventilation needs and traffic constraints.

Nils Petermann is a senior research associate for the Efficient Windows Collaborative, a project by the Alliance to Save Energy.
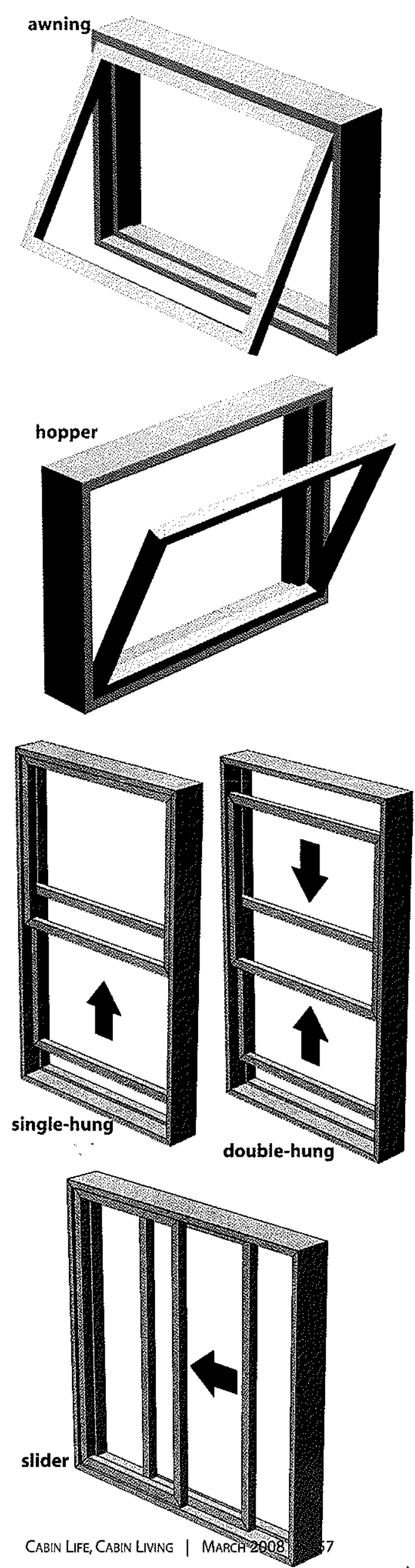
Approximate Energy Performance of Glazing with Thermally Broken Aluminum Frame

\begin{tabular}{|l|l|l|l|}
\hline Glazing Type & U-Factor & SHGC & VT \\
\hline Double Pane Clear & 0.6 & 0.6 & 0.6 \\
\hline Double Pane, Low-E & 0.45 & 0.35 & 0.55 \\
\hline Double Pane, Low-E, Tinted & 0.45 & 0.3 & 0.4 \\
\hline Double Pane, Triple Silver Low-E, Argon & 0.4 & 0.25 & 0.5 \\
\hline Double Pane, Reflective & 0.55 & 0.2 & 0.1 \\
\hline
\end{tabular}

Note: These values approximate the performance of typical windows with thermally broken aluminum frames. The performance of specific products can differ greatly from these examples.

\section{Energy-Efficient Glazing Basics}

\section{Choosing the right energy-efficient glazing for your building can reduce operating costs by lowering heating and cooling bills}

Windows connect building occupants to the outdoors via daylight, views, and natural ventilation while protecting them from the elements. Or, at least that's the ideal. Even so, in many older buildings (and even in some newer ones), windows fail to weatherize occupied space and are prone to water leakage, condensation, or noise transmission. The consequences can include high energy bills, occupant discomfort, and water damage. For this reason, window improvements are in high demand; while upfront costs can be a barrier, overall cost savings can be achieved if improvements are made with energy efficiency in mind.

High-performance glass is central to window energy efficiency. Given the long lifespan of glazing and the high cost of retrofits, it's crucial to understand what's available in today's commercial glazing market and the attributes that each product offers.

Three properties are integral to evaluating glazing energy performance: insulating performance (U-factor), solar heat gain coefficient (SHGC), and visible light transmittance (VLT or VT). The ideal properties depend on the local climate, building type, and design. For instance, a low U-factor (less heat loss) is most important in a cold climate; a low SHGC (less solar heat gain) is a priority where overheating is a concern. Visible transmittance is important when daylight is incorporated into the project design.

Low-E coatings can combine the advantages of a reduced U-factor and SHGC while maintaining high levels of visible light transmittance. These microscopically thin layers of metal or metallic oxide can be designed to filter radiation so as to reflect UV and infrared radiation while transmitting visible wavelengths. The latest generation of low-E coatings, referred to as triple silver low- $E$ for their three layers of silver oxide, is the most powerful solution to date for reflecting solar heat without sacrificing daylight. Where too much light transmission may lead to glare, tinted glass used in combination with low-E coatings can provide some glare control while reducing solar heat gain even further.
In climates where cooling load reduction is the priority, reflective coatings offer a tool for maximum solar control. Unlike low-E coatings, reflective coatings reject a high level of infrared solar heat and visible light, allowing building occupants access to views while reducing solar heat gain and glare.

When windows or window glass are replaced, opting for high-performance glazing over standard options comes at a relatively low incremental cost; however, since replacement of the existing glazing isn't always practicable or affordable, retrofit window films are available with low- $\mathrm{E}$, reflective, or tinted properties. These can be applied to existing glazing. Although they provide only a minor improvement to the U-factor, applied films can be very effective for reducing SHGC.

It's important to note that glazing energy performance not only depends on the type of coating and/or tint used, but also on the design of the whole window system, including spacers, frame, multiple panes, and possible gas fills. To express the interaction of these components, the National Fenestration Rating Council (www.nfrc.org) has developed standards for rating the U-factor, SHGC, and VT ratings of whole windows, including all of their components. These standards allow an apples-to-apples comparison among products and are referenced in building energy codes.

Those who seek a basic assessment of various glazing options can use the Façade Design Tool at www.commer cialwindows.org, or download the beta version of COMFEN, a free simulation tool under development by Lawrence Berkeley National Laboratory (windows.lbl.gov/software).

These tools, as well as more comprehensive energy modeling software, take into account the impacts of climate and orientation, and provide valuable information on how high-performance glazing can lower heating and cooling costs, improve occupant comfort, and lower peak demand on HVAC systems. B

Paul Bostrom is an associate at the Efficient Windows Collaborative (www.efficientwindows.org) at the Alliance to Save Energy in Washington, D.C. 


\section{Appendix E - Discussions of Energy Performance Tiers and Indicators}

E-1 Alliance to Save Energy recommendations to DOE for ENERGY STAR windows label modification

E-2 Higher Performance Tiers for Residential Windows - draft ideas for initial discussion

E-3 "Performance Tiers for Energy Efficient Commercial Windows”, an assessment by the Efficient Windows Collaborative 


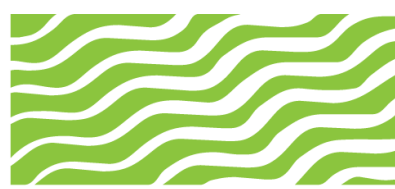

HONORARY CHAIR U.S. Senator Mark Pryo CO-CHAIR James E. Rogers

Duke Energy

ONORARY VICE-CHAIRS U.S. Senator Jeff Bingaman U.S. Senator Susan M. Collins U.S. Senator Larry Craig

U.S. Senator Byron L. Dorgan

U.S. Representative Ralph Hall

U.S. Representative Ralph Hall
U.S. Representative Steve Israel

U.S. Representative Edward J. Markey

U.S. Representative Zach Wamp

FOUNDING CHAIR

Charles H. Percy

CO-CHAIR EMERITUS

Dean T. Langford

PRESIDENT

Kateri Callahan

TREASURER

Robert Pratt

Henry P. Kendall Foundation

SECRETARY

Jeff Rea

DIRECTORS

Frances Beinecke

NRDC

Stephen Brobeck Consumer Federation of America

Dr. Marilyn A. Brown Georgia Institute of Technology

James H. DeGraffenreidt, Jr.

Washington Gas

Robert J. Dixon

Siemens Building Technologies, Inc.

Thomas K. Dreessen EPS Capital Corporation

John R. Fielder Southern California Edison

Robert Foster

City of Long Beach, CA

John Fox

Perseus, LLC

Thomas Grumbly

Lockheed Martin Information Technology

Geoffrey Hunt

OSRAM SYLVANIA

William Keese

Tom King National Grid

Thomas R. Kuhn

Edison Electric Institute

Michael Lawrence

Johns Manville

William T. Morrow

Pacific Gas and Electric Company

William A. Nitze

Oceana Energy Company

Earle H. O'Donnell

White and Case LLP

Jackalyne Pfannenstie California Energy Commission

John W. Rowe

Exelon Corporation

Peter Smith

Pataki-Cahill Group

Rich Wells

The Dow Chemical Company

RE: Comment on the proposed revision of ENERGY STAR for windows, doors, and skylights. Recommendation that labels include a simple indicator of relative solar heat gain

Dear Rich:

The Alliance to Save Energy proposes that the ENERGY STAR label include a simple indicator of whether the labeled product is a "high solar heat gain," "moderate solar heat gain,", or "low-solar heat gain" product. Such a simple indicator would facilitate good fenestration selection based on orientation, local climate conditions, and occupant preferences and thus help consumers and professionals save energy and improve comfort at no added cost.

In northern climates, the existing as well as the proposed new ENERGY STAR criteria allow for a wide range of SHGC values among qualifying fenestration. The new proposed criteria for climate zones ES4 and ES5, with trade-offs available between U-factor and SHGC, are expected to increase the availability of the currently rare higher-gain options within this range. We acknowledge that this increase in the range of commonly available SHGC levels opens up more design possibilities, but we also caution that it increases the need for designers, builders, and buyers, to be made aware of the potential for unwanted solar heat gain from unshaded west-facing and south-facing glass. To facilitate optimum window selection, we strongly suggest that simple and clear information on relative solar heat gain be included on the ENERGY STAR label and encouraged in manufacturer product literature.

The trade-offs in the proposed ES4 and ES5 criteria take into account the average benefits of solar heat gain in a heating climate. Ideally, however, fenestration for a specific house should be selected based on the building's actual orientation and shading conditions instead of average values calculated for a prototype house. It is not easy for product-based criteria such as those used for ENERGY STAR fenestration to take into account all the different circumstances in which these fenestration products may be installed. What the ENERGY STAR program can and should do, however, is provide a simple indicator of relative solar heat gain as a basis for house-specific decisions, and as a platform for information campaigns, incentives, and other market transformation activities by utility companies, energy educators, and others.

The indicator of relative solar heat gain should be based on the rated SHGC value. The SHGC number is already provided with all ENERGY STAR fenestration, but by itself does not offer an easy-to-use indicator of whether a given product is at the high or low end of solar gain from available ENERGY STAR compliant products. ${ }^{1}$ A simple, 3-level indicator of where a fenestration product falls within the SHGC ranges that meet the ENERGY STAR criteria would offer much clearer information, allowing consumers to identify the ENERGY STAR product that is best suited to each application.

${ }^{1}$ Even literature on window performance does not always help to clarify the question of what is a low or a high SHGC. On the one hand, many older and even some recent publications still reference the shading coefficient (SC) whereas some other literature provides design guidance based on center-ofglass SHGC values. Neither SC nor COG SHGC values provide good points of comparison for wholewindow SHGC values. A case in point is the guidance on passive solar window design by EERE (http://apps1.eere.energy.gov/consumer/your_home/windows_doors_skylights/index.cfm/mytopic=133 $\underline{60})$. Here, a SHGC of greater than 0.60 is recommended for south facing windows. While this is not stated, this recommendation is likely based on the center-of-glass SHGC. In the RESFEN 5.0 window library, the only high-solar-gain low-E option with an SHGC of greater than 0.60 is the aluminumframed option without thermal breaks (see http://efficientwindows.org/glazing .cfm?id=6). This shows the potential for confusion even among professionals if the SHGC provides the sole guidance for selecting windows with solar heat gain considerations in mind.

E-1-1 
The reason why we propose a simple indicator for solar heat gain but not for the U-factor is as follows. The Ufactor's range is limited under the proposed criteria, which allow a considerable range only in cooling-dominated climates where the effect of the U-factor is minimal. Therefore consumers are assured that any ENERGY STAR fenestration product will provide good performance in terms of the U-factor. The same is not always true for the SHGC. The proposed criteria allow a wide range of SHGC in the northern zones. Thus, a buyer who wants to emphasize passive solar heating cannot depend on all ENERGY STAR fenestration to admit enough solar gain. At the same time, where the main concern is with controlling unwanted solar gains, the buyer cannot rely on all ENERGY STAR fenestration to provide this protection.

Although LBNL's analysis ensures that windows with different combinations of U-factor and SHGC values all provide good energy performance on an annual basis for the average home, it can make a big difference to individual home owners whether they install windows with an SHGC of 0.50 or 0.25 - including the impact on thermal comfort, peak electricity demand, and air conditioning sizing which are not reflected in a calculation of annual HVAC energy alone. The dominance of heating demand in the North does not mean that solar heat gain can be neglected, either in terms of its ability to offset heating needs and provide winter comfort or in terms of its implications for cooling demand and summer comfort. From this, we conclude that while consumers can trust in the ENERGY STAR to guide them toward close-to-optimum choices in terms of the U-factor, additional information is needed, in a clear and easily understood form, to provide that same guidance with regards to solar heat gain.

The proposed new criteria for ENERGY STAR windows offer a basis for defining 3 categories of high, moderate, and low solar gain:

- Windows with an SHGC that can only qualify in the northern climate zones ES4, ES5, and ES5a (SHGC $>0.40$ ) could be considered "high solar heat gain."

- Windows meeting the criteria of cooling-dominated climates ES2 (SHGC $<=0.30$ ) could be considered "low solar heat gain."

- Windows with an SHGC of 0.31-0.40 that meets the mixed-climate criteria of ES3 but does not qualify further south could be considered "moderate solar heat gain" (see Figure 1).

- Under the new criteria as presently proposed, this classification could work for both Phase 1 and Phase 2. However, the average SHGC of products qualifying in Phase 2 can be expected to be substantially lower, not only because of a more stringent SHGC limit in ES1, but also because of the lower SHGC that comes with triple-pane windows. Therefore it seems reasonable to use lower SHGC numbers for the classification of relative solar heat gain in Phase 2 (see Figure 2). For dynamic windows with variable SHGC, "variable solar heat gain" would be the appropriate designation.

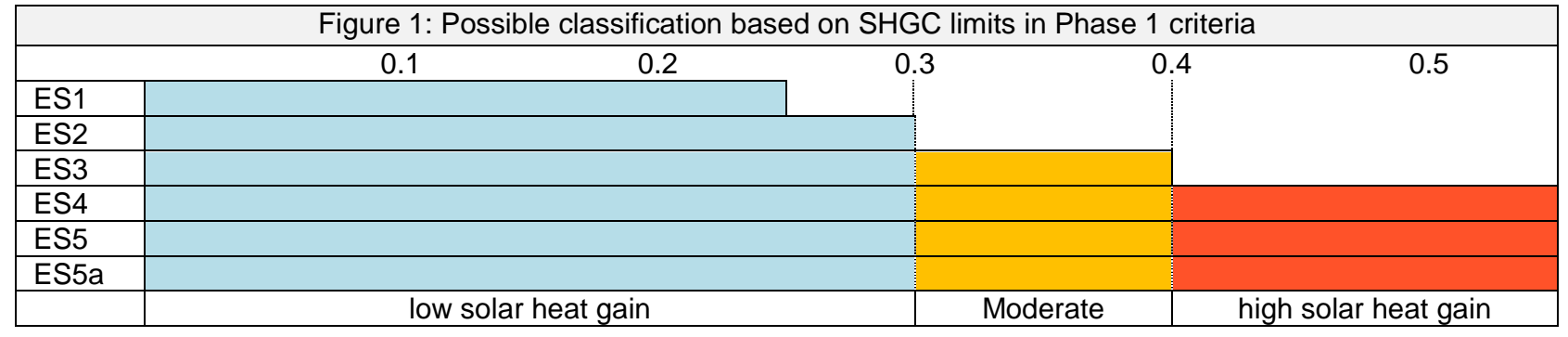

$\bullet$

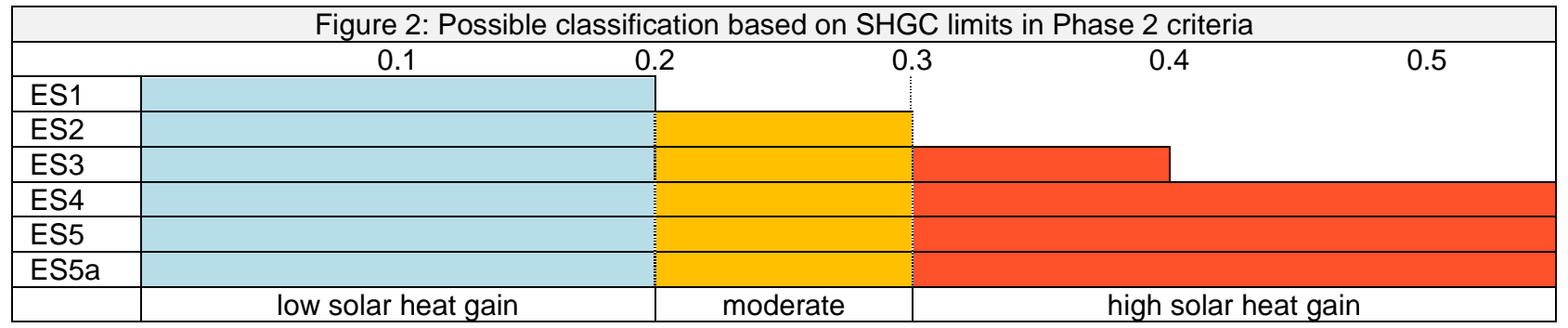


The Alliance to Save Energy is aware of the need to retain the simplicity of the ENERGY STAR label. Adding an indicator of a fenestration product's relative solar heat gain by using three simple categories based on the SHGC would enhance rather than detract from ENERGY STAR's clear and simple message - while at the same time helping to guard the integrity of the label by discouraging selection of an ENERGY STAR window that is poorly matched to the needs of a specific application and could lead to lower energy savings, reduced comfort, or other consumer problems. ENERGY STAR is a highly-visible designation trusted by consumers.

Our proposed addition to the label would reinforce this trust, at no added cost, by providing an easy tool for designers, consumers, and utility programs to choose the right window for the right application and thus maximize energy savings and value.

Sincerely,

Nils Petermann

Project Manager, Efficient Windows Collaborative

Alliance to Save Energy

\section{Suggested Format for Displaying a Solar Heat Gain Indicator}

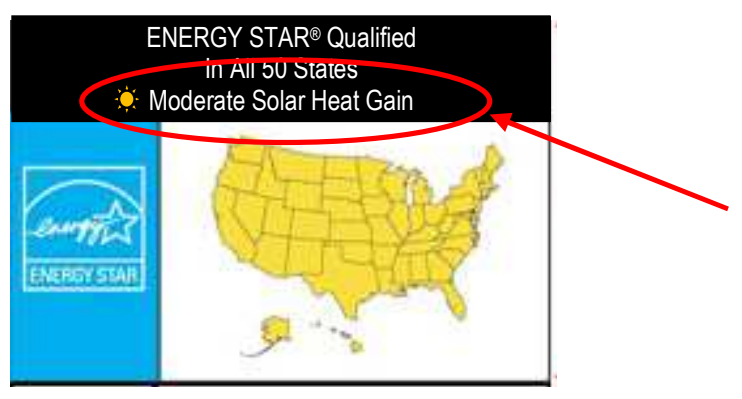

This illustrates a possible approach to display an indicator of relative solar heat gain on the ENERGY STAR label (based on the current label design). Under the line "In All 50 States" (in this example), one line of text and a simple symbol could be added with little increase in space requirements. 


\section{Higher Performance Tiers for Residential Windows}

To qualify for the ENERGY STAR label, windows must meet climate-specific performance criteria that can best be met with insulated low-E glazing. Combined with warm-edge spacers and gas fills, low-E glazing provides a cost-effective means to increase window energy performance over that of conventional double-paned windows. The ENERGY STAR performance criteria for windows and similar performance tiers required by building energy codes are effective in promoting these technologies, so that they have become the standard in many parts of the country. However, neither the ENERGY STAR program nor common building energy codes such as the IECC provide higher performance tiers that reward more advanced options such as triple glazing or glazing for superior solar control. For these options to really catch on in the market, endorsement and incentive programs based on higher performance tiers than those presently set for ENERGY STAR Windows will be needed.

\section{The next big step: Highly insulating, high solar control, or dynamic windows}

The lowest U-factor and SHGC specified by the ENERGY STAR for windows program and the IECC are U-factor 0.35 and SHGC 0.40 . These performance criteria can be met by typical soft-coat low-E windows with argon gas fill and a vinyl or wood frame (Ufactor 0.34 and SHGC 0.30 according to the RESFEN library). Such windows hold a large share of the U.S. market. The text box on the right shows prominent examples of programs that include somewhat higher performance criteria, although none of these goes beyond 0.30 for $\mathrm{U}$-factor and SHGC. This is despite the fact that far betterperforming products are available or under development:

\section{Highly insulating windows}

Triple pane windows with a U-factor of 0.25 or less have been around since at least

Highest present performance tiers

\section{ENERGY STAR Homes}

The National Builder Option Package for ENERGY STAR Homes requires a somewhat stricter SHGC for the South Zone (0.35) than ENERGY STAR Windows need to have (0.40).

Weatherization specifications by Bonneville Power Administration In the Northwest (ID, MT, OR, WA), windows with a $0.30 \mathrm{U}$-factor have achieved sufficient market penetration so that Bonneville Power Administration (BPA) changed the specifications for its weatherization program to an areaweighted U-factor of 0.30 . The specification had previously been 0.35 , which in most of the BPA area is equal to the code requirements. A range of doublepane windows with different frame types are available that meet U-factor 0.30 without substantial cost increases.

\section{LEED for Homes}

The LEED for Homes Program Pilot Rating System gives credits for windows that exceed the requirements in the ENERGY STAR Homes Builder Option Package. The highest performance tier in the latest draft version (February 2007) credits windows with a $0.30 \mathrm{U}$-factor (North) or 0.30 SHGC (South). See the appendix for a table of the LEED for Homes window credits.

the early 1990s. A range of windows with a U-factor between 0.15 and 0.20 are also available (particularly with fiberglass frames). These windows bring substantial energy 
and comfort benefits, particularly in cold climates and when accompanied by HVAC downsizing.

DOE's goal is to make highly insulating windows available at a cost premium of no more than 10-20\% over today's ENERGY STAR Windows (ca. \$3-4 per square foot cost premium). According to some Canadian manufacturers, windows with a U-factor of less than 0.20 can already be supplied at such relatively low cost premiums if the market runs smoothly.

\section{High solar control glazing}

An SHGC of 0.35 or less is typical for windows with soft coat low-E, and an SHGC of 0.30 or less is also achieved by a variety of windows. According to the RESFEN library, a typical vinyl or wood-framed window with low-solar-gain low-E achieves SHGC 0.30.

With present technologies, an SHGC of 0.25 is just barely achievable without significant visible transmittance reduction. If tints are avoided, design options for achieving such a low SHGC are limited.

\section{Dynamic windows}

Dynamic windows are an emerging technology that at the present stage is costprohibitive for the mainstream building sector.

\section{Specification examples for the next big step}

\section{ENERGY STAR criteria}

The following is an example for where ENERGY STAR criteria could go in order to provide significant energy savings over the present criteria and provide some headroom for different product options:

\begin{tabular}{|l|c|c|c|c|}
\hline \multirow{2}{*}{ Metric } & \multicolumn{4}{|c|}{ ENERGY STAR Climate Zones } \\
\cline { 2 - 5 } & North & North/Central & South/Central & South \\
\hline U-factor & 0.25 & 0.30 & 0.30 & 0.35 \\
\hline SHGC & Any & 0.45 & 0.30 & 0.30 \\
\hline
\end{tabular}

Stricter criteria, providing less headroom for different product options, could look like this:

\begin{tabular}{|l|c|c|c|c|}
\hline \multirow{2}{*}{ Metric } & \multicolumn{4}{|c|}{ ENERGY STAR Climate Zones } \\
\cline { 2 - 5 } & North & North/Central & South/Central & South \\
\hline U-factor & 0.20 & 0.25 & 0.30 & 0.30 \\
\hline SHGC & Any & 0.35 & 0.30 & 0.25 \\
\hline
\end{tabular}

These examples are only for illustrative purposes to show what criteria could be used in order to endorse the use of highly insulating windows in the north and superior solarcontrol glazing in the south. Such criteria would call for triple-pane windows in the north, which would mean a higher cost premium for northern than for southern ENERGY 
STAR Windows. On the other hand, the cost premium for southern ENERGY STAR Windows could be even higher where impact resistant insulated glass is used.

\section{Implementing of higher performance criteria for ENERGY STAR Windows}

\section{New construction}

- Highest potential for energy savings is in new construction (HVAC downsizing);

- To create incentives for builders, higher performance tiers could be integrated into utility programs or home performance endorsement (ENERGY STAR Homes, LEED for Homes);

- Where building energy codes are enforced, builders that do not choose windows meeting the high performance tier would have to go with windows that come close to present ENERGY STAR performance;

- More efficient window choices are likely, energy savings effect depends on accuracy of HVAC sizing.

\section{Replacement}

- Endorsement of high-end windows will increase consumer awareness for high-end windows, with more affluent consumers most likely to choose these products;

- Higher performance criteria will result in a higher cost premium and a smaller market share for ENERGY STAR Windows than is the case with present performance criteria;

- With a smaller market share for ENERGY STAR Windows, it will become more important what windows are bought by consumers who do not choose ENERGY STAR Windows;

Present ENERGY STAR criteria distinguish low-E windows from less efficient windows. If the bar is raised and ENERGY STAR becomes more exclusive, the distinction of many low-E products from clear-glazed products will be lost. Policies will be needed to make sure that consumers at least choose low-E windows even if they do not opt for ENERGY STAR Windows. Possible policies include:

a) Better energy code enforcement in the replacement window market;

b) Labeling of code-compliant products;

c) Mandatory requirement for the use of low-E glass by window manufacturers;

d) Climate-specific minimum window energy performance standards set by the Federal government.

Raising the bar for ENERGY STAR Windows toward a more exclusive endorsement of high-end products would ideally be accompanied by policies to raise the floor as well, so

that the lower end of the market consists at least of low-E windows. It could be preferable 
to leave enough time for the implementation of such policies before raising the bar for ENERGY STAR Windows. In the nearer term, however, high performance tiers could already be adopted by the ENERGY STAR Homes program, which should demonstrate the benefits of combining high-end windows with HVAC down-sizing.

\section{Higher window performance specifications for the ENERGY STAR Homes program}

It could be beneficial to consider the inclusion of higher window performance specifications in the ENERGY STAR Homes program even before such criteria are adopted for ENERGY STAR Windows.

- Possibly, raising the bar for windows in the ENERGY STAR Homes program could be accomplished faster than raising the bar for ENERGY STAR Windows per se;

- High-end windows are most cost effective if combined with good insulation and proper sizing of the HVAC system; by requiring such measures in addition to efficient windows, the ENERGY STAR Homes program can assure that high-end windows live up to expectations;

- Good performance of high-end windows in ENERGY STAR Homes would set the stage for higher criteria for ENERGY STAR Windows.

Of course, higher performance tiers would not have to be restricted to ENERGY STAR Homes as a whole-house program. Green home programs can also help with the introduction of advanced windows at a larger scale.

\section{Conclusion}

Since many building energy codes and a major part of the U.S. windows market have caught up with the performance criteria for ENERGY STAR Windows, a more exclusive endorsement of high-end window products would be beneficial. Higher window performance tiers would be particularly beneficial in the new construction sector, where utility programs and the ENERGY STAR Homes program could provide incentives for windows that substantially exceed codes as well as for accordingly down-sized HVAC systems. In the replacement sector, higher performance tiers would also improve the market by raising awareness for high-end products among more affluent consumers. However, since energy code requirements are more difficult to enforce in the replacement sector, more exclusive endorsement of high-end products should be accompanied by additional policies to complete the inclusive transformation of the windows market toward low-E windows. 


\section{APPENDIX - LEED for Homes windows performance tiers}

In its latest draft version (February 2007) the LEED for Homes Program Pilot Rating System sets the following windows criteria (note that the minimum performance for LEED Homes windows is identical with the requirements in the ENERGY STAR Homes Builder Option Package):

\begin{tabular}{|l|l|c|c|c|c|}
\hline \multirow{2}{*}{ LEED credits } & \multirow{2}{*}{ Metric } & \multicolumn{4}{|c|}{ IRC / IECC Climate Zones } \\
\cline { 3 - 6 } & & CZ 5-8 & CZ 4 & CZ 3 & CZ 1 and 2 \\
\hline \multirow{2}{*}{$\begin{array}{l}\text { LEED } \\
\text { Minimum }\end{array}$} & U-factor & 0.35 & 0.40 & 0.40 & 0.55 \\
\cline { 2 - 6 } & SHGC & Any & 0.45 & 0.40 & 0.35 \\
\hline \multirow{2}{*}{ 2 LEED points } & U-factor & 0.32 & 0.35 & 0.35 & 0.55 \\
\cline { 2 - 6 } & SHGC & Any & 0.40 & 0.35 & 0.33 \\
\hline \multirow{2}{*}{ 3 LEED points } & U-factor & 0.30 & 0.32 & 0.32 & 0.55 \\
\cline { 2 - 6 } & SHGC & Any & 0.40 & 0.30 & 0.30 \\
\hline
\end{tabular}

Source: http://www.usgbc.org/ShowFile.aspx?DocumentID=2267

Just like in the ENERGY STAR Homes Builder Option Package, these criteria become more stringent for a window-to-floor area of above 18 percent.

\section{Suggestions for advanced LEED for Homes criteria}

The performance tiers for LEED credits listed below are an example of how highly insulating windows and windows with a very low SHGC could be endorsed by the LEED for Homes program.

\begin{tabular}{|l|l|c|c|c|c|}
\hline \multirow{2}{*}{ LEED credits } & \multirow{2}{*}{ Metric } & \multicolumn{4}{|c|}{ IRC I IECC Climate Zones } \\
\cline { 2 - 6 } & & CZ 5-8 & CZ 4 & CZ 3 & CZ 1 and 2 \\
\hline \multirow{2}{*}{$\begin{array}{l}\text { LEED } \\
\text { Minimum }\end{array}$} & U-factor & 0.35 & 0.40 & 0.40 & 0.55 \\
\cline { 2 - 6 } & SHGC & Any & 0.45 & 0.40 & 0.35 \\
\hline \multirow{2}{*}{ L LEED points } & U-factor & 0.30 & 0.30 & 0.30 & 0.35 \\
\cline { 2 - 6 } & SHGC & Any & 0.40 & 0.35 & 0.30 \\
\hline \multirow{2}{*}{ 3 LEED points } & U-factor & 0.25 & 0.25 & 0.30 & 0.35 \\
\cline { 2 - 6 } & SHGC & Any & 0.35 & 0.30 & 0.25 \\
\hline \multirow{2}{*}{ 4 LEED points } & U-factor & 0.20 & 0.20 & 0.30 & 0.30 \\
\cline { 2 - 6 } & SHGC & Any & 0.30 & 0.25 & 0.25 \\
\hline
\end{tabular}

Additional credits and/or criteria could also be considered:

- Requirement that windows provide a VT of at least 0.40 in order to be considered for LEED points, to assure that windows are not credited for a low-SHGC that is achieved by blocking light and views.

- Additional credit for windows that can dynamically adjust their SHGC by a minimum range. 


\section{Performance Tiers for Energy Efficient Commercial Windows}

\section{An Assessment by the Efficient Windows Collaborative}

\section{Introduction}

In this paper, the Efficient Windows Collaborative (EWC) suggests two simple performance tiers that could be used for programs promoting energy-efficient commercial windows. These suggestions, shown in the tables below, are derived from window energy performance criteria in prominent energy standards and guidelines. They are preliminary in nature since the EWC has yet to gather feedback on these criteria or estimate the energy savings based on the suggested performance tiers. Nevertheless, by relating the suggested performance tiers for commercial windows to established standards and guidelines, it is ensured that these tiers are achievable while providing the potential for energy savings through utility incentives or other energy efficiency programs.

\begin{tabular}{|l|c|c|c|c|c|c|c|c|}
\hline & \multicolumn{1}{|c|}{ Suggested Tier 1 Criteria } \\
\cline { 2 - 10 } Metric & $\mathbf{1}$ & $\mathbf{2}$ & $\mathbf{3}$ & $\mathbf{4}$ & $\mathbf{5}$ & $\mathbf{6}$ & $\mathbf{7}$ & $\mathbf{8}$ \\
\hline U-factor (metal frame) & 1.20 & 0.75 & 0.55 & 0.55 & 0.55 & 0.55 & 0.45 & 0.45 \\
\hline U-factor (nonmetal frame) & 1.20 & 0.75 & 0.55 & 0.40 & 0.35 & 0.35 & 0.35 & 0.35 \\
\hline SHGC & 0.25 & 0.25 & 0.25 & 0.40 & 0.40 & 0.40 & 0.45 & 0.45 \\
\hline
\end{tabular}

\begin{tabular}{|l|c|c|c|c|c|c|c|c|}
\hline \multicolumn{10}{|c|}{ Suggested Tier 2 Criteria } \\
\hline \multirow{2}{*}{ Metric } & $\mathbf{1}$ & $\mathbf{2}$ & $\mathbf{3}$ & $\mathbf{4}$ & $\mathbf{5}$ & $\mathbf{6}$ & $\mathbf{7}$ & $\mathbf{8}$ \\
\cline { 2 - 10 } & 1.20 & 0.75 & 0.50 & 0.42 & 0.42 & 0.42 & 0.35 & 0.35 \\
\hline U-factor (metal frame) & 0.95 & 0.55 & 0.40 & 0.30 & 0.30 & 0.30 & 0.25 & 0.25 \\
\hline U-factor (nonmetal frame) & 0.25 & 0.25 & 0.25 & 0.30 & 0.30 & 0.30 & 0.45 & 0.45 \\
\hline SHGC & 0.25 & 0.30 & $0.35+$ & $0.35+$ & $0.35+$ & $0.35+$ & $0.35+$ & $0.35+$ \\
\hline VT (daylight glazing only) & $0.30+$ & $0.30+$ & $0.30+$ & 7
\end{tabular}

\section{The Rationale for Window Energy Performance Tiers}

Utility or state programs can achieve large-scale energy savings and peak load reduction by encouraging that windows in new construction and retrofit applications meet the criteria of certain energy performance tiers. Window energy performance tiers can be used to encourage the use of windows that reduce energy use and peak demand for heating and cooling. If daylighting strategies are applied, energy use will also be reduced for lighting. While energy efficiency goals can also be stated in terms of simulated performance instead of prescriptive criteria, the latter approach is simpler and is helpful where a simple message increases the leverage of programs.

The most prominent example of energy performance tiers for commercial windows are the prescriptive requirements in building energy standards such as the International Energy Conservation Code ${ }^{\circledR}$ (IECC) or ASHRAE Standard 90.1 "Energy Standard for Buildings Except Low-Rise Residential Buildings." These standards establish prescriptive energy-efficiency minimums for fenestration and have been widely adopted by states and smaller jurisdictions. However, it cannot be assumed that all windows meet the 
prescriptive requirements of these standards: adoption and enforcement is not uniform across the country and alternative compliance paths allow flexibility for the building envelope design. Therefore, promotion of these prescriptive requirements as a window energy performance tier can still yield energy and peak demand savings in many cases.

More substantial energy savings can of course be achieved by promoting performance tiers for markedly higher energy efficiency than prescribed by building codes. Whereas the prescriptive requirements of codes and standards represent what is deemed to be an achievable minimum of energy efficiency, there are available options meeting far more ambitious energy efficiency goals. By promoting more advanced energy performance tiers, utilities or jurisdictions can stimulate wider adoption of the most energyefficient options in the market. The challenge here is to ensure that the goals presented are achievable and cost-effective enough to find acceptance. For residential windows, the U.S. Department of Energy has established ENERGY STAR ${ }^{\circledR}$ criteria as an advanced tier for energy performance that meets the needs of the market. No such commonly-recognized criteria exist for commercial windows, mostly due to the complexities of the commercial market. Nevertheless, there are some good examples of voluntary criteria for advanced commercial windows. Referencing these criteria and common building code requirements suggests energy performance tiers that can provide guidance and information to those who consider promoting energy-efficient commercial windows.

\section{Defining Energy Performance}

The energy performance of windows is expressed in their U-factor, solar heat gain coefficient (SHGC), visible light transmittance (VT or VLT), and air leakage (AL). These values allow us to compare windows and are used as the basis for the prescriptive fenestration requirements in building energy codes and for the qualification criteria of voluntary programs such as ENERGY STAR and utility incentives. ENERGY STAR, however, applies primarily to residential windows, whereas the commercial window sector is more diverse and criteria for energy-efficient commercial windows are more difficult to define.

Windows used in some commercial buildings such as schools, hospitals, or smaller office buildings may be comparable to residential windows. However, since internal loads in these smaller commercial buildings are higher than in homes, more stringent SHGC criteria are crucial for energy efficiency. Other commercial fenestration, such as curtain walls, storefront windows, and commercial-grade metal windows differ substantially from residential windows. For these fenestration types in commercial buildings, energy performance criteria need to take into account not only the importance of solar control, but also the different window dimensions and the structural need for strong frames(typically made of metal) and the effect of metal frames on the U-factor.

Building energy standards such as the IECC and ASHRAE Standard 90.1 take into account the different conditions among building and window types. In their prescriptive requirements, they differentiate between residential and commercial windows as well as, depending on the standard version, between metal and non-metal windows or between fixed and operable windows. The suggestions also differentiate between frame materials and discuss the effect of operator types.

\section{Approach for Identifying Performance Tiers}

Based on the rationale for window performance tiers (see Section 2), the approach for identifying commercial window performance tiers is the following: 
- Suggest two tiers. Tier 1: Criteria that reflect relatively common, but energy-efficient practice. Tier 2: Advanced criteria that are achievable but ambitious.

- Base Tier 1 on the most stringent prescriptive requirements found among prominent building energy standards. While these requirements might already be in place in parts of the country, the existence of compliance alternatives and the uneven adoption of standards mean that these criteria remain a tier to be aspired to across large parts of the U.S. commercial buildings sector.

- Base Tier 2 on advanced criteria in prominent voluntary programs or high-performance standards or guidelines. Examples are the proposed ASHRAE Standard 189, "Standard for the Design of High-Performance Green Buildings Except Low-Rise Residential Buildings", the Core Performance Guide by the New Buildings Institute, and the specifications set by the Commercial Windows Initiative, a project by the Northwest Energy Efficiency Alliance (see references).

\section{Prescriptive Window Requirements in Commercial Building Energy Standards}

To identify the criteria for Tier 1, the most prominent building energy standards currently available are compared. These are the most recent version of the International Energy Conservation Code (the 2006 IECC) and the two most recent versions of ASHRAE Standard 90.1 (90.1-2004 and 90.1-2007). Although the 2007 version of the 90.1 Standard has been released in early 2008, it has not yet come into effect in any state as of summer 2008. Anticipating its future adoption, we include 90.1-2007 in the comparison along with the widely adopted 2004 version of this standard.

Tables 1 through 3 display these three standards' U-factor and SHGC requirements for vertical fenestration in non-residential buildings. A few notes to these tables:

- For a map of the climate zones used in these standards, refer to Appendix A.

- The most stringent requirements in a given climate are highlighted.

- These requirements cover vertical fenestration only and, in the 2006 IECC and 90.1-2007, do not apply to curtain walls.

- Standard 90.1-2004 requirements depend on the ratio of vertical fenestration as part of the wall, ranging from 0 to 50 percent. To allow a direct comparison with the 2006 IECC and 90.1-2007 requirements, which are used for fenestration areas of up to 40 percent of the wall area, the 90.12004 requirements shown in the following tables assume a fenestration area of no more than 40 percent.

- Since the purpose is to identify the most stringent criteria among the different standards, the table shows only the somewhat more stringent requirements for fixed windows in 90.1-2004. The 2006 IECC and 90.1-2007 requirements cover both fixed and operable windows.

The highlighted cells in Tables 1-3 contain the most stringent requirements for a given climate zone among these three standards. These values help to establish the suggested Tier 1. 
Table 1. U-factor requirements for metal-framed windows in the three standards.

\begin{tabular}{|c|c|c|c|c|c|c|c|c|}
\hline \multirow{2}{*}{ Standard } & \multicolumn{8}{|c|}{ Climate Zone } \\
\hline & 1 & 2 & $3^{\star \star}$ & 4 & 5 & 6 & 7 & 8 \\
\hline $90.1-2004^{*}$ & 1.22 & 1.22 & 0.57 & 0.57 & 0.57 & 0.57 & 0.57 & 0.46 \\
\hline 2006 IECC & 1.20 & 0.75 & 0.65 & 0.55 & 0.55 & 0.55 & 0.50 & 0.50 \\
\hline $90.1-2007$ & 1.20 & 0.75 & 0.65 & 0.55 & 0.55 & 0.55 & 0.45 & 0.45 \\
\hline
\end{tabular}

* 90.1-2004 requirements are for fixed vertical glazing at $30.1 \%$ to $40 \%$ window-to-wall ratio

** In Marine 3 (coastal CA), 90.1-2004 requires only a $1.22 \mathrm{U}$-factor.

Table 2. U-factor requirements for windows with nonmetal frames in the three standards. Standard 90.12004 does not base its requirements on frame material, so that the requirements of this standard are identical with those in Table 1.

\begin{tabular}{|c|c|c|c|c|c|c|c|c|}
\hline \multirow{2}{*}{ Standard } & \multicolumn{8}{|c|}{ Climate Zone } \\
\hline & 1 & 2 & $3^{\star \star}$ & $4^{\star \star \star}$ & 5 & 6 & 7 & 8 \\
\hline $90.1-2004^{*}$ & 1.22 & 1.22 & 0.57 & 0.57 & 0.57 & 0.57 & 0.57 & 0.46 \\
\hline 2006 IECC & 1.20 & 0.75 & 0.65 & 0.40 & 0.35 & 0.35 & 0.35 & 0.35 \\
\hline $90.1-2007$ & 1.20 & 0.75 & 0.65 & 0.40 & 0.35 & 0.35 & 0.35 & 0.35 \\
\hline
\end{tabular}

* 90.1-2004 requirements are for fixed vertical glazing at $30.1 \%$ to $40 \%$ window-to-wall ratio

** In Marine 3 (coastal CA), 90.1-2004 requires only a $1.22 \mathrm{U}$-factor.

*** In Marine 4 (western OR and WA and northwestern CA, the 2006 IECC requires a $0.35 \mathrm{U}$-factor for vertical fenestration.

Table 3. Solar heat gain coefficient (SHGC) requirements for windows in the three standards. These requirements apply to windows of all frame types. These requirements apply to unshaded windows. Both the IECC and Standard 90.1 relax their SHGC requirements if permanent projections are in place.

\begin{tabular}{|c|c|c|c|c|c|c|c|c|}
\hline \multirow{2}{*}{ Standard } & \multicolumn{8}{|c|}{ Climate Zone } \\
\hline & 1 & 2 & 3 & 4 & 5 & 6 & 7 & 8 \\
\hline $90.1-2004^{*}$ & 0.25 & 0.25 & 0.25 & 0.39 & 0.39 & 0.39 & 0.49 & NR \\
\hline 2006 IECC & 0.25 & 0.25 & 0.25 & 0.40 & 0.40 & 0.40 & NR & NR \\
\hline $90.1-2007$ & 0.25 & 0.25 & 0.25 & 0.40 & 0.40 & 0.40 & 0.45 & 0.45 \\
\hline
\end{tabular}

$\mathrm{NR}=$ No requirement

* $90.1-2004$ requirements are for fixed vertical glazing at $30.1 \%$ to $40 \%$ window-to-wall ratio facing east, west, or south.

\section{Window Criteria in Voluntary Programs or High-performance Standards or Guidelines}

To establish Tier 2, information was derived from following prominent voluntary standards or guidelines for advanced energy performance:

- The proposed ASHRAE Standard 189, "Standard for the Design of High-Performance Green Buildings Except Low-Rise Residential Buildings";

- The Core Performance Guide by the New Buildings Institute, a non-profit organization supported by the U.S. Environmental Protection Agency as well as regional and state organizations;

- The specifications set by the Commercial Windows Initiative (CWI), a project by the Northwest Energy Efficiency Alliance;

Tables 4 and 5. $U$-factor criteria in the above-named standards or guidelines for windows with metalframes and non-metal frames respectively. The CWI criteria only apply to the Pacific Northwest, which 
includes climate zones 4, 5 and 6. The most stringent criteria for each climate zone are highlighted in yellow.

\begin{tabular}{|c|c|c|c|c|c|c|c|c|}
\hline \multirow{2}{*}{ Standard } & \multicolumn{8}{|c|}{ Climate Zone } \\
\hline & 1 & 2 & 3 & 4 & 5 & 6 & 7 & 8 \\
\hline Proposed Standard 189 & 1.20 & 0.75 & 0.55 & 0.45 & 0.45 & 0.45 & 0.35 & 0.35 \\
\hline Core Performance Guide & 0.57 & 0.57 & 0.50 & $0.42^{*}$ & $0.42^{*}$ & $0.42^{*}$ & 0.35 & 0.35 \\
\hline CWI & & & & 0.42 & 0.42 & 0.42 & & \\
\hline
\end{tabular}

* In the humid parts of climate zones 3, 4 and 5, the Core Performance guide sets the maximum U-factor at 0.45 .

\begin{tabular}{|l|c|c|c|c|c|c|c|c|}
\hline \multicolumn{10}{|c|}{ Table 5: U-factor - Nonmetal-Framed Windows } \\
\hline \multirow{2}{*}{ Standard } & \multicolumn{7}{c|}{ Climate Zone } \\
\cline { 2 - 10 } & $\mathbf{1}$ & $\mathbf{2}$ & $\mathbf{3}$ & $\mathbf{4}$ & $\mathbf{5}$ & $\mathbf{6}$ & $\mathbf{7}$ & $\mathbf{8}$ \\
\hline Proposed Standard 189 & 1.20 & 0.75 & 0.45 & 0.30 & 0.25 & 0.25 & 0.25 & 0.25 \\
\hline Core Performance Guide & 0.57 & 0.57 & 0.40 & $0.35^{\star}$ & 0.35 & 0.35 & 0.35 & 0.35 \\
\hline CWI & & & & 0.35 & 0.35 & 0.35 & & \\
\hline
\end{tabular}

* In Humid 3, the Core Performance guide sets the maximum U-factor at 0.40 .

Table 6. SHGC criteria in the advanced standards or guidelines. It should be noted that the Core Performance Guide criteria shown apply to unshaded windows whereas Standard 189 requires a projection factor of at least 0.5 in addition to the SHGC specifications. Therefore, Standard 189 actually places more emphasis on solar heat gain control than the Core Performance Guide.

\begin{tabular}{|l|c|c|c|c|c|c|c|c|}
\hline \multicolumn{7}{|c|}{ Table 6: SHGC - All Windows } \\
\hline \multirow{2}{*}{ Standard } & \multicolumn{7}{|c|}{ Climate Zone } \\
\cline { 2 - 9 } & $\mathbf{1}$ & $\mathbf{2}$ & $\mathbf{3}$ & $\mathbf{4}$ & $\mathbf{5}$ & $\mathbf{6}$ & $\mathbf{7}$ & $\mathbf{8}$ \\
\hline Proposed Standard 189 & 0.25 & 0.25 & 0.25 & 0.35 & 0.35 & 0.40 & 0.45 & 0.45 \\
\hline Core Performance Guide & 0.24 & 0.24 & 0.24 & 0.24 & 0.30 & 0.30 & 0.49 & 0.49 \\
\hline CWI & & & & 0.40 & 0.40 & 0.40 & & \\
\hline
\end{tabular}

\section{Recommended Criteria for Efficient Window Performance Tiers $\mathbf{1}$ and 2}

Based on the comparison of minimum as well as advanced energy standards and guidelines, two window performance tiers are established. The first tier represents the most stringent energy performance levels found among prominent building energy standards whereas the second tier is derived from by criteria found among voluntary programs or high-performance standards or guidelines.

The suggested criteria for Tier 1 are shown in Table 7. For the most part, these match the prescriptive requirements of ASHRAE Standard 90.1-2007, which are the most stringent requirements expected to be adopted among a larger number of states in the near future. Windows meeting these criteria should currently qualify under the requirements of building energy codes in most states as long as window areas do not exceed 40 percent of gross wall area.

\begin{tabular}{|l|c|c|c|c|c|c|c|c|}
\hline \multicolumn{10}{|c|}{ Table 7: Suggestions for Tier 1 Criteria } \\
\cline { 2 - 9 } Metric & $\mathbf{1}$ & $\mathbf{2}$ & $\mathbf{3}$ & $\mathbf{4}$ & $\mathbf{5}$ & $\mathbf{6}$ & $\mathbf{7}$ & $\mathbf{8}$ \\
\hline U-factor (metal frame) & 1.20 & 0.75 & 0.55 & 0.55 & 0.55 & 0.55 & 0.45 & 0.45 \\
\hline U-factor (nonmetal frame) & 1.20 & 0.75 & 0.55 & 0.40 & 0.35 & 0.35 & 0.35 & 0.35 \\
\hline SHGC & 0.25 & 0.25 & 0.25 & 0.40 & 0.40 & 0.40 & 0.45 & 0.45 \\
\hline
\end{tabular}

The suggested Tier 2 criteria are decidedly more stringent than the prescriptive requirements of any of the prevailing energy codes. Table 8 shows the recommendations for Tier 2 criteria, partly derived from the most stringent criteria found among advanced and voluntary standards and guidelines (see Section 6). 
Generally, the aim is for criteria to closely match the most stringent criteria found in Section 6 as advanced but realistic goals. These matches are highlighted in Table 8. In the other cases, there are slightly different criteria for the reasons explained below.

\begin{tabular}{|l|c|c|c|c|c|c|c|c|}
\hline \multirow{2}{*}{ Table 8: Suggestions for Tier 2 Criteria } \\
\hline \multirow{2}{*}{ Metric } & \multicolumn{7}{c|}{ Climate Zone (see appendix A) } \\
\cline { 2 - 11 } & $\mathbf{1}$ & $\mathbf{2}$ & $\mathbf{3}$ & $\mathbf{4}$ & $\mathbf{5}$ & $\mathbf{6}$ & $\mathbf{7}$ & $\mathbf{8}$ \\
\hline U-factor (metal frame) & 1.20 & 0.75 & 0.50 & 0.42 & 0.42 & 0.42 & 0.35 & 0.35 \\
\hline U-factor (nonmetal frame) & 0.95 & 0.55 & 0.40 & 0.30 & 0.30 & 0.30 & 0.25 & 0.25 \\
\hline SHGC & 0.25 & 0.25 & 0.25 & 0.30 & 0.30 & 0.30 & 0.45 & 0.45 \\
\hline VT (daylight glazing only) & $0.30+$ & $0.30+$ & $0.30+$ & $0.35+$ & $0.35+$ & $0.35+$ & $0.35+$ & $0.35+$ \\
\hline
\end{tabular}

The rationale for the criteria in Table 8 that do not match with the most stringent criteria in Section 6 is as follows:

- Climate Zone 1: Although the Core Performance Guide calls for a U-factor of 0.57 or less in this climate, due to the negligible role of the U-factor criteria were chosen that do not preclude the use of monolithic glazing. A $1.20 \mathrm{U}$-factor for metal-framed windows and a $0.95 \mathrm{U}$-factor for nonmetal-framed windows are the default values given in the 2006 IECC.

- Climate Zone 2: Instead of the 0.57 U-factor criterion in the Core Performance Guide, a 0.75 Ufactor criterion as in the proposed Standard 189 was chosen. Solar heat gain control is paramount in this climate, so that a $0.75 \mathrm{U}$-factor criterion that does not necessitate the use of thermal breaks may be warranted. This allows for flexibility in regions where structural strength has priority and condensation is of no concern.

- Climate Zone 4: Although the SHGC criterion for climate zone 4 is 0.24 in the Core Performance Guide, a 0.30 criterion was chosen that matches with the criteria in Zones 5 and 6. The 0.30 SHGC criterion makes it easier to meet the minimum visible transmittance of 0.40 for Zones 4-6 (see below).

- Climate Zones 5 and 6: For nonmetal-framed windows in these climate zones, the proposed Standard 189 requires a $0.25 \mathrm{U}$-factor whereas the Core Performance Guide and CWI criterion is a $0.35 \mathrm{U}$-factor. A $0.30 \mathrm{U}$-factor was chosen so as to provide a criterion that goes beyond Tier 1 (0.35) but can be met with double-pane windows. The $0.42 \mathrm{U}$-factor requirement for metalframed windows can be achieved without the use of triple-glazing, and the same option should be given to nonmetal-framed windows. A $0.25 \mathrm{U}$-factor can typically only be achieved with triple glazing.

To illustrate the possible window choices under the suggested criteria for Tiers 1 and 2, Appendix B provides examples of generic window types that can meet these criteria.

\section{Visible Light Transmission}

Due to the potential to reduce electric lighting needs through daylighting, adequate levels of visible light transmission are recommended for advanced commercial fenestration. Adequate levels of light transmission are best determined on a building-specific basis, but for ease of use, a simple climatespecific criteria for minimum visible light transmission (VLT or VT) was set. The criteria are inspired by the following provisions in advanced guidelines and standards: 
- The Advanced Energy Design Guide for Small Office Buildings recommends a VT of at least 0.35 for vertical fenestration. The criteria follow this recommendation except in Climate Zones 1-3, where the need for a low SHGC may justify the use of less transparent glazing.

- The proposed Standard 189 requires that the product of the VT of vertical fenestration and its area as a percentage the gross wall area is at least 0.10 in Climate Zones 1-3 and 0.15 in Climate Zones 4-8. Assuming a window-to-wall ratio of 0.40 , the minimum VT would be 0.25 in Zones 1 3 and 0.38 in Zones 4-8. A slightly higher minimum VT criteria was chosen for Climate Zones 13 , given that typical window areas are less than 40 percent of the gross wall area. In Climate Zones $4-8$, however, the minimum VT was not set above 0.35 , as this would disqualify many otherwise very desirable triple-pane options.

- For daylight glazing, the Core Performance Guide specifies a VT of at least 150 percent of the fenestration's SHGC. The suggested VT criteria ensure that windows generally have a higher VT than SHGC. 


\section{Appendix A: Climate Zone Map}

The map below shows the climate zones used in the standards and guidelines referenced in this paper: the 2006 International Energy Conservation Code, ASHRAE Standards 90.1-2004 and 90.1-2007, the proposed ASHRAE Standard 189, and the Core Performance Guide.

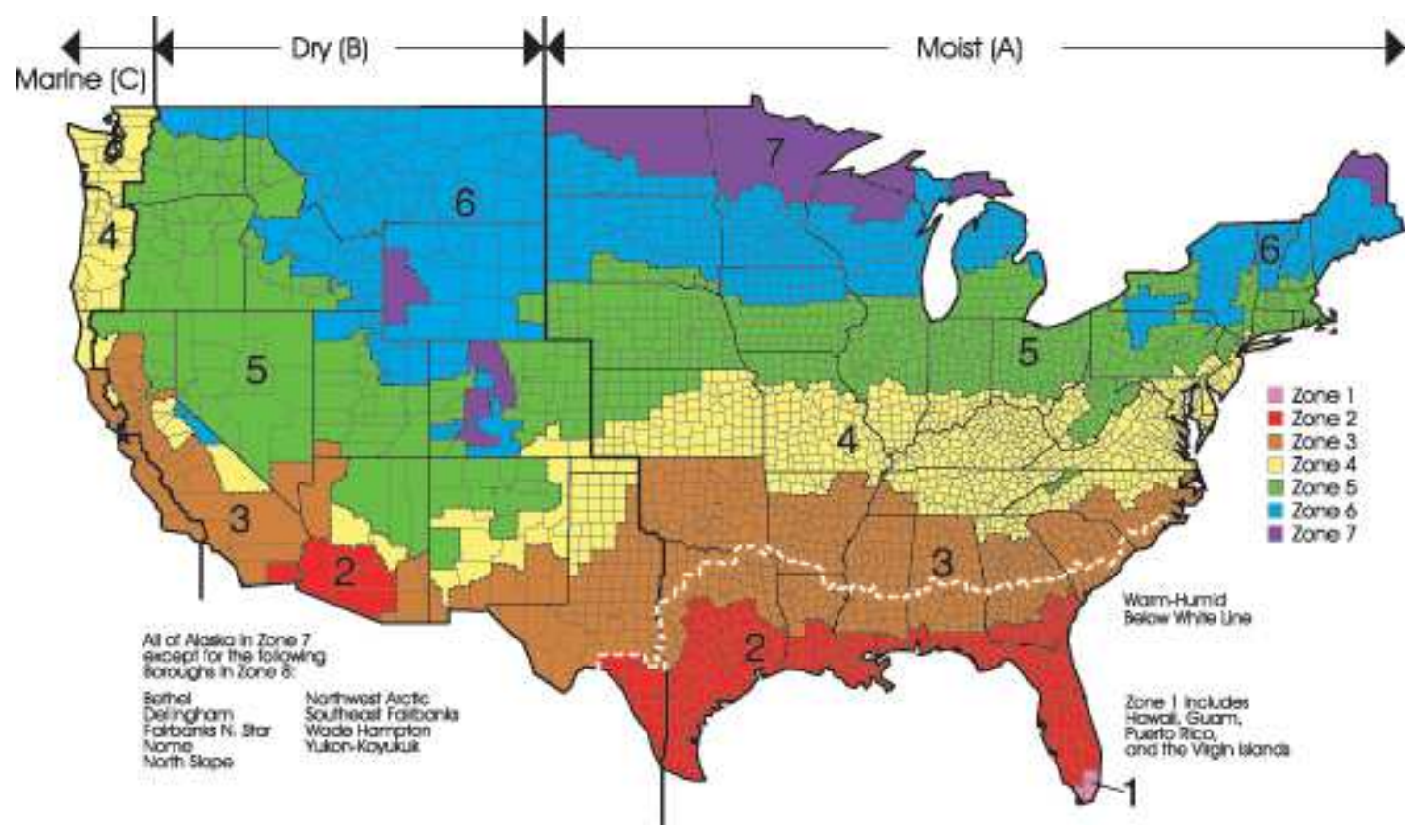




\section{Appendix B: Examples of Window Types Meeting Performance Tiers}

\begin{tabular}{|c|c|c|c|c|c|c|}
\hline Climate & Tier $1 \mathrm{Cr}$ & & Example Window Type & Tier 2 Cr & & Example Window Type \\
\hline 1 & $\begin{array}{l}\text { U-factor: } \\
\text { SHGC: }\end{array}$ & $\begin{array}{l}1.20 \\
0.25\end{array}$ & $\begin{array}{l}\text { Aluminum } \\
\text { Single glazing, reflective coating }\end{array}$ & $\begin{array}{l}\text { U-factor: } \\
\text { SHGC: } \\
\text { VT: }\end{array}$ & $\begin{array}{l}1.20 \\
0.25 \\
0.30_{+}\end{array}$ & $\begin{array}{l}\text { Aluminum } \\
\text { Double glazing, low-transparency } \\
\text { low-E }\end{array}$ \\
\hline 2 & $\begin{array}{l}\text { U-factor: } \\
\text { SHGC: }\end{array}$ & $\begin{array}{l}0.75 \\
0.25\end{array}$ & $\begin{array}{l}\text { Aluminum } \\
\text { Double glazing, reflective coating }\end{array}$ & $\begin{array}{l}\text { U-factor: } \\
\text { SHGC: } \\
\text { VT: }\end{array}$ & $\begin{array}{l}0.75 \\
0.25 \\
0.30+\end{array}$ & $\begin{array}{l}\text { Aluminum } \\
\text { Double glazing, low-transparency } \\
\text { low-E }\end{array}$ \\
\hline 3 & $\begin{array}{l}\text { U-factor: } \\
\text { SHGC: }\end{array}$ & $\begin{array}{l}0.55 \\
0.25\end{array}$ & $\begin{array}{l}\text { Aluminum } w / \text { thermal break } \\
\text { Double glazing, reflective coating }\end{array}$ & $\begin{array}{l}\text { U-factor: } \\
\text { SHGC: } \\
\text { VT: }\end{array}$ & $\begin{array}{l}0.50 \\
0.25 \\
0.30+\end{array}$ & $\begin{array}{l}\text { Aluminum } w / \text { thermal break } \\
\text { Double glazing, triple silver low-E }\end{array}$ \\
\hline 4-6 & $\begin{array}{l}\text { U-factor: } \\
\text { SHGC: }\end{array}$ & $\begin{array}{l}0.55 \\
0.40\end{array}$ & $\begin{array}{l}\text { Aluminum w/ thermal break } \\
\text { Double glazing, spectrally } \\
\text { selective low-E }\end{array}$ & $\begin{array}{l}\text { U-factor: } \\
\text { SHGC: } \\
\text { VT: }\end{array}$ & $\begin{array}{l}0.42 \\
0.35 \\
0.35+\end{array}$ & $\begin{array}{l}\text { Aluminum w/ thermal break } \\
\text { Double glazing, spectrally } \\
\text { selective low-E, gas fill }\end{array}$ \\
\hline $7-8$ & $\begin{array}{l}\text { U-factor: } \\
\text { SHGC: }\end{array}$ & $\begin{array}{l}0.45 \\
0.45\end{array}$ & $\begin{array}{l}\text { Aluminum w/ thermal break } \\
\text { Double glazing, spectrally } \\
\text { selective low-E, gas fill }\end{array}$ & $\begin{array}{l}\text { U-factor: } \\
\text { SHGC: } \\
\text { VT: }\end{array}$ & $\begin{array}{l}0.35 \\
0.45 \\
0.35+\end{array}$ & $\begin{array}{l}\text { Aluminum } w / \text { thermal break } \\
\text { Triple glazing, spectrally selective } \\
\text { low-E, gas fill }\end{array}$ \\
\hline
\end{tabular}

\begin{tabular}{|c|c|c|c|c|c|c|}
\hline $\begin{array}{l}\text { Climate } \\
\text { Zone }\end{array}$ & Tier $1 \mathrm{Cr}$ & & Example Window Type & Tier 2 Cri & & Example Window Type \\
\hline 1 & $\begin{array}{l}\text { U-factor: } \\
\text { SHGC: }\end{array}$ & $\begin{array}{l}1.20 \\
0.25\end{array}$ & $\begin{array}{l}\text { Nonmetal frame } \\
\text { Single glazing, reflective coating }\end{array}$ & $\begin{array}{l}\text { U-factor: } \\
\text { SHGC: } \\
\text { VT: }\end{array}$ & $\begin{array}{l}0.95 \\
0.25 \\
0.30+\end{array}$ & $\begin{array}{l}\text { Nonmetal frame } \\
\text { Double glazing, triple silver low-E }\end{array}$ \\
\hline 2 & $\begin{array}{l}\text { U-factor: } \\
\text { SHGC: }\end{array}$ & $\begin{array}{l}0.75 \\
0.25\end{array}$ & $\begin{array}{l}\text { Nonmetal frame } \\
\text { Double glazing, reflective coating }\end{array}$ & $\begin{array}{l}\text { U-factor: } \\
\text { SHGC: } \\
\text { VT: }\end{array}$ & $\begin{array}{l}0.55 \\
0.25 \\
0.30+\end{array}$ & $\begin{array}{l}\text { Nonmetal frame } \\
\text { Double glazing, triple silver low-E }\end{array}$ \\
\hline 3 & $\begin{array}{l}\text { U-factor: } \\
\text { SHGC: }\end{array}$ & $\begin{array}{l}0.55 \\
0.25\end{array}$ & $\begin{array}{l}\text { Nonmetal frame } \\
\text { Double glazing, reflective coating }\end{array}$ & $\begin{array}{l}\text { U-factor: } \\
\text { SHGC: } \\
\text { VT: }\end{array}$ & $\begin{array}{l}0.40 \\
0.25 \\
0.30+\end{array}$ & $\begin{array}{l}\text { Nonmetal frame } \\
\text { Double glazing, triple silver low-E }\end{array}$ \\
\hline 4-6 & $\begin{array}{l}\text { U-factor: } \\
\text { SHGC: }\end{array}$ & $\begin{array}{l}0.35 \\
0.40\end{array}$ & $\begin{array}{l}\text { Nonmetal frame } \\
\text { Double glazing, spectrally } \\
\text { selective low-E }\end{array}$ & $\begin{array}{l}\text { U-factor: } \\
\text { SHGC: } \\
\text { VT: }\end{array}$ & $\begin{array}{l}0.30 \\
0.35 \\
0.35+\end{array}$ & $\begin{array}{l}\text { Nonmetal frame } \\
\text { Double glazing, spectrally } \\
\text { selective low-E, gas fill }\end{array}$ \\
\hline $7-8$ & $\begin{array}{l}\text { U-factor: } \\
\text { SHGC: }\end{array}$ & $\begin{array}{l}0.35 \\
0.45\end{array}$ & $\begin{array}{l}\text { Nonmetal frame } \\
\text { Double glazing, spectrally } \\
\text { selective low-E }\end{array}$ & $\begin{array}{l}\text { U-factor: } \\
\text { SHGC: } \\
\text { VT: }\end{array}$ & $\begin{array}{l}0.25 \\
0.45 \\
0.35+\end{array}$ & $\begin{array}{l}\text { Nonmetal frame } \\
\text { Triple glazing, spectrally selective } \\
\text { low-E, gas fill }\end{array}$ \\
\hline
\end{tabular}

Table B3 shows the performance values assumed to be typical for the window type examples in Tables B1 and B2. These assumptions are based on center of glass and frame performance values found in Carmody et al. Low-E glazing in thermally broken aluminum or nonmetal frames is assumed to have low-conductance spacers.

\begin{tabular}{|c|c|c|c|c|c|c|c|}
\hline & Assumed typ & rmanc & so & ple w & pes & & \\
\hline \multirow{2}{*}{ Frame Type } & \multirow{2}{*}{ Glazing Type } & \multicolumn{2}{|c|}{ U-Factor } & \multicolumn{2}{|c|}{ SHGC } & \multicolumn{2}{|c|}{ VT } \\
\hline & & Overall* & COG & Overall* & COG & Overall* & COG \\
\hline \multirow{3}{*}{ Aluminum } & Single, reflective coating & 1.13 & 0.93 & 0.23 & 0.21 & 0.11 & 0.15 \\
\hline & Double, reflective coating & 0.72 & 0.40 & 0.20 & 0.17 & 0.10 & 0.13 \\
\hline & Double, low-transparency low-E & 0.60 & 0.28 & 0.25 & 0.24 & 0.30 & 0.37 \\
\hline \multirow{5}{*}{$\begin{array}{l}\text { Aluminum, } \\
\text { thermal break }\end{array}$} & Double, reflective coating & 0.54 & 0.40 & 0.17 & 0.17 & 0.10 & 0.13 \\
\hline & Double, triple silver low-E & 0.41 & 0.24 & 0.23 & 0.27 & 0.51 & 0.64 \\
\hline & Double, spectrally selective low-E & 0.44 & 0.29 & 0.34 & 0.38 & 0.57 & 0.71 \\
\hline & Double, selective low-E, gas fill & 0.42 & 0.26 & 0.34 & 0.38 & 0.57 & 0.71 \\
\hline & Triple, selective low-E, gas fill & 0.32 & 0.15 & 0.24 & 0.26 & 0.37 & 0.46 \\
\hline \multirow{4}{*}{ Nonmetal } & Double, reflective coating & 0.40 & 0.40 & 0.15 & 0.17 & 0.10 & 0.13 \\
\hline & Double, triple silver low-E & 0.29 & 0.24 & 0.22 & 0.27 & 0.51 & 0.64 \\
\hline & Double, selective low-E, gas fill & 0.30 & 0.26 & 0.31 & 0.38 & 0.57 & 0.71 \\
\hline & Triple, selective low-E, gas fill & 0.22 & 0.15 & 0.22 & 0.26 & 0.37 & 0.46 \\
\hline
\end{tabular}




\section{References}

ASHRAE. "Energy Standard for Buildings Except Low-Rise Residential Buildings."

ANSI/ASHRAE/IESNA Standard 90.1-2007. Atlanta: American Society of Heating, Refrigerating and Air-Conditioning Engineers, 2007.

. "Proposed Standard 189, Standard for the Design of High-Performance Green Buildings Except Low-Rise Residential Buildings.” BSR/ASHRAE/USGBC/IESNA Standard 189P. Atlanta: American Society of Heating, Refrigerating and Air-Conditioning Engineers, 2007.

Advanced Energy Design Guide for Small Office Buildings: 2004, ASHRAE, AIA, IESNA, USGBC, DOE.

Carmody J., S. Selkowitz, E. S. Lee, D. Arasteh, T. Willmert. Window Systems for High Performance Buildings. Norton, 2004.

Commercial Windows Initiative. Designers Guide for Energy Efficient Commercial Windows. CWI, 2005.

Core Performance Guide: 2007, New Buildings Institute.

IECC. International Energy Conservation Code. International Code Council, 2006.

\section{Acknowledgement and Disclaimer}

Acknowledgment: This paper is based upon work supported by the Department of Energy, National Energy Technology Laboratory under Award Number DE-FC26-06NT42766.

Disclaimer: This publication was prepared as an account of work sponsored by an agency of the United States Government. Neither the United States Government nor any agency thereof, nor any of their employees, makes any warranty, express or implied, or assumes any legal liability or responsibility for the accuracy, completeness, or usefulness of any information, apparatus, product, or process disclosed, or represents that its use would not infringe privately owned rights. Reference herein to any specific commercial product, process, or service by trade name, trademark, manufacturer, or otherwise does not necessarily constitute or imply its endorsement, recommendation, or favoring by the United States Government or any agency thereof. The views and opinions of authors expressed herein do not necessarily state or reflect those of the United States Government or any agency thereof.

The Efficient Windows Collaborative - A Project by the Alliance to Save Energy 


\section{Appendix F - Utility Program Listings, Analyses and Recommendations}

F-1 "Potential Energy Savings from Replacing pre-1990 Windows in Connecticut Homes"

F-2 “Estimates of Potential Energy Savings with High Performance Windows”, report by the Alliance to Save Energy for the Consortium for Energy Efficiency

F-3 Windows section in the March 2010 draft of the Consortium for Energy Efficiency Existing Homes Program Guide

F-4 “Outreach Plan for Gas Utility Window Efficiency Programs”, May 2008

F-5 “Commercial Windows Utility Provider Promotional Inventory”, July 2008

F-6 "Incremental Cost Estimates for Higher Window Performance Tiers for Minneapolis and Denver Office Buildings”, July 2008 


\section{Potential Energy Savings from Replacing pre-1990 Windows in Connecticut Homes}

\section{Estimated by the Alliance to Save Energy}

This white paper summarizes estimates of average energy savings that can be achieved from replacing windows installed in Connecticut homes prior to 1990 with ENERGY $\operatorname{STAR}^{\circledR}$ qualified windows.

\section{The Simulation Tool}

The impact of windows on residential heating and cooling energy consumption can be simulated with RESFEN, a computer program developed by Lawrence Berkeley National Laboratory (windows.lbl.gov/software/resfen). RESFEN assumes a number of given parameters for a house (e.g. structural and internal mass, thermostat settings, duct losses), it allows the user to configure variables such as home size, window area and orientation, and window performance.

The average existing U.S. home typically assumed by the Efficient Windows Collaborative is a 2000 sq. $\mathrm{ft}$. house with $300 \mathrm{sq} \mathrm{ft}$ of window area (15\% of floor area). The windows are equally distributed on all four sides of the house and include typical shading (interior shades, overhangs, trees, and neighboring buildings). The mechanical system consists of a furnace (fueled by heating oil in the CT case) and central air conditioning. For more detailed information about the given and selected house characteristics, see Appendix A.

\section{Window Energy Performance Parameters}

The energy performance parameters affected by window replacement are the windows' insulation value (U-factor), solar heat gain coefficient (SHGC), and air leakage (AL). For our simulations, we need to make assumptions about the U-factor, SHGC and AL of existing windows installed prior to 1990 as well as of the ENERGY STAR windows to be installed in their stead.

\section{The Assumed Average Performance of ENERGY STAR ${ }^{\circledR}$ Windows}

The performance of ENERGY STAR qualified replacement windows can be approximated in a relatively straightforward fashion. To qualify under the present ENERGY STAR specifications for the Connecticut climate, a window must have a Ufactor of no higher than 0.35 . This specification is under revision and might become more stringent in 2009. The new U-factor specification has not yet been defined, but preliminary parameters have been published by the U.S. Department of Energy ${ }^{1}$, suggesting a U-factor limit of between 0.30 and 0.33 for the CT climate. For the purpose of our simulations, we are assuming a U-factor of 0.32 for ENERGY STAR windows, since this U-factor is already common among present ENERGY STAR windows and has a good chance of meeting the upcoming criteria.

\footnotetext{
${ }^{1}$ http://www.dwmmag.com/articles/documents/2ndCriteriaRevisionAnnouncement.pdf
} 
In the CT climate, any SHGC qualifies under the ENERGY STAR criteria. Depending on what kind of low-E coating is used for the glazing, the SHGC of ENERGY STAR windows typically varies between 0.20 and 0.55 . Yet most window manufacturers design windows with a SHGC of no higher than 0.40 as this is is the a qualification criterion for ENERGY STAR windows in southern climates. Therefore, we are assuming a SHGC of 0.40 for our simulations.

The air leakage rating (AL) of replacement windows must not exceed 0.30 according to the International Energy Conservation Code. Modern sliding windows (such as doubleor single-hung windows) typically have an AL of about 0.20 , whereas the AL of projecting windows (casement, awning, or hopper) tends to be below 0.10 . We are assuming an AL of 0.20 for ENERGY STAR windows in our simulations.

To sum up, the energy parameters assumed for ENERGY STAR windows in our simulations are:

$\begin{array}{ll}\text { U-factor: } & 0.32 \\ \text { SHGC: } & 0.40 \\ \text { AL: } & 0.20\end{array}$

\section{The Assumed Average Performance of Existing Windows in Connecticut Homes}

Since the energy performance of existing windows in Connecticut homes varies greatly from case to case, we can only make very general assumptions about the average performance of the window stock.

As a starting point it is assumed that the windows to be replaced have been installed prior to 1990. The estimated average U-factor and SHGC of pre-1990 windows can be found in a 2006 study by Joshua Apte and Darius Arasteh of Lawrence Berkeley National Laboratory, ${ }^{2}$ based on a previous study by Huang et al. ${ }^{3}$ This study shows the estimated energy properties of windows in single-family homes in the New England census region in 1991. Homes with a pre-1990 vintage are estimated to have windows with a U-factor of 0.55-0.72 and an SHGC of 0.67-0.72. Since these values do not yet take into effect the absorbing effect of dirt and dust that tends to be found on older windows and storm windows, we assume that the lower end of the SHGC range (0.67) is more representative. These performance values can be assumed to be representative of older combinations of wood-framed single-pane windows with storm windows or of older double-pane windows without storm windows. Although many of these windows would have been replaced since 1991, a large share of this older window stock still exists in Connecticut homes.

The air leakage through older windows is a significant contributor to heating and cooling loads. The ASHRAE Handbook of Fundamentals states that an estimated 15 percent of

\footnotetext{
${ }^{2}$ Apte, J., Dariush A. 2006. Window-Related Energy Consumption in the US Residential and Commercial Building Stock. Lawrence Berkeley National Laboratory. http://gaia.lbl.gov/btech/papers/60146.pdf.

${ }^{3}$ Huang, J., Hanford, J., et al. 1999. Residential Heating and Cooling Loads Component Analysis.

Lawrence Berkeley National Laboratory.
} 
infiltration in homes on average can be contributed to windows. ${ }^{4}$ Based on this estimate and on Huang et al.'s estimates of the heating load impact of infiltration, window solar gain and conduction, we can estimate that air leakage contributes between 17 and 32 percent to the overall net-heat loss through pre 1990 windows in New England homes. Assuming, as noted above, windows with a U-factor of 0.55-0.72 and an SHGC of 0.67, we used RESFEN to determine what AL these windows would have to have so that 17-32 percent of their net-heating impact on a typical home would be due to air leakage. The result was an AL of 0.8 to 1.1. While this rate of air leakage may seem high compared to the code-prescribed AL of 0.30 for new windows, it should be noted that this is an estimate of average air leakage through older existing windows, which include windows that lack weatherstripping and sashes that do not shut tight due to the long-term contraction or expansion of frame components.

To sum up, in our simulations the following ranges are assumed for the energy parameters of average pre-1990 windows:

$\begin{array}{ll}\text { U-factor: } & 0.55-0.72 \\ \text { SHGC: } & 0.67 \\ \text { AL: } & 0.8-1.1\end{array}$

\section{Simulated Building Types}

RESFEN allows for limited variations in the simulated building types. For the purpose of our simulations, we are looking at 2-story, wood-framed houses with basement, a common building type for single-family houses in Connecticut. The average floor space of houses with pre-1990 windows is assumed to be 1,875, which was stated as the average size of U.S. homes in 1993. ${ }^{5}$ Assuming an average window-to-floor ratio of 14 percent, we used a total window area of $264 \mathrm{ft}^{2}$ for these houses, which represents 22 windows of $12 \mathrm{ft}^{2}$ each.

Heating oil is the most common heating fuel in New England homes. The heating system assumed in RESFEN is a natural gas furnace with an annual fuel utilization efficiency (AFUE) of 78 percent, but we assumed the use of heating oil in furnaces of the same efficiency.

For older existing buildings in the Connecticut climate, RESFEN assumes R-22 Ceiling insulation, R-7 wall insulation, and no floor or basement insulation.

\section{Simulation Results}

The results shown are RESFEN-simulated annual energy use estimates for the whole house.

\section{House type: 2-story, wood-framed, basement}

Existing windows (U-factor 0.55-0.72, SHGC 0.67, AL 0.8-1.1)

o Heating energy use: 101.4-110.6 Mbtu

o Cooling energy use: $1338-1353 \mathrm{kWh}$

${ }^{4}$ ASHRAE. 2005. ASHRAE Handbook - Fundamentals. American Society of Heating, Refrigerating and Air-Conditioning Engineers.

${ }^{5}$ Energy Information Administration: http://www.eia.doe.gov/emeu/recs/sqft-measure.html 
o Peak cooling load: $\quad 4.13-4.23 \mathrm{~kW}$

ENERGY STAR windows (U-factor 0.32, SHGC 0.40, AL 0.2)

o Heating energy use: $95.3 \mathrm{Mbtu}$

o Cooling energy use: $964 \mathrm{kWh}$

o Peak cooling load: $3.40 \mathrm{~kW}$

\section{Estimated Savings}

The above-shown simulated savings from replacing existing windows with ENERGY STAR windows result within the following range:

Annual heating savings (Mbtu): $\quad 6.1-15.3$

Annual cooling savings (kWh): $\quad 374-389$

Cooling peak demand reduction $(\mathrm{kW}): \quad 0.73-0.83$

As percentages of overall heating and cooling energy use and cooling peak load, the results can be shown as follows:

Annual heating savings: $\quad 6 \%-14 \%$

Annual cooling savings: $\quad 28 \%-29 \%$

Cooling peak demand reduction: $\quad 18 \%-20 \%$

\section{Heating and Cooling Cost Savings}

o Average residential retail price per gallon of heating oil (140,000 Btu) in the heating season of 2007/08: $\$ 3.35^{6}$

0 Average residential retail price per $\mathrm{kWh}$ of electricity in the summer (JuneAugust) of 2007: $\$ 0.188^{7}$

Annual heating cost saving (2007/08 heating oil prices): 6.1 - 15.3 MBtu heating energy savings $=44-109$ therms saved $=\$ 147-\$ 365$ heating cost savings

Annual cooling cost savings (2007 electricity prices): $374-389 \mathrm{kWh}$ savings $=\$ 70-\$ 73$ cooling cost savings

Total annual energy cost savings based on 2007/08 energy prices: \$214 - \$438

\section{Window Replacement Cost and Payback}

The cost of window installations varies greatly not only be the product type but also depending on the manufacturer, vendor, and installer.

The Reed Construction Data publication RS Means (2005 version) estimates the total installed cost of a 37" x 49" (12 ft $\left.{ }^{2}\right)$ vinyl window with low-E coating to be $\$ 224$ in Hartford, CT. ${ }^{8}$ This price is for new construction, which is not directly comparable to the price for the installation of replacement windows. Lawrence Berkeley National Laboratory (LBNL), on the other hand, has a Home Energy Saver tool (http://hes3.lbl.gov/hes), which states the typical price for a $12 \mathrm{ft}^{2}$ ENERGY STAR

\footnotetext{
${ }^{6}$ Energy Information Administration, “Weekly Residential Heating Oil Prices by Region and State: http://tonto.eia.doe.gov/oog/info/hopu/hopu.asp.

${ }^{7}$ Energy Information Administration: http://www.eia.doe.gov/cneaf/electricity/page/sales_revenue.xls

8 RS Means. 2005. Residential Cost Data. Reed Construction Data. P. 433.
} 
window with argon gas fill, wood or vinyl frame and low-E coating as \$262 to \$786, including the labor cost for window replacement.

Based on LBNL's cost estimates for installed ENERGY STAR replacement windows, we can assume a rough cost range of $\$ 6,000$ to $\$ 17,000$ for the 22 windows in the typical Connecticut home used for our simulations. With a simulated annual energy savings of $\$ 214$ to \$438 - based on today’s energy prices - this cost would be recouped in 14 to 79 years. The higher end of this range would assume that windows in a relatively good condition are replaced with windows on the high end of the price range due to their appearance, durability, or other for other regions. The lower end - around 15-30 years would mean that windows in poor conditions are replaced with more affordable ENERGY STAR windows.

\section{Payback from Replacing Single Pane Windows without Functioning Storm Windows}

Although most Connecticut homes with single-pane windows are expected to have storm windows, older storm windows often fail to provide any benefits. They might break, jam, or otherwise malfunction so that no additional insulating benefit is provided to the prime windows. Homes with single-pane windows and without functioning storm windows are simulated to have the following energy consumption:

\section{House type: 2-story, wood-framed, basement}

Existing windows (U-factor 0.95, SHGC 0.72, AL 1.1) ${ }^{9}$

o Heating energy use: $118.9 \mathrm{Mbtu}$

o Cooling energy use: $1397 \mathrm{kWh}$

o Peak cooling load: $4.42 \mathrm{~kW}$

Based on the simulation results in section 6, the estimated savings from installing ENERGY STAR windows in these homes are as follows:

Annual heating savings (Mbtu): $\quad 23.6$

Annual cooling savings (kWh): 433

Cooling peak demand reduction $(\mathrm{kW})$ : $\quad 1.02$

Annual heating cost saving (2007/08 heating oil prices): 23.6 MBtu heating energy savings $=169$ gallons saved $=\$ 566$ heating cost savings

Annual cooling cost savings (2007 electricity prices): $433 \mathrm{kWh}$ savings $=\$ 81$ cooling cost savings

Total annual energy cost savings based on 2007/08 energy prices: \$647

Assuming a $\$ 6,000$ to $\$ 17,000$ cost for replacing the existing windows with ENERGY STAR windows, the simple payback period would be 9 to 26 years.

\footnotetext{
${ }^{9}$ The default U-factor for nonmetal-framed single-pane windows according to the International Energy Conservation Code is 0.95 . The default SHGC is 0.80 . For this estimate, we assume the SHGC to be 10 percent lower due to the obstruction from non-functioning storm windows.
} 


\section{Estimates of Potential Energy Savings with High Performance Windows}

With input from Lawrence Berkeley National Laboratory and the Consortium for Energy Efficiency, the Alliance to Save Energy conducted simulations to estimate the energy savings potential and economics of specifying high-performance windows for new homes and window replacement. The simulation tool used was RESFEN 5.0, a program based on DOE-2.1E and developed by LBNL for modeling the thermal performance of homes based on window choices. ${ }^{1}$ The results of these simulations and the assumptions used are summarized below.

\section{Purpose}

The primary purpose of our estimates is to determine whether deeper energy savings beyond those achieved through the market penetration of ENERGY STAR ${ }^{\circledR}$ windows are viable. We are mainly looking at the potential of highly-insulating windows that significantly exceed the performance of typical ENERGY STAR Windows in cold and mixed climates. To date, the potential of these windows has remained largely untapped, primarily because of higher retail cost, resulting from higher manufacturing cost and lacking economies of scale.

Highly-insulating windows provide superior energy performance due to advanced frames combined with three glass panes or a heat-reflecting film between two panes of glass. These windows surpass dual-pane windows in energy savings, peak demand reduction and enhanced comfort. Simulated energy savings and peak demand reduction are part of our analysis.

In addition to highly-insulating windows, we looked at the cooling demand reduction potential for solar control windows in cooling climates.

\section{Window Types Examined}

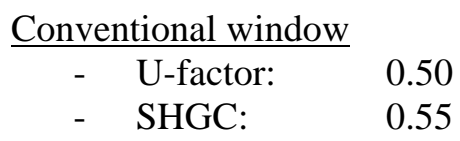

Double-pane windows without low-E coatings in vinyl, wood, or hybrid/composite frames. Although many building energy codes and incentive programs encourage the use of windows with better energy performance than conventional windows can offer, use of these windows is still relatively common due to trade-off options in building codes and lacking code enforcement.

\section{Conventional code-compliant window (South) \\ - U-factor: $\quad 0.50$ \\ - SHGC: $\quad 0.40$}

If trade-off options in codes are not used, most codes in the U.S. require in their prescriptive path that windows with better than conventional solar control are used. The U-factor requirements of windows in southern climates are rarely more stringent than 0.50 , which is less energy-efficient than the U-factor needed to qualify for ENERGY STAR. Nevertheless, southern codes widely require an SHGC of no more than 0.40 to limit cooling demand.

\footnotetext{
${ }^{1}$ RESFEN can be downloaded at http://windows.lbl.gov/software/resfen/resfen.html.
}

Acknowledgment: "This material is based upon work supported by th 1 Department of Energy, National Energy Technology Laboratory under Award Number DE-FC26-06NT42766."

Disclaimer: "This publication was prepared as an account of work sponsored by an agency of the United States Government. Neither the United States Government nor any agency thereof, nor any of their employees, makes any warranty, express or implied, or assumes any legal liability or responsibility for the accuracy, completeness, or usefulness of any information, apparatus, product, or process disclosed, or represents that its use would not infringe privately owned rights. Reference herein to any specific commercial product, process, or service by trade name, trademark, manufacturer, or otherwise does not necessarily constitute or imply its endorsement, recommendation, or favoring by the United States Government or any agency thereof. The views and opinions of authors expressed herein do not necessarily state or reflect those of the United States Government or any agency thereof." 


\section{Efficient Windows Collaborative}

December 2007

Typical Energy Star window

- U-factor: $\quad 0.35$

- SHGC: $\quad 0.50$ (high solar gain), 0.30 (low solar gain)

In our analysis, we define a typical ENERGY STAR window as a window that meets the ENERGY STAR Ufactor criterion for the Northern climate zone (0.35). Such windows typically include low-E coatings, gas fills, and low-conductance spacers. In the North, ENERGY STAR windows can either have high-solar-gain, lowsolar-gain, or low-E coatings. The type of low-E coating used can alter the SHGC dramatically. In the South, only windows with a low SHGC qualify for ENERGY STAR.

The prescriptive requirements of most northern energy codes specify windows with a U-factor of 0.35 or less. Therefore we did not include a separate category for common code-compliant windows in the North, as this would be equivalent to ENRGY STAR windows. However, due to trade-off options in codes and imperfect code compliance, conventional windows still hold substantial market share in many northern states.

Solar control low-E window

- U-factor: 0.35

- SHGC: $\quad 0.25$

These windows are similar in performance to typical low-E windows, but have advanced low-E coatings that provide maximum control of solar radiation while still transmitting most visible light.

Moderate cost highly-insulating window

- U-factor: $\quad 0.25$

- $\quad$ SHGC: $\quad 0.40$ (high solar gain), 0.25 (low solar gain)

Window U-factor can be reduced to 0.25 or below through glazing upgrades (additional glazing layers and/or krypton gas fills) without expensive upgrades of the frame. Depending on the choice of low-E coatings, highly-insulating windows can be designed for high or low solar gain.

Best-case highly-insulating window

- U-factor: $\quad 0.20$

- $\quad$ SHGC: $\quad 0.40$ (high solar gain), 0.25 (low solar gain)

Windows with optimized glazing, spacer, and frame performance are available with U-factors below 0.20. Depending on the choice of low-E coatings, highly-insulating windows can be designed for high or low solar gain.

Future highly-insulating window

- U-factor: $\quad 0.17$

- $\quad$ SHGC: $\quad 0.40$ (high solar gain), 0.25 (low solar gain)

In its 2007-12 multi-year plan for window research and development, U.S. DOE states the goal of developing and deploying cost-competitive windows with a 0.17 U-factor by 2010. Such performance increases and cost effectiveness can be achieved either through new lower cost window technologies, such as currently researched by LBNL, or through economies of scale for current best-performing technologies. 


\section{Efficient Windows Collaborative}

December 2007

\section{Selected Analysis Results}

The energy-saving technologies used in typical ENERGY STAR windows have found wide acceptance as cost-effective energy-efficiency features. Highly-insulating windows with additional glazing layers, on the other hand, can be substantially more expensive. Therefore it is not surprising that we found the costeffectiveness of currently available highly-insulating windows to be low when compared to typical ENERGY STAR windows (see Figure 1 in the appendix). However, this finding does not account for the ancillary benefits of highly-insulating windows: reduced heating and cooling peak demand and opportunities for HVAC system downsizing.

If conventional windows instead of ENERGY STAR windows are used as the baseline for comparison, the cost-effectiveness of highly-insulating windows is more significant. However, it is important to note the differences between highly-insulating windows that allow high solar gain (Figures 2 through 5) and those made for low solar gain (Figure 6 and 7), since solar heat gain improves overall annual energy savings in heating dominated climates.

High-solar-gain windows save more energy in the heating-dominated North and are thus more cost effective. However, low-solar-gain windows provide much higher cooling peak load reduction (Figures 8 and 9).

In addition to the energy and peak demand saving benefits that we estimated through simulation, there are other benefits of high-performance windows that are harder to simulate but that could lead to further substantial energy and cost savings:

- If integrated in a well-insulated building envelope, highly-insulating windows make the consideration of alternative duct designs possible. For instance, traditional perimeter heating, which is used to offset discomfort from cold window surfaces, is not necessary for a highly-insulated envelope. By avoiding perimeter heating and reducing duct runs, energy loss from duct leakage as well as first cost for duct installation can be reduced. ${ }^{2}$

- High-performance windows improve the comfort of building occupants. Studies by the Center for the Built Environment at UC Berkeley have found that occupants tend to compensate for thermal discomfort, such as from cold window surfaces or strong solar radiation, by setting their thermostat at more extreme temperatures, thus further increasing energy use. ${ }^{3}$ Our savings estimates do not take this effect into account, which leads to somewhat conservative results.

\section{Free Riders vs. Spill-over}

Although typical ENERGY STAR windows are currently more cost effective than highly-insulating windows, promotion of highly-insulating windows has the potential to create spill-over effects and lasting market transformation. While continued promotion of ENERGY STAR windows can help further increase the market share of energy-efficient windows where energy codes provide insufficient traction, financial incentives for current ENERGY STAR windows are bound to create free riders. Incentives for highly-insulating windows, on the other hand, would potentially provide a spill-over effect by promoting underutilized high-efficiency options that can become more attractive with increasing awareness and economies of scale.

\section{Incremental cost of High-Performance Windows}

It is difficult to make assumptions about the incremental cost of one window option versus another because the market is very diverse and window retailers tend to set prices depending on what customers are willing to pay. Nevertheless, a few general assumptions can be made about the incremental cost of energy-efficient windows compared to more conventional windows. Here, we concentrate on the basic window options used in our simulations:

\footnotetext{
${ }^{2}$ Building America contractor Ibacos (www.ibacos.com) can serve as a source on compact duct design.

${ }^{3}$ Huizenga et al. 2006. Window Performance for Human Thermal Comfort. University of California, Berkeley.
} 
- Conventional windows. Windows without low-E coatings, gas fills, or similar energy-efficiency features are our baseline option and thus have no incremental cost.

- Typical ENERGY STAR Windows (U-factor 0.35). These windows have low-E coatings, which, according to U.S. DOE's website, typically increase window prices by $10-15$ percent. ${ }^{4}$ Northeast Energy Efficiency Partnerships surveyed retailers about the incremental cost for their customers to purchase ENERGY STAR Windows instead of conventional double-pane windows and received answers that ranged from 5-15 percent, depending on market saturation. If $\$ 15 / \mathrm{ft}^{2}$ is assumed as the base cost, an average cost premium of $\$ 1.50 / \mathrm{ft}^{2}$ could be assumed, which matches closely with observations made by the Southwest Energy Efficiency Project. ${ }^{5}$ According to PNNL's Building Energy Codes Resource Center, low-E windows typically retail for only about $\$ 1 / \mathrm{ft}^{2}$ more than nonlow-E windows. ${ }^{6}$ Since we define typical ENERGY STAR windows as having gas fills and lowconductance spacers in addition to low-E coatings, we assume an incremental cost of $\$ 1.50 / \mathrm{ft}^{2}$.

- Moderate-cost highly-insulating windows (U-factor 0.25). Literature is sparser on the incremental cost of windows that exceed ENERGY STAR performance. In its evaluation of windows with a Ufactor of less than 0.25 , ACEEE assumes a cost increment of $\$ 5 / \mathrm{ft}^{2}$ over conventional windows. ${ }^{7}$ Based on conversations with window retailers and window manufacturers, we conclude that this assumption is too optimistic if used for retail prices. A more realistic assumption is the goal set by DOE of achieving an incremental cost of no higher than $\$ 5 / \mathrm{ft}^{2}$ for windows with a $0.2-0.25 \mathrm{U}$-factor by 2007 relative to typical windows used in new construction (which would include low-E windows). ${ }^{8}$ In conversations with manufacturers, we learned that window U-factor can be reduced to 0.25 or below through glazing upgrades (additional glazing layers and/or krypton gas fills) without modifications in the frame. This can be achieved at an incremental cost as low as $\$ 2.50 / \mathrm{ft}^{2}$ wholesale price compared to typical ENERGY STAR windows. For retail, we assume the incremental cost for a $0.25 \mathrm{U}$-factor window to be $\$ 4.5 / \mathrm{ft}^{2}$ if compared to a window with a $0.35 \mathrm{U}$-factor and $\$ 6$ per square foot if compared to a conventional window.

- Best-case highly-insulating windows (U-factor 0.20). Since windows with a U-factor of 0.25 (moderate-cost HI windows) generally have three glazing layers, improving the U-factor to 0.20 (best-case HI windows) does not require the addition of glazing layers. However, changes in the frame may be necessary to allow for optimum gap width between the glazing layers or to improve frame insulation and stability. Anecdotal price data from window manufacturers suggests that improving the U-factor to 0.20 yields a 50 percent higher incremental cost than going from U-factor 0.35 to 0.25 . For our simulations, we therefore assume that the incremental cost of best-case $\mathrm{HI}$ windows is $\$ 2.50 / \mathrm{ft}^{2}$ over moderate-cost $\mathrm{HI}$ windows and $\$ 7 / \mathrm{ft}^{2}$ over typical ENERGY STAR windows.

- Future highly-insulating windows (U-factor 0.17). In its 2007-12 multi-year plan for window research and development, U.S. DOE states the goal of achieving an incremental cost by 2010 of no more than $\$ 5 / \mathrm{ft}^{2}$ for windows with a $0.17 \mathrm{U}$-factor compared to currently common windows. For our simulations, we assume this to be the incremental cost relative to typical code-compliant windows. Such performance increases coupled with cost reduction can be achieved either through new lower

\footnotetext{
${ }^{4}$ U.S. Department of Energy. A Consumers Guide to Energy Efficiency and Renewable Energy: Low-emissivity Window Glazing and Glass. Accessed November 27, 2007. http://www.eere.energy.gov/consumer/your_home/windows_doors_skylights/index.cfm/mytopic=13430.

${ }^{5}$ Larry Kinney. 2004. Windows and Window Treatments. Southwest Energy Efficiency Project.

${ }^{6}$ Pacific Northwest National Laboratory. Low Solar Heat Gain Windows - Successful Market Transformation in Georgia and Texas. Last modified January 11, 2006. http://resourcecenter.pnl.gov/cocoon/morf/ResourceCenter/article/1298.

${ }^{7}$ Sachs, Harvey et al. 2004. Emerging Energy-Saving Technologies and Practices for the Buildings Sector as of 2004. American Council for an Energy Efficient Economy.

${ }^{8}$ U.S. Department of Energy. Multy Year Program Plan 2007-2012. Last updated January 2007. http://www.eere.energy.gov/buildings/about/pdfs/mypp_2007/mypreport_ch2.pdf.
} 


\section{Efficient Windows Collaborative}

December 2007

cost window technologies, such as currently researched by LBNL, or through economies of scale for current best-performing technologies.

In Europe, windows with a $0.17 \mathrm{U}$-factor are already becoming more common (for example, windows certified as Passive House windows), while a Swiss market study asserts that due to the maturing triple-pane window market, "the cost for triple glazing (coated and inert-gas-filled) decreases faster than the one of the already well-established double glazing and, therefore, the costs of the two glazing types can be expected to converge in the longer term". ${ }^{9}$ The same is likely to happen once the market for triple-glazed windows reaches maturity in the United States.

Presently, there are few incentives for the use of beyond-code windows in the US, so the demand for highlyinsulating windows among home-builders remains low. Therefore, most retailers of highly-insulating windows are focusing on niches in the replacement market. To change this situation and enable window manufacturers develop economies of scale for beyond-code windows, market transformation efforts are essential.

\section{Other Basic Assumptions Used in the Analysis}

Locations

Since highly-insulating windows provide the most benefits in heating-dominated climates, we mostly focused our savings estimates on locations throughout the northern part of the United States. However, to also assess the potential of windows with special solar-control low-E glass, we included two locations in coolingdominated climates in the analysis.

\section{Building types}

We simulated the performance of windows for both new construction and replacement. We simulated new construction with 2,400 $\mathrm{ft}^{2}$ floor space and $360 \mathrm{ft}^{2}$ window area and existing homes with 2,000 $\mathrm{ft}^{2}$ floor space and $300 \mathrm{ft}^{2}$ window area. For building shell performance and other parameters, the climate-specific settings of the RESFEN software were used. All homes are assumed to be heated with natural gas furnaces (AFUE 0.78) and cooled with central air conditioning (SEER 13 in new construction, SEER 10 in existing buildings).

\section{Energy prices}

Natural gas prices used for the analysis were based on ASE (Alliance to Save Energy) projections, which used EIA data of historic winter heating fuel prices and EIA projections of price developments for the winter of 2007 to project state-specific residential retail prices for natural gas used for heating. The electricity prices used in the analysis are average residential retail prices by state for the warm months (May through September) of 2006. EIA has not yet published the complete state-specific residential retail prices for the period of May-September 2007.

Cost per saved therm of natural gas

Modeled after the CEC formula to determine the levelized cost of conserved energy, we used the following formula to determine the cost per saved therm of natural gas as a result of window efficiency increases:

\section{X CRF / S}

$\mathrm{I}=$ Incremental cost for higher performing windows

$\mathrm{CRF}=$ Capital recovery factor $=r(1+r)^{n-1} /(1+r)^{n-1}$

$r=$ discount rate (we used 5\%)

$\mathrm{n}=$ planning horizon / measure lifetime: $(25 \text { years })^{10}$

$\mathrm{S}=$ annual savings in therms

\footnotetext{
${ }^{9}$ Martin Jakob and Reinhard Madlener. 2003. Exploring Experience Curves for the Building Envelope: An Investigation for Switzerland for 1970-2020. Centre for Energy Policy and Economics, Swiss Federal Institutes of Technology: p. 27.

${ }^{10} 25$ years is, for example, used by Questar Gas as the measure lifetime for window energy-efficiency measures (see http://www.psc.utah.gov/gas/05docs/05057T01/QGC\%20DSM\%20Exhibit\%201.5\%20(Audit\%20\&\%20Wx)12-506.doc).
} 


\section{APPENDIX}

Figure 1: $\quad$ Annual return on investment in higher-performing windows Base case: Code compliant / ENERGY STAR Windows

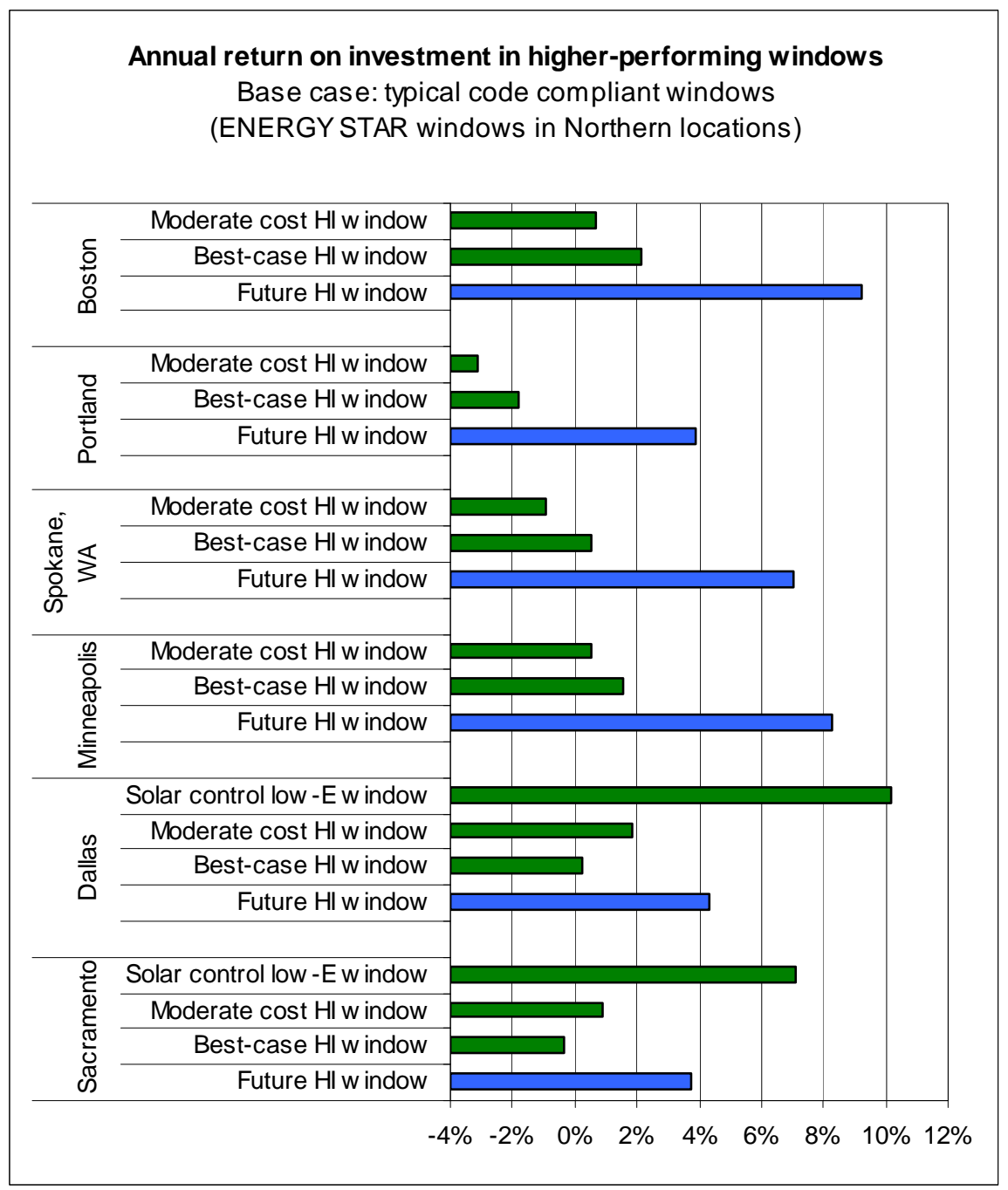

If windows meeting prescriptive energy code requirements (ENERGY STAR windows in the North) are used as the base case, the energy savings that can be achieved with current highly-insulating (HI) windows are estimated to provide only low return on their incremental cost. Only the more cost-effective highlyinsulating windows that DOE is envisaging for 2010 (highlighted in blue) would provide good return on investment in cold climates. In hot climates, good return on investment can presently be achieved with solar control low-E windows. 
APPENDIX

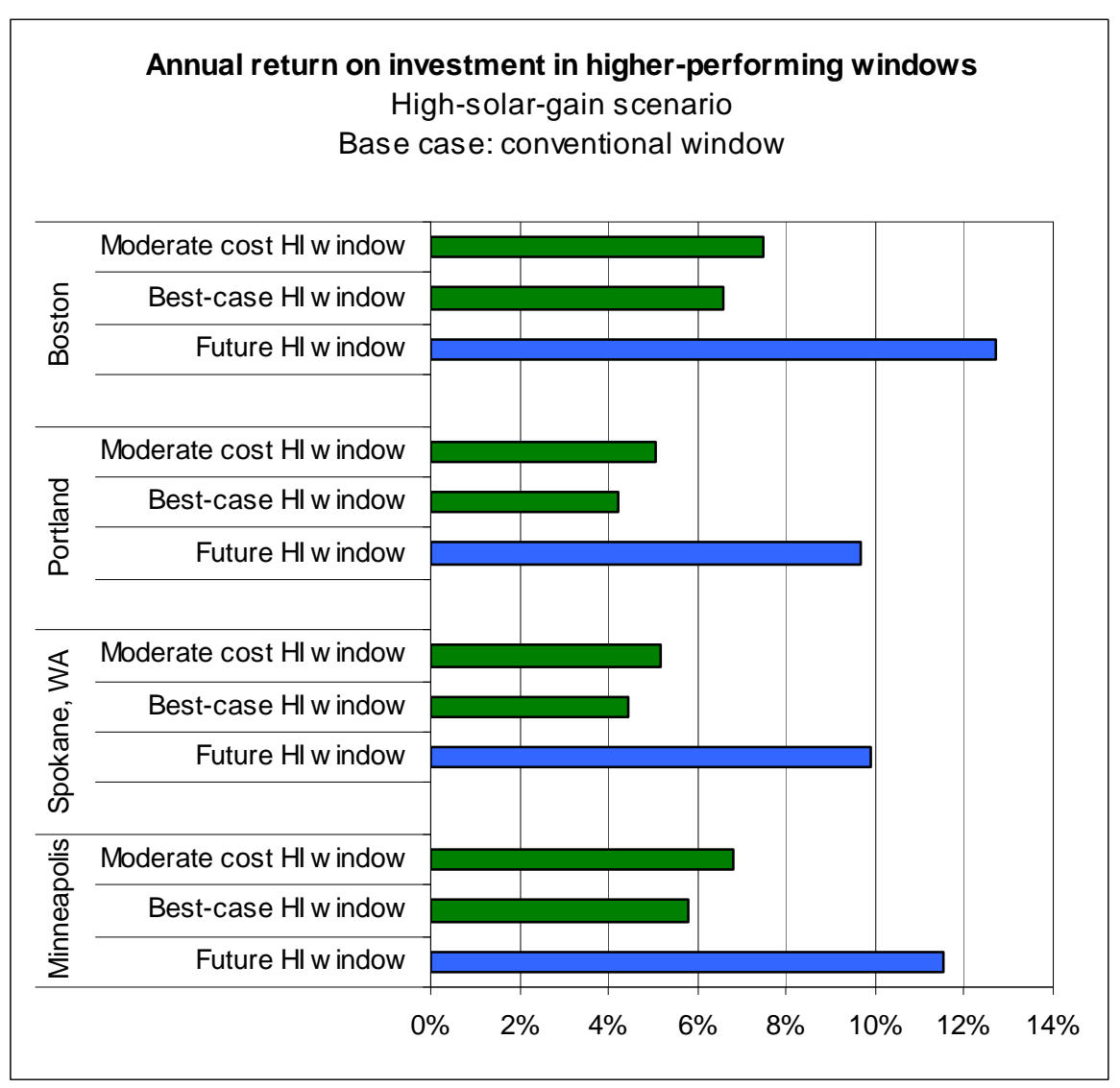

Figure 2: Annual return on investment in high-solargain high-performance windows

Base case: Conventional windows

If conventional windows are used as the base case, the energy savings that can be achieved with current highlyinsulating (HI) windows designed for high solar gain are estimated to offer significant return on investment in cold climates with high energy prices. Even more cost-effective highlyinsulating windows are envisaged by DOE for 2010 (highlighted in blue).

Figure 3: Cost per saved therm of natural gas with high-solar-gain high-performance windows Base case: Conventional window

With highly-insulating windows that allow high solar gain, substantial heating energy use reductions can be achieved. Current highly-insulating windows are still a very expensive option for natural gas savings, but market transformation toward economies of scale and improved performance can lead to very costeffective options for cold climates.

* Note: the average natural gas price used here is the projected average retail price for natural gas for residential heating in the respective states according to Alliance to Save Energy projections that are based on regional price projections by the Energy Information Administration..

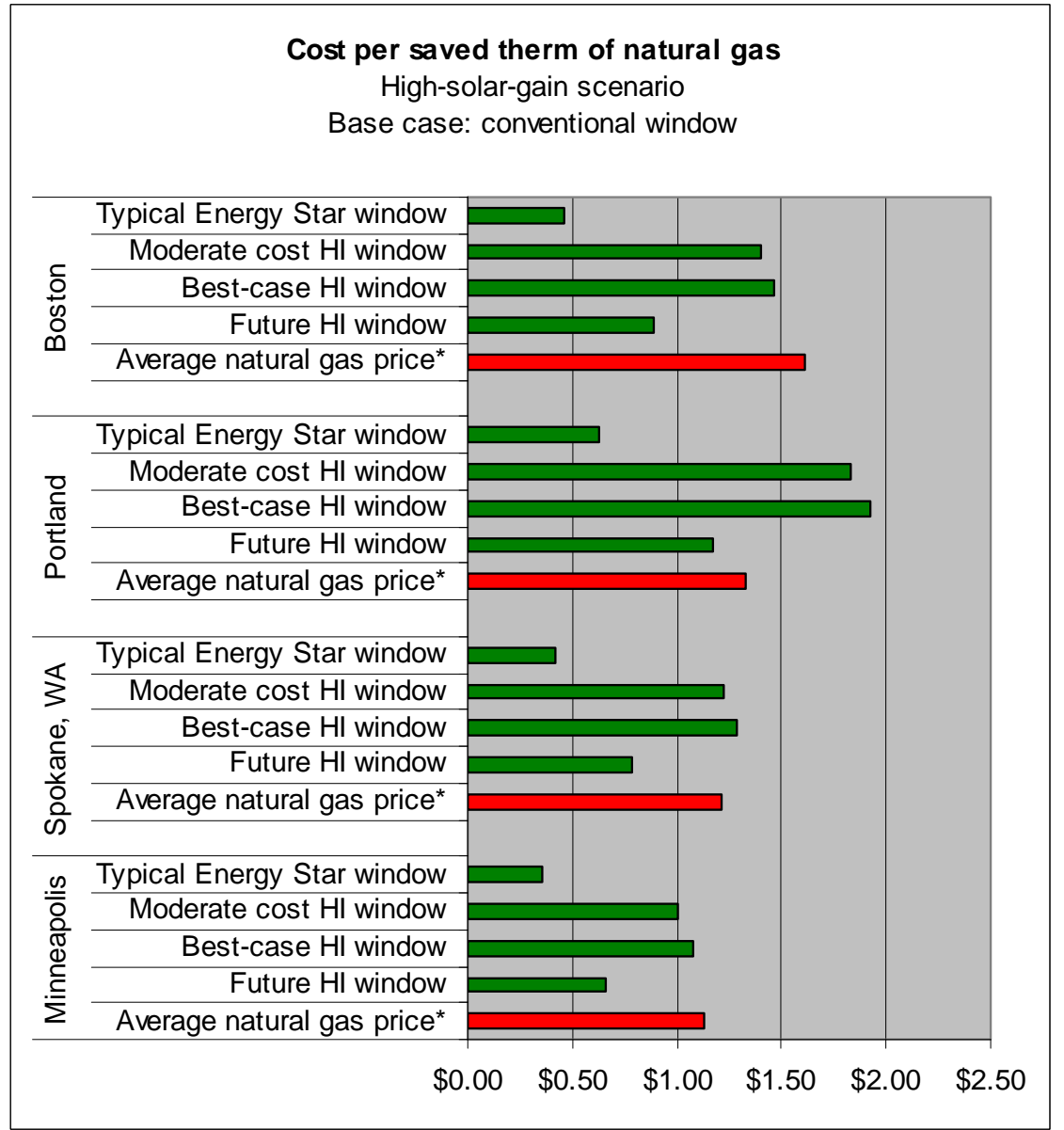


Figure 4: Heating gas savings in new homes with high-solar-gain high-performance windows Base case: Conventional windows

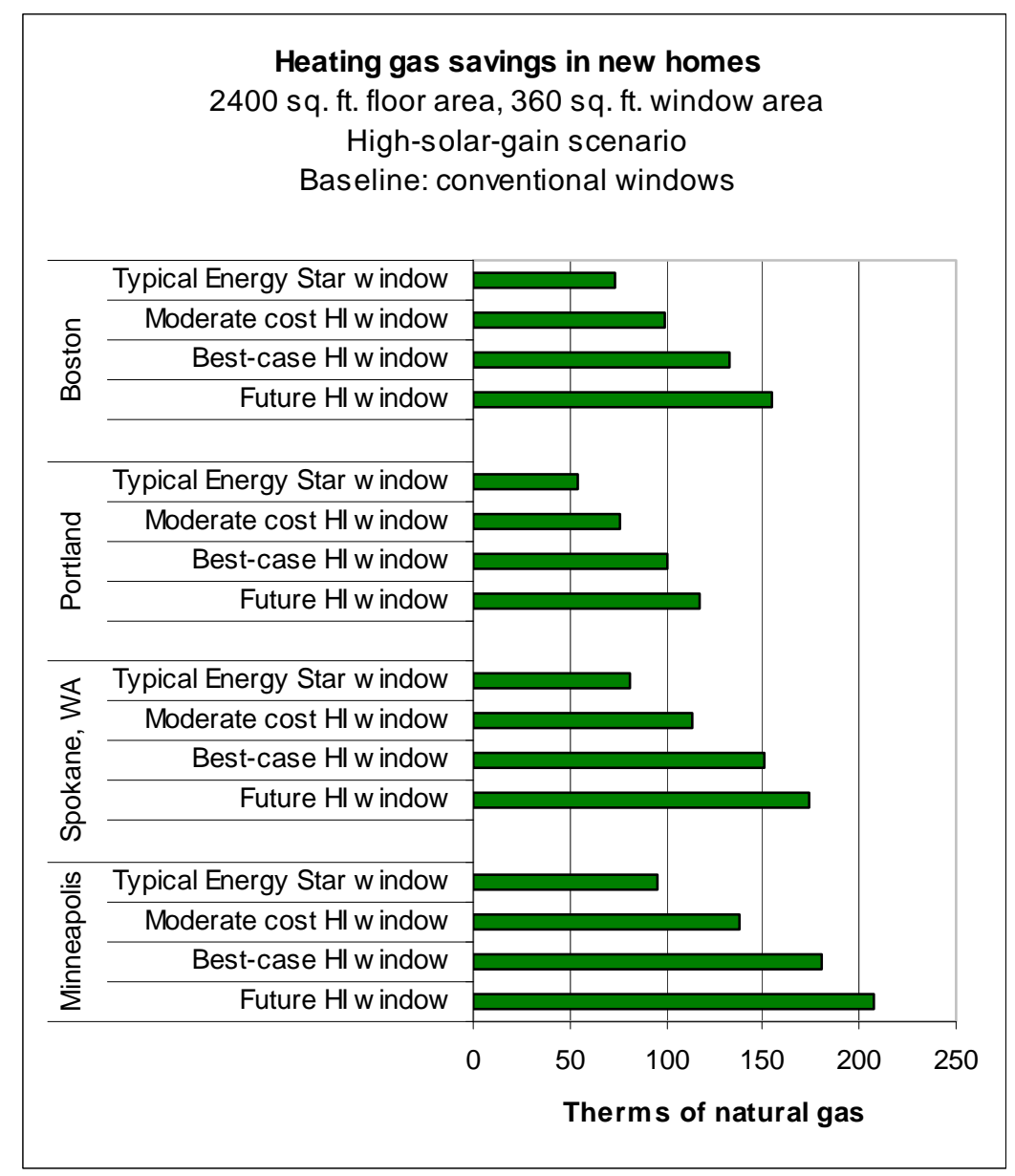

In our estimates, average natural gas consumption for heating across the four sample climates is about 18 percent lower in homes with future highly-insulating windows than in homes with conventional windows, and about 11 percent lower than in homes with typical ENERGY STAR windows. 
APPENDIX

Figure 5: Annual return on investment in low-solar-gain high-performance windows Base case: Conventional windows

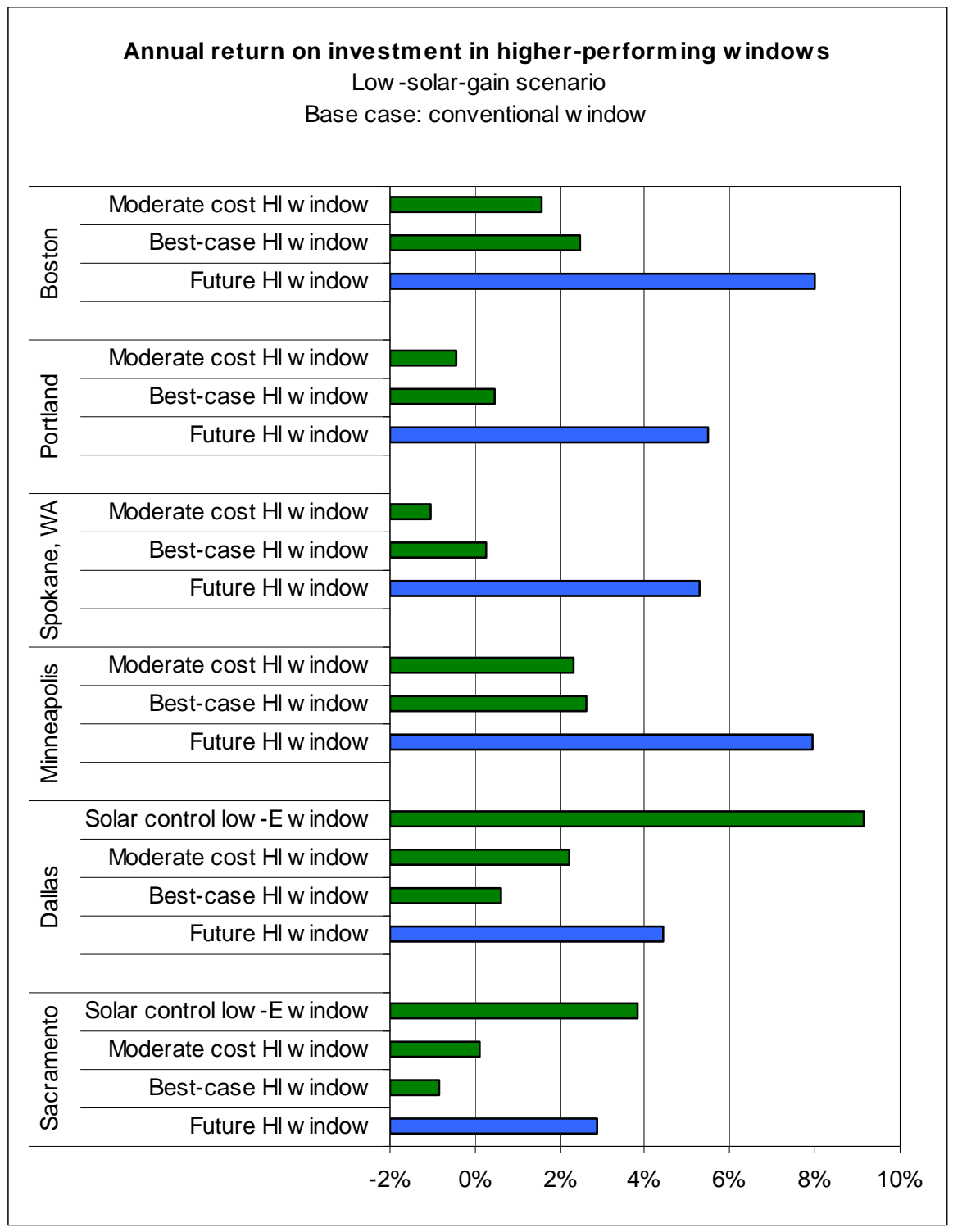

In heating-dominated climates, windows designed for low solar gain are not estimated to provide as high energy savings as windows designed for high solar gain. Nevertheless, low-solar-gain windows can provide substantial cooling peak load reductions and allow for HVAC system downsizing (see Figure 5). 
APPENDIX

Figure 6: Heating gas savings in new homes with low-solar-gain high-performance windows Base case: Conventional windows

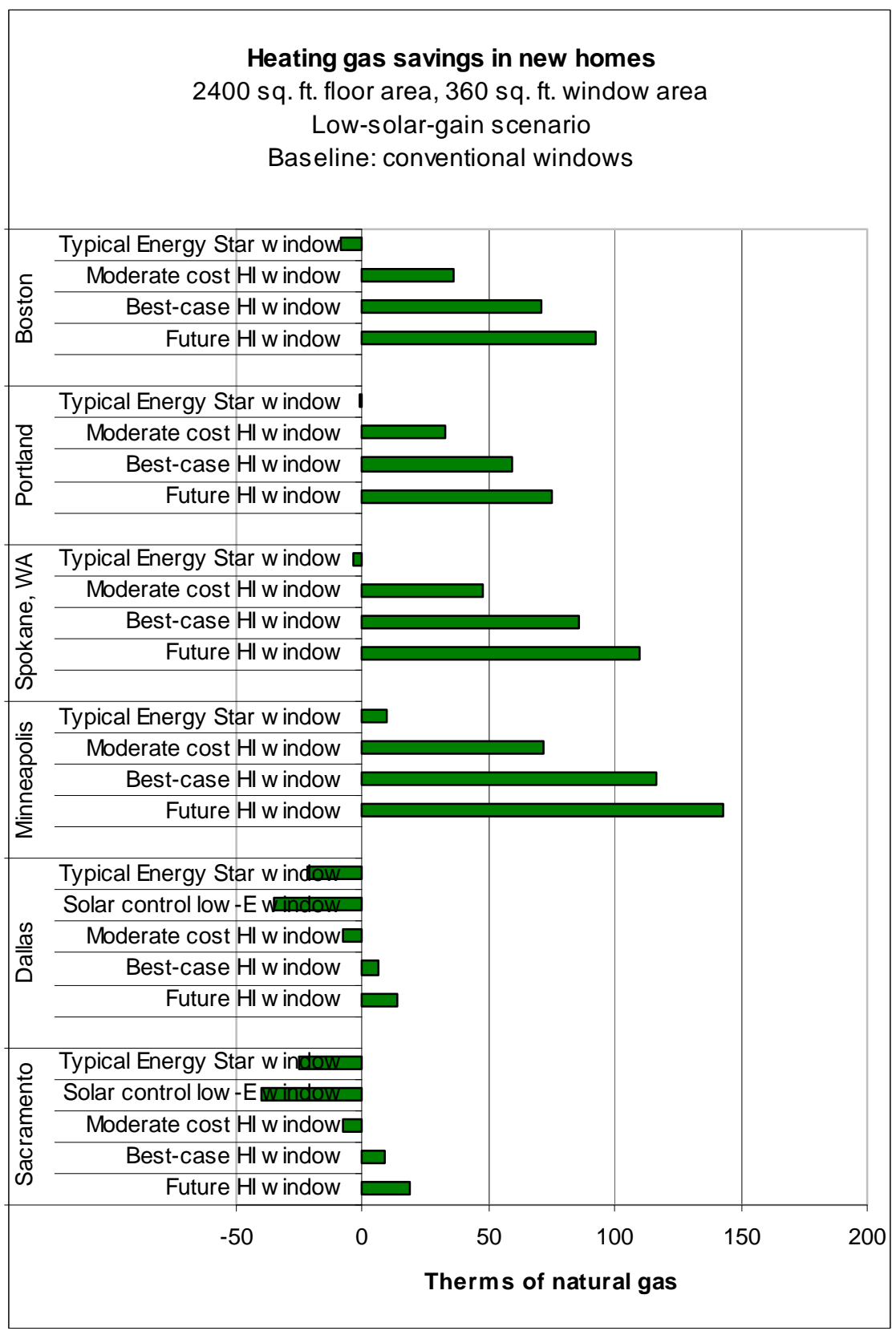

High performance windows can lead to more heating energy use if they block a substantial fraction of solar heat gain. This is particularly obvious in climates with strong solar heat even in wintertime. 
Figure 7: Cooling peak load in new homes depending on window type (low-solar-gain windows marked blue)

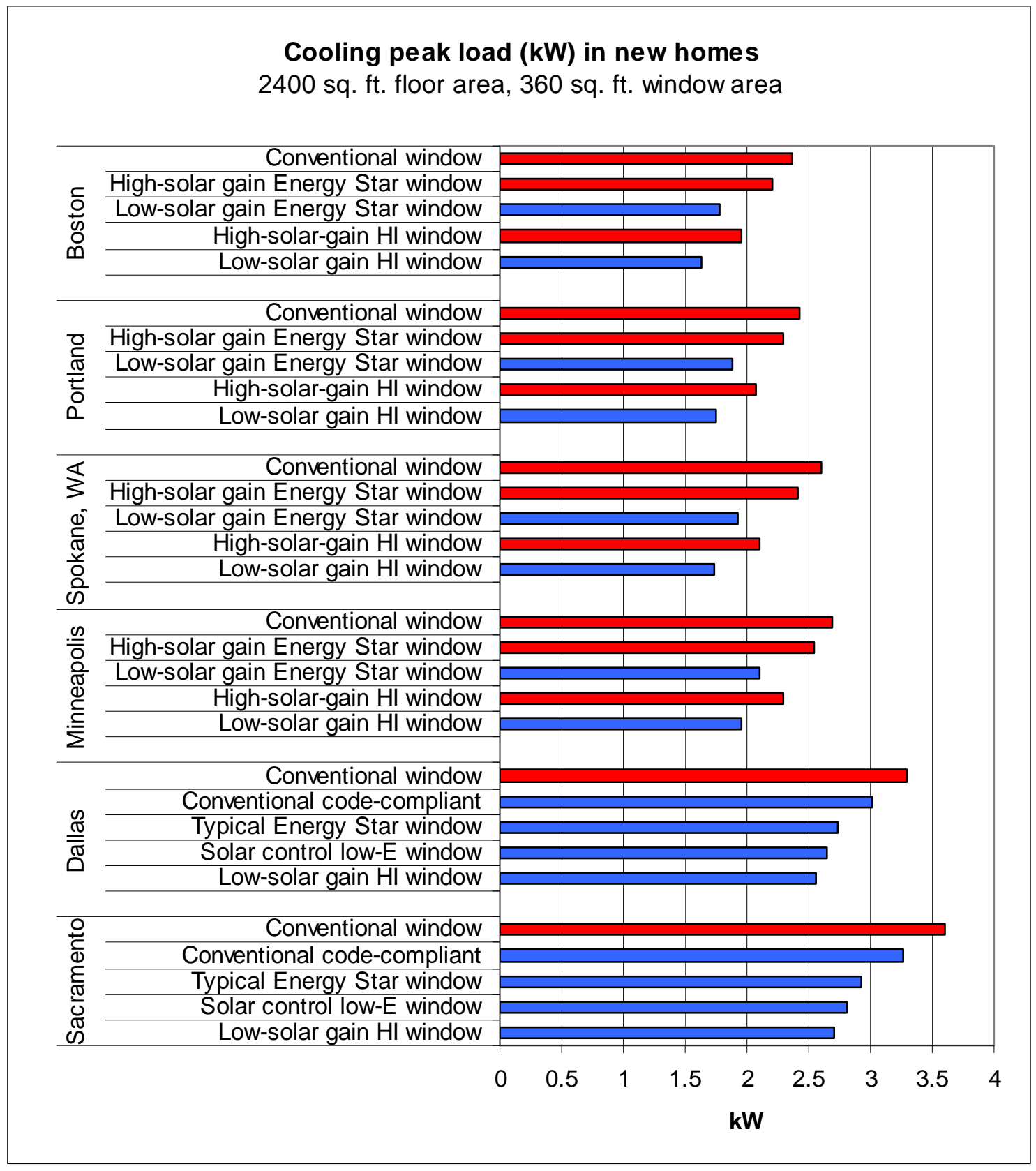

According to our estimates, low-solar-gain HI windows reduce peak cooling load by an average 28 percent if compared with conventional windows across different climates. Even high-solar-gain HI windows would achieve an average peak load reduction by 18 percent. 


\section{APPENDIX}

Figure 8: Cooling peak load reduction in new homes depending on window type (low-solar-gain windows marked blue)

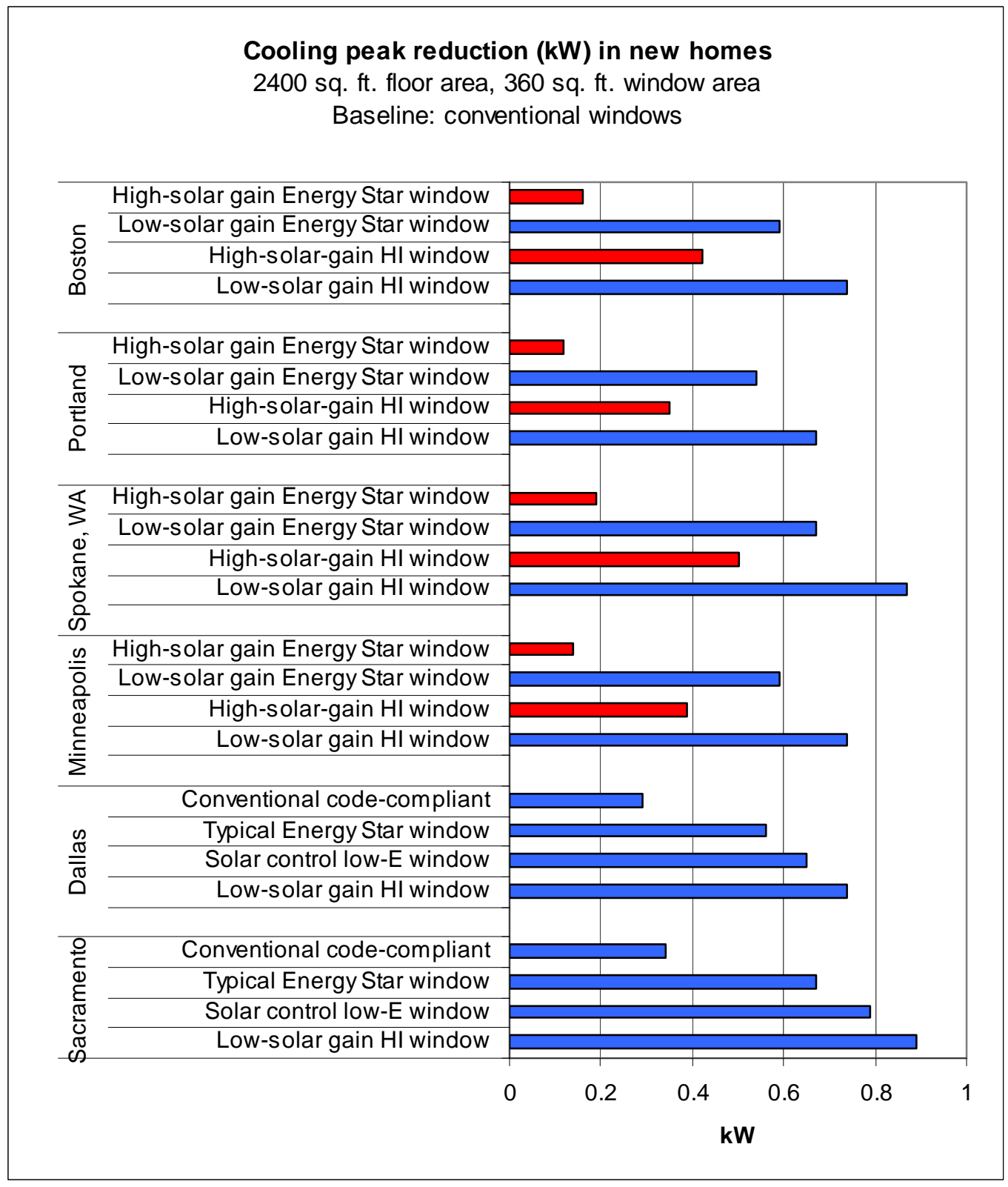




\section{APPENDIX}

Figure 9: Cooling electricity savings in new homes depending on window type (low-solar-gain windows marked blue)

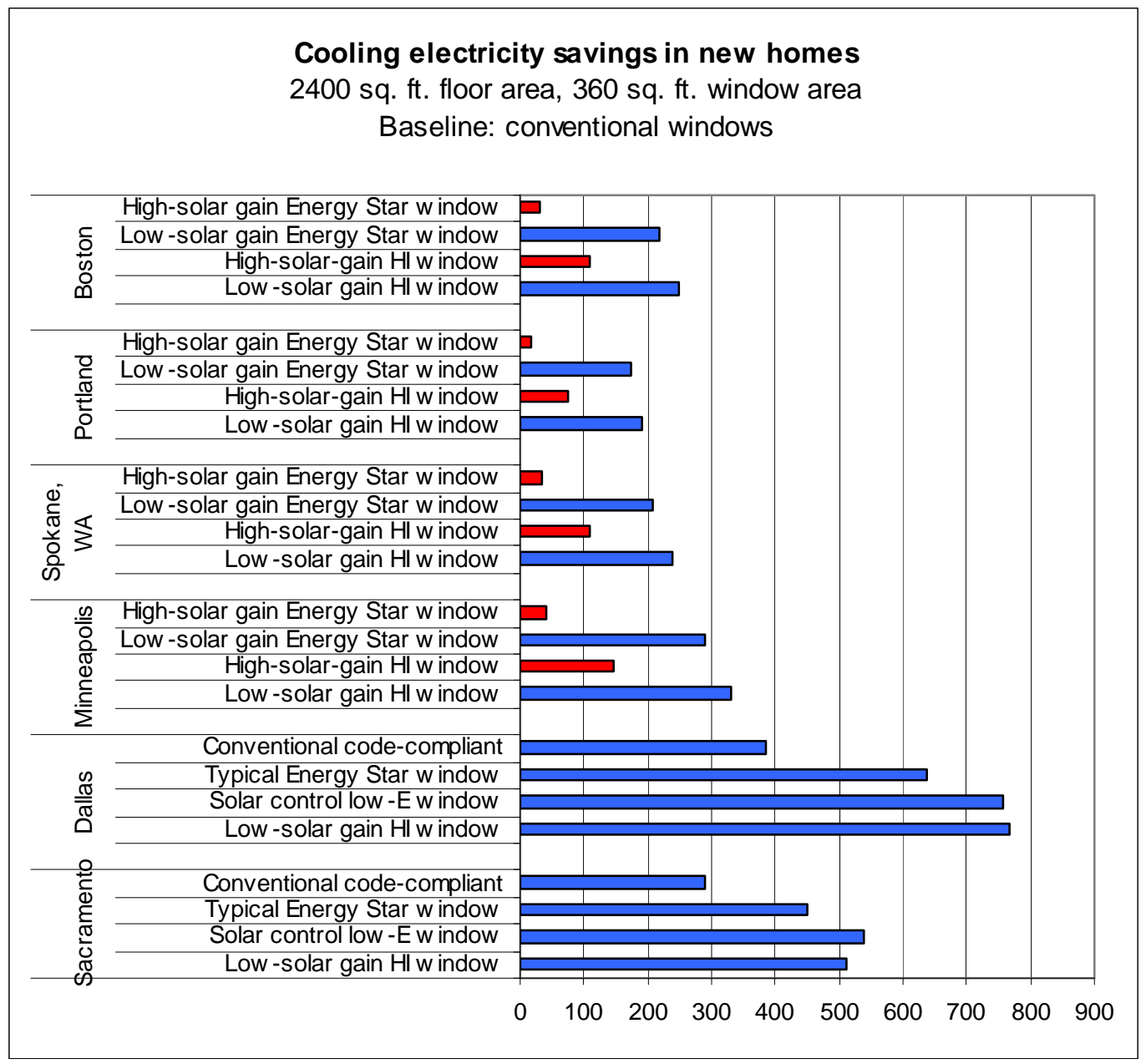


installed. The receipt for loose-fill must show the type of insulation, coverage area, thickness, $\mathrm{R}$-value, and number of bags installed. The manufacturer must also provide a manufacturer's fact sheet. The fact sheet for loose-fill insulation must contain the manufacturer's name, address, type of insulation, and a chart containing the R-value. Installers must have this information and show it to the customer before they agree to buy the insulation.

\subsubsection{Barriers}

Proper installation is essential for insulation to perform properly. Knowledge of vapor retarders, air infiltration, ventilation, recessed lighting, and water pipes are just a few of the areas critical to proper insulation installation. The Insulation Contractors Association of America (ICAA) provides a checklist for inspection of insulation installations.

\subsubsection{Program Design Considerations}

Energy efficiency programs promoting the upgrade of insulation levels are operating in many areas of the U.S. The DSIRE database is one source of information for these programs. Anecdotal evidence indicates that financial incentives, such as those offered by energy efficiency programs and tax credits, appear to positively affect market penetration. One approach energy efficiency program administrators can consider is to establish higher performance tiers that encourage homeowners to evaluate and upgrade the insulation that was originally installed in their home.

\subsubsection{Windows}

In US homes, windows on average account for more than 20 percent of the heating and 40 percent of the cooling load. ${ }^{22}$ Windows also have a large impact on peak energy demand and occupant comfort.

The role of windows in the energy equation of buildings is larger than their share of the building envelope area would suggest. This is due to the low insulating value of typical windows in the building stock, the transparency of windows to the sun's light and heat, and air leakage through older windows. The impact of windows on heating and cooling loads would be even higher if some of this impact was not offset by solar heat gain in the heating season and natural ventilation in the cooling season.

\subsubsection{Primary factors of window energy performance}

- Heat Loss: The largest impact of windows on energy use. Multiple glazing layers and lowE coatings and can reduce heat loss to a fraction of conventional window heat loss.

- Solar Heat Gain: Can offset heating needs but has a strong potential to cause overheating. Low-E coatings can control solar heat gain without rejecting visible light. External shading devices such as awnings or overhangs can provide very effective solar control depending on orientation and sun angles.

- Daylighting: Daylight has the potential to improve the indoor environment and reduce lighting energy use. In homes, tinted glass is uncommon, so that daylight access is usually more a matter of window placement than of the window properties.

\footnotetext{
${ }^{22}$ Arasteh et al. 2006.
} 


\title{
5.2.4.2 Technology and Performance Metrics
}

Over the past three decades, dramatic improvements have been achieved in the energy efficiency of windows and related components (such as internal and external shading devices, skylights, and window film).

A large portion of the US building stock remains equipped with only single-pane windows with an insulation value of R-1, while modern window design can achieve R-values of up to five or six. Codes and standards express the insulation value of windows by the $U$-factor, which is the inverse of the R-value. Low U-factors (high insulation values) are achieved with multiple glazing layers (double or triple pane) low-emissivity (low-E) coatings, lowconductance spacers, and gas fills. In addition to their insulating properties, low-E coatings can also reflect solar infrared radiation, thereby reducing cooling loads. The solar heat gain coefficient (SHGC) indicates a window's resistance to solar heat gain (the lower the SHGC, the less solar heat gain).

\subsection{Typical window U-factors}

Single-pane window

Conventional double-pane window

Double-pane ENERGY STAR window

Advanced triple-pane window
U-factor 1.0
$U$-factor 0.5
U-factor 0.3 to 0.35
$\mathrm{U}$-factor 0.2

\subsection{Typical window SHGC}

Conventional window (clear glass)

\author{
SHGC 0.5 to 0.8 \\ SHGC 0.2 to 0.5 \\ SHGC 0.2 to 0.3
}

Low-E window

\subsubsection{Installation}

Similar to most other energy efficiency measures, the best window technologies are only effective if the windows are installed correctly. Improper installation can contribute to air leakage, unnecessary heat loss, condensation, and water leakage. This leads to diminished energy performance as well as deterioration of walls, insulation, and the window unit itself.

Given the importance of proper installation, the American Society for Testing and Materials (ASTM International) has developed E 2112, Standard Practice of the Installation of Exterior Windows, Doors and Skylights and the American Architectural Manufacturers Association (AAMA) has developed InstallationMasters, an installer training and registration program. The Energy and Environmental Building Association's (EEBA) Water Management Guide is another excellent resource.

\subsubsection{Impact on HVAC System Sizing}

Another important factor to be considered when windows are installed is the impact of window performance on heating and cooling loads and thus on the demand placed on HVAC systems. This is important when determining the adequate HVAC system size for homes. Oversized HVAC systems should be avoided to prevent system short cycling, thus minimizing energy waste and providing for proper dehumidification in climates with humidity issues. Last but not least, smaller HVAC systems cost less.

In addition to the potential for HVAC downsizing, energy efficient windows may allow for compact HVAC distribution systems. Significantly smaller distribution systems are possible with highly insulating windows, which may provide for occupants to be comfortable with 
registers or baseboards located closer to the center of the building, rather than the standard practice of delivering heating and cooling near exterior windows.

\subsubsection{Market}

In 2005, an estimated 46 percent of homes still featured single-pane windows and less than 8 percent of residential buildings had windows with low-E coatings, despite the fact that low-E glazing is essentially required to meet ENERGY STAR criteria and modern code requirements. This picture is changing steadily, as more and more ENERGY STAR windows are being installed in existing and new homes. In 2008, the DOE reported that the market share of ENERGY STAR windows, doors, and skylights was at 59 percent nationally, and close to 90 percent in the replacement market.

The large market share of ENERGY STAR windows led DOE to conclude that ENERGY STAR no longer differentiated energy efficient windows, doors, and skylights from standard products. Therefore, DOE released new more stringent ENERGY STAR criteria that became effective in January 2010. As before, these criteria differ by climate zone, but in general they encourage windows with a $U$-factor of no more than 0.30 in the north and a SHGC of no more than 0.30 in the south. The specific criteria for each climate zone can be viewed on the ENERGY STAR Web site. Previously, the maximum northern U-factor was 0.35 and the maximum southern SHGC 0.40 .

The American Reinvestment and Recovery Act includes a tax credit for replacement windows (up to $\$ 1,500$ ) with a maximum $U$-factor and SHGC of 0.30. As opposed to ENERGY STAR, this tax credit does not differentiate between climate zones. It applies through 2009 and 2010.

\subsubsection{Barriers to Greater Efficiency}

Although building energy codes and ENERGY STAR have been successful in transforming the windows market so that double-pane, low-E windows have become standard practice, a vast demand for upgrades of existing windows (often single-pane) remains. The cost of window replacement is a barrier, which means that in many cases alternatives to replacement need to be considered, including window repairs, storm windows, weather stripping, and window film.

When windows are replaced, some barriers to optimum energy efficiency persist:

- Highly-insulating windows with U-factors close to 0.20 exist and could increase savings in cold climates significantly although incremental cost for these products is high due to lacking economies of scale. One reason is that neither the ENERGY STAR program nor common building energy codes such as the International Energy Conservation Code (IECC) provide higher performance tiers that reward highly-insulating options such as triple glazing.

- Quality control for installation is not universally provided. Although ASTM International 2112 provides a standard for window installation, training according to this standard and verification of proper installation are nowhere near universal.

- Coordination between window and HVAC contractors is often non-existent. As window energy performance increases, the excess capacity of oversized HVAC systems and resulting short-cycling becomes even more of an issue, especially regarding the need for proper dehumidification.

\subsubsection{Program Design Considerations}

Many energy efficiency programs promoting window energy efficiency are focusing on incentives for ENERGY STAR windows. The effectiveness of such incentives has diminished as 
the high market penetration of ENERGY STAR windows has led to substantial free ridership, although the more stringent ENERGY STAR criteria that will take effect in January 2010 will reduce market share and free ridership to some extent.

Ideas submitted for program design (each described in detail below) were:

- market transformation

- low-income solutions

- installation quality control

- $\quad$ systems approach

\subsection{Market Transformation}

ENERGY STAR, building energy codes, and the federal tax credit only provide pass/fail criteria, leading the windows market to aim for performance that just meets these criteria. Utility programs, however, can establish higher performance tiers that encourage energy performance beyond business as usual. Higher performance tiers help minimize free ridership and may lead to lasting market transformation. Initially, products meeting such higher tiers would cost significantly more than more common products, but increasing awareness and economies of scale can bring down cost in the long run.

A good example for a higher performance tier would be a U-factor of about 0.2 for heatingdriven climates, which can be achieved by the best triple-pane windows in high performance frames. DOE is currently soliciting bids from window manufacturers and their distributors to provide high performance windows that meet a U-factor of 0.22 to $0.20(R-5)$. The window products from qualified vendors will be available directly from the vendors listed on the volume purchase web site. DOE is also working with potential purchasers to make them aware of the windows and with utilities to consider customer incentives for these high performance windows to reduce the cost of these products.

\subsection{Low Income}

Window replacement is often cost-prohibitive for low-income customers. To allow lowincome customers to improve the performance of their windows, most state and utility programs offer weather-stripping and caulking services. While these measures reduce air leakage, they do not reduce heat transfer through the glass, which can instead be achieved by storm windows (less heat loss) and window films (less solar heat gain). The cost effectiveness of storm windows can be increased if low-E glass is used. Low-E storm windows reduce heat loss far more than conventional storm windows.

\subsection{Installation Quality}

An effective program that addresses windows will focus on installation procedures. This effort may be best focused on identifying an industry accepted standard for the proper installation of windows, and ensuring that quality control is applied to actual jobs.

\subsection{Systems Approach}

Any improvement in window energy performance - including replacement, repairs, re-glazing, solar control films, secondary glazing, and shading devices - may reduce the demand on the HVAC system. In most cases, this affects the optimal sizing of HVAC units, but in the case of highly-insulating windows, improved surface temperatures may even warrant a radically simplified system without perimeter heating. A key barrier is that window and HVAC contractors do not typically coordinate their work. Utility companies could play a role in establishing such coordination so that maximum comfort, energy savings, and cost reduction opportunities are realized. 


\section{Outreach Plan for Gas Utility Window Efficiency Programs}

The Efficient Windows Collaborative (EWC) is determining the potential to promote efficient windows through natural gas utility efficiency programs. Efficient windows that reduce building heat loss can have a substantial effect on natural gas demand since natural gas is the predominant heating fuel used in the U.S. building sector. The use of natural gas for cooling purposes, on the other hand, is negligible, so that the impact of windows on cooling loads is of little importance with respect to gas utility efficiency programs.

EWC outreach efforts focusing on gas utility efficiency programs will mainly focus on colder climate zones with substantial demand for natural gas as a heating fuel. In particular, the northern zone among the ENERGY STAR ${ }^{\circledR}$ climate zones (see below) is of interest here. In the eastern and western parts

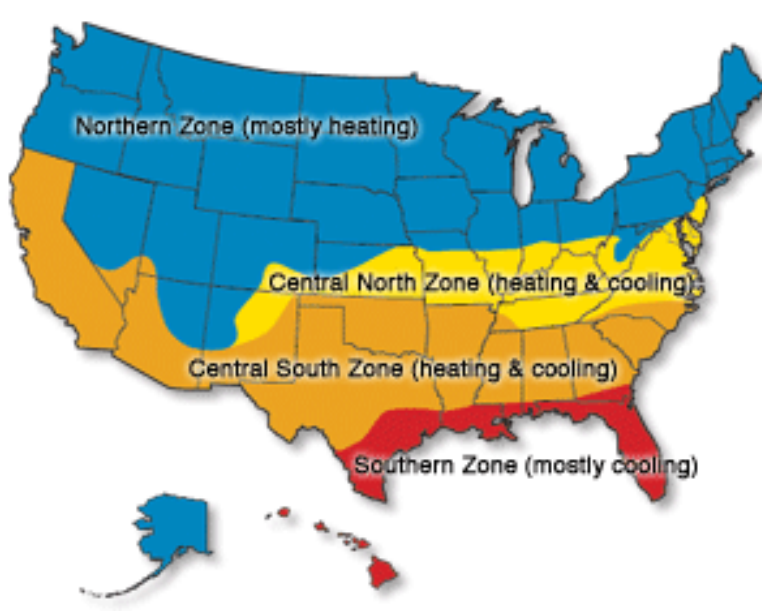
of this northern zone, the market share of efficient ENERGY STAR windows is already at the highest levels nationwide (about 75 percent compared to 50-60 percent nationwide). In the central parts of this zone - the East North Central, West North Central and Mountain census regions - the market penetration of ENERGY STAR windows is around the national average (see graphic on the bottom left).

Taking into account climate and market conditions, the EWC determines the following three priorities for window efficiency programs by gas utilities:

1. Promotion of ENERGY STAR windows by utility companies in the Midwest and Rocky Mountain regions, where the heating demand is high and the market share of ENERGY STAR windows is not very high;

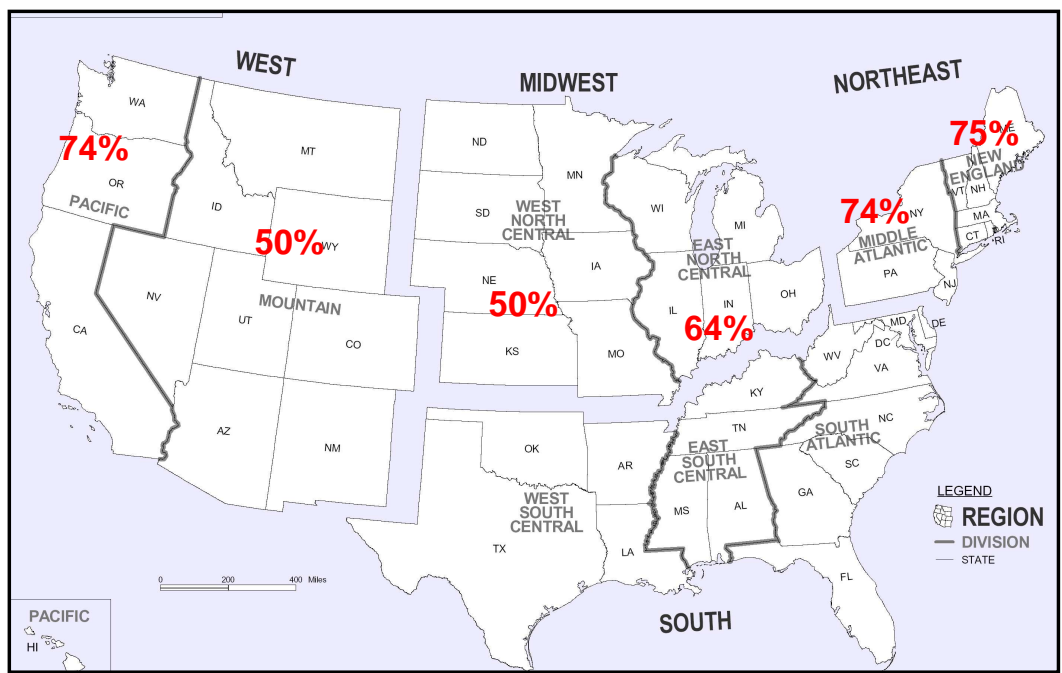

Market share of ENERGY STAR windows by census region.

Source: D\&R International 2006
2. Promotion of highlyinsulating windows with Ufactors that exceed ENERGY STAR criteria in regions where the market share of ENERGY STAR windows is already high (Northeast and Pacific Northwest).

3. Promotion of effective alternatives to window replacement, such as low-E storm windows in heating climates. 


\section{Promotion of ENERGY STAR windows in the Midwest and Rocky Mountain regions}

The market share of ENERGY STAR windows is still relatively low in the Midwest and Rocky Mountains, although many of the states in these regions have building energy codes that specify a U-factor of 0.35 in their prescriptive requirements for replacement windows and for windows in new homes with average window-to-wall ratios. Reasons for this low market penetration, which is estimated to be around 50 percent across these regions, might be lacking code enforcement, tradeoffs allowed by the codes, and smaller replacement jobs not covered by codes. In addition, there may be a lack of awareness for the benefits of ENERGY STAR windows.

The EWC has presented information about ENERGY STAR windows, highly-insulating windows, and low-E storm windows to utility companies at a forum of the Midwest Energy Efficiency Alliance (MEEA). Among the MEEA members are several Midwest gas utility companies. To our knowledge, only one of these (Alliant Energy) offers rebates specifically dedicated to windows. The long payback time associated with efficient windows is the reason why incentives for efficient window replacement are not more common. Nevertheless, here are a few examples for such programs in the Midwest and Rocky Mountain regions:

Colorado

Colorado Springs Utilities: Rebate of $\$ 50, \$ 100$ or $\$ 200$ for ENERGY STAR Windows. For electric and natural gas customers.

Idaho

Avista Utilities: $\$ 3 / \mathrm{sq} \mathrm{ft}$ for upgrading to windows with a U-factor of 0.35 or lower. For electric and natural gas customers.

Iowa

Alliant Energy: Low-interest financing $(\$ 1,500$ to $\$ 25,000)$ for equipment including ENERGY STAR Windows. Rebate of $\$ 25$ per replacement ENERGY STAR window, window sash, or door. For electric and natural gas customers.

Minnesota

Aliant Energy: Rebate of \$20 per replacement ENERGY STAR window, window sash, or door. For electric and natural gas customers.

Minnesota Power: Rebates for high thermal performance standards in new constructions. $\$ 300$ for windows with a U-factor of 0.28 or less. For electric and natural gas customers.

Nebraska

Nebraska Energy Office: Loans for home energy improvements including windows with a Ufactor of 0.33 or less, replacement sashes, storm windows and window repairs for residential and commercial buildings.

The EWC will contact these utility program providers to learn about their experience with their window programs and to communicate suggestions to other utilities in the Midwest and Rocky Mountain regions. We will coordinate this with MEEA and EWC advisory group partners located in the Midwest. We will inquire whether EWC can assist these and other utilities with educational material and whether specific incentives for highly-insulating windows and low-E storm windows could also be considered. 


\section{Promotion of highly-insulating windows}

In regions where ENERGY STAR windows already account for a large share of the windows market, it may be more attractive for utility companies to promote highly-insulating windows with U-factors that exceed the ENERGY STAR specification of 0.35 for the northern climate. Incentives for highly-insulating windows ensure that freeridership by customers who would have installed ENERGY STAR windows anyway is reduced. In December 2007, LBNL and the EWC estimated potential heating fuel savings from installing windows with $\mathrm{U}$-factors of 0.25 or 0.20 instead of 0.35 in homes in different climates. The utility companies Xcel Energy (Minnesota) and Questar (Utah) found that incentive programs using such higher performance tiers could be marginally cost-effective in their service areas, although this strongly depends on the incremental cost of such highly-insulating windows.

EWC will continue to coordinate efforts with the Consortium for Energy Efficiency and the Midwest Energy Efficiency Alliance to inform utility companies across the heating climate about heating fuel opportunities with windows meeting more stringent $\mathrm{U}$-factor performance tiers.

\section{Promotion of low-E storm windows}

A field study performed in collaboration by the NAHB Research Center, LBNL, and Utilivate Technologies has found substantial heating demand reduction from installing low-E storm windows instead of regular storm windows in homes with single-pane prime windows. ${ }^{1}$ Since storm windows primarily reduce heating needs without affecting cooling demand much, natural gas programs are the most obvious type of utility programs for promoting this technology.

To date, no specific programs for low-E storm windows exist yet. However, the NFRC is developing a rating system for storm windows that would strongly facilitate the promotion of higher-performance low-E storm windows by utility companies. The EWC is involved in the NFRC process and will provide information to utility companies once the rating program has been established.

The American Gas Association reports that in 2007, 42 of 50 surveyed local distribution companies (LDCs) for natural gas offered low-income weatherization programs. ${ }^{2}$ If only part of these LDCs were to consider promoting low-E storm windows, the presently low demand for this niche technology could be greatly increased, resulting in affordable and very cost-effective natural gas saving measures.

\footnotetext{
${ }^{1}$ Drumheller et al. 2007. Field Evaluation of Low-E Storm Windows. ASHRAE.

${ }^{2}$ American Gas Association. 2007. LDC Natural Gas Energy Efficiency Programs Report 2007. http://www.aga.org/NR/rdonlyres/E5D4AC53-49D8-4C66-9143-D85449E38951/0/0802EEREPORT.pdf
} 


\section{Technical Memorandum}

\section{Commercial Windows Utility Provider Promotional Inventory}

The Efficient Windows Collaborative has compiled an inventory of programs promoting energyefficient windows for commercial buildings. ${ }^{1}$ The list on the following pages provides an overview of the programs we have found in a review of prominent listings of utility energy efficiency programs:

- The Edison Electric Institute's "Highlights of EEI Member and Non-Member Residential/Commercial/Industrial Efficiency and Demand Response Programs for 2008" http://www.eei.org/industry issues/retail services and delivery/wise energy use/progra ms and incentives/progs.pdf

- The Consortium for Energy Efficiency's commercial program summary - September 2007. http://www.cee1.org/com/2007-ps/

From these documents, we have gathered information on a sample of 31 energy efficiency program providers that offer incentives for window energy efficiency, either directly by rewarding the use of efficient windows or window film, or indirectly by rewarding energy and demand savings in new building design or through retrofits.

12 of these 31 program providers offer direct incentives for the use of efficient windows, and 9 of these specify window performance based on NFRC ratings (U-factor, SHGC, and/or visual transmittance). In addition, 7 of the 31 program providers offer direct incentives for solar control window film, either specifying the film's SHGC or its shading coefficient (SC) which is an outdated rating method. 15 program providers in the sample incentivize windows only indirectly, either by requiring energy modeling of new construction or renovations and awarding incentives for projected energy or peak demand savings, or by providing low-interest loans for/rebates on the incremental cost of efficiency improvements.

From the perspective of the market for energy-efficient windows, prescriptive rebates based on window performance ratings are advantageous because they streamline the choice of energyefficient window options. We discussed this issue with a few utility program providers, who realized the benefit of presenting specifiers with simple, prescriptive values instead of requiring complex energy modeling. However, the same program providers are currently requiring energy modeling due to the difficulty of determining the average benefits of a given level of window performance due to the large variety of buildings and window types in the commercial sector.

We will continue discussions with commercial window program providers to assess whether new developments such as the COMFEN software and the NFRC's Component Modeling Approach will make it easier for program providers to create prescriptive tiers and incentives for specific window performance levels.

\footnotetext{
${ }^{1}$ In this context, we define commercial buildings as those buildings that would not be eligible for utility programs aimed at individual home owners or homebuilders of low-rise houses. We thus include, among others, high-rise multifamily buildings, small commercial buildings, schools, and office buildings in our definition of commercial buildings for this purpose.
} 


\section{Summary of the types of incentives included in the programs sample}

Programs that encourage higher fenestration energy efficiency, either directly or indirectly, can include incentives based on a variety of different criteria. The criteria used in the sample of programs studied by us can be divided into five categories. Whereas many programs do not explicitly require any specific

fenestration performance and instead provide incentives based on modeled energy savings or incremental cost, several programs do specify windows or window film performance. Of these programs, only some specify NFRC performance values (U-factor, SHGC, VT for windows, SHGC for films).

\begin{tabular}{|c|c|c|c|c|c|c|}
\hline State & Program provider & $\begin{array}{l}\text { Incentives based on } \\
\text { improvement compared } \\
\text { to code (kWh saved or } \\
\text { percent improvement) }\end{array}$ & $\begin{array}{l}\text { Incentives based on } \\
\text { kW or kWh saved } \\
\text { compared to prior } \\
\text { condition }\end{array}$ & $\begin{array}{l}\text { Window film incentives } \\
\left({ }^{*} \text { program references }\right. \\
\text { SHGC) }\end{array}$ & $\begin{array}{l}\text { Window incentives } \\
\left({ }^{\star} \text { program }\right. \\
\text { references NFRC } \\
\text { specs) }\end{array}$ & $\begin{array}{l}\text { Incentives based on } \\
\text { cost or incremental } \\
\text { cost of improve- } \\
\text { ments }\end{array}$ \\
\hline \multirow{3}{*}{ CA } & Anaheim Public Utilities & $\bullet$ & $\bullet$ & & & \\
\hline & Pacific Gas \& Electric & & & •* & & \\
\hline & Savings by Design & $\bullet$ & & & & \\
\hline $\mathrm{CO}$ & Xcel Energy & - & & & & \\
\hline CT & United Illuminating & & & & & $\bullet$ \\
\hline \multirow{3}{*}{$\mathrm{FL}$} & $\begin{array}{l}\text { Florida Power and } \\
\text { Light }\end{array}$ & & & $\bullet$ & $\bullet$ & \\
\hline & $\begin{array}{l}\text { Florida Power } \\
\text { Corporation }\end{array}$ & & & $\bullet *$ & & \\
\hline & $\begin{array}{l}\text { Tampa Electric } \\
\text { Company }\end{array}$ & & & $\bullet$ & & \\
\hline $\mathrm{HI}$ & $\begin{array}{l}\text { Hawaiian Electric } \\
\text { Company }\end{array}$ & & & $\bullet$ & & \\
\hline \multirow{2}{*}{ IA } & Alliant Energy & & & & $\bullet^{*}$ & \\
\hline & MidAmerican Energy & $\bullet$ & & & & \\
\hline ID & Idaho Power & & & •* & •* & \\
\hline \multirow{2}{*}{ MN } & Alliant Energy & & & & •* & \\
\hline & Minnesota Power & & $\bullet$ & & & \\
\hline NC & $\begin{array}{l}\text { North Carolina State } \\
\text { Energy Office }\end{array}$ & & & & & $\begin{array}{c}\text { Low-interest loan } \\
\text { covering measure cost }\end{array}$ \\
\hline NE & $\begin{array}{l}\text { Nebraska Energy } \\
\text { Office }\end{array}$ & & & & $\bullet$ & \\
\hline $\mathrm{NH}$ & $\begin{array}{l}\text { Public Service } \\
\text { Company of New } \\
\text { Hampshire }\end{array}$ & & & & & $\bullet$ \\
\hline NV & Sierra Pacific Power & & $\bullet$ & & & \\
\hline
\end{tabular}




\begin{tabular}{|c|c|c|c|c|c|c|}
\hline State & Program provider & $\begin{array}{l}\text { Incentives based on } \\
\text { improvement compared } \\
\text { to code (kWh saved or } \\
\text { percent improvement) }\end{array}$ & $\begin{array}{l}\text { Incentives based on } \\
\text { kW or kWh saved } \\
\text { compared to prior } \\
\text { condition }\end{array}$ & $\begin{array}{l}\text { Window film incentives } \\
\text { (* program references } \\
\text { SHGC) }\end{array}$ & $\begin{array}{l}\text { Window incentives } \\
\text { (* program } \\
\text { references NFRC } \\
\text { specs) }\end{array}$ & $\begin{array}{l}\text { Incentives based on } \\
\text { cost or incremental } \\
\text { cost of improve- } \\
\text { ments }\end{array}$ \\
\hline \multirow{5}{*}{ OR } & Energy Trust of Oregon & $\bullet$ & $\bullet$ & & $\bullet^{*}$ & \\
\hline & $\begin{array}{l}\text { Eugene Water \& } \\
\text { Electric Board }\end{array}$ & & & & $\bullet *$ & \\
\hline & Idaho Power & & & •* & $\bullet *$ & \\
\hline & $\begin{array}{l}\text { Lane Electric } \\
\text { Cooperative }\end{array}$ & & & & & $\begin{array}{c}\text { Low-interest loan } \\
\text { covering measure cost }\end{array}$ \\
\hline & $\begin{array}{l}\text { Oregon Department of } \\
\text { Energy }\end{array}$ & & & & & $\begin{array}{c}\text { Tax credit based on } \\
\text { measure cost }\end{array}$ \\
\hline \multirow{5}{*}{ TX } & Austin Energy & & & & $\bullet *$ & \\
\hline & AEP Efficiency & & $\bullet$ & & & \\
\hline & Center Point Energy & & $\bullet$ & & & \\
\hline & $\begin{array}{l}\text { Texas-New Mexico } \\
\text { Power Company }\end{array}$ & & $\bullet$ & & & \\
\hline & TXU Energy & & & & •* & \\
\hline \multirow{2}{*}{ WA } & Seattle City Light & & & & $\bullet$ & \\
\hline & Puget Sound Energy & $\bullet$ & & & ๑* & $\bullet$ \\
\hline WI & Focus on Energy & $\bullet$ & & & & \\
\hline
\end{tabular}

Dots in the "window incentives" category that are highlighted red indicate that the NFRC specifications for the incentive apply only to residential-type windows, either because ENERGY STAR ${ }^{\circledR}$ windows are specified or because the incentive is for multifamily residential buildings. 


\section{Overview of Individual Programs}

\begin{tabular}{|c|c|c|c|}
\hline State & Program Provider & Program Elements & Eligibility \\
\hline \multirow{3}{*}{ CA } & $\frac{\text { Anaheim Public Utilities }}{\text { Phone: } 714-765-4311}$ & $\begin{array}{l}\text { New construction and major renovation: } \$ 300 \text { per kW } \\
\text { avoided compared to Title } 24 \text { performance } \\
\text { Retrofit measures (including window tinting or } \\
\text { replacement): } \$ 150 \text { per kW reduction }\end{array}$ & Commercial, industrial and institutional facilities \\
\hline & $\frac{\text { Pacific Gas \& Electric }}{\text { Phone: } 800-468-4743}$ & $\begin{array}{l}\text { Window film with an SHGC of } 0.39 \text { or less on clear, } \\
\text { single-pane glass facing west, east or south may } \\
\text { qualify for a } \$ 1.35 / \mathrm{sq} \mathrm{ft} \text { rebate. }\end{array}$ & $\begin{array}{l}\text { PG\&E business customers } \\
\text { More details here (page 2). }\end{array}$ \\
\hline & Savings by Design & $\begin{array}{l}\text { Design assistance and incentives for projects with at } \\
\text { least } 10 \% \text { estimated annual energy savings compared } \\
\text { to the Title } 24 \text { baseline. }\end{array}$ & $\begin{array}{l}\text { Nonresidential new construction or major } \\
\text { renovation projects located within the service } \\
\text { territories of: } \\
\text { - } \quad \text { Pacific Gas and Electric } \\
\text { - San Diego Gas and Electric } \\
\text { - Southern California Edison } \\
\text { - Sacramento Municipal Utility District }\end{array}$ \\
\hline $\mathrm{CO}$ & $\frac{\text { Xcel Energy }}{\text { Phone: } 800-481-4700}$ & $\begin{array}{l}\text { Energy design assistance including free consulting, } \\
\text { computer modeling and targeted incentives. }\end{array}$ & $\begin{array}{l}\text { - New construction, additions, major } \\
\text { renovations } \\
\text { - Commercial buildings of more than } 50,000 \\
\text { sq ft } \\
\text { - Housing \& condominium projects of more } \\
\text { than } 150,000 \mathrm{sq} \mathrm{ft}\end{array}$ \\
\hline CT & $\begin{array}{l}\text { United Illuminating } \\
\text { Phone: 203-499-2025 } \\
\text { Mr. Roy W. Haller }\end{array}$ & $\begin{array}{l}\text { Cash incentives for energy-efficiency measures for } \\
\text { new construction and renovations: } \\
\text { Energy Conscious Blueprint program: Up to 100\% of } \\
\text { incremental cost for higher efficiency measures, } \\
\text { including building envelope measures among others. } \\
\text { Energy Opportunities program: Up to 50\% of installed } \\
\text { cost for retrofit measures, also including building } \\
\text { envelope. }\end{array}$ & Commercial and industrial customers \\
\hline
\end{tabular}




\begin{tabular}{|c|c|c|c|}
\hline State & Program Provider & Program Elements & Eligibility \\
\hline \multirow{3}{*}{$\mathrm{FL}$} & $\begin{array}{l}\text { Florida Power and Light } \\
\text { (FPL Energy) }\end{array}$ & $\begin{array}{l}\text { Window film, solar screen, or high efficiency glazing } \\
\text { incentives: up to } \$ 1 / \mathrm{sq} \mathrm{ft} \text { for windows facing west, } \\
\text { southwest or northwest. }\end{array}$ & $\begin{array}{l}\text { - Customer's A/C system operates between } 3 \\
\text { p.m. and } 6 \text { p.m. weekdays, April through } \\
\text { October } \\
\text { - Work is pre-approved by FPL and performed } \\
\text { by an FPL Participating Independent } \\
\text { Contractor. }\end{array}$ \\
\hline & $\begin{array}{l}\text { Florida Power Corporation } \\
\text { (Progress Energy - Florida) }\end{array}$ & $\begin{array}{l}\text { Window film or solar screen incentive: } \$ 0.75 / \mathrm{sq} \text { ft. For } \\
\text { facilities with multiple guest rooms (hotels, motels, } \\
\text { hospitals, etc.): up to } \$ 55 \text { per room. } \\
\text { - Shading coefficient of film must be } 0.45 \text { or less, or } \\
\text { solar heat gain coefficient must be } 0.40 \text { or less. } \\
\text { - Window film must have a five-year or greater } \\
\text { warranty. }\end{array}$ & $\begin{array}{l}\text { South-, east-, and west-facing windows in } \\
\text { commercial new construction or existing } \\
\text { buildings. Existing windows must have a shading } \\
\text { coefficient of } 0.84 \text { or greater and cannot be more } \\
\text { than } 50 \text { percent shaded by external elements. } \\
\text { Jalousie, double or triple pane, frosted or plastic } \\
\text { windows and skylights are not eligible for an } \\
\text { incentive. }\end{array}$ \\
\hline & $\begin{array}{l}\text { Tampa Electric Company } \\
\text { (TECO Energy) }\end{array}$ & $\begin{array}{l}\text { Window film or solar screen incentive: } \$ 1 \text { per square } \\
\text { foot of glass area covered (up to } \$ 55 \text { per room). } \\
\text { Shading coefficient of film must be } 0.45 \text { or less. }\end{array}$ & $\begin{array}{l}\text { Business customers. Only film on east- or west- } \\
\text { facing glazing with at least } 50 \% \text { direct solar } \\
\text { exposure qualifies. }\end{array}$ \\
\hline $\mathrm{HI}$ & Hawaiian Electric Company & $\begin{array}{l}\text { Window film incentive: } \$ 0.35 / s q \mathrm{ft} \text {. Window film must } \\
\text { have a shading coefficient of } 0.40 \text { or less. }\end{array}$ & Business customers \\
\hline \multirow{2}{*}{ IA } & Alliant Energy & $\begin{array}{l}\text { ENERGY STAR qualified windows/sashes and up to } \\
10 \text { ENERGY STAR qualified doors: } \$ 25 \text { rebate each. } \\
\text { Effective January } 1,2008 \text {, through December } 31 \text {, } \\
2008 \text {, and subject to periodic review and modification. }\end{array}$ & Business customers \\
\hline & MidAmerican Energy & $\begin{array}{l}\text { Incentives for design achieving savings of at least } 5 \% \\
\text { compared to IA code. Incentives range from } \$ 0.05 \text { to } \\
\$ 0.14 \text { per kWh saved and are also available for natural } \\
\text { gas savings. }\end{array}$ & Commercial new construction \\
\hline ID & $\underline{\text { Idaho Power }}$ & $\begin{array}{l}\text { Windows rebates: U-factor } 0.30 \text { or less, SHGC } 0.30 \text { or } \\
\text { less. } \$ 0.50 / \mathrm{sq} \mathrm{ft} \text { incentive. Incentive increases to } \$ 1 / \mathrm{sq} \\
\mathrm{ft} \text { if VT of windows is } 0.50 \text { or more. } \\
\text { Window film rebates: SHGC } 0.40 \text { or less. } \$ 0.50 / \mathrm{sq} \mathrm{ft} \\
\text { incentive. }\end{array}$ & Commercial construction or retrofits \\
\hline
\end{tabular}




\begin{tabular}{|c|c|c|c|}
\hline State & Program Provider & Program Elements & Eligibility \\
\hline \multirow{3}{*}{ MN } & Alliant Energy & $\begin{array}{l}\text { ENERGY STAR qualified windows/sashes: } \$ 20 \text { rebate } \\
\text { each. Effective January } 1,2008, \text { through December } \\
31,2008 \text {, and subject to periodic review and } \\
\text { modification. }\end{array}$ & Business customers \\
\hline & \multirow[t]{2}{*}{ Minnesota Power } & $\begin{array}{l}\text { Rebate based on kilowatt (kW) or kilowatt-hours (kWh) } \\
\text { saved. Eligible equipment may, among others, include } \\
\text { windows, tinting, and daylighting. } \\
\text { Maximum annual rebates available determined by } \\
\text { average billing demand: }\end{array}$ & Commercial, industrial, agricultural customers \\
\hline & & $\begin{array}{cc}\text { Customer Demand } & \text { Maximum Rebate(s) } \\
0 \text { to } 100 \mathrm{~kW} & \$ 10,000 \\
101 \text { to } 300 \mathrm{~kW} & \$ 25,000 \\
\text { Over } 300 \mathrm{~kW} & \$ 50,000\end{array}$ & \\
\hline NC & $\begin{array}{l}\text { North Carolina State Energy } \\
\underline{\text { Office }}\end{array}$ & $\begin{array}{l}\text { Low-interest loan program for energy efficiency } \\
\text { improvements including building envelope measures } \\
\text { such as windows and doors. }\end{array}$ & $\begin{array}{l}\text { Customers except residential customers and } \\
\text { state or federal agencies }\end{array}$ \\
\hline NE & Nebraska Energy Office & $\begin{array}{l}\text { Low-interest financing for up to ten years. Eligible } \\
\text { energy efficiency improvements include replacement } \\
\text { of commercial windows. New windows must have at } \\
\text { least equivalent performance of } 2 \text { panes, low-E, gas } \\
\text { fills, and thermally broken aluminum frames. }\end{array}$ & $\begin{array}{l}\text { Nebraska residents, Nebraska-chartered } \\
\text { corporations, subdivisions of the Nebraska } \\
\text { government (except public school districts) }\end{array}$ \\
\hline $\mathrm{NH}$ & $\begin{array}{l}\text { Public Service Company of } \\
\underline{\text { New Hampshire }}\end{array}$ & $\begin{array}{l}\text { Rebates are available for custom projects. Rebate } \\
\text { amount is the smaller of either } 75 \% \text { of incremental } \\
\text { cost or buy down to one-year payback. }\end{array}$ & Commercial and industrial customers \\
\hline NV & $\underline{\text { Sierra Pacific Power }}$ & $\begin{array}{l}\text { Weatherization and energy-efficiency retrofit project } \\
\text { grants awarded based on electrical energy savings. } \\
\text { Individual projects may be funded in full up to } \$ 5,000 \text {. } \\
\text { For grants between } \$ 5,000 \text { and } \$ 10,000 \text {, a } 50 \% \\
\text { matching investment will be required. Improvement } \\
\text { projects must be completed by October } 1,2008 \text {. }\end{array}$ & $\begin{array}{l}501(c)(3) \text { non-profit customers physically located } \\
\text { within the company's service area (Nevada } \\
\text { customers only). }\end{array}$ \\
\hline
\end{tabular}




\begin{tabular}{|c|c|c|c|}
\hline State & Program Provider & Program Elements & Eligibility \\
\hline \multirow{7}{*}{ OR } & \multirow{3}{*}{ Energy Trust of Oregon } & $\begin{array}{l}\text { Multifamily home energy solutions. Upgrading existing } \\
\text { windows to U-factor } 0.32: \$ 1.75-\$ 2.50 / \text { sq ft. Upgrading } \\
\text { to U-factor } 0.30: \$ 2.25-\$ 3.00 / s q \text { ft. Exact amount } \\
\text { depends on existing window type and heating system. } \\
\text { For windows to be eligible, floor insulation must be R- } \\
11 \text { and attic insulation R-19. }\end{array}$ & $\begin{array}{l}\text { Owners of multifamily properties ( } 5 \text { units or } \\
\text { larger) served by Portland General Electric, } \\
\text { Pacific Power, NW Natural, or Cascade Natural } \\
\text { Gas. }\end{array}$ \\
\hline & & $\begin{array}{l}\text { Retrofit custom incentives for projects involving non- } \\
\text { lighting equipment or measures: up to } 35 \% \text { of the total } \\
\text { approved cost not to exceed } \$ 0.20 / \text { annual kWh saved } \\
\text { and } \$ 1 / \text { therm saved. }\end{array}$ & $\begin{array}{l}\text { Existing commercial, institutional and agricultural } \\
\text { facilities served by Portland General Electric, } \\
\text { Pacific Power, NW Natural, or Cascade Natural } \\
\text { Gas. }\end{array}$ \\
\hline & & $\begin{array}{l}\text { Incentives for high performance new construction. } \\
\text { Custom incentives: } \$ 0.10 / \text { annual kWh saved and } \\
\$ 0.80 / \text { therm saved compared to minimum OR code } \\
\text { requirements. }\end{array}$ & $\begin{array}{l}\text { New commercial, institutional and agricultural } \\
\text { facilities served by Portland General Electric, } \\
\text { Pacific Power, NW Natural, or Cascade Natural } \\
\text { Gas. }\end{array}$ \\
\hline & $\begin{array}{l}\text { Eugene Water \& Electric } \\
\text { Board }\end{array}$ & $\begin{array}{l}\$ 2 / \mathrm{sq} \mathrm{ft} \text { rebate for replacing single-pane windows with } \\
\text { windows with a U-factor of } 0.42 \text { or lower (if metal } \\
\text { framed) or } 0.35 \text { or lower (if non-metal framed) and an } \\
\text { SHGC of } 0.40 \text { or lower. }\end{array}$ & Existing business facilities \\
\hline & $\underline{\text { Idaho Power }}$ & $\begin{array}{l}\text { Window rebate: } \mathrm{U} \text {-factor } 0.30 \text { or less, SHGC } 0.30 \text { or } \\
\text { less. } 0.50 / \mathrm{sq} \mathrm{ft} \text { incentive. Incentive increases to } \$ 1 / \mathrm{sq} \\
\mathrm{ft} \text { if } \mathrm{VT} \text { of windows is } 0.50 \text { or more. } \\
\text { Window film rebate: SHGC } 0.40 \text { or less. } \$ 0.50 / \mathrm{sq} \mathrm{ft} \\
\text { incentive. }\end{array}$ & Commercial construction or retrofits \\
\hline & $\begin{array}{l}\text { Lane Electric Cooperative } \\
\text { Phone: } 541-484-1151\end{array}$ & $\begin{array}{l}\text { Zero-interest loan (up to } \$ 10,000) \text { or cash grant }(50 \% \\
\text { of cost up to } \$ 2,500) \text { for weatherization measures. } \\
\text { Window replacement qualifies only if building } \\
\text { insulation meets minimum standards. }\end{array}$ & Residential and commercial customers \\
\hline & $\begin{array}{l}\text { Oregon Department of } \\
\text { Energy }\end{array}$ & $\begin{array}{l}\text { Tax credit for buildings meeting LEED }{ }^{\mathrm{TM}} \text { standards or } \\
\text { rated by a comparable program approved by the } \\
\text { Oregon Department of Energy. The tax credit can } \\
\text { cover all costs directly related to the project, including } \\
\text { equipment cost, engineering and design fees, } \\
\text { materials, supplies and installation costs. }\end{array}$ & Sustainable commercial buildings in OR \\
\hline
\end{tabular}




\begin{tabular}{|c|c|c|c|}
\hline State & Program Provider & Program Elements & Eligibility \\
\hline \multirow{6}{*}{ TX } & Austin Energy & $\$ 0.65 / \mathrm{sq}$ ft rebate for glazing with $0.41 \mathrm{SHGC}$. & $\begin{array}{l}\text { Business customers. Non-profit and small } \\
\text { business customers may qualify for } 20 \% \text { bonus } \\
\text { on rebate. }\end{array}$ \\
\hline & AEP Efficiency & $\begin{array}{l}\text { Providers of energy efficiency services receive } \\
\text { incentives for installing measures that reduce peak } \\
\text { demand. For large commercial and industrial } \\
\text { customers ( }>100 \mathrm{~kW} \text { demand) measure must reduce } \\
\text { peak demand by at least } 10 \mathrm{~kW} \text {. }\end{array}$ & $\begin{array}{l}\text { Incentive goes to service provider. Measures can } \\
\text { be installed for residential, commercial and } \\
\text { industrial customers. }\end{array}$ \\
\hline & CenterPoint Energy & $\begin{array}{l}\text { Incentives for measures including solar control film for } \\
\text { south- and west-facing windows. } \$ 175 \text { per kW } \\
\text { reduction and } \$ 0.06 \text { per kWh saved. }\end{array}$ & $\begin{array}{l}\text { Available to all C\&I customers with peak demand } \\
\text { of at least } 100 \mathrm{~kW} \text { at a single site or a combined } \\
\text { peak demand of at least } 250 \mathrm{~kW} \text { at multiple sites. }\end{array}$ \\
\hline & \multirow{2}{*}{$\begin{array}{l}\text { Texas-New Mexico Power } \\
\underline{\text { Company }}\end{array}$} & $\begin{array}{l}\text { Residential and Small Commercial Standard Offer } \\
\text { Program: Incentives ( } \$ 278 \text { per kW reduction, } \$ 0.095 \\
\text { per kWh saved) for measures to improve home energy } \\
\text { efficiency with a useful lifetime of at least } 10 \text { years. }\end{array}$ & $\begin{array}{l}\text { Residential and small commercial building } \\
\text { owners. Incentives are paid to energy efficiency } \\
\text { service providers or small commercial customers }\end{array}$ \\
\hline & & $\begin{array}{l}\text { The Commercial and Industrial Standard Offer } \\
\text { Program: Incentives ( } \$ 195 \text { per kW reduction, } \$ 0.067 \\
\text { per kWh saved) for measures to improve home energy } \\
\text { efficiency with a useful lifetime of at least } 10 \text { years. }\end{array}$ & $\begin{array}{l}\text { Incentives are paid to energy efficiency service } \\
\text { providers (EESPs). }\end{array}$ \\
\hline & $\underline{\text { TXU Energy }}$ & $\begin{array}{l}\text { Small commercial program: includes incentives for } \\
\text { ENERGY STAR windows } \\
\text { Commercial program: incentives for approved } \\
\text { measures in commercial or public buildings }\end{array}$ & Commercial customers \\
\hline \multirow[b]{2}{*}{ WA } & $\underline{\text { Seattle City Light }}$ & $\begin{array}{l}\text { \$5/sq ft for replacing single-pane with double-pane } \\
\text { windows. } \$ 3 / \mathrm{sq} \mathrm{ft} \text { for replacing aluminum-framed } \\
\text { double-pane with vinyl-framed double-pane windows. }\end{array}$ & Multifamily buildings \\
\hline & Puget Sound Energy & $\begin{array}{l}\text { Custom grants: up to } 100 \% \text { of the incremental cost for } \\
\text { energy-efficiency projects. Thermal envelope } \\
\text { improvements such as glazing with a U-factor of up to } \\
0.35 \text { qualify. Incentives may also be based on above- } \\
\text { code performance of the whole building. }\end{array}$ & Business customers \\
\hline
\end{tabular}


OVERVIEW OF PROGRAMS - WISCONSIN

\begin{tabular}{|c|c|c|c|c|c|c|}
\hline State & Program Provider & \multicolumn{4}{|c|}{ Program Elements } & Eligibility \\
\hline \multirow{5}{*}{ WI } & \multirow{5}{*}{ Focus on Energy } & \multicolumn{4}{|c|}{$\begin{array}{l}\text { Design (including windows and daylighting) that is } \\
\text { modeled to achieve energy cost savings compared to } \\
\text { standard practice qualifies for incentives: }\end{array}$} & \multirow[t]{5}{*}{$\begin{array}{l}\text { New construction, addition, or major renovation } \\
\text { for business customers. }\end{array}$} \\
\hline & & $\%$ savings & \multicolumn{3}{|c|}{ Incentive } & \\
\hline & & $10-20 \%$ & $\$ 125 / \mathrm{kW}$ & $\$ 0.04 / \mathrm{kWh}$ & $\$ 0.40 /$ Therm & \\
\hline & & $20-30 \%$ & $\$ 160 / \mathrm{kW}$ & $\$ 0.05 / \mathrm{kWh}$ & $\$ 0.50 /$ Therm & \\
\hline & & $30 \%+$ & $\$ 200 / \mathrm{kW}$ & $\$ 0.06 / \mathrm{kWh}$ & $\$ 0.60 /$ Therm & \\
\hline
\end{tabular}




\section{Incremental Cost Estimates for Higher Window Performance Tiers}

\section{for Minneapolis and Denver Office Buildings}

On the following pages, the Efficient Windows Collaborative discusses window performance tiers (based on U-factor and SHGC) that would provide realistic goals for window retrofits in office buildings in the Minneapolis, MN and Denver, CO climates. These tiers go beyond common practice and could be used as the basis for incentive programs. Energy and peak demand savings can be simulated by comparing the performance of windows installed according to common practice (baseline performance) to that of windows meeting the discussed higher performance tiers:

\section{Baseline Wind ow Performance}

To compare higher window performance tiers to common practice, we must first determine baseline window performance values - the performance of windows installed in the absence of incentive programs. A straightforward means of doing so is to assume that baseline performance closely conforms to the building code's prescriptive fenestration requirements. Nonetheless, we should keep in mind that building envelope tradeoffs or whole-building performance methods allowed by building codes often result in installed window performance that does not meet the prescriptive requirements of codes.

Based on prescriptive code requirements, we determined that the following window performance may be defined as the baseline window performance for metal windows in non-residential buildings in Denver and Minneapolis: U-factor 0.50, SHGC 0.40

These values would, for instance, match the following generic window type described in a prominent windows source book by LBNL and the University of Minnesota: ${ }^{1}$

\begin{tabular}{|c|l|l|c|c|c|c|}
\hline \multicolumn{7}{|c|}{ Baseline Window Based on Prescriptive Code Requirements } \\
\hline$\#$ & Glazing type & Frame type & U-factor & SHGC & VT & $\begin{array}{c}\text { Incremental } \\
\text { cost }\left(\$ \text { per } \mathrm{ft}^{2}\right)\end{array}$ \\
\hline A & $\begin{array}{l}\text { 2-pane, 1x bronze tint, } \\
\text { 1 low-E }\end{array}$ & Aluminum, thermal break & 0.49 & 0.39 & 0.36 & Baseline \\
\hline
\end{tabular}

The baseline U-factor and SHGC of 0.50 and 0.40 are values that would meet the prescriptive code requirements in both Colorado and Minnesota. In Colorado, codes differ by jurisdiction, but in Denver, the 2006 IECC applies. For metal windows in non-residential buildings with no more than 40 percent window-to-wall area, the 2006 IECC has the following prescriptive requirements: U-factor 0.55 or less, SHGC 0.40 or less. $^{2}$ The present (2008) version of the Minnesota Energy Code has prescriptive provisions that differ from the IECC: U-factor 0.50 or less, SHGC 0.70 or less. For the purpose of this discussion, we assume a baseline window performance that meets either set of requirements (i.e. U-factor 0.50, SHGC $0.40)$, as is exemplified by the generic option shown above.

\footnotetext{
${ }^{1}$ Carmody et al. 2004. Window Systems for High-Performance Buildings. Norton.

${ }^{2}$ These requirements are matched in the 2007 version of ASHRAE Standard 90.1, which may be adopted by many jurisdictions in the near future.
} 
If the whole-building performance method or building envelope tradeoff options are used, a common alternative to this baseline window type could be the following, cheaper option.

\begin{tabular}{|c|l|l|c|c|c|c|}
\hline \multicolumn{7}{|c|}{ Baseline Window Based on Prescriptive Code Requirements } \\
\hline$\#$ & Glazing type & Frame type & U-factor & SHGC & VT & $\begin{array}{c}\text { Incremental } \\
\text { cost }\left(\$ \text { per } \mathbf{f t}^{2}\right)\end{array}$ \\
\hline B & 2-pane, 1x bronze tint & Aluminum, thermal break & 0.60 & 0.42 & 0.38 & Minus $\$ 1.50$ \\
\hline
\end{tabular}

\section{Tier 1 Window Performance: U-factor 0.45, SHGC 0.35}

There are relatively low-cost means of improving window performance beyond baseline to what we might call Tier 1 performance. With incremental upgrades such as improved spacers, advanced spectrally selective low-E coatings, improved thermal breaks or spacers, window performance can be improved to meet or exceed these criteria: $U$-factor 0.45 , SHGC 0.35 .

A generic window type example meeting these criteria would be the following: ${ }^{3}$

\begin{tabular}{|c|l|l|c|c|c|c|}
\hline \multicolumn{6}{|c|}{ Baseline Window Based on Prescriptive Code Requirements } \\
\hline$\#$ & Glazing type & Frame type & U-factor & SHGC & VT & $\begin{array}{c}\text { Incremental } \\
\text { cost }\left(\$ \text { per ft }^{2}\right)\end{array}$ \\
\hline C & $\begin{array}{l}\text { 2-pane, 1x spectrally } \\
\text { selective low-E, argon gas }\end{array}$ & Aluminum, thermal break & 0.43 & 0.34 & 0.57 & \\
\hline
\end{tabular}

While a U-factor of 0.45 and an SHGC of 0.35 for Tier 1 represent only incremental improvements over our assumed baseline performance, it should be kept in mind that not all windows necessarily meet baseline performance. Windows that meet Tier 1 provide substantially better performance than some window options used in cases where the building envelope tradeoff or whole-building performance methods are applied.

The Tier 1 criteria of U-factor 0.45 and SHGC 0.35 are closely reflected in criteria presented by prominent above-code performance documents. The Advanced Energy Design Guide for Small Office Buildings, developed by ASHRAE in collaboration with other organizations, recommends windows with a U-factor of no more than 0.42 for the Denver and Minneapolis climates. ${ }^{4}$ The May 2007 Public Review Draft of ASHRAE Proposed Standard 189p for high performance buildings recommends a U-factor of 0.45 for metal windows in these climates along with an SHGC of 0.35 for the Denver climate, and of 0.40

\footnotetext{
${ }^{3}$ These performance values are based on a generic window type included in Carmody et al., with the exception that the window type in the book does not have argon gas filling and has a U-factor of 0.46 . Based on common performance values found in the NFRC certified products directory (www.nfrc.org), we assume that adding argon gas to a typical window reduces the $U$-factor by 0.03 . Similar performance improvements may be achieved by using improved spacers and/or improved thermal breaks.

${ }^{4}$ ASHRAE, AIA, IESNA, NBI, U.S. DOE. 2008. Advanced Energy Design Guide for Small Office Buildings: Achieving 30\% Energy Savings Over ANSI/ASHRAE/IESNA Standard 90.1-1999. Atlanta, GA: American Society of Heating, Refrigerating, and Air-conditioning Engineers. www.ashrae.org/aedg.
} 
for the Minneapolis climate. ${ }^{5}$ Based on these recommendations, a U-factor of 0.45 and an SHGC of 0.35 would be reasonable criteria for better-than-baseline window performance.

Tier 2 Window Performance: U-factor 0.35, SHGC 0.25

For medium-sized window openings, options are available with an energy performance that is substantially better than baseline, meeting or exceeding these criteria: U-factor 0.35 , SHGC 0.25 .

These criteria can be met by options including highly-insulating glazing (triple glazing with an inner pane of glass or suspended film) or low-conductance frames (generally all non-metal frames) or both. These options are less common in larger commercial buildings due to the weight and cost of triple glazing and the structural advantages of metal frames. However, in buildings where the use of triple-glazing with its thicker sashes and/or of non-metal frames is structurally sound, such window options can substantially reduce the need for perimeter heating.

The following generic window types described in Carmody et al. are examples that would meet Tier 2 criteria:

\begin{tabular}{|c|l|l|c|c|c|c|}
\hline \multicolumn{6}{|c|}{ Baseline Window Based on Prescriptive Code Requirements } \\
\hline \# & Glazing type & Frame type & U-factor & SHGC & VT & $\begin{array}{c}\text { Incremental } \\
\text { cost }\left(\$ \mathbf{p e r} \mathbf{f t}^{2}\right)\end{array}$ \\
\hline D & 3-pane, 2x low-E & Aluminum, thermal break & 0.35 & 0.24 & 0.37 & $\$ 10$ \\
\hline E & $\begin{array}{l}\text { 2-pane, 1x low-E, High- } \\
\text { performance tint }\end{array}$ & $\begin{array}{l}\text { Non-metal (wood, vinyl, } \\
\text { composite, fiberglass) }\end{array}$ & 0.32 & 0.24 & 0.43 & $\begin{array}{c}\text { Depends on } \\
\text { frame type }\end{array}$ \\
\hline
\end{tabular}

The incremental cost for triple-pane windows is relatively high, not only due to the improved glazing itself but also because of different sash requirements and, in the case of three glass panes, more weight to be lifted during installation. Nevertheless, this option may make economic sense if it leads to substantially reduced demand for perimeter heating and thus the option to reduce HVAC installation cost. Improving thermal performance through the use of non-metal frames might be a cheaper alternative to triple-glazing, but its applicability depends on the structural requirements of specific buildings and on the ability of non-metal frames to meet these requirements.

\footnotetext{
${ }^{5}$ BSR/ASHRAE/USGBC/IESNA. 2007. Public Review Draft: Proposed Standard 189, Standard for the Design of HighPerformance Green Buildings Except Low-Rise Residential Buildings. Atlanta, GA: American Society of Heating, Refrigerating, and Air-conditioning Engineers.
} 


\section{Summary of Performance Tiers}

The previously discussed window performance tiers can be summarized as follows:

\begin{tabular}{|l|c|c|c|c|}
\hline Performance Tier & Window Type Examples & U-factor & SHGC & Estimated incremental cost (\$ per ft²) \\
\hline Baseline & A & 0.50 & 0.40 & Baseline \\
\hline Tier 1 & C & 0.45 & 0.35 & $\$ 1$ \\
\hline Tier 2 & D, E & 0.35 & 0.25 & $\$ 10$ \\
\hline
\end{tabular}

The estimated incremental cost for Tiers 1 and 2 are based on the assumption that the window type examples below represent typical windows used under the different tiers. Example B represents windows that might be used if cheaper-than-baseline windows are specified that do not meet prescriptive code requirements but would be allowed if the overall building performance complies with the code.

\begin{tabular}{|c|l|l|c|c|c|c|}
\hline \multicolumn{7}{|c|}{ Window Type Examples with Default Performance Values } \\
\hline \# & Glazing type & Frame type & U-factor & SHGC & VT & $\begin{array}{c}\text { Incremental } \\
\text { cost (\$ per ft' }\end{array}$ \\
\hline A & $\begin{array}{l}\text { 2-pane, 1x bronze tint, } \\
\text { 1 } \text { low-E }\end{array}$ & Aluminum, thermal break & 0.49 & 0.39 & 0.36 & Baseline \\
\hline B & 2-pane, 1x bronze tint & Aluminum, thermal break & 0.60 & 0.42 & 0.38 & minus $\$ 1.50$ \\
\hline C & $\begin{array}{l}\text { 2-pane, 1x spectrally } \\
\text { selective low-E, argon gas }\end{array}$ & Aluminum, thermal break & 0.43 & 0.34 & 0.57 & $\$ 1$ \\
\hline D & 3-pane, 2x low-E & Aluminum, thermal break & 0.35 & 0.24 & 0.37 & $\$ 10$ \\
\hline E & $\begin{array}{l}\text { 2-pane, 1x low-E, High- } \\
\text { performance tint }\end{array}$ & $\begin{array}{l}\text { Non-metal (wood, vinyl, } \\
\text { composite, fiberglass) }\end{array}$ & 0.32 & 0.24 & 0.43 & $\begin{array}{c}\text { Depends on } \\
\text { frame type }\end{array}$ \\
\hline
\end{tabular}

\section{Assumptions behind our incremental cost estimates}

A: The baseline cost of a window can strongly vary depending on its size, operator type, durability, and structural requirements.

B: According to RSMeans 2007, the incremental installed cost of low-E glass versus standard insulated glass is about $\$ 1.50 / \mathrm{sq} \mathrm{ft}^{6}$ Since Option B only differs from Option A by its lack of a low-E coating, we estimate the incremental cost difference to be these $\$ 1.50 / \mathrm{sq} \mathrm{ft}$.

C: In contrast to Option A, Option C has a more advanced low-E coating (spectrally selective), and an argon gas fill. The cost premium for the advanced low-E coating can be offset if no tint is used - with spectrally selective low-E, no tint is necessary to achieve an SHGC of 0.35 or less. According to a 2002 fenestration market study, the use of argon gas costs about $\$ 0.25 / \mathrm{sq} \mathrm{ft}$ to $\$ 0.50 / \mathrm{sq} \mathrm{ft}$, while thermally improved spacers are estimated at $\$ 1.00$ per sq ft of window area. ${ }^{7}$ Assuming that either argon gas or thermally improved spacers are used to meet the Tier 1 criteria we estimate the average incremental cost to be $\$ 1 / \mathrm{sq} \mathrm{ft}$ including profit.

\footnotetext{
${ }^{6}$ RSMeans. 2007. Repair \& Remodeling Cost Data. $28^{\text {th }}$ Edition. Commercial/Residential. Reed Construction Data.

${ }^{7}$ Eley Associates. 2002. A Characterization of the Nonresidential Fenestration Market. Northwest Energy Efficiency Alliance.
} 
D: According to RSMeans 2007, the difference in the installed cost of aluminum sashes with double glazing versus aluminum sashes with triple glazing is about $\$ 8.25 / \mathrm{sq} \mathrm{ft}$. Since this cost increment would not yet include the additional low-E coating included in Option D, we estimate this incremental cost to be roughly $\$ 10 / \mathrm{sq} \mathrm{ft}$.

E: We have no means of accurately estimating the cost difference between frame types. In buildings without wind load requirements, non-metal windows might not cost more than aluminum windows. In higher buildings, however, wind loads would require the use of premium material and reinforcements, which could increase the cost substantially. 